UCRL-CR- 120929

B280344

Academy of Sciences, Russian Federation

Institute for Dynamics of the Geospheres

\title{
CHARACTERISTICS OF SEISMIC WAVES FROM SOVIET PEACEFUL NUCLEAR EXPLOSIONS IN SALT
}

\author{
V. V. Adushkin \\ Director of IDG RAS \\ P. B. Kaazik \\ V. N. Kostyuchenko \\ O. P. Kuznetsov \\ N. I. Nedoshivin \\ Kh.D. Rubinshtein \\ D. D. Sultanov
}

April 1995

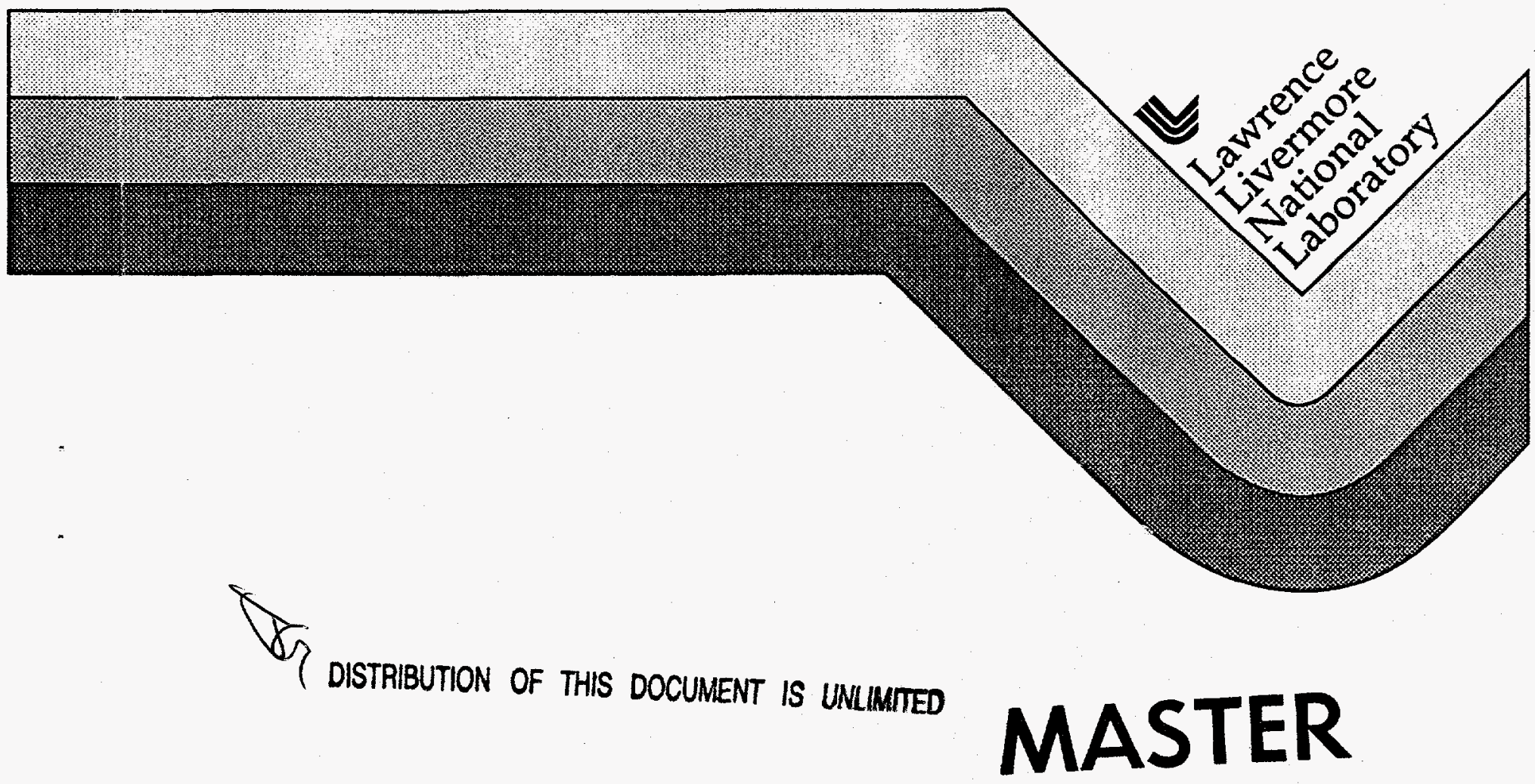




\section{DISCLAIMER}

This document was prepared as an account of work sponsored by an agency of the United States Covernment. Neither the United States Covernment nor the University of California nor any of their employees, makes any warranty, express or implied, or assumes any legal liability or responsibility for the accuracy, completeness, or usefulness of any information, apparatus, product, or process disclosed, or represents that its use would not infringe privately owned rights. Reference herein to any specific commercial product, process, or service by trade name, trademark, manufacturer, or otherwise, does not necessarily constitute or imply its endorsement, recommendation, or favoring by the United States Government or the University of California. The views and opinions of authors expressed herein do not necessarily state or reflect those of the United States Government or the University of California, and shall not be used for advertising or product endorsement purposes. 


\section{DISCLAIMER}

Portions of this document may be illegible in electronic image products. Images are produced from the best available original document. 
ACADEMY OF SCIENCES, RUSSIAN FEDERATION INSTITUTE FOR DYNAMICS OF THE GEOSPHERES

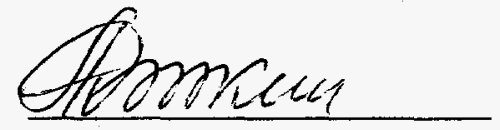

U.U.ADUSHKIH

DIRECTOR OF IDG RAS

HARCH $31, \quad 1995$

CHARACTERISTICS OF SEISMIC WAUES FROM SOUIET PEACEFUL

NUCLEAR EXPLOSIONS IN SALT

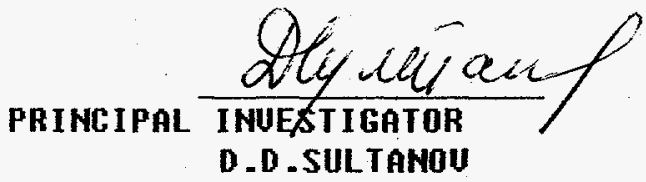

Moscow 1995

DISTRIBUTION OF THIS DOCUMENT IS UNUMTED 


\section{LIST OF ALTHOFS}

Different sections of the report were written by following IDG researchs:

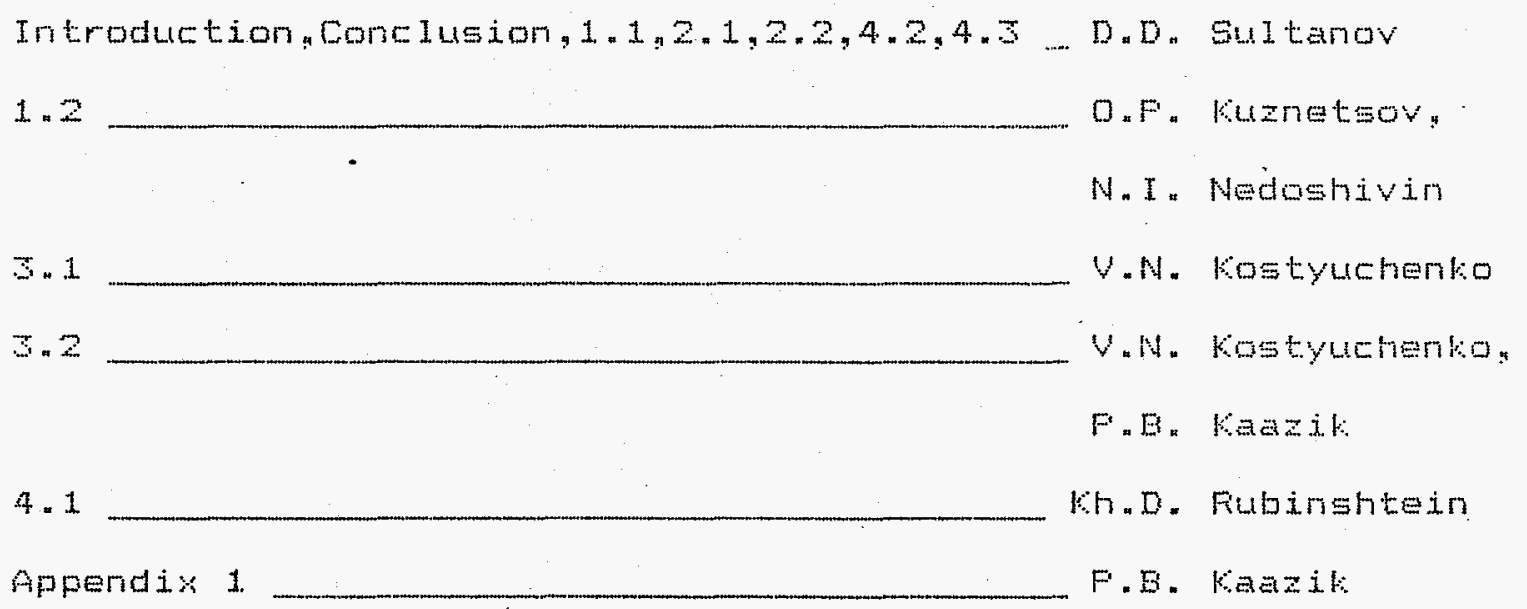

The conversion of the original photographic paper records in to the digital formathas been done by 0.F.kuznetsov and P.E.Kaarik Calculation and graphic work have been done by T. V.Danilova.

I. O.Kitor hass translated this report into English. 
TABIE OF CONIENTS

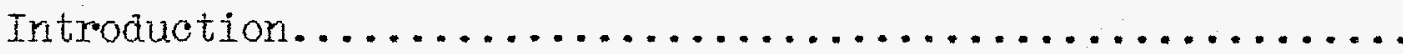

GHAPTER 1. Conditions of explosions conduotion at the Sites Azgir and Vega. Seismic measurements procedure

1. Actual data and geological conditions of the explosions conduction at the sites Azgir and Vega $\ldots \ldots \ldots \ldots \ldots \ldots \ldots \ldots \ldots \ldots \ldots \ldots \ldots \ldots \ldots \ldots$

2. Procedure of seismic observations and equipment .... 15

CHAPTER 2. Investigation of amplitudes and periods of seismic waves recorded in the local zone by portable seismic stations

1. Content of experimental date .............. 20

2. Parameters of seismic waves irom the explosions at the gites Azgir and Vega ................ 21

CHAPPER 3. Spectral characteristios of seismic wave in near field zone of explosions

1. Principal characteristics of source ........... 44

2. Analysis of experimental results $=\ldots \ldots \ldots \ldots \ldots$ 
CHAPTER 4. Regional and teleseismic data of seismio observations

1. Seismological Bulletines of soviet seismic

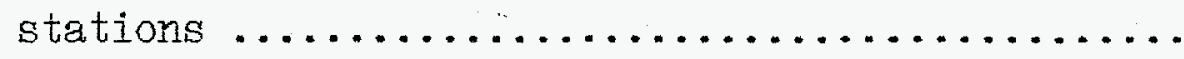

2. Analysis of data from the selsmological

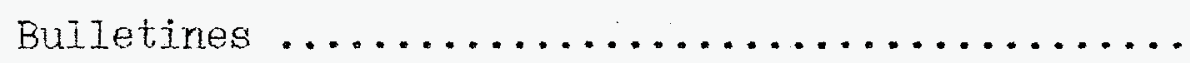

3. Seismic efficiency of the underground nuclear explosions conducted in salt ................

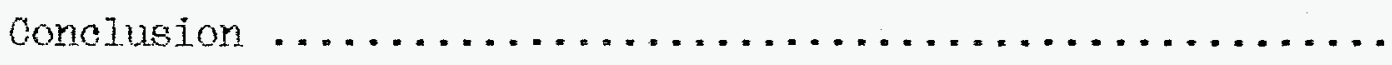

References $\ldots \ldots \ldots \ldots \ldots \ldots \ldots \ldots \ldots \ldots \ldots \ldots \ldots \ldots \ldots$

Figures $\ldots \ldots \ldots \ldots \ldots \ldots \ldots \ldots \ldots \ldots \ldots \ldots \ldots \ldots \ldots \ldots$

Appendix 1. Procedure of photographic paper record digitizing $\ldots \ldots \ldots \ldots \ldots \ldots \ldots \ldots \ldots \ldots$ 
ABSTRACT

The report is carried out by the Institute for Dynamics of the Geospheres, Russian Academy of Sciences under contract NB280344 with Lawrence Livermore National Laboratory, University of California. The work inoludes investigation of seismic waves generation and propagation from soviet peaceful underground nuclear explosions in salt based on the data from temporary and permanent seismic stations. The explosions were conducted at the sites Azgir and Vega within the territory of the Caspian depression of the Russian platform. The data used were obtained in the following conditions of conduction : epicentral distance range from 0 to 60 degrees, yields from 1 to $65 \mathrm{kt}$ and depths of burial from 160 to $1500 \mathrm{~m}$.

One of the goals of the work was to create a data bank of peaceful nuclear explosions including original data on explosions conduction and materials of seismic measurements from the explosions. Original data inolude coordinates, origin times, yields, and depths of burial as well as geological conditions. Selsmic data include digitized waveforms recorded in Iocal zone in the range from 0 to $260 \mathrm{~km}$ and Bulletines of Soviet seismic network in the range from 4 to 60 degrees.

The seismic data from five individual explosions $A-1, A-2$, $\mathrm{A}-3, \mathrm{~A}-4$, and $\mathrm{A}-5$ fired at the site Azgir and from four similar explosions 7T, 6T, 5T, and 3T fired at the site Vega with time delay of about 5 minutes were' generally studied. All the 
explosions were detonated in boreholes drilled in salt domes. There were also other peaceful nuclear explosions in salt domes and bedded salt conducted at the sites and different regions of the USSR which were used in the analysis.

Prinoipal characteristics of seismic waves associated with complex geological stmucture (thick sediments, sharp velocity defferentiation, abrupt diping of salt dome wings eto.) were revealed as a result of the data analysis. Relationships between peak amplitudes of displacement, velocity, and acceleration and range/yield were obtained. Empirical relationships of amplitude decay vs. distance are characterized by strong scattering with mean square deviation of two times from averaged Iines. Due to strong scattering of amplitudes in local zone beyond $10-15 \mathrm{~km}$ there is no distinct differencies in amplitudes and periods in body waves from explosions with yields varying in two times.

Spectral processing of the seismic data recorded at the distance of $75 \mathrm{~km}$ from the Azgir explosions allowed to compare seismic source function predictions by different models. It is obtained that spectral amplitudes in different frequency bands depend on yield in different ways. Low-frequency spectral levels show that seismic efficiency of deep explosions is reduced.

Regional and teleseismic data reveal a good correlation of seismic wave amplitude and yield. Relationship of magnitude from body waves and yield of explosion has been established from 21 explosions with yields from 1 to $65 \mathrm{kt}$ fired within the 
territory of the Caspian depression and adjacent regions. Standard deviation of the relationship is of $\pm 20-25 \%$. Seismic efficiency of deep explosions $(1500$ to $2500 \mathrm{~m}$ ) is 2 to 3 times lower relative to shallower explosions (less than $1100 \mathrm{~m}$ ).

The results of the study described in the report reveal some important features of seismic waves in broad epicentral range from 0 to 60 degrees from explosions in salt domes detonated within the territory of ancient platform covered by thick sediment layer. The results can be used for improvement of seismic monitoring procedures in the seismic verification of Nuclear Testing Treaties. 
INTRODUCTION

This report is done according to the contract B280344. between Lawrence Livermore National Laboratory, University of Califormia, and the Institute for Dynamies of Geospheres of Russian Academy of Sciences.

The report contains experimental investigation of characteristics of seismic waves from soviet peaceful nuclear explosions conducted in salt domes at the sites Azgir and Vege. The sites are about $100 \mathrm{~km}$ apart Irom each other in the north-south direotion. All the explosions were conducted in. boreholes and were single and tamped.

Explosions in salt are interesting for seismio investigation due to following principal reasons:

- a good part from all of the Soviet PNE's (more than 40 from 122) was conducted in salt;

- salt in domes is probably one of the most homogeneous media, independent on site position;

- regions with salt deposits of high thiokness are favorable for conduction of explosions with reduced seismic efficiency (decoupled).

It is well known also that USA conducted two underground nuclear explosions in salt: Salmon and Gnome during the plowshare program.

In this report seismic data obtained Irom 5 explosions at. 
the site Azgir (official title: Site Galite) conducted in boreholes $A-1,2,3,4,5$ with yields ranging from 1 to $65 \mathrm{kt}$ and depths ranging from 160 to $1500 \mathrm{~m}$ are used. There were also 12 explosions conducted at this scientifio test site: 6 explosions in the water-filled cavity of the A-2 borehole, one explosion in the air-filled cavity of the A-3 borehole, and four group explosions in the $A-7,8,10,11$ boreholes in which a set of two or three (A-11) charges was placed. At the Vega site situated within Astrakhan gas condensate field, five series with total of 15 explosions were conducted in the period from 1980 to 1984 (one series per year). The series Vega-1 contained one explosion in the borehole 1T (1980). The series Vega-2 included two explosions (boreholes $4 T$ and $2 T$ ) (1981). The series Vega-3 had four explosions (7T,6T,5T, and 3T) (1982). The series Vega-4 (1983) included six explosions (8T,9T, 11T, 13T, 10T, 12T). The last series, Vega-5 (1984) included two explosions (14T and 15T). Time delay between explosions in the series Vega-2 was of 4 minutes and in the other series was of 5 minutes. Seismic data from 13 explosions from the first four series were analyzed. Eleven explosions had yield of $8.5 \mathrm{kt}$, the fourth explosion (3T) from the series Vega-3 had the highest yield of $13.5 \mathrm{kt}$, and the third explosion from the series Vega-4 was of $3.5 \pm 0.7 \mathrm{kt}$. Depths of the explosions were in the range from 900 to $1100 \mathrm{~m}$.

Original data on the explosion were published in [1]. We 
have added true origin times and coordinates. Actual depths and yields of the explosions were also corrected in some cases. Unfortunately, correct origin times were not recorded for the first explosions at the Azgir site.

The work done under the contract also includes an aim of creation of seismic data bank on powerful explosions for studing of detection and indentification of seismic events of different types by seismic monitoring at regional distances. So, a part of the work is magnetic tapes containing digital waveforms obtained by the IDG from the explosions at Azgir to a range of $260 \mathrm{~km}$, and at Vega to a range of $60 \mathrm{~km}$, as well as bulletines of Soviet permanent seismic stations to distances beyond $6000 \mathrm{~km} .296$ seismic waveforms are presented in total which were recorded on 66 seismograms at 33 observation points from 9 explosions $\mathrm{A}-1,2,3,4,5$ and $7 \mathrm{~T}, 6 \mathrm{~T}, 5 \mathrm{~T}$, and $3 \mathrm{~T}$.

The bulletines were compiled in the IDG from the reports of seismic stations of the Unified Seismological Network of the USSR. Operators' mistakes were corrected when olear. Epicenters were determined by the Central Seismological observatory in obninsk by standard program of location adopted by Seismological Service of the USSR.

Additional to the IDG materials, data from the Institute NIPIPromtechnologia were also used. The data include seismic observations in local $(<50 \mathrm{~km})$ zone whioh were previously used 
in joint investigations.

Following prinoipal tasks were under investigation during the analysis of the local, regional and teleseismic data:

- studing of principal charateristios of seismic wavefield and seismograms' fine structure from the regions characterized by thick salt sediments outeroping in dome-like shape;

- studing of relationships between seismic waves' parameters (amplitudes, periods, spectra) and epicentrai distance and yield;

- investigation of influence of stochastio variations of seismic signals on estimation of yield from local, regional and teleseismio data.

This report includes introduction, four chapters, conolusion and Appendix. Chapter 1 contains original data on the explosions and geological conditions at the sites. Procedures of seismic observations and equipment are also described. Chapter 2 presents the results of seismic parameters measurements in local zone of the explosions at the Azgir and Vega sites. Quantitative relationships of peak displacement amplitudes, peak particle velocites and acoeleration vs. distance and yield are established. The influence of this factors as well as depth on periods are considered. High variations of seismic waves" amplitudes at permanent seismic stations from explosions of the same yield and situated not far from each other are noted. The 
reason of such variations are discussed. Chapter 3 is devoted to analysis of speotra of seismio signals and those fit to simple. models of underground explosions. Chapter 4 presents the data of regional and teleseismic observations from the bulletines of permanent seismic stations for each explosion. Detailed analysis of network magnitudes and magnitudes obtained from our estimations was conducted. Accuracy of yield determination from network magnitudes is evaluated. Appendix describes the procedure of digitizing of seismograms recorded on photographic paper.

Principal results are compiled in Conclusion. Also possible future investigations are proposed. 
CHAPPER - 1

CONDITIONS OF EXPIOSIONS CONDUCTION AT THE SITES AZGIR

AND VEGA. SEISMIC MEASUREMENTS PROCEDURE.

1. Aotual data and geological conditions of the explosions conduction at the sites Azgir and Vega.

This report summarizes actual origin data and geologioal conditions' description dealing with the tamped individual explosions at the Azgir site and similar explosions from the series' Vega-3 at the site Vega. These data were obtained from the published works of Russian seismologists and the report issued by "NIPIpromtechnologia" according to the contract with Institute for Dynamics of the Geospheres, RAS. .

All the explosions were fully contained and were conducted in salt domes of the Caspian depression. Soaled depths of the explosions range from 156 to $715 \mathrm{~m} / \mathrm{kt}^{1 / 3}$. The two sites conditions are described below separately.

\section{Azgir site}

Soientific test site Azgir is situated in the central part, of the Caspian depression of the Russian platform, at the territory of Kazakhstan neighboring to Astrakhan Region of Russia, 70-85 $\mathrm{km}$ to the east from Knarabaly town. The caspian depression is characterized by salt deposites of high thickness 
( 5 to $7 \mathrm{~km}$ ) and well-developed salt-dome tectonics. Salt layer is usually bedded at the depth of 1 to $2 \mathrm{~km}$ and salt domes are ussualy covered by sediments of 200 to $400 \mathrm{~m}$ thickness or outcrop as near town of Azgir. The Caspian depression is filled by terrigeneous, salt and carbonaceous deposites of very high thickness. The maximum depth of basement from geological and gravimetric estimations can be as large as 12 to $16 \mathrm{~km}$.

The Azgir site is situated within large salt-dome structure - the salt field Large Azgir. The structure represents a wide brachy-anticline of diapir type complicated by two salt-dome uplifts: the Eastern and Western Azgir. The two uplifts are separated by 10 to $15 \mathrm{~km}$ of compensation depression. The domes are alongated in submeridional direction by $1,5 \mathrm{~km}$ and have widths of 7 to $8 \mathrm{~km}$. At the southerm part of the westerm Azgir, salt lays near the surface. In the other parts along the axis of the central Western and Easterm domes salt layer of Kungurian age of Permian is covered by terrigeneous deposits of Mesozoic and Cenozoicage, and thickness of 250 to $400 \mathrm{~m} .17$ underground peaceful nuclear explosions were conducted within the territory of the Large Azgir field trrough the period of time from 1966 to 1979. They were detonated for studing some scientific problems as well as developing new technogies of peaceful applications of nuclear explosions. Five individual explosions: $A-1, A-2, A-3$, $A-4$, and A-5 were conduoted in the period from 1966 to 1977 to 
elaborate the procedure of stable and dry underground cavity creation. The cavities were supposed to be used for long-term gas storage and chemical waste disposal. The $A-1$ and $A-2$ explosions were conduoted within the Western Azgir and other-within the Eastern Azgir.

The report describes the data of seismological observations during the five explosions. Table 1 contains the data on actual conditions of the explosions condition, network magnitudes obtained by the USGS, ISO and USSR seismological survey. There are no true shot times for $\mathrm{A}-2, \mathrm{~A}-3$, and $\mathrm{A}-4$. The explosions coordinates are obtained from a map of 1:100000 scale. The shots depths are measured with $\pm 5 \mathrm{~m}$ accuracy. Hydrodynamic method of yield estimation gave $\pm 10+15 \%$ accuracy.

Figure 1 shows relative positions of the explosions at the site Azgir. It is worth noting that the cavites were opened, surveyed and measured long time after the explosions. The cavities created by the $\mathrm{A}-1$ and $\mathrm{A}-2$ explosions inside the Westem Azgir were filled by water and have maximum radia of 12-13 and 31-32 m respectively. The A-3 cavity had a radius of 37-38 $\mathrm{m}$ and was dry.

Three main geological complexes can be derived from technological boreholes:

1. above salt sand and clay complex (clay, sandstone, sand);

2. caprook of salt dome formed by gypsum and anhydrite; 
Table 1. Actual data and magnitudes of 5 tamped explosions at Azgir site

\begin{tabular}{|c|c|c|c|c|c|c|c|c|c|}
\hline \multirow{2}{*}{$\begin{array}{l}\text { NN } \\
\text { bore- } \\
\text { hole }\end{array}$} & Data & \multirow{2}{*}{$\begin{array}{l}\text { Time } \\
\text { (Greenwich) }\end{array}$} & \multirow{2}{*}{$\begin{array}{l}\text { Coordinates } \\
\text { latitude } \mathrm{N} \\
\begin{array}{c}\text { longitude } \mathrm{E} \\
\mathrm{O},\end{array}\end{array}$} & \multirow{2}{*}{$\begin{array}{c}\text { Depth, } \\
\text { m }\end{array}$} & \multirow{2}{*}{$\begin{array}{l}\text { Salt } \\
\text { roof } \\
\text { depth, } \\
\text { m }\end{array}$} & \multirow{2}{*}{$\begin{array}{l}\text { Yield, } \\
\text { kt }\end{array}$} & \multicolumn{3}{|c|}{ Magnitude $m_{b}$} \\
\hline & $d \mathrm{~m} \quad \mathrm{y}$ & & & & & & USGS & ISC & USSR \\
\hline$A-1$ & 22.04 .66 & $02-58-00.26$ & $\begin{array}{lll}47 & 49 & 45 \\
47 & 56 & 05\end{array}$ & 161.3 & $0-5$ & 1.1 & 4.7 & 4.7 & - \\
\hline$A-2$ & 01.07 .68 & $04-02-$ & $\begin{array}{lll}47 & 54 & 31 \\
47 & 54 & 43\end{array}$ & 597.2 & 305 & 25 & 5.5 & 5.5 & - \\
\hline$A-3$ & 22.12 .71 & $107-00-$ & $\begin{array}{lll}47 & 53 & 48 \\
48 & 08 & 00\end{array}$ & 987 & 255 & 65 & 6.0 & 6.0 & - \\
\hline$A-4$ & 29.07 .76 & $05-00-$ & & 997.6 & 248 & 58 & 5.9 & 5.9 & 5.9 \\
\hline$A-5$ & 30.09 .77 & $06-59-58.433$ & & 1503.5 & 335 & 9.3 & 5.1 & 5.0 & 5.0 \\
\hline
\end{tabular}

3. rocky salt.

In the A-1 borehole, salt is close to the surface and covered by several meters of modern deposites.

Figure 2 displays lithologic cross-section of the A-5 borehole of the Easterm dome and the A-2 borehole of the Western dome. The distance from the shot point to the salt - rool was of 290 and $1170 \mathrm{~m}$ respectively.

Following velocity intervals of shear and compressional - waves were measured by seismic exploration of the caspian depression in defferent lithological complexes:

$$
\mathrm{Vp}, \mathrm{km} / \mathrm{s} \quad \mathrm{Vs}, \mathrm{km} / \mathrm{s}
$$

above salt sand and clay complex $\quad 1.8-2.22 \quad 0.4-0.6$ 


$\begin{array}{lrr}\text { gypsum and anhydrite. } & \sim 3.0 & \sim 1.5 \\ \text { rooky salt } & 4.0-4.8 & \sim 2.3-2.5 \\ \text { carbonateous complex beneath salt } & 5.2-5.5 & \\ \text { basement } & 6.0-6.5 & 3-3.5\end{array}$

The thickness of sediments from seismic exploration is of 8 $\mathrm{km}$ in average which is much lower that obtained by different geophysical methods.

Deep seismic sounding results indicate following thicknesses and inlayer wave $\mathrm{P}$ velocities of the crust:

sediments

"granitic" layer

"basalt" layer

Moho boundary
$16 \mathrm{~km}$

$11 \mathrm{~km}$

$14 \mathrm{~km}$
$4.2-4.4 \mathrm{~km} / \mathrm{s}$ $6.4 \mathrm{~km} / \mathrm{s}$ $7.2 \mathrm{~km} / \mathrm{s}$ $8.0-8.4 \mathrm{~km} / \mathrm{s}$

Note relatively thin "granitic" layer. Some researchers do not exclude the possiblility of total absence of the layer in the southem part adjacent to the Caspian Sea.

Physical and mechanical properties of salt, anhydrite, and gypsum within the Large Azgir field were measured from the A-1 and $A-5$ boreholes samples and placed in Table 2. The properties do not depend on depth.

Following parameters are usually used in the simulations of the explosions effeots at the Azgir site: volume weight - 2.2 $\mathrm{g} / \mathrm{cm}^{3}$, compressional strength $-270 \mathrm{~kg} / \mathrm{cm}^{2}, \mathrm{Vp}-4250 \mathrm{~m} / \mathrm{s}$. 
Table 2. $\quad$ Physical and mechanical parameters of rocks at the Large Azgir field

\begin{tabular}{|c|c|c|c|c|c|c|c|c|}
\hline \multirow[t]{3}{*}{ Property } & \multirow[t]{3}{*}{ Dimens } & \multicolumn{4}{|c|}{ Borehole A1 } & \multicolumn{3}{|c|}{ Borehole A5 } \\
\hline & & \multicolumn{4}{|c|}{ salt } & salt & annydrite & gypsum \\
\hline & & $\max$ & $\min$ & av. & $\begin{array}{l}\text { numb. } \\
\text { samples }\end{array}$ & mean & mean & mean \\
\hline $\begin{array}{l}\text { Specific } \\
\text { weight }\end{array}$ & $\mathrm{g} / \mathrm{cm}^{3}$ & 2.21 & 2.14 & 2.16 & 183 & & & \\
\hline $\begin{array}{l}\text { Volume } \\
\text { weight }\end{array}$ & $\mathrm{g} / \mathrm{cm}^{3}$ & 2.15 & 1.98 & 2.09 & 192 & 2.15 & 2.84 & 2.15 \\
\hline Porrosity & $\%$ & 7.79 & 0.7 & 2.9 & 181 & 2.27 & 3.78 & 15.25 \\
\hline Humidity & $\%$ & 1.03 & 0.03 & 0.16 & 142 & 0.33 & 1.8 & 23.9 \\
\hline Solubility & & & & & & & & \\
\hline $15^{\circ} \mathrm{C}$ & 96 & 31.83 & 29.4 & 30.5 & 47 & & & \\
\hline $100^{\circ} \mathrm{C}$ & $\%$ & 33.0 & 31.2 & 32.2 & 47 & & & \\
\hline $\begin{array}{l}\text { Compression } \\
\text { strenght }\end{array}$ & $\mathrm{kg} / \mathrm{cm}^{2}$ & 420 & 103 & 263 & 177 & 270 & 592 & 177 \\
\hline $\begin{array}{l}\text { Dynamic } \\
\text { elastie } \\
\text { module }\end{array}$ & $\begin{array}{c}\mathrm{kg} / \mathrm{cm}^{2} \mathrm{x} \\
10^{-5}\end{array}$ & 2.3 & 7.8 & 1.7 & 111 & 3.2 & 6.4 & 3.1 \\
\hline $\begin{array}{l}\text { Poisson } \\
\text { ratio }\end{array}$ & & 0.29 & 0.07 & 0.23 & 92 & 0.29 & 0.33 & 0.3 \\
\hline$v_{p}$ & $\mathrm{~m} / \mathrm{c}$ & & & & & 4420 & 5680 & 4200 \\
\hline$V_{\text {s }}$ & $\mathrm{m} / \mathrm{c}$ & & & & & 2410 & 2310 & 2250 \\
\hline
\end{tabular}

\section{Vega site}

The Vega site is situated within the territory of Astrakhan gas-condensate deposits inside the southerm part of the Caspian depression of the Russian platform. The site Vega is 10 to $20 \mathrm{~m}$ 


\section{below sea level.}

15 underground peaceful nuclear explosion were conducted at the Vega site within the Seitov salt dome from 1980 to 1984. The purpose of the explosions was oreating of cavities for condensate storage and waste disposal within the seitov (Aksarai) dome. The Seitov salt dome has a horseshoe-like shape (Figure 3). In the central part of the dome, salt was reached at a depth of 690 to $800 \mathrm{~m}$, and at the slopes of the dome at a depth of $1000 \mathrm{~m}$. Salt layer thickness is of $3000 \mathrm{~m}$. Dolomitic anhydrite layer of 15 to $30 \mathrm{~m}$ thickness covers salt.

Table 3 presents actual data on all the fifteen explosion as well as network magnitudes of the USGS, ISO and USSR seismological Survey.

The true shot times are given with an acouracy of \pm 5 msec, and the depth are $\pm 5 \mathrm{~m}$ accurate. The designed data are given in brackets. Coordinates are obtained from a map with 1:100000 scale.

Figure 3 shows isobaths of the salt roof within the site and positions of technological (T) and exploratory (F) boreholes (scale 1:100000).

Geological section of the territory is presented by Quartemary, Neogene (Apsheron and Akonegyl stages), and Permian deposits. The section is characterized by lithological section of the borehole $1 \mathrm{~T}$ (explosion 10/8/80), shown in Figure 4 . 
13

Table 3. Actual data and magnitudes of 15 explosions at the site Vega

\begin{tabular}{|c|c|c|c|c|c|c|c|c|c|c|}
\hline \multirow{2}{*}{$\begin{array}{c}\text { Data } \\
\text { Series } \\
\text { title }\end{array}$} & \multirow{2}{*}{$\begin{array}{c}\text { Time } \\
\text { (Greenwich) }\end{array}$} & \multirow{2}{*}{ bor } & \multirow{2}{*}{$\begin{array}{c}\text { Coordi- } \\
\text { nates } \\
\varphi^{\circ} \mathrm{N} \\
\lambda^{\circ} \mathrm{E}\end{array}$} & \multirow{2}{*}{$\begin{array}{l}\text { Shot } \\
\text { depth. }\end{array}$} & \multirow{2}{*}{$\begin{array}{l}\text { Salt } \\
\text { roof } \\
\text { depth, } \\
\text { m }\end{array}$} & \multirow{2}{*}{$\begin{array}{c}\text { Abso- } \\
\text { lute } \\
\text { eleva } \\
\text { tion, } \\
\text { m }\end{array}$} & \multirow{2}{*}{$\begin{array}{l}\text { Yield, } \\
\text { kt }\end{array}$} & \multicolumn{3}{|c|}{ Magnitude $m_{b}$} \\
\hline & & & & & & & & USGS & ISC & USSR \\
\hline $\begin{array}{c}08.10 .80 \\
\text { Vega-1 }\end{array}$ & $06-00-00.290$ & $1 \mathrm{~T}$ & & 1050 & 743 & & 8.8 & 5.2 & 5.2 & 5.2 \\
\hline $\begin{array}{c}26.09 .81 \\
\text { Vega-2 }\end{array}$ & $\begin{array}{r}05-00-00.275 \\
-03-59.941\end{array}$ & $\begin{array}{l}4 \mathrm{~T} \\
2 \mathrm{~T}\end{array}$ & & $\begin{array}{l}1050 \\
1050\end{array}$ & $\begin{array}{l}735 \\
732\end{array}$ & & $\begin{array}{l}8.4 \\
8.4\end{array}$ & $\begin{array}{l}5.2 \\
5.3\end{array}$ & 5.2 & $\begin{array}{l}5.1 \\
5.2\end{array}$ \\
\hline $\begin{array}{c}16.10 .82 \\
\text { Vega-3 }\end{array}$ & $\begin{array}{r}06-00-00.148 \\
-05-00.075 \\
-10-00.102 \\
-15-00.169\end{array}$ & $\begin{array}{l}7 \mathrm{~T} \\
6 \mathrm{~T} \\
5 \mathrm{~T} \\
3 \mathrm{~T}\end{array}$ & & $\begin{array}{r}970 \\
990 \\
1100 \\
1050\end{array}$ & $\begin{array}{l}728 \\
772 \\
773 \\
742\end{array}$ & & $\begin{array}{r}8.4 \\
8.8 \\
8.8 \\
13.5\end{array}$ & $\begin{array}{l}5.2 \\
5.2 \\
5.2 \\
5.4\end{array}$ & $\begin{array}{l}5.2 \\
5.2 \\
5.2 \\
5.4\end{array}$ & $\begin{array}{l}5.0 \\
5.1 \\
5.0 \\
5.2\end{array}$ \\
\hline \multirow[t]{5}{*}{$\begin{array}{c}24.09 .83 \\
\text { Vega-4 }\end{array}$} & $05-00-00.030$ & 89 & $\left.\begin{array}{l}46.7831 \\
48.3152\end{array}\right)$ & 1050 & 735 & -13.4 & 8.4 & 5.1 & 5.2 & 4.8 \\
\hline & $-05-00.030$ & 92 & $\begin{array}{l}46.7878 \\
48.2972\end{array}$ & 1060 & 770 & -15.6 & 8.4 & 5.0 & 5.1 & 4.8 \\
\hline & $-10-00.075$ & $11 \mathrm{~T}$ & $\begin{array}{l}46.7672 \\
48.3106\end{array}$ & 920 & 733 & -14.6 & $4.2-28$ & 4.9 & 5.0 & 4.7 \\
\hline & $-15-00.144$ & 139 & $\begin{array}{l}46.7494 \\
48.3025\end{array}$ & 1100 & 753 & -13.4 & 8.4 & 5.2 & 5.2 & 4.9 \\
\hline & $-19-59.934$ & $10 \mathrm{~m}$ & $\begin{array}{l}46.7539 \\
48.2894\end{array}$ & 950 & 742 & -16.6 & 8.4 & 5.2 & 5.4 & 5.0 \\
\hline- & $-25-00.000$ & $12 T$ & $\begin{array}{l}46.7658 \\
48.2744\end{array}$ & 1050 & 774 & -17.7 & 8.4 & 5.2 & 5.3 & 4.9 \\
\hline $\begin{array}{c}27.10 .82 \\
\text { Vega-5 }\end{array}$ & $\begin{array}{l}06-00- \\
06-05-\end{array}$ & $\begin{array}{l}14 \mathrm{~m} \\
15 \mathrm{~m}\end{array}$ & & $(700)$ & & & $(3.2)$ & $\begin{array}{l}5.0 \\
5.0\end{array}$ & $\begin{array}{l}5.0 \\
5.0\end{array}$ & $\begin{array}{l}5.0 \\
4.7\end{array}$ \\
\hline
\end{tabular}

Quartermary deposits are presented by sandy clays with sand lamination with a thickness of $170 \mathrm{~m}$ and averaged 
compressional wave velooity $\nabla=1800 \mathrm{~m} / \mathrm{s}$ from seismic exploration. Neogen deposits $460 \mathrm{~m}$ thick and with $\nabla \mathrm{p}=2200 \mathrm{~m} / \mathrm{s}$ are formed by argillite with sandstone and sand lamination. Below are Mesozoio 50-70 m thiok high velooity deposits formed by argillite, limestone and marl. The thickness of the layer sharply increases at the slopes. Dolomatic anhydrite is a caprock of the salt dome. Mesozoic deposits and caprock average compressional velooity reaones $5500 \mathrm{~m} / \mathrm{s}$. All the explosions were detonated in the north-east part of the seitov dome in the deposites of middle - and large-grained salt. The rock texure is massive, brecoiated and laminated. SaIt is highly deformed during the dome development. Averaged velocity in salt is of $4200 \mathrm{~m} / \mathrm{s}$.

Following physical and meohanical properties are obtained from laboratory analysis of the samples from the seitov salt dam:

volume weight

compression strenght

extention strenght

dynamio elastic limit

Poisson ratio (dynamio)

The highest water-filled layer ranges from 150 to $300 \mathrm{~m}$ with output of $300 \mathrm{~m}^{3}$ water is gas-1illed and pressurized.

Figure 5 shows Seitov dome's geological structure by the

$$
2.21 \mathrm{~g} / \mathrm{cm}^{3}
$$

$264 \mathrm{~kg} / \mathrm{cm}^{2}$

$18 \mathrm{~kg} / \mathrm{cm}^{2}$

$3.2610^{+5} \mathrm{~kg} / \mathrm{cm}^{2}$

0.26

m

.


profile orossing explosion boreholes 1T, 3T, 4T, exploratory boreholes $T P$ and $2 P$ and structure borehole 280 drilled to 3700 . m.

This report considers seismic data from the Vega-3 experiment. The experiment included 4 explosions placed in the comers of quadrangle of total area of $3.5 \times 1.5^{2} \mathrm{~km}$. The charges were fired with 5 minute delay. The closest observation point was inside the quadrangle near the 1T borehole (Vega-1 explosion).

2. Procedure of seismic observations and equipment.

Seismic measurements from the explosions at the Azgir and Vega sites were conducted by the IDG and NIPIPromtechnologia in the range from 0.2 to $260 \mathrm{~km}$. The range of measurements can be divided into epicentral zone (from 0.2 to $7 \mathrm{~km}$ ) and following zone (from 7 to $260 \mathrm{~km}$ ).

During most of the explosions at the Azgir site, profiles in the epicentral zones were oriented to of town Azgir, and at the Vega site to the borehole $1 \mathrm{~T}$. Beyond $7 \mathrm{~km}$, portable seismic stations were established within towns and other populated areas for the sake of seismic safety which was thoroughly investigated. In side large towns (Astrakhan, Volgograd) several seismic stations were established to estimate maximum possible yield depending on engineering soil properties. 
Following types of measurements were used during observations:

- straight channel of displacement, particle velocity and acceleration recording; sometimes different types of seismometers were used at one observation point;

- recording of two motion components: displacement and velocity from one seismometer:

- recording of pressure by hydrophone placed into the water-filled borehole $\mathrm{A}-1$ at a depth of $164 \mathrm{~m}$ during the explosion $\mathrm{A}-5$.

Vibrographs of strong motion, VBP, and accelerographs were usually used in the nearby zone for measuring of displacement or acceleration of vertical (Z) and radial (X) components. At larger distances, three-component motion (vertical, radial, and tangential (Y)) were usually measured. Radial component was oriented to epicenter, and tangential was perpendicular to radial one. During group explosion Vega-3, horizontal sensors in the near by zone were oriented to each of the four boreholes except acceleration recording where sensor was oriented to the first explosion in the borehole 7 T.

In the range below $70 \mathrm{~km}$, during explosions at the Azgir site and $15 \mathrm{~km}$ at the Vega site seismic stations were established in the desert zone of the Caspian depression in different azimuths. At larger distances, seismic stations were 
related to populated areas along Volga river and its branches.

Tables 4 and 5 summarize data on the portable seismic stations established by the IDG during explosions at the Azgir and Vega sites. The data included in Tables 4 and 5 . on seismograms of components $(Z, X, Y)$ of displacement (W), velocity $(U)$ and accelation (A) indicate waveforms available in digital form on the tape attached to the report. Each explosion has its own directory: $\mathrm{A}-1$ - az1; $\mathrm{A}-2$ - az2; $\mathrm{A}-3$ - az3; $\mathrm{A}-4$ - az4; $\mathrm{A}-5-$ az5; and vega - av3 (v31, v32, v33, v34).

Particle velooity and displacement were measured in broad dynamic range by sensor VBP, USF, SM, VIB-A (natural period of 1.5 to $2 \mathrm{sec}$ ) and $\mathrm{S} 5 \mathrm{~S}(5 \mathrm{sec})$. Seismometers were connected to galvanometers of different types. Straight channel of displacement was obtained by connecting to overdamped galvanometer of magnetoelectric type GB-III-3 with natural period of $5 \mathrm{~Hz}$ and damping $\mathrm{D}_{\mathrm{g}}=10$ to 15 . Velocity channel was obtained by using of galvanometers GB-IV-V-3 with natural frequency of $120 \mathrm{~Hz}$ and damping of $\mathrm{D}_{\mathrm{g}} \approx 1$. Galvanometers were established in the magnetic blocks of electromechanical oscilloscopes OMS-2M, $\mathrm{POB}-12$, and N-700. Signals were recorded on photographic paper with a rate of 20 to $50 \mathrm{~mm} / \mathrm{sec}$. To measure acceleration, laboratory sample of accelerograph with straight optic recording was used. Accelerometers with natural frequency. of 20 to $30 \mathrm{~Hz}$ installed in the accelerograph were used to 
Table 5. Data of seismic measurements from Vega-3 series presented by digitized waveforms

\begin{tabular}{|c|c|c|c|c|c|c|c|}
\hline \multirow{2}{*}{ Station } & \multicolumn{4}{|c|}{$\begin{array}{c}\text { Distance to } \\
\text { borehole, km }\end{array}$} & \multicolumn{3}{c|}{ Motion component } \\
\cline { 2 - 8 } & $7 \mathrm{~T}$ & $6 \mathrm{~T}$ & $5 \mathrm{~T}$ & $3 \mathrm{~T}$ & $\mathrm{~W}$ & $\mathrm{U}$ & $\mathrm{A}$ \\
\hline 1T & 2.23 & 1.51 & 1.65 & 1.94 & & & zXy \\
Seitovka & 14.6 & 15.6 & 18.1 & 19.0 & zXy & zXy & \\
Krasny Yar & 25.8 & 24.2 & 26.0 & 25.0 & zXy & zxy & \\
Astrakhan-1 & 42.5 & 41.0 & 45.0 & 44.5 & zxy & zXy & \\
-2 & 46.5 & 45.0 & 49.0 & 48.5 & zxy & zXy & \\
\hline
\end{tabular}

measure three components. Rate was of $120 \mathrm{~mm} / \mathrm{sec}$. Dynamic range of seismic channels was not larger than $30 \mathrm{~dB}$.

Working channels of described types allowed to conduct undisturbed recording of dynamic parameters of oscillations in the frequency range from 1 to $15-20 \mathrm{~Hz}$ where gain is constant. S5S seismograph is characterized by lower frequenoy of constant gain reaching $0.3 \mathrm{~Hz}$. Standard frequency characteristics are presented in Figure 8. Constant amplification of each digitized record is indicated in the header.

Seismic sensors were established in specially digged vaults 70 to $80 \mathrm{~cm}$ deep, and in towns, in underground stages of buildings at cement or conorete fioor. 
CHAPTER 2

\section{INVESTIGATION OF AMPLITUDES AND PERIODS OF \\ SEISMTO WAVES RECORDED IN THE LOCAI ZONE \\ BY PORTABLE SEISMIO STATIONS}

1. Content of experimental data.

Seismio waves generated by the explosions in salt at the sites Azgir and Vega were measured at the free surface by portable seismic stations established in the epicentral distance range from 0.2 to $260 \mathrm{~km}$. The prinoipal goal of the seismic measurements was obtaining experimental data in order to investigate general features of seismic waves generation and propagation as well as development of methods predicting seismic waves parameters and seismic effects on constructions and buildings.

To characterize seismic signal, following parameters of oscillations are usually used: maximum (peak) amplitudes of displacement (W), velocity $(V)$, and acceleration (a) measured at vertical (Z) and horizontal radial (X) components of ground motion, as well as periods of oscillations (T) in that maximum phase. Statistical relationships between damages of buildings and constructions of different types and the peak radial velocity, $U_{x}$, have been obtained from previous experience. Thus, peak velooity, $\mathrm{U}_{x}$, in body waves group with period from 0.1 to $0.7 \mathrm{sec}$ corresponding to usuall natural periods of typioal. constructions is used as a principal parameter of seismio oscillations. In the near-field zone of borehole explosions, it 
is also necessary to take into account vertical component of motion, $\mathrm{U}_{z}$, which can be several times larger than radial one.

As noted above, the seismio measurements in the local zone of the explosions at the sites Vega and Azgir have been conducted by the IDG and NIPIPromtechnologia. Peak amplitudes and their periods in seismic waves were estimated from seismograms of these measurements from the explosions $\mathrm{A}-1,2,3,4,5$ at the site Azgir and $1 \mathrm{~T}-13 \mathrm{~T}$ at the site Vega. Thus the data from the series Vega-1,2,4 were added to the data from the Vega-3.

Seismograms recorded by the IDG on photographic paper by using galvanometers were digitized and added to the report on a DATape. This DATape includes 296 waveforms digitized from 64 paper seismograms obtained from the explosions $A-1,2,3,4,5$ and Vega-3. Tables 3 and 4 contain information on the waveforms, and appendix 1 describes technique of digitization. Digital waveforms were used during spectral analysis (Chapter 3 ).

2. Parameters of seismic waves from the explosions at the sites Azgir and Vega.

Principal features of seismic wavefield in the local zones of the explosions Vega and Azgir are similar. Paper [2] describes general features of wavefield in the local zone of explosions in salt.

All the original seismic records from explosions in salt represent a superposition of seismic waves of different types. Structure of wavefield recorded at distances shorter than $300 \mathrm{~km}$ 
does not depend on explosion parameters and is determined by geological structure of sedimentary layer in regions with : salt-dome tectonics. The regions of the observations are characterized by sharp velocity differentiation at the boundary between salt roof and low-velocity sedimentary layer, sharp slopes of salt domes wings, and relatively sharp velooity boundary at the bottom of salt layer - carbonates sediments. Incident angle of seismic wave at the free surface is close to vertical due to refraction on salt-sediments boundary. Due to sharp velocity differentiation at this boundary, intensive converted shear waves of PS type are generated. So, longitudinal waves of different types are observed at vertical component, and shear waves are observed at horizontal component. Shear waves' time delay relative to longitudinal wave, $\Delta t$, depends on the thickness of deposites above salt and velocities of seismic waves in this layer. When steep slope of the boundary exists, it is natural to wait strong variation of amplitudes of seismic waves outgoing under different angles from the salt layer. Sharp boundary at the bottom of the salt layer also generates strong reflected waves.

Principal features of the seismic records are as follows:

- longer total duration of horizontal oscillations;

- PS converted waves dominating on horizontal component of recordings;

- low amplitude surface wave in the range of observations.

Following principal seismic phases in the range of observations can be distinguished in longitudinal waves: $P_{0}, P_{g}$, 
$P_{M} P$, and $P_{M}$ at vertical component and their converted phases at horizontal component. Pure (straight) shear waves can not be deteoted by kinematio features due to absence of distinct arrival on the records.

$\mathrm{P}_{\mathrm{o}}$ - wave with apparent velocity of 3.5 to $4.2 \mathrm{~km} / \mathrm{sec}$ can be traced in the first arrival to a distance of 10 to $15 \mathrm{~km}$ from the epicenter, and represents straight longitudinal wave propagating from the source to seismio station within salt and above salt sediments. $P_{g}$ - wave related to "granitic" layer of the Earth crust is traced in the first arrival with apparent velocity of 6.0 to $6.2 \mathrm{~km} / \mathrm{sec}$ from 10 to $15 \mathrm{~km}$. This wave is dominant in the first part of the records, i.e. is of the highest amplitude relative to other phases and wave types.

In the range from 80 to $250 \mathrm{~km}$ at continental platforms, wave $P_{M} P$ refleoted from " $M$ " boundary dominantes at above critically angles. Existance and amplitude of $P_{M} P$ - wave depend on the Earth crust geological and velocity structure and character of N-boundary (velocity and density differentiation, transient layer etc.).

From waveforms shapes and growth of amplitudes in following arrivals, this wave apparently exists in the wave field from the Azgir explosions. Sparce seismic profile beyond $100 \mathrm{~km}$, however, does not allow to identify this wave reliably by kinematic and dynamic features.

Guide or weak refracted wave $P_{M}$ associated with the boundary $M$ represents low amplitude seismic phase and is identified in the first arrival beyond $180 \mathrm{~km}$ with apparent 
velocity of 7.7 to $8.1 \mathrm{~km} / \mathrm{sec}$.

Thus, peak amplitudes of seismic waves at vertical component are related to waves $P_{O}, P_{g}$, and $P_{M} P$ depending on. epicentral distance, and at horizontal component converted waves of $P_{0} S, P_{g} S, P_{M} P S$ dominate.

As noted above, the main goal of the seismic measurements was seismic hazard estimate for explosions from the data on peak amplitudes and periods in body waves in the frequency range 0.1 to 0.7 sec. Due to this goal, the peak parameters of displacement, velocity and acceleration were measured without separating of different seismic phases but searching of peak amplitude in all body waves group. Peak amplitudes at vertical and horizontal component generally were not measured at the same time, of course, in this case.

Table 6 for Azgir and tables 7 and 8 for Vega summarize the peak amplitude measurements of displacement, velocity, and acceleration and related periods in dominating seismic body waves. These tables need to be desoribed more carefully. Table 6 for Azgir, was compiled from the individual explosions $A-1,2,3,4,5$ and containes only peak dispiacements and velocities. This tabie includes the data in the range from 0.2 to $260 \mathrm{~km}$. Table 7 compiled for near-field zone (less than $7 \mathrm{~km}$ ) of the Vega explosions includes peak measurements of displacement, velocity and acceleration depending on range. . Table 8 includes data on displacements and velocities recorded within towns of Stepnoi, Djanai, Seitovka, Aksaraiskaya, Krasny Yar, and Astrakhan which were at distances of 1 to $50 \mathrm{~km}$ from 
Table 6. The maximal amplitudes and periods in body waves for the explosions at the site Azgir

\begin{tabular}{|c|c|c|c|c|c|c|c|c|c|}
\hline Stations & $\begin{array}{c}\text { Rhipo } \\
\mathrm{km}\end{array}$ & \multicolumn{4}{|c|}{ Displacement } & \multicolumn{3}{|c|}{ Velocity of displacement } \\
\cline { 3 - 11 } & & $\mathrm{W}^{\mathbf{z}}, \mathrm{mm}$ & $\mathrm{T}^{\mathbf{z}}, \mathrm{s}$ & $\mathrm{W}^{\mathbf{x}}, \mathrm{mm}$ & $\mathrm{T}^{\mathbf{x}}, \mathrm{s}$ & $\begin{array}{c}\mathrm{U}^{\mathbf{z}}, \\
\mathrm{sm} / \mathrm{s}\end{array}$ & $\mathrm{T}^{\mathbf{z}}, \mathrm{s}$ & $\begin{array}{c}\mathrm{U}^{\mathbf{x}}, \\
\mathrm{sm} / \mathrm{s}\end{array}$ & $\mathrm{T}^{\mathbf{x}}, \mathrm{s}$ \\
\hline 1 & 2 & 3 & 4 & 5 & 6 & 7 & 8 & 9 & 10 \\
\hline
\end{tabular}

\section{EXPIOSION A-I}

\begin{tabular}{|c|c|c|c|c|c|c|c|c|c|}
\hline$N_{1}$ & 0.188 & 340 & 0.092 & - & - & 410 & 0.09 & 79 & 0.2 \\
\hline \multirow[t]{4}{*}{ N2 } & 0.256 & 121 & 0.18 & - & - & 159 & 0.18 & 30 & - \\
\hline & & 112 & 0.18 & - & - & 272 & 0.032 & 56.3 & 0.05 \\
\hline & & 96 & 0.06 & - & - & 278 & 0.05 & 126 & 0.024 \\
\hline & & 155 & 0.38 & - & - & 256 & 0.38 & - & - \\
\hline \multirow[t]{4}{*}{ N3 } & 0.34 & 56.7 & 0.16 & - & - & - & - & - & - \\
\hline & & 60.5 & 0.23 & - & - & 110 & $0: 15$ & 42 & - \\
\hline & & 56.5 & 0.16 & - & - & 124 & 0.16 & 30.9 & 0.044 \\
\hline & & 125 & 0.38 & - & - & 206 & 0.38 & - & - \\
\hline \multirow[t]{5}{*}{ N4 } & 0.526 & 14.4 & 0.13 & - & - & 80 & 0.14 & 15 & 0.088 \\
\hline & & 9.36 & 0.18 & 34 & 0.3 & 79 & 0.088 & 30.1 & 0.3 \\
\hline & & - & - & - & - & 42 & 0.13 & 22 & 0.21 \\
\hline & & - & - & - & - & 60 & 0.1 & 57.6 & 0.07 \\
\hline & & 38.8 & 0.32 & 38.4 & 0.52 & 76 & 0.32 & 48.4 & 0.52 \\
\hline \multirow[t]{3}{*}{ N5 } & 1.013 & 3.15 & 0.12 & - & - & 34 & 0.11 & 36.2 & 0.132 \\
\hline & & 3.6 & 0.12 & 0.77 & 0.25 & 12.1 & 0.13 & 13.6 & 0.25 \\
\hline & & 5 & 0.87 & 10.7 & 0.6 & 8.3 & 0.52 & 24.2 & 0.24 \\
\hline \multirow[t]{2}{*}{ N6 } & 2.3 & 2.31 & 0.23 & 5.83 & 0.8 & 7.24 & 0.23 & 6.34 & 0.3 \\
\hline & & 1.22 & 0.17 & 0.32 & 0.15 & 4.43 & 0.16 & 5 & 0.15 \\
\hline
\end{tabular}




\begin{tabular}{l|c|c|c|c|c|c|c|c|c|}
\hline \multicolumn{1}{|c|}{1} & 2 & 3 & 4 & 5 & 6 & 7 & 8 & 9 & 10 \\
\hline N7 & 7.6 & 0.268 & 0.66 & 0.744 & 1.0 & 0.288 & 0.44 & 0.585 & 1.0 \\
N8 & 15.3 & 0.0238 & 0.64 & 0.148 & 1.16 & 0.06 & 0.73 & 0.141 & 0.45 \\
Balkuduk & 27.2 & 0.008 & 0.46 & 0.058 & 0.44 & 0.078 & 0.35 & 0.082 & 0.44 \\
Harabali & 69 & 0.0095 & 0.8 & 0.0185 & 0.9 & 0.075 & 0.085 & 0.016 & 0.5 \\
H.Baskunchak & 98 & 0.016 & 0.45 & 0.0108 & 0.33 & 0.023 & 0.31 & 0.022 & 0.31 \\
Bolohuni & 112 & 0.0114 & 0.38 & 0.0104 & 0.38 & 0.029 & 0.25 & 0.019 & 0.38 \\
Achtubinsk & 145 & 0.0061 & 0.43 & 0.0042 & 0.48 & 0.009 & 0.43 & 0.0062 & 0.41 \\
Astrachan-I & 161 & 0.0052 & 0.44 & 0.005 & 0.31 & 0.0104 & 0.31 & 0.0103 & 0.4 \\
Astrachan-II & 164 & 0.006 & 0.5 & 0.0062 & 0.5 & 0.008 & 0.5 & 0.009 & 0.45 \\
Astrachan-II & 165 & 0.0034 & 0.47 & 0.0046 & 0.5 & 0.006 & 0.47 & 0.0055 & 0.5 \\
Kapustin Jar & 182 & 0.0016 & 0.48 & 0.0074 & 0.45 & 0.00230 .29 & 0.0103 & 0.45 \\
Volgograd-I & 260 & 0.0011 & 0.46 & 0.0015 & 0.65 & 0.0022 & 0.31 & 0.0018 & 0.3 \\
Volgograd-II & 262 & 0,00145 & 0.35 & 0,0023 & 0.39 & 0,0026 & 0,35 & 0.0037 & 0.39
\end{tabular}

EXPLOSION A-II (S-E profile)

$\begin{array}{llllllllll}\text { N1 } & 0.6 & 285 & 0.033 & - & - & 1160 & 0.02 & - & - \\ \text { N2 } & 0.85 & 257 & 0.47 & 485 & 0.53 & 486 & 0.37 & 364 & 0.53 \\ \text { N3 } & 1.16 & 112 & 0.5 & 70.2 & 0.37 & 168 & 0.5 & 66 & 0.37 \\ \text { N4 } & 1.7 & 81 & 0.4 & 50.8 & 0.45 & 100 & 0.4 & 41.1 & 0.45 \\ \text { N5 } & 2.05 & 8.15 & 0.6 & 34.8 & 0.5 & 81.3 & 0.19 & 50.6 & 0.5 \\ \text { N6 } & 3 & 10.4 & 0.41 & 25 & 0.43 & 17.4 & 0.41 & 11.9 & 1.06\end{array}$

(S-W profile)

$\begin{array}{llllllllll}\text { N1 } & 0.85 & 248 & - & 75 & - & 405 & - & 35.7 & - \\ \text { N2 } & 1.16 & 164 & 0.4 & 72 & 0.48 & 170 & 0.4 & 120 & 0.48\end{array}$




\begin{tabular}{llll|c|c|c|c|c|c|c|}
\hline \multicolumn{1}{|c|}{1} & 2 & 3 & 4 & 5 & 6 & 7 & 8 & 9 & 10 \\
N3 & 1.7 & 47.3 & 0.34 & 42 & 0.38 & 107 & 0.34 & 64 & 0.38 \\
N4 & 3 & 10.7 & 0.33 & 12.8 & 0.41 & 16.9 & 0.33 & 17.5 & 0.41 \\
N5 & 7.5 & 1.4 & 0.54 & 4.6 & 0.63 & 2.1 & 0.33 & 3.8 & 0.39 \\
Balkuduk & 27 & 0.384 & 0.24 & 0.72 & 1.8 & 0.93 & 0.24 & 0.8 & 0.36 \\
Shibarol & 50 & 0.338 & 0.56 & 0.558 & 0.48 & 0.365 & 0.56 & 0.525 & 0.48 \\
Harabali & 70.5 & 0.116 & 0.49 & 0.125 & 0.49 & 0.125 & 0.49 & 0.135 & 0.49 \\
Bolchuni & 127 & - & - & 0.152 & 0.43 & - & - & 0.23 & 0.43 \\
H.Baskunchak & 142 & 0.027 & 0.24 & 0.024 & 0.33 & 0.11 & 0.24 & 0.07 & 0.33 \\
Astrachan & 170 & 0.0437 & 0.45 & 0.061 & 0.32 & 0.064 & 0.45 & 0.11 & 0.32 \\
& & 0.040 & 0.3 & 0.049 & 0.34 & 0.085 & 0.3 & 0.088 & 0.34 \\
& & 0.050 & 0.36 & 0.076 & 0.33 & 0.073 & 0.36 & 0.14 & 0.33 \\
& & 0.046 & 0.32 & 0.051 & 0.32 & 0.09 & 0.32 & 0.1 & 0.32
\end{tabular}

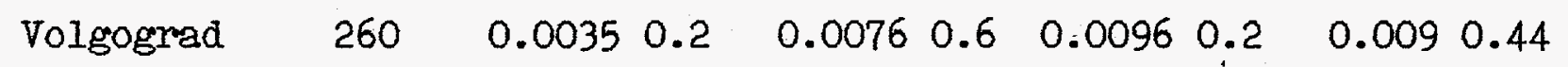
$\begin{array}{llllllll}0.1 & 0.32 & 0.0165 & 0.56 & 0.02 & 0.32 & 0.014 & 0.56\end{array}$ $\begin{array}{llllllll}0.039 & 0.32 & 0.0096 & 0.5 & 0.0076 & 0.32 & 0.01 & 0.5\end{array}$

EXPLOSION A-III

$\begin{array}{llllllllll}\text { N1 } & 2.3 & 53.5 & 0.4 & 53 & 0.38 & 87.5 & - & 68.5 & - \\ \text { N2 } & 4.7 & 21 & 0.44 & 28 & 0.5 & 31.5 & - & 36.5 & - \\ \text { Borehole A-I } & 17.8 & 0.83 & 0.31 & 1.16 & 0.31 & 1.55 & - & 1.72 & 0.23 \\ \text { Azgir } & 18.2 & 1.25 & 0.55 & 1.55 & 0.7 & 1.62 & - & 1.4 & - \\ \text { Asan } & 23 & 1.4 & 0.4 & 2.4 & 0.45 & 2.15 & - & 3.85 & - \\ \text { Batirbek } & 25.5 & 0.93 & 0.65 & 2.0 & 0.9 & 1.27 & - & 1.42 & - \\ \text { Ferma } & 37.5 & 0.44 & 0.39 & 1.02 & 0.67 & 0.72 & - & 0.96 & - \\ \text { Balkuduk } & 42 & 0.61 & 0.55 & 1.0 & 0.6 & 0.65 & - & 1.1 & -\end{array}$




\begin{tabular}{lccc|c|c|c|c|c|c|c|}
\hline 1 & 2 & 3 & 4 & 5 & 6 & 7 & 8 & 9 & 10 \\
\hline Shibarol & 47.5 & 0.63 & 0.7 & 0.9 & 0.65 & 0.6 & - & 0.8 & - \\
Harabali & 84 & 0.21 & 1.14 & 0.25 & 0.55 & 0.14 & 0.68 & 0.16 & 0.55 \\
H.Baskunchak & 113 & 0.45 & 0.45 & 0.35 & 0.51 & 0.62 & - & 0.44 & 0.43 \\
Achtubinsk & 154 & 0.119 & 1.15 & 0.15 & 1.2 & 0.056 & - & 0.095 & - \\
Ishonda & 31 & 0.91 & 0.46 & 1.63 & 0.46 & 1.53 & 0.46 & 1.58 & 0.46 \\
Kalpe Shalash & 39 & 0.33 & 0.54 & 0.42 & 0.68 & 0.45 & 0.54 & 0.42 & 0.68 \\
Bashkirkuduk & 46.5 & 0.3 & 0.99 & 0.57 & 0.78 & 0.3 & 0.99 & 0.5 & 0.78 \\
Kenzegora & 59 & 0.26 & 1.2 & 0.39 & 0.97 & 0.22 & 1.2 & 0.26 & 0.97 \\
Tazgachkan & 69.5 & 0.2 & 1.1 & 0.32 & 0.55 & 0.18 & 1.1 & 0.43 & 0.55 \\
Charabali & 84 & 0.32 & 0.75 & 0.31 & 1.2 & 0.2 & 0.75 & 0.28 & 0.6 \\
Astrachan & 170 & 0.2 & 0.65 & 0.28 & 0.43 & 0.175 & 0.65 & 0.37 & 0.43
\end{tabular}

\section{EXPLOSION A-IV}

$\begin{array}{lrrlllllll}\text { N1 } & 1.17 & 282 & 0.5 & - & - & 480 & 0.23 & - & - \\ \text { N2 } & 1.72 & 160 & 0.43 & 50 & 0.85 & 220 & 0.37 & 36 & 0.59 \\ \text { N3 } & 2.6 & 21 & 0.42 & 25 & 0.46 & 49 & 0.27 & 52 & 0.45 \\ \text { N4 } & 4.12 & 17 & 0.38 & 14 & 0.59 & 28 & 0.3 & 15.5 & 0.39 \\ \text { N5 } & 5.35 & 10 & 0.36 & 9.16 & 0.6 & 16.3 & - & 16.6 & - \\ \text { N6 } & 8 & 7 & 0.43 & 6.8 & 0.38 & 13.2 & 0.32 & 10 & 0.27 \\ \text { Azgir } & 18 & 2.24 & 0.49 & 4.9 & 0.44 & 3.4 & 0.41 & 8 & 0.41 \\ \text { Asan } & 23 & 1.02 & 0.425 & 2 & 0.7 & 1.3 & 0.31 & 1.56 & 0.43 \\ \text { Batirbek } & 27 & 0.55 & 0.52 & 0.68 & 0.48 & 0.66 & 0.33 & 1.15 & 0.3 \\ \text { Balkuduk } & 42 & 0.35 & 1 & 0.77 & 1.2 & 0.31 & 0.85 & 0.85 & 0.5 \\ \text { Shibarol } & 47.5 & 0.375 & 1 & 0.62 & 0.8 & 0.49 & 0.7 & 1.3 & 0.55\end{array}$




\begin{tabular}{lrrr|c|c|c|c|c|c|c|}
\hline 1 & 2 & 3 & 4 & 5 & 6 & 7 & 8 & 9 & 10 \\
\hline N1 & 2.5 & 80 & 0.185 & 19 & - & 24 & 0.142 & 16.4 & 0.184 \\
N2 & 3.45 & 6.3 & - & - & - & 27 & 0.15 & - & - \\
N3 & 4.1 & 3.1 & - & 3.1 & - & 16 & 0.12 & 10.8 & 0.18 \\
N4 & 6.2 & 1.1 & - & 1.3 & - & 6.6 & 0.1 & 6 & 0.13 \\
N5 & 8 & 1.3 & 0.31 & 1.7 & 0.2 & 2.75 & 0.22 & 3.8 & 0.21 \\
Azgir & 18.2 & 0.99 & 0.32 & 1.01 & 0.4 & 1.75 & 0.32 & 2.1 & 0.27 \\
Borehole A-I & 17.8 & 0.28 & 0.16 & 0.5 & 0.3 & 1.4 & 0.16 & 1.15 & 0.19 \\
Ferma & 33 & 0.076 & 0.26 & 0.105 & 0.29 & 0.16 & 0.21 & 0.19 & 0.21 \\
Shibarol & 47.5 & 0.046 & 0.29 & 0.061 & 0.28 & 0.078 & 0.22 & 0.12 & 0.28 \\
Harabali & 75 & 0.015 & 0.53 & 0.026 & 0.27 & 0.03 & 0.4 & 0.037 & 0.55 \\
H.Baskunchak & 115 & 0.073 & 0.3 & 0.055 & 0.34 & 0.085 & 0.2 & 0.087 & 0.3
\end{tabular}


Table 7. Peak amplitudes and periods in body waves as measured at portable seismic stations in the local zone of explosions at Vega

\begin{tabular}{|c|c|c|c|c|c|c|c|c|c|c|c|c|c|}
\hline \multirow{2}{*}{$B / h$} & \multirow{2}{*}{$\begin{array}{l}\mathrm{R}, \\
\mathrm{km}\end{array}$} & \multicolumn{6}{|c|}{ Vertical component } & \multicolumn{6}{|c|}{ Horizontal component } \\
\hline & & W, mm & $\begin{array}{l}\mathrm{T}^{\mathrm{W}} \\
\text { sec }\end{array}$ & $\begin{array}{c}\mathrm{U}, \\
\mathrm{sm} / \mathrm{s}\end{array}$ & $\begin{array}{c}\mathrm{T}^{\mathrm{u}}, \\
\mathrm{sec}\end{array}$ & $\mathrm{a}, \mathrm{s}^{2}$ & $\begin{array}{l}T^{2}, \\
\text { sec }\end{array}$ & $\mathrm{W}, \mathrm{mm}$ & $\begin{array}{c}\mathrm{T}^{\mathrm{w}} \\
\mathrm{sec}\end{array}$ & $\begin{array}{c}\mathrm{U}, \\
\mathrm{sm} / \mathrm{s}\end{array}$ & $\begin{array}{l}\mathrm{T}^{\mathrm{u}}, \\
\mathrm{sec}\end{array}$ & $\begin{array}{l}\mathrm{a}, \\
\mathrm{m} / \mathrm{s}^{2}\end{array}$ & $\begin{array}{l}T^{\mathrm{a}}, \\
\text { sec }\end{array}$ \\
\hline 1 & 2 & 3 & 4 & 5 & 6 & 7 & 8 & 9 & 10 & 11 & 12 & 13 & 14 \\
\hline
\end{tabular}

6T $\quad 0.98 \quad 310.0 \quad 410.0$

5T $\quad \begin{array}{lll}1.1 & 185.0 \quad 210.0\end{array}$

$\begin{array}{llllllllllllll}12 \mathrm{~T} & 1.4 & 77.3 & 0.22 & 155.7 & 0.13 & 71.6 & 0.086 & 24.3 & 0.42 & (36.3) & 0.4 & 7.99 & 0.3\end{array}$

2T $1.45 \quad 87.0 \quad 130.0$

6T $1 / 5 \quad 100.0 \quad 150.0$

$39.0 \quad 39.0$

7 T $\quad 1.65 \quad 18.0 \quad 68.0$

$31.0 \quad 42.0$

$\begin{array}{lll}6 \text { Tा } & 1.8 & 26.0\end{array}$

26.0

$\begin{array}{lll}23.2 & 0.068 & 17.0\end{array}$

27.0

$4.32 \quad 0.10$

$\begin{array}{llll}11 T & 1.9 & 5.92 & 0.16\end{array}$

$\begin{array}{llll}\text { 5T } & 1.9 & 29.0 & 105.0\end{array}$

17.5

12.60 .29

5T 1.98

23.60 .075

23.5

$10 \mathrm{~T} 2$.

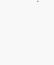

$\begin{array}{llll}7 \mathrm{~T} & 2.25 & 6.2 & 20.0\end{array}$

$\begin{array}{llll}9.52 & 0.114 & 16.0\end{array}$

0.32

3.890 .08

3T 2.20

$32.4 \quad 0.074$

2.800 .10

$4 T \quad 2.25 \quad 8.5$

25.0

7.0

18.0

$\begin{array}{lllll}8 \mathrm{~T} & 2.35 & 5.47 & 0.20\end{array}$

18.5

0.11

8.67

0.111

7.8

0.32

$13.6 \quad 0.34$

$\begin{array}{lll}7 \mathrm{~T} & 2.44 & 5.1\end{array}$

10.7

$8.72 \quad 0.066 \quad 12.5$

22.0

1.930 .113

2P $\quad 2.45 \quad 25.0$

62.0

8.3

20.0

$\begin{array}{llll}13 T & 2.7 & 5.35 & 0.23\end{array}$

16.70 .2

$\begin{array}{lllll}9.35 & 0.104 & 8.12 & 0.34\end{array}$

$\begin{array}{lllllll}15.4 & 0.19 & 2.63 & 0.16\end{array}$ $\begin{array}{lll}4 \mathrm{~T} & 2.8 & 12.5\end{array}$

44.0

5.0

6.1 


\begin{tabular}{|l|l|l|l|l|l|l|l|l|l|l|l|l|l|}
\hline 1 & 2 & 3 & 4 & 5 & 6 & 7 & 8 & 9 & 10 & 11 & 12 & 13 & 14 \\
\hline
\end{tabular}

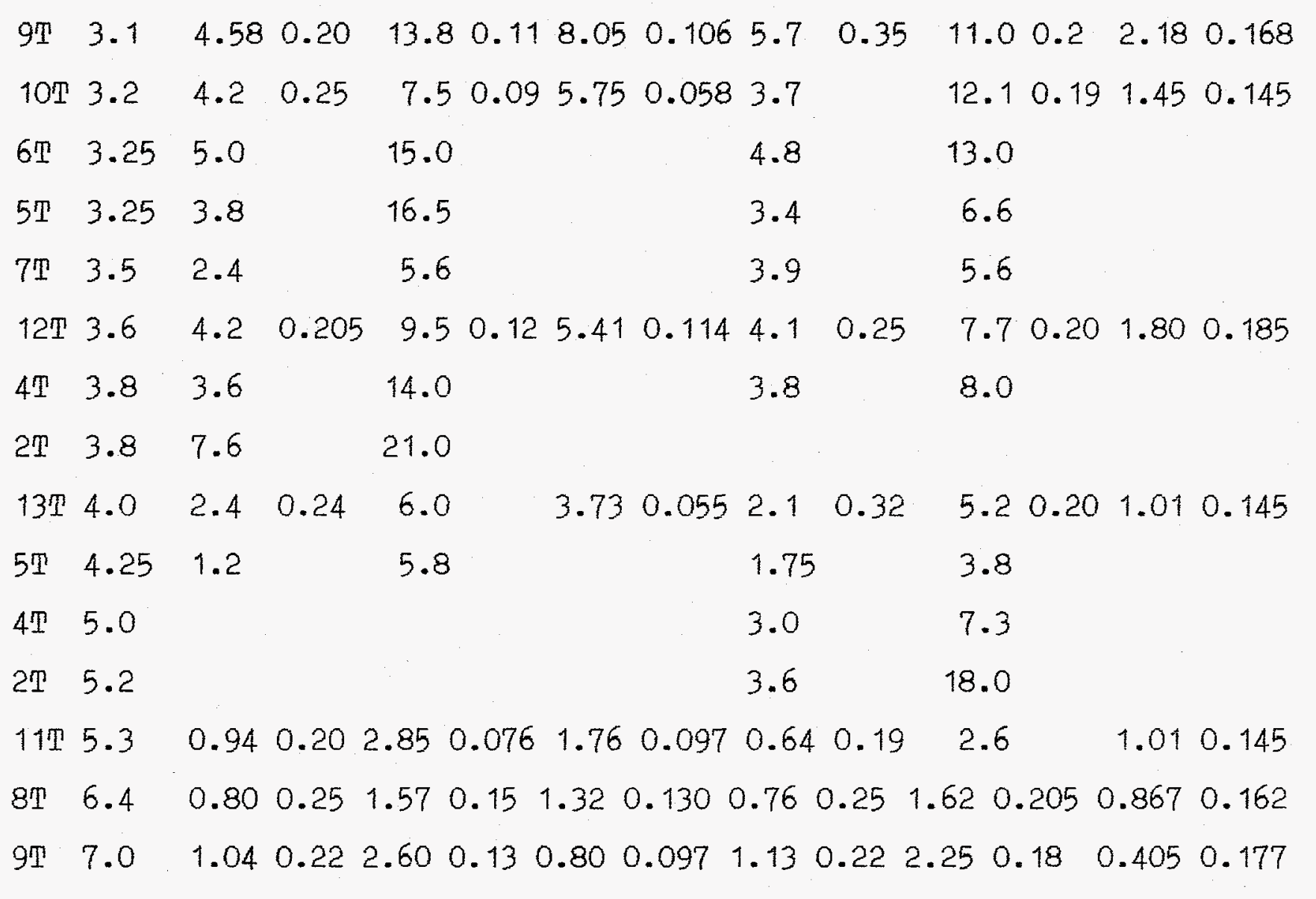


Table 8. Peak amplitudes and periods in body waves as measured in towns from explosions at Vega

\begin{tabular}{|c|c|c|c|c|c|c|c|c|c|}
\hline $\begin{array}{c}\text { Bore- } \\
\text { hole }\end{array}$ & $R, \mathrm{~km}$ & \multicolumn{3}{|c|}{ Vertical component } & \multicolumn{3}{|c|}{ Horizontal component } \\
\cline { 2 - 9 } & W, mm & $\mathrm{T}^{\mathrm{w}}, \mathrm{sec}$ & $\begin{array}{c}\mathrm{U}, \\
\mathrm{sm} / \mathrm{sec}\end{array}$ & $\mathrm{T}^{\mathrm{U}}, \mathrm{sec}$ & $W, \mathrm{~mm}$ & $\mathrm{~T}^{\mathrm{w}}, \mathrm{sec}$ & $\begin{array}{c}\mathrm{U}, \\
\mathrm{sm} / \mathrm{sec}\end{array}$ & $\mathrm{T}^{\mathrm{w}}, \mathrm{sec}$ \\
\hline 1 & 2 & 3 & 4 & 5 & 6 & 7 & 8 & 9 & 10 \\
\hline
\end{tabular}

Stepnoy

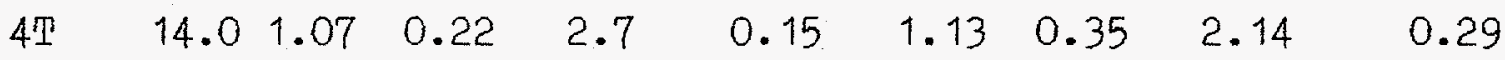

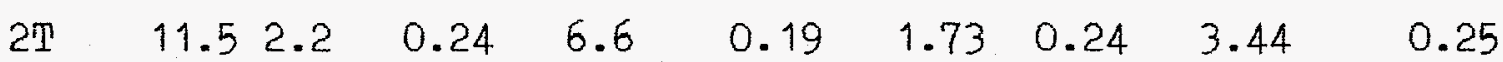

$\begin{array}{llllllllll}7 \mathrm{~T} & 8.5 & 1.18 & 0.23 & 2.77 & 0.23 & 3.5 & 0.3 & 6.54 & 0.26\end{array}$

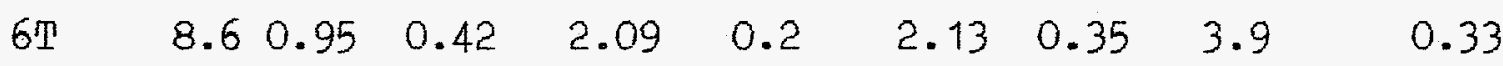

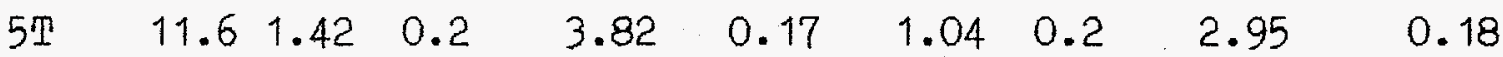

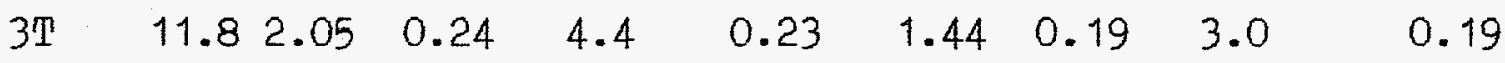

\section{Djanay}

$\begin{array}{lllllllllc}1 \mathrm{~T} & 14.0 & 0.83 & 0.22 & 3.27 & 0.22 & 0.96 & 0.34 & 2.65 & 0.32 \\ \text { 4T } & 19.0 & 0.29 & 0.26 & 0.53 & - & 0.53 & 0.32 & 1.50 & - \\ 2 \mathrm{~T} & 17.0 & 0.38 & 0.33 & 0.9 & - & 1.0 & 0.33 & 1.97 & - \\ \text { TT } & 14.4 & 0.74 & 0.3 & 2.25 & 0.24 & 1.2 & 0.27 & 3.32 & 0.24 \\ 6 \mathrm{~T} & 13.7 & 0.76 & 0.33 & 1.83 & 0.23 & 1.04 & 0.26 & 2.24 & 0.24 \\ 5 \mathrm{~T} & 16.5 & 0.3 & 0.33 & 0.8 & 0.23 & 0.98 & 0.36 & 1.9 & 0.36 \\ \text { 3T } & 15.8 & 0.78 & 0.37 & 1.55 & 0.26 & 2.55 & 0.38 & 4.5 & 0.26\end{array}$

Seitovka-1

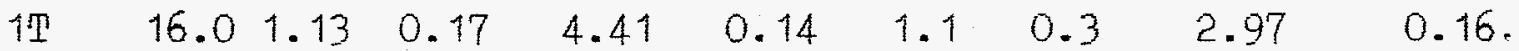

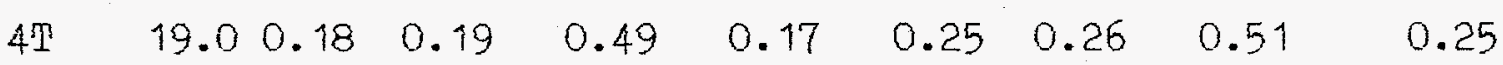




\begin{tabular}{|c|c|c|c|c|c|c|c|c|c|}
\hline 1 & 2 & 3 & 4 & 5 & 6 & 7 & 8 & 9 & 10 \\
\hline 2T & 18.0 & 0.27 & 0.17 & 0.77 & 0.15 & 0.5 & 0.34 & 0.82 & 0.17 \\
TT & 14.6 & 1.68 & 0.21 & 5.81 & 0.16 & 1.33 & 0.17 & 3.42 & 0.17 \\
6T & 15.6 & 1.2 & 0.22 & 3.25 & 0.14 & 1.04 & 0.21 & 2.27 & 0.16 \\
5T & 18.1 & 0.517 & 0.34 & 1.59 & 0.14 & 0.627 & 0.29 & 1.15 & 0.19 \\
3T & 19.0 & 1.16 & 0.2 & 3.37 & 0.18 & 1.1 & 0.3 & 2.3 & 0.17 \\
9T & 19.8 & 0.32 & 0.22 & 0.85 & 0.21 & 0.44 & 0.27 & 0.91 & 0.30 \\
8T & 18.6 & 0.20 & 0.24 & $0.35)$ & - & 0.54 & 0.33 & 0.74 & 0.35 \\
11T & 18.9 & 0.35 & $0.25)$ & 0.96 & 0.16 & 0.3 & 0.18 & 0.93 & 0.15 \\
13T & 18.0 & 0.6 & 0.22 & 1.65 & 0.19 & 0.54 & 0.20 & 1.38 & 0.17 \\
10T & 16.8 & 0.83 & 0.22 & 2.54 & 0.22 & 0.7 & 0.22 & 1.89 & $0.16)$ \\
12T & 16.2 & 0.59 & 0.25 & 1.50 & 0.23 & 0.63 & 0.28 & 1.40 & 0.25
\end{tabular}

Sei tovka-2

$\begin{array}{llllllllll}1 \mathrm{~T} & 16.5 & 1.1 & 0.17 & 4.3 & - & 1.05 & 0.18 & 3.0 & - \\ 4 \mathrm{~T} & 19.0 & 0.18 & 0.18 & 0.53 & - & 0.28 & 0.34 & 0.58 & - \\ 2 \mathrm{~T} & 18.0 & 0.27 & 0.17 & 0.77 & - & 0.59 & 0.34 & 0.76 & - \\ 7 \mathrm{~T} & 14.6 & 2.08 & 0.26 & 5.3 & 0.24 & 1.60 & 0.35 & 3.6 & 0.32 \\ 6 \mathrm{~T} & 15.6 & 1.36 & 0.34 & 3.4 & 0.31 & 1.10 & 0.30 & 2.6 & 0.30 \\ 5 \mathrm{~T} & 18.1 & 0.65 & 0.27 & 1.67 & 0.24 & 0.69 & 0.42 & 1.15 & 0.30 \\ 3 \mathrm{~T} & 19.0 & 1.17 & 0.18 & 2.75 & 0.17 & 1.18 & 0.33 & 2.47 & 0.17\end{array}$

Aksaraiskaya

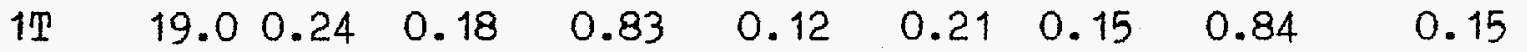

$\begin{array}{llllllllll}4 \mathrm{~T} & 21.5 & 0.44 & 0.48 & 0.58 & 0.48 & 0.65 & 0.55 & 0.74 & (0.55)\end{array}$

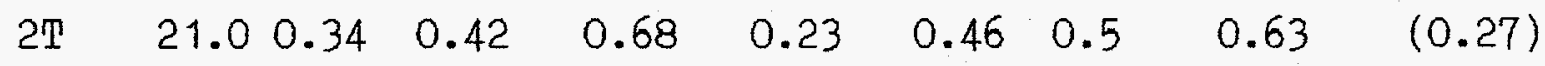




\begin{tabular}{|c|c|c|c|c|c|c|c|c|c|}
\hline 1 & 2 & 3 & 4 & 5 & 6 & 7 & 8 & 9 & 10 \\
\hline $7 \mathrm{~T}$ & 18.8 & 0.39 & 0.18 & 0.96 & 0.19 & 0.48 & 0.22 & 1.37 & $(0.22)$ \\
$6 \mathrm{~T}$ & 20.1 & 0.37 & 0.22 & 1.0 & 0.20 & 0.48 & 0.24 & 1.3 & $(0.22)$ \\
$5 \mathrm{~T}$ & 21.5 & 0.18 & 0.41 & 0.34 & 0.18 & 0.35 & 0.24 & 0.97 & $(0.22)$ \\
$3 \mathrm{~T}$ & 22.9 & 0.29 & 0.25 & 0.48 & 0.20 & 0.5 & 0.26 & 1.2 & $(0.26)$
\end{tabular}

Krasny Yar

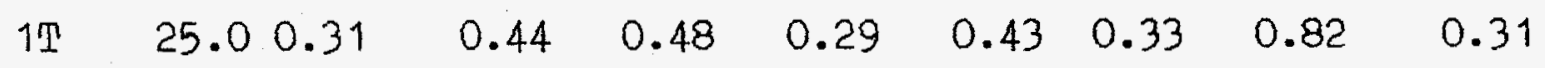

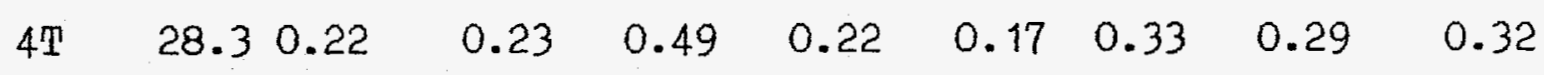

2T $\quad \begin{array}{lllllllll}26.2 & 0.18 & 0.25 & 0.43 & 0.14 & 0.21 & 0.47 & 0.38 & 0.28\end{array}$

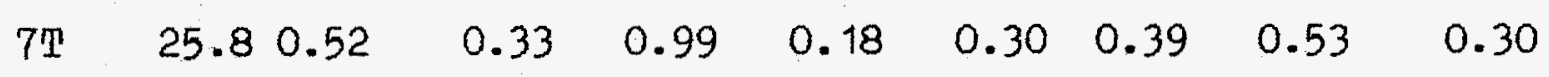

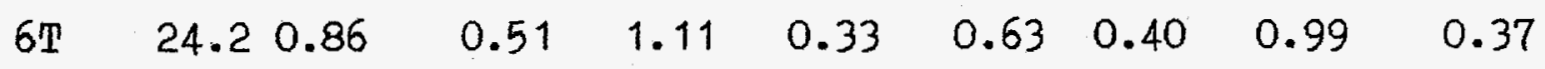

$\begin{array}{llllllllll}5 \text { T } & 26.0 & 0.19 & 0.22 & 0.47 & 0.19 & 0.19 & 0.34 & 0.31 & 0.23\end{array}$

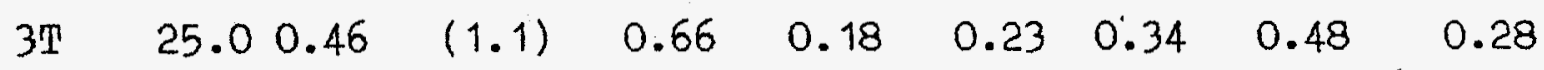

$13 \mathrm{P} \quad \begin{array}{lllllllll}23.0 & 0.26 & 0.26 & 0.63 & 0.25 & 0.22 & 0.32 & 0.43 & 0.30\end{array}$

$\begin{array}{llllllllll}10 \mathrm{~T} & 23.7 & 0.23 & 0.23 & 0.60 & 0.19 & 0.32 & (0.41) & 0.47 & 0.31\end{array}$

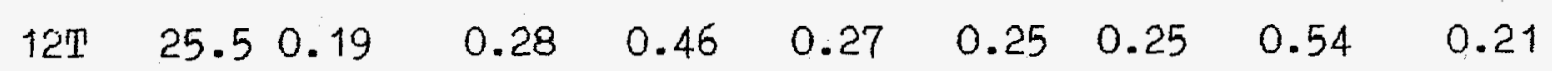

\section{Astrakhan-1}

1 1T $\quad \begin{array}{llllllll}4.0 & 0.20 & 0.6 & 0.18 & - & 0.44 & 0.52 & 0.6\end{array}$

$\begin{array}{llllllllll}4 \mathrm{~T} & 48.0 & 0.114 & 0.5 & 0.17 & 0.30 & 0.24 & 0.61 & 0.29 & 0.26\end{array}$

$\begin{array}{llllllllll}2 \mathrm{~T} & 46.0 & 0.13 & - & 0.15 & 0.36 & 0.24 & 0.45 & 0.33 & 0.38\end{array}$

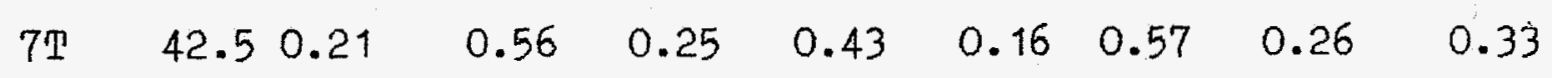

$\begin{array}{llllllllll}6 \mathrm{~T} & 41.0 & 0.21 & 0.56 & 0.25 & 0.43 & 0.24 & 0.59 & 0.31 & 0.43\end{array}$

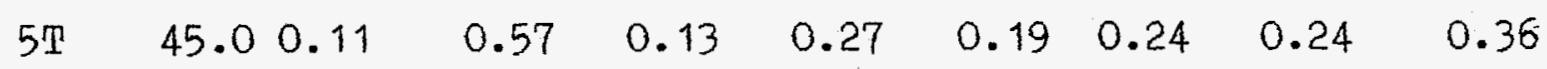

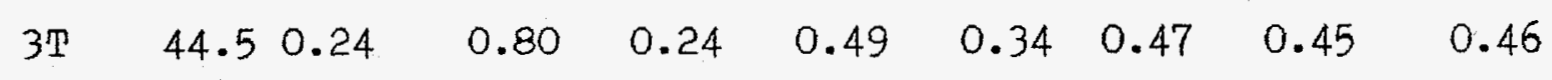




\begin{tabular}{|c|c|c|c|c|c|c|c|c|c|}
\hline 1 & 2 & 3 & 4 & 5 & 6 & 7 & 8 & 9 & 10 \\
\hline $9 \mathrm{~T}$ & 47.0 & 0.050 & 0.34 & 0.10 & 0.25 & 0.15 & 0.63 & 0.17 & 0.34 \\
$8 \mathrm{~T}$ & 46.7 & 0.053 & 0.34 & 0.093 & $(0.31)$ & 0.16 & 0.61 & 0.17 & 0.41 \\
$11 \mathrm{~T}$ & 45.0 & $(0.022)$ & 0.20 & 0.068 & $(0.12)$ & 0.10 & 0.42 & 0.13 & 0.36 \\
$13 \mathrm{~T}$ & $42.5(0.031)$ & $(0.15)$ & 0.13 & 0.25 & 0.17 & 0.36 & 0.26 & 0.24 \\
$10 \mathrm{~T}$ & 42.6 & 0.115 & 0.48 & 0.15 & 0.48 & 0.52 & 0.50 & 0.65 & 0.45 \\
$12 \mathrm{~T}$ & $43.8(0.043)$ & 0.27 & 0.086 & $(0.12)$ & 0.17 & 0.42 & 0.32 & 0.27
\end{tabular}

Astrakhan-2

$\begin{array}{llllllllll}\text { IT } & 48.0 & 0.144 & - & 0.14 & 0.51 & 0.18 & 0.43 & 0.25 & 0.38 \\ \text { 4T } & 52.0 & 0.125 & 0.55 & 0.134 & 0.46 & 0.122 & 0.42 & 0.165 & 0.28 \\ 2 \mathrm{~T} & 50.0 & 0.143 & 0.49 & 0.16 & 0.43 & 0.142 & 0.34 & 0.23 & 0.33 \\ 7 \mathrm{~T} & 46.5 & 0.105 & (1.3) & 0.117 & 0.45 & 0.148 & 0.35 & 0.21 & 0.34 \\ \text { 6T } & 45.0 & 0.18 & 0.45 & 0.22 & 0.42 & 0.27 & 0.52 & 0.28 & 0.37 \\ 5 \mathrm{~T} & 49.0 & 0.105 & 0.63 & 0.121 & 0.49 & 0.134 & 0.43 & 0.16 & 0.39 \\ 3 \mathrm{~T} & 48.5 & 0.25 & 0.83 & 0.24 & 0.77 & 0.29 & 0.63 & 0.31 & 0.61\end{array}$

Astrakhan-3

$\begin{array}{llllllllll}1 & 48.0 & 0.17 & - & 0.27 & 0.19 & 0.11 & 0.36 & 0.19 & 0.33\end{array}$

Astrakhan-4

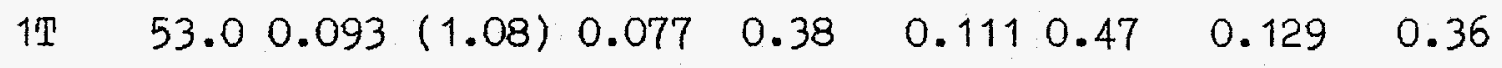

Astrakhan-5

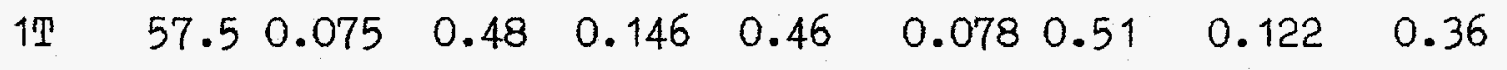


the explosions of the series Vega-1,2,3,4. Thus the range of observations Irom Vega explosions ( 1 to $50 \mathrm{~km}$ ) was shorter than of Azgir where profiles were of length of 180 and $260 \mathrm{~km}$.

3. Analysis of relationship between peak parameters and range and yield for explosions in salt.

Relation of peak amplitude and range and yield was presented in standard form

$$
A_{w, u}=b q^{n} R^{-m} \text {, }
$$

where $\mathrm{A}$ is the peak amplitude of the seismic signal in mm for $W$ and $\mathrm{cm} / \mathrm{sec}$ for $U, q$ is the yield of the explosion in $\mathrm{kt}, \mathrm{R}$ is the hypocentral distance in $\mathrm{km}$.

Relationship (1) was determined in two steps. At firgt, relation of peak amplitude and distance was determined for each explosion. The relations were then averaged over all the explosions. The principal basis of such a procedure was independence of power $m$ from yield established for the investigated set of experimental data in a given yield range. At the second step, from the established relationship $A^{\sim} R^{-m}$ for each explosion coefficient $\mathrm{K}=\mathrm{bq}^{\mathrm{n}}$ has been estimated as well asaveraged values of $b$ and $n$. Averaging has been conducted by using the least squares technic and estimated of the coeffioients $b, n$, and $m$ have been done for vertical and radial displacement, $W_{z}$ and $w_{x}$, and corresponding particle velocities, $\mathrm{U}_{z}$ and $\mathrm{U}_{\mathrm{x}} \cdot$

Let us investigate parameters of seismic waves separetely for the both sites. 


\section{Site Azgir}

Figures 9 through 13 display radial velocity, $U_{X}$, as a function of distance from the experimental data compiled in Table 6 for the explosions A-1,2,3,4,5. As clear from the Figures, data scattering is relatively high and it is hard to reveal any changes in trends of amplitude decay related to ohanges in dominating seismic phases. Only in the range 80 to $150 \mathrm{~km}$, may be noted some amplitude increase possibly related to critical wave $P_{M} P S$. Similar features characterize amplitude graphs for $\mathrm{U}_{\mathrm{z}}, \mathrm{W}_{\mathrm{z}}$, and $\mathrm{W}_{\mathrm{x}}$.

The data on $U_{x}$ as well as on $U_{z}, W_{z}$, and $W_{x}$ were initially processed in three ranges: 0 to $30 \mathrm{~km}, 0$ to $80 \mathrm{~km}$ and in the whole range to 180 or $260 \mathrm{~km}$. In the three ranges estimates of $\mathrm{m}$ were close and only the whole range was considered further. Estimates of $m$ value was used to determine coefficient $K$ in relationship $K=k(b)$ and coefficient $b$ as well. As a result following relationships have been estimated predicting peak velocities with the relationships separated by yields:

$$
\begin{aligned}
& 1-10 \mathrm{kt} \quad W_{2}=9 q^{0.77 R^{-1.65}}( \pm 1.8) \quad W_{X}=6.5 q^{0.77} R^{-1.46}( \pm 1.89) \\
& U_{z}=26 q^{0.65} R^{-1.71}( \pm 1.63) \quad U_{x}=12 q^{0.68} R^{-1.48}( \pm 1.8) \\
& 10-100 \mathrm{kt} \quad U_{z}=47 q^{0.48} \mathrm{R}^{-1.71}( \pm 1.63) \mathrm{U}_{\mathrm{x}}=19 \mathrm{q}^{0.55} \mathrm{R}^{-1.48}( \pm 1.8)
\end{aligned}
$$

Standard deviations are in brackets near each relationship. This means high scattering or uncertainity in amplitude of a factor of 2 at $68 \%$ confidence.

Relationships (4) and (5) were used in the data processing displayed in Figures 9 to 13 and drawn by straight lines. 
It is worth noting some features in structure statistical relaionships (3) to (5) which probably have some physical meaning. Vertical component of motion attenuates more rapidly than radial what can be explained by lower periods of converted waves recorded at radial component. Displacement which is of lower frequency relative to velocity characterized by higher frequency spectrum attenuates less rapidly. So, conclusions from spectral representation proposed by Sharpe [3] and elaborated by Mueller and Murphy [4] for point explosion source seem to be right. Amplitudes of seismic signals from larger explosions depend on yield weaker what is clear from a comparision of the ranges 10 to 100 and 1 to $100 \mathrm{kt}$ for velocity relationships and (5). Similar relation is observed from (3) and (4) relative to low frequenoy (displacement) in comparison with high frequency (velocity) in the range 1 to $100 \mathrm{kt}$.

Figure 14 presents periods of peak partiole velocity as a function of distance at Azgir. As can be seen from the Figure, only period data from the smallest explosion A-1 are available at distances less than $1 \mathrm{~km}$. Periods of body waves at these distances are in the range of 0.03 to $0.2 \mathrm{sec}$, and periods of 0.3 to 0.5 sec prolably are related to surface waves. At distances larger than $2 \mathrm{~km}$, periods from the smallest $\mathrm{A}-1$ explosion are not different from periods of 0.3 to $0.6 \mathrm{sec}$ from the large explosions $A-2,4,3$. This effect can be related to high attenuation in thick low-velocity layer of sediments. It is interesting that periods from the deep explosion $A-5$ in the range 2 to $50 \mathrm{~km}$ are the lowerest (of 0.1 to 0.3 sec) among 
other explosions, but at Iarger distances this difference disappears.

Periods relatively drop to 0.3 or 0.4 sec beyond $80 \mathrm{~km}$. This effect can be associated to critical $P_{M} P S$ wave having maximum amplitude in the range. This feature is traced for displacements as well as particle velocity.

Thus, regional and teleseismic signals when analizing their visual periods will not show relative enhancement with high frequency of spectra of small and deep explosions due to high selected attenuation in real mediums. This feature was not traced by spectra in near-field zone due to absence of related records.

\section{Site Vega}

The measuremenrs from the site Vega give a large set of data on the explosions of equal yield. Actually, 11 from 13 explosions had an yield of $8.5 \mathrm{kt}$ and the whole data set (Tables 7 and 8) allowed to arrange a detailned system of observations in relatively short range from 1 to $50 \mathrm{~km}$. The only two explosions 3T and $11 \mathrm{~T}$ had different yields of 13.5 and $3.5 \mathrm{kt}$ respectively.

Figure 15 shows vertical displacement as a function of distance. It is clear that the relation is not monotonic. There is an amplitude maximum in the range from 7 to $16 \mathrm{~km}$ related to change of seismic phase. The graph's shape in that range corresponds to a shape of amplitude curve of critical reflection from sharp boundary in the geological structure. From kinematio and dynamio characteristics of peak amplitude oscillations it is 
possible to associate reflecting boundary to interface between salt and underlied carbonates.

Other parameters $\mathrm{W}_{\mathrm{x}}, \mathrm{U}_{\mathrm{z}}$, and $\mathrm{U}_{\mathrm{x}}$ have similar amplitude curves. Note that at the all amplitude data from the explosion $11 \mathrm{~T}$ are below others (to 15 times) at ranges less than $7 \mathrm{~km}$. At larger distances, all the data from all the explosions are not distinguishable. Thus, it is possible to consider that in conditions of thick sediment basins with strong differentiation of seismic velooity, amplitude characteristics at distances beyond $10 \mathrm{~km}$ are not very sensible to yield (at least 2.5 times) due to strong variation.

Amplitude data from the site Vega on the explosions of equal yields were approximated by $\log -\log$ relations:

$$
1 g A_{\mathrm{W}, \mathrm{U}, \mathrm{a}}=\mathrm{b}-\mathrm{mIgR}
$$

in three ranges. Estimated coefficients are presented in Table 9, where $b$ and $\mathrm{m}$. Horizontal component of motion from Vega explosions attenuates weaker than vertical as at the Azgir since horizontal motion is associated with longer-period converted waves. Particle velocity at vertical component also attenuates more rapidly than displacement except the range from 1 to $7 \mathrm{~km}$. This range probably is distinguished for borehole explosions due to predominant vertical motion in epicentral zone.

Data measured at permanent seismic stations from the explosions of equal yields at the site Vega allow to study a. stability of seismic signal from explosions with close epicenters. This stability of seismic amplitude characterizes an accuracy of amplitude prediction and yield estimate from seismic 
data in a given region.

Table 9. Iinear regression coefficients, correlation coefficient and confidence of seismic amplitudes Irom Vega explosions

\begin{tabular}{|c|c|c|c|c|c|c|c|c|c|c|c|}
\hline \multirow[t]{2}{*}{$\begin{array}{c}\text { Range, } \\
\mathrm{km}\end{array}$} & \multirow[t]{2}{*}{ Motion } & \multicolumn{5}{|c|}{$\begin{array}{l}\text { Vertical } \\
\text { component }\end{array}$} & \multicolumn{5}{|c|}{$\begin{array}{l}\text { Horizontal } \\
\text { component }\end{array}$} \\
\hline & & $\mathrm{m}$ & $b$ & $-r$ & $\pm \sigma$ & $N$ & $\mathrm{~m}$ & $\mathrm{~b}$ & $-r^{\circ}$ & $\pm \sigma$ & $N$ \\
\hline $1-7$ & $\mathrm{w} \mathrm{mm}$ & 3.02 & 2.22 & 0.936 & 0.236 & 28 & 2.19 & 1.81 & 0 & 34 & 26 \\
\hline $1-7$ & $\mathrm{U} \mathrm{sm} / \mathrm{sec}$ & 2.63 & 2.45 & 0.926 & 0.223 & 28 & 1.68 & 1.84 & 0.861 & 0.183 & 26 \\
\hline $1-7$ & $\mathrm{a} \mathrm{m} / \mathrm{sec}^{2}$ & 2.42 & 2.00 & 0.971 & 0.121 & 13 & 1.60 & 1.06 & 0.961 & 0.099 & 11 \\
\hline $10-60$ & $\mathrm{~W} \mathrm{~mm}$ & 1.71 & 1.88 & 0.838 & 0.236 & 60 & 1.43 & 1.60 & 0.871 & 0.171 & 60 \\
\hline $10-60$ & $\mathrm{U} \mathrm{sm} / \mathrm{sec}$ & 2.27 & 3.10 & 0.921 & 0.212 & 60 & 1.88 & 2.49 & 0.925 & 0.164 & 60 \\
\hline $1-60$ & $\mathrm{~W} \mathrm{~mm}$ & 1.61 & 1.70 & 0.943 & 0.286 & 91 & 1.34 & 1.46 & 0.959 & 0.187 & 89 \\
\hline $1-60$ & $\mathrm{U} \mathrm{sm} / \mathrm{sec}$ & 1.74 & 2.18 & 0.957 & 0.266 & 91 & 1.39 & 1.78 & 0.958 & 0.198 & 89 \\
\hline
\end{tabular}

Figure 16 presents the amplitudes of particie displacement measured at the seismic stations Seitovka, Krasny Yar, Astrakhan from 11 explosions of the same yield at the site Vega. The amplitudes are corrected for distance difference by equation (9) by using table 9. Mean distance was $17 \mathrm{~km}$ to Seitovka, $25.5 \mathrm{~km}$ to Krasny Yar, and $44.5 \mathrm{~km}$ to Astrakhan with a maximum deviation of $15 \%, 14 \%$, and $5 \%$ respectively. Azimuth deviation was of $\pm 5-6^{\circ}$. As clear from Figure 16, maximum variations between edge amplitudes are of 10 times for Seitovka, 3 times to Krasny Yar and Astrakhan.

The variations can be due for various reason. For Seitovka, the explosions fired in the southerm part of the dome give higher amplitudes than in the central and notherm parts. 
Amplitude data from this station correspond to the range where there is a sharp peak at amplitude curve (Figure 15), so a small : charge of distance leads to large change of amplitude of critical reflection. Also, the explosion $7 T$ generally gives higher amplitude at all the stations.

For Krasny Yar and Astrakhan there are no distinct correlation between amplitude and distance/azimuth. One of the possible causes of high amplitude variation especially at close distances can be abmupty diping interfaces (salt dome wings) which lead to strong changes of reflection amplitude even for small changes of incident angle.

Mean square variations of the amplitudes $\mathrm{U}_{2}$ and $\mathrm{U}_{\mathrm{x}}$, however, are lower than maximum deviations: 1.5 to 2 times for Seitovka, 1.4 to 1.5 times for Krasny Yar and Astrakhan. These mean square deviations are in good agreement with similar characteristics of averaged amplitude relatioships (Table 9), what can be a result of commom nature of these variations in the whole range of seismic measurements.

High instability of amplitude revealed in the study when distance changes are small and yields are the same, confirm an assumption of principal stochastic behavior of seismic wave field in close - zone of explosions in complex geological structures.

Figure 17 presents periods of peak displacement, velocity and accelation as a function of distance for the explosions at the site Vega. It is clear that at close distance ( 1 to $10 \mathrm{~km}$ ) there are differenoies in periods of different motion functions 
(displacement, particle velocity, acceleration) of vertical and horizontal components. The periods decrease from displacement to acceleration, and periods on horizontal component are of 1.5 to 2 times longer than on vertical. Difference in periods between the explosion $11 \mathrm{~T}$ and others is in the range of scattering. Similar features were revealed from the Azgir data.

At larger distances, from 10 to $50 \mathrm{~km}$, these differencies disappea. In the range from 15 to $50 \mathrm{~km}$ periods grow from $0.2-0.3$ to 0.4 to $0.5 \mathrm{sec}$.

In total, in the range of the measurements from 1 to 260 $\mathrm{km}$, the periods in body waves are in the range from 0.1 to 0.6 sec which corresponds to natural periods of buildings and constructions. 
CHAPTER 3

SPECTRAT CHARACTERISTICS OF SEISMIO WAVES RECORDED

IN NEAR-FIELD ZONE OF UNDERGROUND EXPIOSIONS

1. Principal characteristics of source.

conoentrated underground explosion is usually considered as a source of expanding spherical elastic wave. Such a representation allows relatively simple determination of principal parameters of generated longitudinal waveform, so called, reduced displacement potential, $\Phi$, and it's derivatives.

Following reiationships can be derived for displacement $U(R, t)$, particle velocity $V(R, t)$, and radial stress $\sigma_{R}$ $(\tau=t-R / 0 \geq 0)$

$$
\begin{aligned}
& \mathrm{U}(\mathrm{R}, \mathrm{t})=-\frac{\partial}{\partial \mathrm{R}}\left(\frac{\Phi(\tau)}{\mathrm{R}}\right)=\left(\frac{\Phi^{\prime}(\tau)}{\mathrm{R} c}\right)+\frac{\Phi(\tau)}{\mathrm{R}^{2}} \\
& V(\mathrm{R}, \mathrm{t})=\frac{\Phi^{\prime \prime}(\tau)}{\mathrm{R} c}+\frac{\Phi^{\prime}(\tau)}{\mathrm{R}^{2}} \\
& \sigma_{\mathrm{R}}(\mathrm{R}, \mathrm{t})=-\rho \mathrm{c}^{2}\left[\frac{\Phi^{\prime \prime}(\tau)}{\mathrm{Re}^{2}}+\frac{2(1-2 v)}{(1-\nu)}\left(\frac{\Phi^{\prime}(\tau)}{\mathrm{R}^{2} \mathrm{c}}+\frac{\Phi(\tau)}{\mathrm{R}^{3}}\right)\right]
\end{aligned}
$$

where $R$ is the distance from the source, $O$ is the longitudinal wave velocity, $\rho$ is the density, and $\nu$ is the Poisson ratio. Derivatives by $\tau$ are indicated by marks'

Initial values of $\Phi(0)$ and $\Phi,(0)$ are equal to zero: $\Phi(0)=$ $\Phi(0)=0$ because of zero initial displacement at the moment $\tau=$ o. Similar conditions are usually used for the second derivative 
of the reduced displacement potential, i.e. $\Phi^{\prime \prime}(0)=0$. Such a condition implies that particle velocity grows gradually after wave arrival. In principle, step velocity or stress $\sigma_{R}$ propagation is possible on the wave front.

The Fourier transform is used to characterize the spectra of the generated wave. Common mepresentation for broad classes of functions $f(t)$ and spectrum $f(\omega)$, where $w$ is the angular frequenoy, are as follows

$$
f(\omega)=\int_{-\infty}^{\infty} f(t) e^{-1 \omega t} d t ; f(t)=\frac{1}{2 \pi} \int_{-\infty}^{\infty} f(\omega) e^{1 \omega t} d \omega
$$

By using (7) and (8) one oan obtain following useful relationships:

$$
\begin{aligned}
& U(R, \omega)=\frac{1}{R^{2}}\left[1+\frac{i \omega R}{c}\right] \Phi(\omega) \\
& V(R, \omega)=\frac{1}{R^{2}}\left[1+\frac{i \omega R}{c}\right] \Phi^{\prime}(\omega), \Phi^{\prime}(\omega)=i \omega \Phi(\omega) \\
& \sigma_{R}(R, \omega)=\frac{\rho c^{2}}{R^{3}}\left[\frac{2(1-2 v)}{1-\nu}+\frac{2(1-2 v)}{1-v} \frac{R}{c}-\left[\frac{\omega R}{c}\right)^{2}\right] \Phi(\omega)
\end{aligned}
$$

Relationships (9) can be used to estimate speotral characteristics of the reduced displacement potential, if the functions $U(\omega), V(\omega)$ or $\sigma_{R}(w)$ are known at a given distance $R$. For example, having the function $\sigma_{R}(w)$ one can obtain from (9) following expression: 


$$
\Phi(\omega)=-\frac{\sigma_{\mathrm{R}}(\omega) \mathrm{R}^{3}}{\rho \mathrm{c}^{2}} \frac{i \omega}{\left[\frac{2(1-2 v)}{1-\nu}+\frac{2(1-2 v)}{1-D} \frac{i \omega \mathrm{R}}{\mathrm{c}}-\left[\frac{\omega \mathrm{R}}{\mathrm{c}}\right)^{2}\right]}
$$

Some special features of the reduced displacement potential $\Phi$ can be derived from relationship (10). Trus, if the radius of unelastic source zone is $\mathrm{R}_{0}$ and the pressure at this radius is a step fuction with a constant amplitude Po, which can be treated as a function $\mathrm{P}(\tau)=\mathrm{Poe}^{-\alpha \tau}$, where $\alpha \rightarrow 0$ and $\mathrm{P}(\tau)=0, \tau<0$, then from (10) it follows

$$
\Phi^{\prime}(\omega)=\frac{\mathrm{PoRo}^{3}}{\rho c^{2}} \frac{1}{\left[\alpha+\alpha(\mathrm{i} \omega \mathrm{Ro} / \mathrm{c})-(\omega \mathrm{Ro} / \mathrm{c})^{2}\right]}
$$

where $d=2(1-2 v) /(1-v)$. The Poisson ratio for common rooks is of $\nu=1 / 3$, and $d=1$. One can derive low- and high-frequency limits of $\Phi$ (w) from (11). When $\omega \rightarrow 0$, and assuming from (1) that for $t \rightarrow \infty$ $\frac{\mathrm{PoRo}^{3}}{\rho \mathrm{o}^{2} \mathrm{a}}=\Phi \mathrm{O}$, where $\Phi_{0}$ is the asymptotio value, we obtain

$$
\Phi^{\prime}(\omega)=\Phi 0 .
$$

High-frequency limit of (11) giveg

$$
\Phi^{\prime}(\omega)=\frac{\Phi \circ d}{(\omega \mathrm{Ro} / 0)^{2}} \sim \frac{1}{\omega^{2}}
$$

So called comer frequency determines the frequency where 
relations (12) and (13) are separated. The comer frequenoy is estimated from relationship

$$
\omega_{c}=c / R_{0} \text {. }
$$

Thus, the values $\Phi_{0}$ and $\omega_{0}$ can be treated as the principal parameters of generated seismio signal or seismio wave source. Relationship (11) can be generalized easily by using different pressure functions at the elastio source radius, Ro. This problem is well known as Sharp's problem and is often discussed in the different works devoted to explosion source. It should be noted, however, that the pressure function $P(\tau)$ has to be

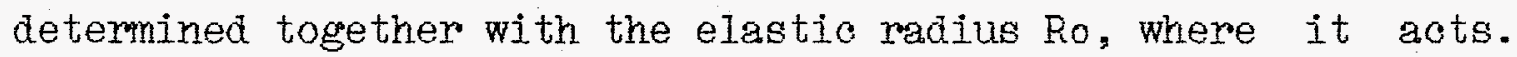
It means that when analizing experimental data one should evaluate in which zone the data were measured and to which extent noniinear and effect can influence the reduced displacement potential estimates. Theoretical calculations play a principal role in solving these complicated problems and our understanding of processes occuring during actual explosions in real rocks. Monographie [5,6] should be mentioned, which summarize theoretical results obtained before 1970-1971. It has been shown by comparing of natural observation results with theoretical calculations by different schems [5], that some complicated processes of rock behaviour under high loading should be included. In particular, delatanoy effects, i.e. rook density changes under pure shear stress, were obtained.

Following investigations $[7,8]$ have shown that 
sophisticated medium models including different factors have to: be elaborated for the theoretical calculations, as a result, these models include a lot of parameters which are not well determined for real rocks behaviour in nonlinear zone of explosions. So, the models are misleading sometimes. In this work, we will use more simple but more clear approaches to the problem of seismic wave generation by the explosion in hard rocks $[9,10,11]$.

The authors of $[9,10]$ numerically study the spherically symmetric case of an explosion. Their approach is very close to elastio case but includes plastio yielding which is one of the principal processes during an explosion. It is assumed, that yielding is govered by von-Mizes oriterion

$$
\left(\sigma_{R}-\sigma_{\varphi}\right)^{2}=3 Y^{2}
$$

where $\mathrm{Y}$ is the elastic limit under shear stress, of is the tangential stress.

It was found that two plastic zones are created by the explosion cavity expansion. The first zone is adjacent to the cavity, and the second narrow zone is close to wave front. The calculations were conducted in the broad range of the parameters $Y / \rho c^{2}$ and $p_{1} / \rho c^{2}$, where $\rho_{1}$ is the initial pressure in the cavity, and oan be summarized by the following relationships for the maximum radius of the cavity $\left(r_{m}\right)$ and the second zone $\left(b_{m}\right)$ :

$$
r_{m}=0.31(E / Y)^{1 / 3}\left(\frac{Y}{\rho_{1}}\right)^{0.04}\left(\rho \sigma^{2} / P_{1}\right)^{0.01}
$$




$$
b_{m}=0.31(E / Y)^{1 / 3}\left(\rho c^{2} / Y\right)^{0.3}\left(\frac{Y}{\rho_{1}}\right)^{0.04},
$$

where $\mathrm{E}$ is the yield of the explosion. The pressure changes in the cavity is govemed by adiabatic law when the cavity expands. The radius of the first plastio zone is a half of the second one. When plastic motion near the cavity is finished generated elastio wave has a typical shape. The pressure in the wave, which is proportional to $\Phi^{\prime \prime}(\tau)$, has a positive first phase of $\tau_{1}$ duration and following negative (rarefication) phase with twice as large duration and half an amplitude. Further calculations will be based on a simple approximation obtained from [9,10] for $\Phi^{\prime}(\tau)$

$$
\Phi^{\prime}(x)=\Phi_{0} / \theta\left[\frac{1}{2} x^{2} e^{-x}\right], x=\tau / \theta_{0}
$$

where $\varphi_{0}=0.9\left(Y / \rho \mathrm{c}^{2}\right) \mathrm{b}^{3}, \theta_{0}=\tau_{1 / 2}=0.28 \mathrm{bm} / 0$

Reduced displacement potential will be as following

$$
\Phi(\tau)=\Phi_{0} / \theta \int_{0}^{\tau}\left[\overline{2}^{1} x^{2} e^{-x}\right] d \tau=\Phi_{0} \int_{0}^{x}\left[\left[\bar{x}^{2} e^{-x}\right] d x\right.
$$

It follows from (18) that when $\tau+\infty, \Phi(\tau)+\Phi_{0}$, i.e. $\Phi_{0}$ is asymptotio value of reduced displacement potential.

The spectrum of $\Phi^{\prime}(\omega)$ can be obtained from (17)

$$
\Phi^{\prime}(0)=\Phi o /(1+i \operatorname{to} \theta 0)^{3}
$$


The spectrum (19) falls beyond the corner frequency faster. that the spectrm (11). The comer frequency of (19) is $1 / \theta 0$. These differences arise due to gradual pressure or velocity inorease in the wave front which is opposite to step funotion used in (11).

Relatively simple approximation for low-frequency part of seismic wave, generated by an explosion was eleborated in [11] by analysing of the prinoipal processes oocuring during explosion cavity expansion in hard rocks.

According to this approach, the final stage of the cavity expansion is characterized by the existance of two regions: plastic zone around the cavity ( $r \leq R \leq b)$ and elastic zone ( $R>b)$. In the first zone the relation between principal stresses $\sigma_{\mathrm{R}}$ and op is well known in rock mechanios as law

$$
\sigma_{R}-\sigma_{\varphi}=K / 2 \sigma_{R}-\sigma_{S}
$$

In partioular, when $\mathrm{K}=0$ (20) coinsides with (15), and $a_{S}=(3)^{1 / 2} Y$. In elastic zone it is assumed that stresses distribution at a given time is close to static one, i.e.

$$
-\sigma_{R}(t)=\sigma *(b(t) / R)^{3}
$$

at the interface between the plastic and elastio zones $R=b$ the relationship of displacement and stress is as follows $(v=1 / 3)$ : 


$$
U(t)=\left(\sigma * / \rho c^{2}\right) b(t)
$$

In equations (21) and (22) the value $\sigma^{*}$ is used as a strenght, when $k=0, \sigma_{*}=2 / 3 \sigma_{\mathrm{s}}=(2 / \sqrt{ } 3)$ Y.

Following expressions for maximum cavity radius, bm, peak displacement, $u m$, at $R=b m$, and $\Phi \circ(k=0, v=1 / 3)$ can be obtained from the equations of motion and boundary condition (22):

$$
\begin{aligned}
& b_{m}=0.2\left(E / \sigma^{*}\right)^{1 / 3}\left(\rho c^{2} / \sigma^{*}\right)^{1 / 3} \\
& u_{m}=\left(\sigma^{*} / \rho 0^{2}\right) b_{m} \\
& \Phi_{o}=b_{m}^{3}\left(\sigma^{*} / \rho c^{2}\right)
\end{aligned}
$$

Expression for potential is as follows

$$
\Phi^{\prime}(\omega)=\frac{\Phi o}{\left(1+i \omega \frac{b m}{c}\right)\left[1+i \omega \frac{b m}{c}-\left(\frac{w b m}{c}\right)^{2}\right]}
$$

Expession (24) has the same speotrum roll-off beyond corner frequenoy as (19). The oomer frequenoy is $\omega_{c}=\frac{c}{b_{m}}$.

The data measured from the explosion SaImon in salt are used to compare the results of calculations by the two discribed schems. The data from the explosion salmon were thoroughiy analized by many researchers. It is worth noting two recent papers $[12,13]$ where all the principal previons investigations are mentioned. The total energy release of the Salmon was $E=$ 
$2.210^{13} \mathrm{~J}$ as follows from the yield of $5.3 \mathrm{kt}$. It was adapted in: the calculations from [12] and other souroes that $\rho=2.2 \mathrm{~g} / \mathrm{cm}^{3}$. $c=4.55 \mathrm{~km} / \mathrm{sec}$. The main problem is how to estimate $\sigma *$ or $Y$ which are very similar, as was mentioned above, for the both approaches. We adopted conventional relation $0 * / \rho 0^{2} \cong 10^{-3}$ for rocky massifs [5]. When $\sigma * / \rho 0^{2} \cong \mathrm{Y} / \rho \mathrm{c}^{2} \cong 10^{-3}$, one can obtain for rocky salt $\sigma^{*}=460$ bar. For this $Y$ value from the first approach iy follows

$$
\begin{aligned}
& \mathrm{bm}_{\mathrm{m}}=150 \mathrm{~m}, \Phi_{0}=310^{3} \mathrm{~m}^{3}, \theta_{0}=9.4 \mathrm{~ms}, \\
& a_{\mathrm{c}}=1 / \theta_{0}=1001 / \mathrm{c}
\end{aligned}
$$

It was assumed that for the explosion with high initial energy density in the cavity $P_{1} \cong \rho c^{2}$.

The calculations from the second approach give:

$$
b_{m}=155 m, \Phi_{0}=3.710^{3} m^{3}, w_{c}=c / b m=301 / c
$$

As clear from the values, $b_{m}$ and $\Phi_{0}$ are very olose, but wo are quite difierent.

Figure 18 displays the result of the calculations of the potential (upper frame) and spectrum $/ \Phi^{\prime}(\omega) /$ (Iower frame) by the two methods. Solid line represents the methods and dashed. line is for quazistatio approach. The results of the actual measurements are also shown by different marks. The data on the . potential [14] at different ranges are shown in the upper frame * of Figure 18. The potential rize time grows with distance and the final value, $\phi_{0}$, deoreases. Small rise at closer ranges can be explained by high-frequency component of the signal and are 
better simulated by the first method. When range increases the high-frequenoy component effectively attenuates and the signal is better described by the second method which does not inciude the initial part of the wave. These differences are confirmed by the spectra of seismic waves measured at large distances. The data from [15] are shown on the lower frame as well as the calculated spectra. The data dispersion is shown by bars.

\section{Analysis of observations}

Let us analyze now the results of spectral processing of seismic records from the explosions at the site Azgir. Figures 19 thru 23 present spectra of the records from the explosions A-1 thru A-5. These Figures contain the amplitude speotra, $S$ (mm sec), of vertical displacement recorded at the same point of observations - town of Kharabali. The spectra were calculated in four time windows starting from the first arrival of longitudinal wave. As can be seen from the Figures, there is a systematic increase of spectral level with increasing time window. The complexity of the spectra $S(f)$ (number of peaks in spectrum) also increases with time window growth especially at high frequencies. Note, that the duration of the longest window is of 18.6 sec or almost equal to $S-P$ time delay at this distance of $75 \mathrm{~km}$.

It is interesting to consider the results presented on Figures 19 thru 23 in the frame of analytical models of the seismic source presented above. Solid thick line presents the result of calculation from a simple soheme when the source 
characteristics are determined by equations (23) and (24). Salt: parameters were the same as around Salmon. Relationship (9) was. used to calculate amplitude decay with distance, i.e. ray approximation in elastic medium was used.

Sharpe's model prediction is presented by dashed line in Figures 19 thru 23 (11). It was assumed for the sake of simplicity that oo for the explosions coinside with predicted by (23), but oomer frequenoy, $\omega_{0}$, was two times lower than from the first soheme. Here we used estimates done by Mueller and Murphy [4] for elastic radius, bm, of the Salmon event which is $\mathrm{bm}=300$. This value is two times larger than that of relation (23) gives $(\mathrm{bm}=155 \mathrm{~m})$.

By comparing experimental and theoretical spectra one can note that observational and predicted by different models results are similar in the limits of scattering. So, weak dependence of low frequency spectral amplitude and relatively sharp spectral drop at high frequencies are clear. Unfortunately, scattering of the experimental amplitudes and complexity of the spectra $S(f)$ in the high frequency range do not allow to aistinguish between the models. Moreover, attenuation at high frequenoies during propagation at large distance should be also considered.

Digital filtering of the records by six bandpass Boaterworth filters has been used to average the spectra. * Filter's roll-of was of $\mathrm{f}^{-6}$. The first filter was in the band Irom 0.7 to $1 \mathrm{~Hz}$, the second - from 1 to 1.4, the third - from 1.4 to 2 , and 2 to $2.8 ; 2.8$ to $4 ; 4$ to 5.8 for the following. 
The results of such a data processing from the explosions at the site Azgir are presented in Figures 24 to 28. The upper frames of the Figures present the records of vertical displacement at the same point - town of Kharabali. Amplitude scale is digplayed in the left part, and time scale is at the bottom. The filteres are numbered at the curves. As can be seen, the peak amplitudes for all the filters are observed between 10 and 15 sec after the first arrival. By using these results, one can estimate relationship between peak spectral amplitude, which was estimated as a peak displacement amplitude for each filter divided by $\Delta f$, and yield, $q$. These relationships are presented in Figure 29. As olear Irrom the Frigure, for inoreasing central irequency of the filter a slope of the lines in log-log scale $(\operatorname{logs} \sim \log q)$ decreases what means decrease of a power of $q$ from 0.9 to 0.35 for the filter $N 6$. Such a change in the relationships of spectral amplitude vs. yield is consistent with the seismic source function representations. Let us recall that at low frequemcies $S^{\sim} q$ and at high frequencies dependence $S(q)$ should be weaker. The power of $q$ generally speaking should also depend for the selected frequency band at high frequencies on $\mathrm{q}$ since for small charges corner frequency should be compared with seleoted one.

Figures 30 to 32 present a comparison of amplitude spectra S obtained after filtering by desribed above filteres with speotral oharaoteristios from three explosions $A-1, A-2$ and $A-3$ ( time window is of 18 sec). The filetrs are numbered as previousiy in Figure 29. As clear from the Figures, spectral. 
amplitudes averaged by the filteres are consistent with spectral: changes with Irequency. So, a stable spectral peak in the band from 0.5 to $1 \mathrm{~Hz}$ can be distinguished as well as some following oscillations of mean spectral ampiitudes related probably to the traces of waves propagation. In particular, the spectral peak at $1 \mathrm{~Hz}$ may be related to the relatively thick layer of sediments beneath recording point reaching 0.5 to $1 \mathrm{~km}$ with longitudinal wave velocity of $2 \mathrm{~km} / \mathrm{sec}$.

One can try to evaluate the influence of the path of propsgation on the spectra for the relatively far point of observation in the town of Kharabali. The spectrum of the recorded signal can be separated into three parts : $X(f)$ is the effect of the path, $F(f)$ - j.s the source function, and $P(f)$ is the sensor responce :

$$
S(\hat{f})=F(f) X(f) P(\hat{I})
$$

Sensor's responce is well known and will not be considered further after correcting of the record.

For two explosions of different yields $q_{1}$ and $q_{2}$ it is Loliows from (25)

$$
\mathrm{S}_{2}(f) / \mathrm{S}_{1}(\mathrm{f})=\left(\mathrm{Fa}(f) / \mathrm{F}_{1}(\tilde{I})\right)\left(\mathrm{X}_{2}(f) / \mathrm{X}_{1}(f)\right)
$$

When the explosions are in the same poirt, $\mathrm{X}_{1}(f)=\mathrm{X}_{2}(1)$ and. hence, 


$$
\mathrm{S}_{2}(f) / \mathrm{S}_{1}(\mathrm{f})=\mathrm{F}_{2}(\mathrm{f}) / \mathrm{F}_{1}(\mathrm{f})
$$

Thus, speotral changes with yield can be derived Irom differences between expiosions $q_{1}$ and $q_{2}$. The resuits of such a procedure for the spectra of vertical displacement at the town of Knarabali with the event $A-2$ as reference are presented on Figures 33 and 34. Relative speotra are muoh oloser to each other than original although some peaks are changed a little. This probably results from differences in paths, with stronger differences being due to near source effects but not due to geological structure beneath receiver. It should be noted here that reference explosion A-2 was placed within the westerm dome and the events $A-3, A-4$, and $A-5$ were fired within the easterm dome (see Fig. 1). Figure 35 presents relative spectra of the explosions with the event $A-3$ as a reference. The relative spectra are similar in the frequency band and at high frequency relative spectra of the events A-4 and A-5 are olose to 1 with some scattering.

It is too early to discuss the procedure of speotra processing of the records from close explosions proposed in this work. This procedure, however, could be helpful in seismio source function analysis.

Figure 36 shows averaged by a comb of Boaterworth iilters spectro $\bar{S}$ from the events $A-1, A-3$ and $A-5$ with $A-2$ as $a$ reference event $\left(\bar{S}_{2}\right)$. Theoretical relative speotra for the two models discussed above are presented by solid and dashed lines (see Figures 19 to 23). As clear from Figure 36, the models give 
different relative spectra at high frequenoies with inoresing: yield. This fact can be explained by different spectral roll-off with frequency in the models. From Sharpe's model it follows that $S^{\sim} q^{1 / 3}$ at high frequency, i.e. relative spectra is proportional to $\left(q_{1} / q_{2}\right)^{1 / 3}$. The second model gives $S^{\sim} 1 / f^{3}$, i.e. spectrum does not depend on yield and amplitude of relative spectra is equal to one.

The seismio data obtained can not distinguished between the models, although there are some advantages of the second model of quasistatic expansion [11]. According to this model, it is possible to negiect high-frequenoy component of spectrum since a formt of seismic wave is broadened when it is emitted. One of the causes is the influence of large cracks and faults near the source of the explosion. Fapers $[16,17]$ desoribe analysis of longitudinal wave propagation effects from powerful industrial and nuclear explosions in hard rooks.

Spectral ampiitude at low frequency from the event $A-1$ is larger than predicted by comparison of the events $A-1$ and $A-2$. Some estimates show that effective yieid of the event $A-1$ was of 2 kt. The apparent increase of seismic efficiency is due shallow depth of burial $(161 \mathrm{~m})$.

The event $A-5$ is characterized by two times Iower seismic efficiency than predicted from $A-2$ to $A-5$ spectral comparison. The explosion was fired very deep (1500m) what can be a reason of low seismic efficiency. 
CHAPTER 4

REGIONAI AND TELESEISMIO DATA OF

SEISMIC OBSERVATIONS

1. Seismological blletines of Soviet sismic stations.

The Bulletines include seismological data on explosions in 9 boreholes: 5 individual tamped explosions at Azgir A-1,2,3,4,5 and 4 similar explosions of the Vega-3 series near the town of Astrakhan: $7 \mathrm{~T}, 6 \mathrm{~T}, 5 \mathrm{~T}$ and $3 \mathrm{~T}$ which were fired in indicated sequenoe with time delay of $5 \mathrm{~min}$.

The Institute for Dynamics of the geospheres compiled teletype notes from operators of permanent seismic stations of the Former USSR on all the large-scale explosions. These notes after exception of "crude mistakes" are the basis of the Bulletines included in the report. The data were obtained in the range from 4 to 60 degrees, i.e. embrace the range of regional and teleseismic distances from the Caspian depression in the south-east part of the Russian platform.

It is necessary to note that the number of seismic stations in the USSR substantionally grew from 1966-1977 to 1982, i.e. in the time gap between the explosions at Azgir and Vega sites.

In the preface of each explosion bulletin the data on the prinoipal parameters of the explosion (date, origin time, coordinates, magnitude) are presented. These data were obfained as a result of the processing of information from seismio stations of United Soviet service of seismic observations 
(ECCH). Averaged magnitudes from longitudinal (P) and surface (I) waves are given by vertical (MLV) and horizontal (MPH and MLH) components recorded at short-period (A), mediate (B) and long-period (C) equipment with the indication of a number of recording stations used in brakets.

For each soviet station in the bulletines following informations is presented:

- seismograph type;

- epicentral range and epicenter-station azimuth;

- type of seismic wave and its maximum (PM, SM, IM)

- arrival times of detected phases (GMT)

- maximum phase period

- amplitudes in microns for three components;

- magnitudes by longitudinal and surface wave;

- residual times in comparison with Jeffreys-Bullen time-distance curve.

Phase identification, arrival times determination, amlitude and period measurements, magnitude calculation were carried out by operators at each seismic station. Epicentral distances, azimuths and residual times were determined in the center of seismic data processing (Obninsk) using Jeffreys-Bullen time-distance curve.

The data presented in the bulletines were obtained by short-period (SKM, SH, VEG, USF, Benioff), intermediate (SK, SG, SKD) and long-period seismographs (SD-1, SD-2). These types of seismographs are characterized by the range of periods with the 
61

amplitude-frequency response level at 0,9 of the maximum: short-period : $0,2-1,2 \mathrm{~s}$ intermediate : $0,3-11 \mathrm{~s}(\mathrm{SK}, \mathrm{SG})$ and $0,2-20 \mathrm{~s}$ (SKD) long-period : $17-50 \mathrm{~s}$ 
62

BUHUETINS

OF SOVIET SEISMIC STAPIONS FOR THE EVERTS AT VEGA AND AZGIR SITES

AV3 16 october 1982 (region Astrachan) - explosion 1

USSR: $0=05-59-56.5$

$0=46^{\circ} 87 \mathrm{~N}$

$\lambda=48.26 \mathrm{E} \quad \mathrm{h}=0 \mathrm{kM}$

$\operatorname{MPV}(A)=5.0(9)$

\begin{tabular}{|c|c|c|c|c|c|c|c|c|c|c|c|c|}
\hline NN & $\begin{array}{c}\text { Kod } \\
\text { station }\end{array}$ & $\begin{array}{l}\text { Chan- } \\
\text { nel }\end{array}$ & $\Delta^{\circ}$ & $\mathrm{Az}^{\circ}$ & Phase & $\begin{array}{c}\text { Arrival } \\
\text { time }\end{array}$ & \multirow{2}{*}{ Ts } & \multicolumn{3}{|c|}{ A micrometr } & $\begin{array}{c}\text { Nag } \\
\text { mb }\end{array}$ & Res \\
\hline 1 & 2 & 3 & 4 & 5 & 6 & 7 & 8 & 9 & 10 & 11 & 12 & 13 \\
\hline
\end{tabular}

1. MAK SKM 4.01188 iP 06-01-02.8

$\begin{array}{llll}P M & 03.2 & 0.7 & 0.7\end{array}$

2. PYA SKM $4.68 \quad 234$ iP $06-01-08.5$

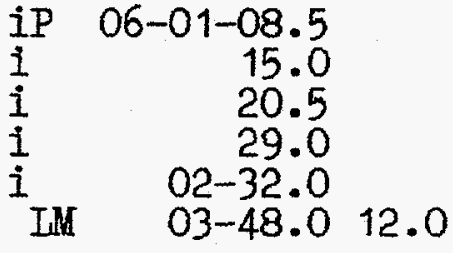

$-1.0$

SK $4.68 \quad 234$

3. TI2 SKM $5.77208+i P \quad 06-01-25.6$

4. BKR SKM 6.16 $215+i P$ 06-01-31.5

$\begin{array}{rrrrr}\text { iP } & 06-01-31.5 & & & 0.6 \\ \text { PM } & 36.0 & 0.8 & 0.2 & \\ \text { SM } & 02-30.0 & & 0.47 & \end{array}$

5. KRV SKM $6.33 \quad 194$ iP $06-01-33.0$

6. $\mathrm{ABS}$

SKM

$6.40 \quad 220+i P \quad 06-01-34.4$

$0.3 \quad 0.05$

7. AKH

SKM $6.45 \quad 213$-iP $06-01-35.0$

8. STE

SKM

6.49

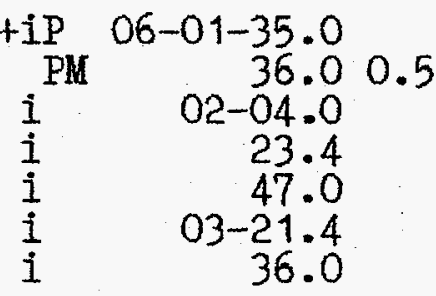


63

\begin{tabular}{|c|c|c|c|c|c|c|c|c|c|c|c|c|}
\hline 1 & 2 & 3 & 4 & 5 & 6 & 7 & 8 & 9 & 10 & 11 & 12 & 13 \\
\hline 9. & BAK & SK & 6.56 & 170 & $e P$ & $06-01-39.0$ & & & & & & \\
\hline 10. & $\mathrm{SOC}$ & SKM & 6.87 & 244 & ${ }_{e}^{i P}$ & $\begin{array}{r}06-01-41.5 \\
02-13.5\end{array}$ & & & & & & 0.6 \\
\hline 11. & LEN & SKD & 6.88 & 209 & eP & $06-01-42.0$ & & & & & & 0.9 \\
\hline 12. & GRS & VEG & 7.49 & 191 & $-i p$ & $06-01-48.6$ & & & & & & -1.0 \\
\hline 13. & ANN & & 7.86 & 259 & $\begin{array}{l}\text { ep } \\
\text { eS }\end{array}$ & $\begin{array}{r}06-01-54.4 \\
03-17.0\end{array}$ & & & & & & $\begin{array}{l}-0.5 \\
-8.0\end{array}$ \\
\hline 14 & INKK & & 8.08 & 177 & $\mathrm{P}$ & $06-01-57.0$ & & & & & & \\
\hline 15. & KAT & SK & 9.78 & 141 & $\mathrm{eP}$ & $06-02-21.0$ & & & & & & \\
\hline 16.1 & Niohnevo & SKM & 10.44 & 325 & $-i p$ & $06-02-29$ & $\begin{array}{l}0.5 \\
0.8 \\
0.5\end{array}$ & 0.282 & $\begin{array}{l}0.136 \\
0.136\end{array}$ & 60.350 & & \\
\hline 17 . & OBN & SKM & 11.05 & 322 & $\underset{I M}{+i P}$ & $\begin{array}{r}06-02-38.9 \\
14-00.0\end{array}$ & 8.0 & & 0.4 & $0.4 \mathrm{~N}$ & $\begin{array}{l}\mathrm{MLH}=3.7 \\
\mathrm{MLV}=3.7\end{array}$ & $7^{0.1}$ \\
\hline 18. & MOS & $\mathrm{sX}$ & 11.08 & 327 & $\underset{P M}{-I P}$ & $\begin{array}{r}06-02-39.0 \\
43.0\end{array}$ & 2.0 & & & 0.28 & & -0.3 \\
\hline 19. & $A R U$ & $\underset{\mathrm{SKD}}{\mathrm{SKM}}$ & 11.49 & 29 & $\begin{array}{l}\mathrm{eP} \\
\mathrm{IM}\end{array}$ & $\begin{array}{r}06-02-42.3 \\
09-06.0\end{array}$ & 13.0 & & & $0.5 \mathrm{~N}$ & $\mathrm{MLV}=3.6$ & $6^{-2.5}$ \\
\hline 20. & VAN & SKM & 11.50 & 137 & eP & $06-02-41.7$ & & & & & & -3.2 \\
\hline 21. & ASH & $\mathrm{SK}$ & 11.61 & 136 & $\mathrm{eP}$ & $06-02-45.0$ & & & & & & -1.5 \\
\hline 22. & SVE & $\underset{\text { SKD }}{\text { SKM }}$ & 12.55 & 32 & $\stackrel{i p}{L M}$ & $\begin{array}{r}06-02-57.2 \\
10-02.0\end{array}$ & 10.0 & 0.5 & & $0.9 \mathrm{~N}$ & $\begin{array}{l}\mathrm{MLH}=3.8 \\
\mathrm{MLV}=4.0\end{array}$ & $8^{-1.8}$ \\
\hline 23. & $B R V$ & $\operatorname{SK}(\mathbb{M})$ & 15.42 & 58 & $\begin{array}{c}+\underset{P M}{+i P} \\
\text { eS }\end{array}$ & $\begin{array}{r}06-03-33.5 \\
37.0 \\
06-18.0\end{array}$ & 0.7 & & & 0.140 & & \\
\hline 24. & SAM & SK & 15.40 & 111 & $\begin{array}{l}e P \\
e \\
e \\
e \\
e \\
e\end{array}$ & $\begin{array}{r}06-03-35.0 \\
43.2 \\
05-13.2 \\
06-36.9 \\
08-32.0\end{array}$ & & & & & & -1.7 \\
\hline
\end{tabular}


64

\begin{tabular}{r|c|c|c|c|c|c|}
\hline 1 & 2 & 3 & 4 & 5 & 6 & 7 \\
\hline
\end{tabular}

25. TAS SKM 16.09103 eP $06-03-43.2$ i $\quad 50.2$

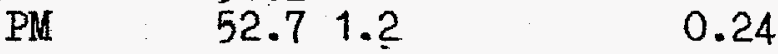

26. IVV SKD 16.38289 eP $06-03-45.6$

27. PUL VEG 16.71327 eP O6-03-52.0

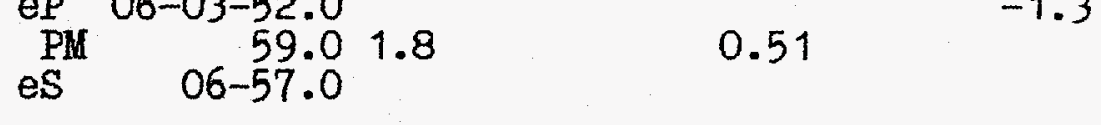

28. DSH SK 17.17111 eP $06-03-59.2$

i $\quad 09-02.2$

29. UZH SKM 17.52285 -iP 06-04-01.0

$\begin{array}{lll}\text { PM } & 02.01 .5 & 0.123\end{array}$

30. NAM SKM 17.84101 eP $06-04-06.8$

31. GAR SKM 17.91 108 iP $06-04-05.51 .1 \quad 0.06$

32. KUL SK 18.32112 eP $06-04-12.8$

$\begin{array}{lr}\text { PM } & 06-04-12.8 \\ e & 08-04.1\end{array}$

0.6

33. ANR SKM 18.41100 eP 06-04-14.8

SK

$\begin{array}{lr}\text { PM } & 16.2 \\ \text { PM } & 1.2 \\ & 2.0\end{array}$

0.12

0.2

0.2

34. FRU SKM 19.08 92 eP 06-04-22.8

35. KHO SK 19.57110 eP $06-04-30.2$

1.6

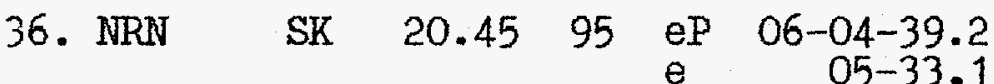

1.0

37. AAA SKM 20.5990 eP 06-04-41.0

38. MUR SK 20.61105 eP $06-04-42.4$

39. $A A B$ SM $20.73 \quad 89+i P \quad 06-04-42.2$
PM
$44.7 \quad 1.1$
$0.17 \quad 5.4$ 
65

\begin{tabular}{|l|l|l|l|l|l|l|l|l|l|l|l|l|}
\hline 1 & 2 & 3 & 4 & 5 & 6 & 7 & 8 & 9 & 10 & 11 & 12 & 13 \\
\hline 40. PRZ & SKM 21.82 & 90 & eP & $06-04-55.0$ \\
PM & \multicolumn{5}{c|}{57.0} & 0.8 & & & 0.16 & 5.5 & 2.9
\end{tabular}

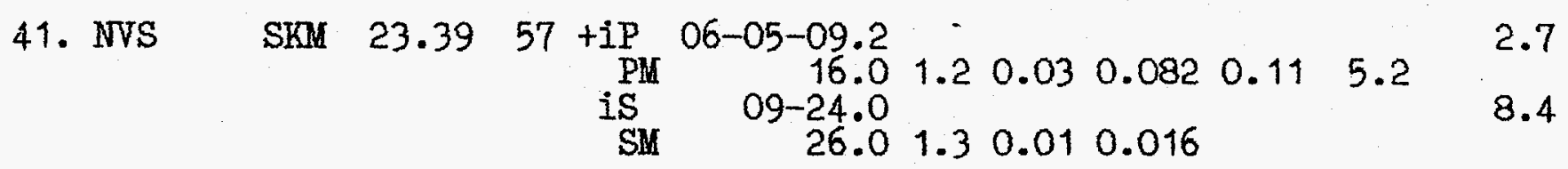

42. USK SKM 24.2067 +iP $06-05-18.00 .9 \quad 0.14$

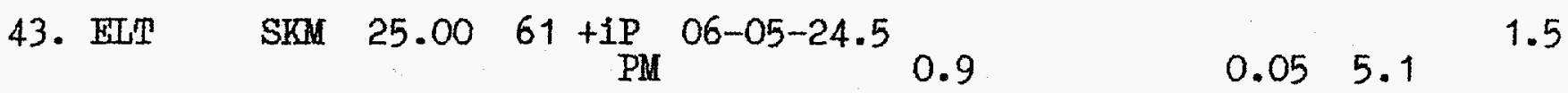

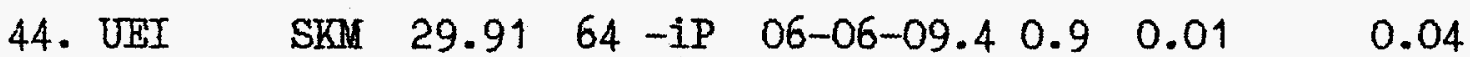

45. NRI SKM $29.9226-\mathrm{eP}$ 06-06-10.0

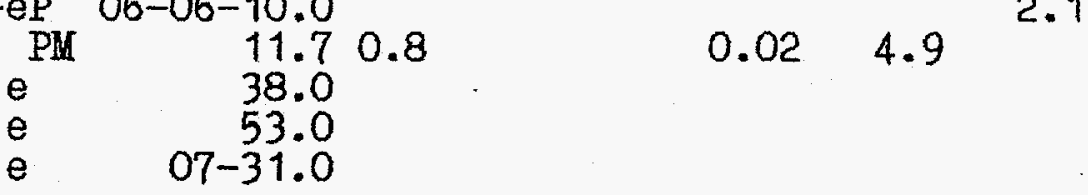

46. BOD

SKM $40.15 \quad 49+$ iP $06-07-35.0$

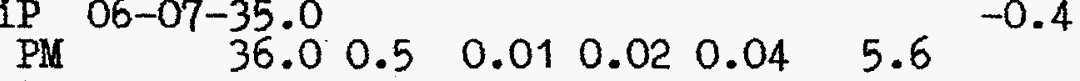

47. TIK SKM 43.4927 +eP 06-08-04.5

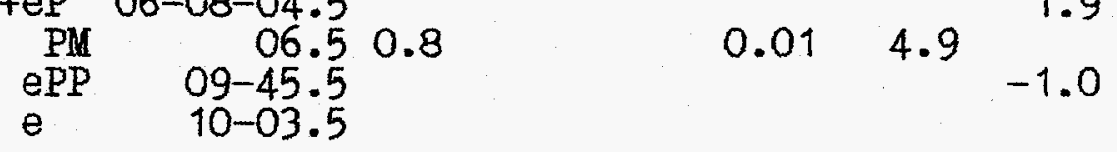

48. YAK SKM $46.41 \quad 40$-IP 06-08-26.7

$0.06 \quad 5.7$

49. KID SKM 53.0955 eP 06-09-19.0

50. ILT SKM $60.27 \quad 18 \mathrm{eP} \quad 06-10-08.0$ 
66

AV3 16 october 1982 (region Astrachan) - explosion 2

USSR: $0=06-04-57.3$

$\begin{array}{ll}\mathrm{p}=46^{\circ}, 79 \mathrm{~N} \\ \lambda=48.22 \mathrm{E}\end{array} \quad \mathrm{h}=0 \mathrm{KMM}$

$\operatorname{MPV}(A)=5.1(9)$

\begin{tabular}{|c|c|c|c|c|c|c|c|c|c|c|c|c|}
\hline \multirow[t]{2}{*}{$\mathrm{NN}$} & \multirow{2}{*}{$\begin{array}{c}\text { Kod } \\
\text { station }\end{array}$} & \multirow{2}{*}{$\begin{array}{l}\text { Ohan- } \\
\text { nel }\end{array}$} & \multirow{2}{*}{$\Delta^{0}$} & \multirow{2}{*}{$A z^{\circ}$} & \multirow[t]{2}{*}{ Phase } & \multirow{2}{*}{$\begin{array}{l}\text { Arrival } \\
\text { time }\end{array}$} & \multirow[t]{2}{*}{ Ts } & \multicolumn{3}{|c|}{ A micrometr } & \multirow{2}{*}{$\underset{\mathrm{mb}}{\mathrm{Mag}}$} & \multirow[t]{2}{*}{ Res } \\
\hline & & & & & & & & NS & $E W$ & $\mathrm{z}$ & & \\
\hline 1 & 2 & 3 & 4 & 5 & 6 & 7 & 8 & 9 & 10 & 11 & 12 & 13 \\
\hline 1. & MAKK & SKM & .92 & 18 & $\begin{array}{c}\text { iP } \\
\text { PM } \\
\text { IS } \\
\text { SH }\end{array}$ & $\begin{array}{r}06-06-02 \\
03 \\
07-50 \\
52\end{array}$ & $\begin{array}{l}0.5 \\
1.0\end{array}$ & 5.1 & 3.2 & .8 & & \\
\hline
\end{tabular}

2. PYA SKM 4.61.235 iP 06-06-08.5

SK

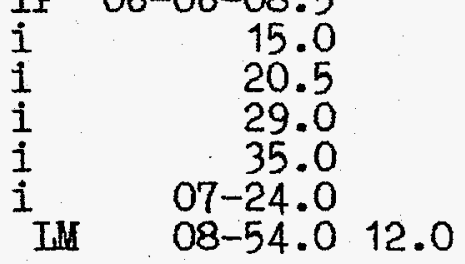

$1.19 \mathrm{MLV}=3.3$

3. TI2 SKM $5.68 \quad 208$ +iP $06-06-25.0$

$\begin{array}{lr}i & 47.4 \\ i & 08-34.0\end{array}$

4. BKR SKM 6.08 215 - IP $06-06-30.5$

$\begin{array}{lrrrr} & & & \\ \text { SKD } & i_{\text {SM }} & 07-30.0 & 0.8 & 0.2 \\ & & & 1.4 & 0.47\end{array}$

5. KRV SKM $6.24 \quad 194$ iP 06-06-33.0

0.7

6. AKK SKM $6.37 \quad 214$ +iP $06-06-35.4$

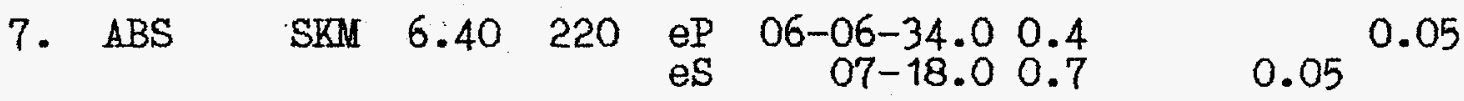

8. STE SKM 6.41 207 tiP $06-06-35.0$

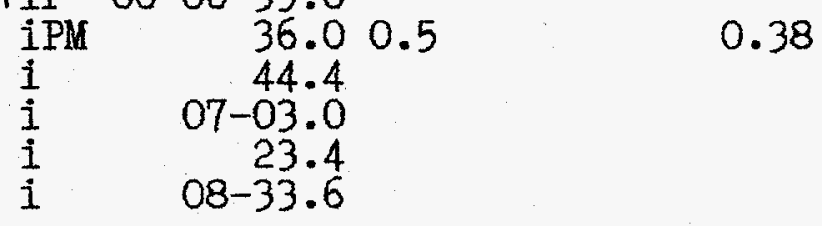


67

\begin{tabular}{|l|c|c|c|c|c|c|}
\hline 1 & 2 & 3 & 4 & 5 & 6 & 7 \\
\hline 9. SOC & SKM & 6.81 & 244 & iP & $06-06-41.5$ \\
& & & & $07-11.0$ \\
10. GRS & VEG & 7.41 & 191 & $-\mathrm{iP}$ & $06-06-48.4$ \\
& & & & i & 52.6 \\
& & & & $07-31.2$
\end{tabular}

11. ANN SKM $7.82 \quad 259$ eP $06-06-54.5$ $08-15.0$ -0.2
-9.7

12 LNKK

8.00177 P $\quad 06-06-56.0$

13. Michnevo SKM 10.49325 -iP 06-07-30

$$
\begin{aligned}
& 0.4 \\
& 0.6
\end{aligned} 0.200^{0.1500 .250}
$$

14. $O B N$

$$
\text { SKM } 11.09322 \text {-iP } 06-07-39.0
$$

0.3

15. ARU

$$
\begin{array}{llllrl}
\text { SKM } & 11.57 & 29 & \text { eP } & 06-07-42.5 & \\
\text { SKD } & & & \text { LM } & 14-14.0 & 12.0
\end{array}
$$$$
0.5 \mathrm{MLV}=3.6^{-4.2}
$$

16. SVE

$$
\text { SKM } 12.63 \quad 32+1 \mathrm{P} \quad 06-07-56.7
$$

SKD

$$
\begin{aligned}
& \text { PM } \quad 57.7 \quad 0.5 \\
& \text { IM } \quad 14-51.0 \quad 12.0 \quad 0.6
\end{aligned}
$$

0.27

$0.7 \quad$ MLH $=3.8$

17. BRV

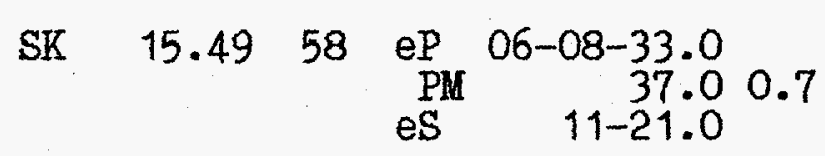

0.136

18. TAS SKM 16.10102 iP 06-08-(50.2)

$$
\begin{aligned}
& \text { SK } \\
& \begin{array}{lrl}
\text { PM } & 52.0 & 1.5 \\
\text { IM } & 11-23.0 & 10.0
\end{array}
\end{aligned}
$$

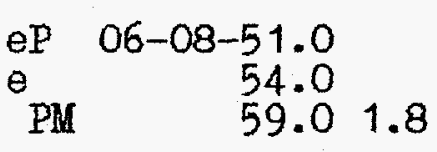

19. PUL

$$
\text { VEG }
$$$$
16.76327
$$

13

$$
0.6
$$


68

\begin{tabular}{|c|c|c|c|c|c|c|c|c|c|c|c|c|}
\hline 1 & 2 & 3 & 4 & 5 & 6 & 7 & 8 & 9 & 10 & 11 & 12 & 13 \\
\hline 22. & KUL & SK & 18.21 & 111 & $e^{\mathrm{eP}}$ & $\begin{array}{r}06-09-11.3 \\
14.7 \\
14-15.7\end{array}$ & 1.8 & & & 0.4 & & -1.7 \\
\hline 23. & ANR & $\begin{array}{l}\text { SKM } \\
\text { SK }\end{array}$ & 18.42 & 100 & $\begin{array}{l}\mathrm{eP} \\
(\mathrm{PM}) \\
\mathrm{e} \\
(\mathrm{IM})\end{array}$ & $\begin{array}{r}06-09-(08.0 \\
10.0 \\
20.6 \\
20.0\end{array}$ & $\begin{array}{l}0) \\
2.0 \\
* \quad 7.0\end{array}$ & 1.2 & & $\begin{array}{l}0.12 \\
0.7\end{array}$ & & $-7.6 *$ \\
\hline 24. & FRU & SKM & 19.11 & 92 & $+\underset{P M}{P P}$ & $\begin{array}{r}06-09-23.8 \\
28.0\end{array}$ & 0.8 & & & 0.1 & & -0.1 \\
\hline 25. & KHO & SK & 19.57 & 109 & $\mathrm{eP}$ & $06-09-28.4$ & & & & & & -1.0 \\
\hline 26. & NRN & SK & 20.47 & 95 & $\mathrm{eP}$ & $06-09-39.8$ & & & & & & 0.6 \\
\hline 27. & AAA & SKM & 20.61 & 90 & $\mathrm{eP}$ & $06-09-40.0$ & & & & & & \\
\hline 28. & MUR & SK & 20.61 & 105 & $e P$ & $06-09-43.4$ & & & & & & \\
\hline 29. & $A A B$ & SM & 20.76 & 89 & $\stackrel{e P}{P M}$ & $\begin{array}{r}06-09-42.6 \\
44.3\end{array}$ & 1.2 & & & 0.27 & 5.5 & 0.5 \\
\hline
\end{tabular}

30. PRZ SKM 21.8590 eP $06-09-55.0$

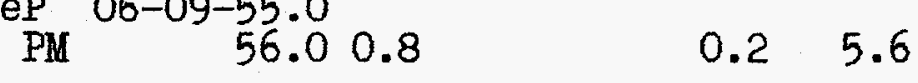

31. NVS SKM $23.3656+$ iP 06-10-09.0

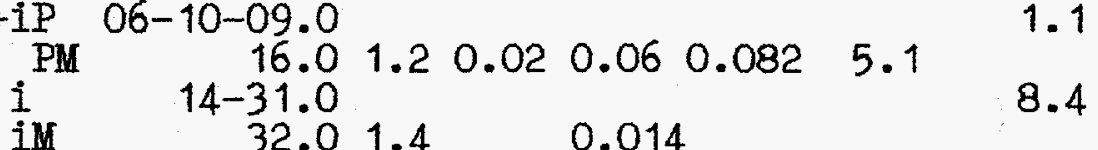

32. USK SKM $24.26 \quad 67$ tiP $06-10-18.00 .9 \quad 0.074$

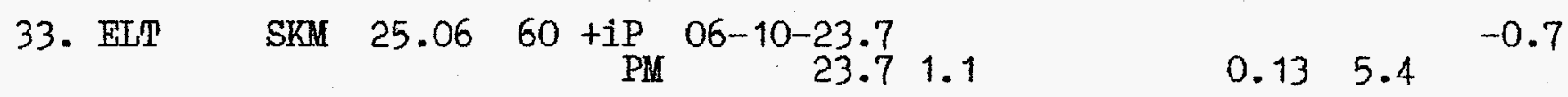

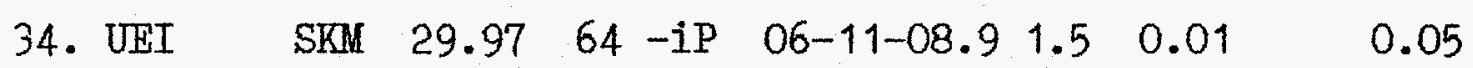

35. NRI SKM $30.0026-\mathrm{eP}$ 06-11-09.8

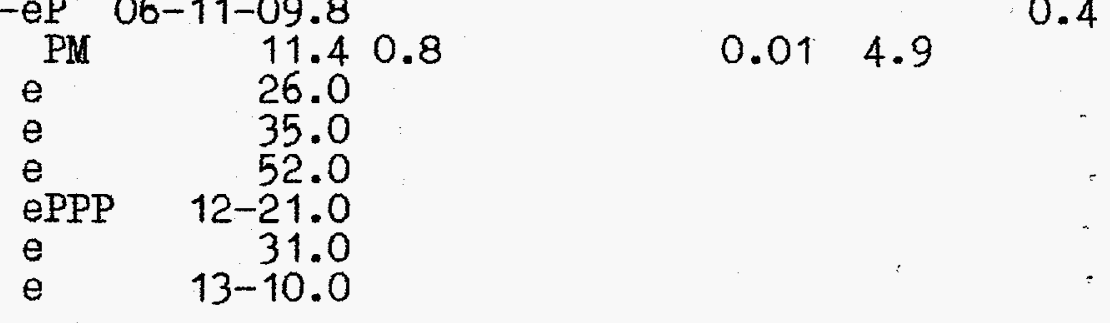


69

\begin{tabular}{|c|c|c|c|c|c|c|c|c|c|c|c|c|}
\hline 1 & 2 & 3 & 4 & 5 & 6 & 7 & 8 & 9 & 10 & 11 & 12 & 13 \\
\hline 36. & OD & SKM & 40.22 & 49 & $\underset{P M}{+i P}$ & $\begin{array}{r}06-12-36.2 \\
37.5\end{array}$ & 0.5 & 0.01 & 0.02 & 0.05 & 5.7 & -0.6 \\
\hline 37. & TIK & SKM & 43.57 & 26 & $\begin{array}{l}+\underset{P M}{P} \\
\text { ePP }\end{array}$ & $\begin{array}{r}06-13-04.5 \\
07.5 \\
14-45.5\end{array}$ & 0.5 & & & 0.01 & 5.0 & $\begin{array}{r}0.4 \\
-2.5\end{array}$ \\
\hline
\end{tabular}

38. KID SKM $53.16 \quad 55 \quad \mathrm{P}$ 06-14-18.7 
70

AV3 16 october 1982 (region Astrachan) - explosion 3

USSR: $0=06-09-57.2$

$\varphi=46,95 \mathrm{~N}$

$\lambda=48.14 \mathrm{E} . \quad \mathrm{h}=0 \mathrm{maM}$

$\operatorname{MPV}(A)=5.0(8)$

\begin{tabular}{|c|c|c|c|c|c|c|c|c|c|c|c|c|}
\hline \multirow[t]{2}{*}{$\mathrm{NN}$} & \multirow{2}{*}{$\begin{array}{c}\text { Kod } \\
\text { station }\end{array}$} & \multirow{2}{*}{$\begin{array}{l}\text { Chan- } \\
\text { nel }\end{array}$} & \multirow{2}{*}{$\Delta^{\circ}$} & \multirow{2}{*}{$A Z^{\circ}$} & \multirow[t]{2}{*}{ Phase } & \multirow{2}{*}{$\begin{array}{l}\text { Arrival } \\
\text { time }\end{array}$} & \multirow[t]{2}{*}{ Ts } & \multicolumn{3}{|c|}{ A micrometr } & \multirow{2}{*}{$\begin{array}{r}\mathrm{Mag} \\
\mathrm{mb}\end{array}$} & \multirow[t]{2}{*}{ Res } \\
\hline & & & & & & & & NS & EW & $\mathrm{Z}$ & & \\
\hline 1 & 2 & 3 & 4 & 5 & 6 & 7 & 8 & 9 & 10 & 11 & 12 & 13 \\
\hline
\end{tabular}

1. MAK SKM 4.08187 iP 06-11-02.2

PM $\quad 04.0 \quad 0.5$

0.9

2. PYA SKM 4.67233 eP $06-11-08.5$

$$
\text { i }
$$

IM $\quad 13-48.0 \quad 10.0$
$1.0 M \mathrm{MV}=3.4$

3. TI2 SKM $5.80206+i P \quad 06-11-25.6$

4. BKR SKM 6.18 214 -iP 06-11-32.0

SKD

$$
\begin{array}{rrr}
\text { PM } & 32.0 & 0.8 \\
1 . & 12-31.0 & \\
\text { SM } & & 1.4
\end{array}
$$

0.18

5. IRRV SKM 6.39193 iP 06-11-33.0

6. $A B S$

SKM 6.41

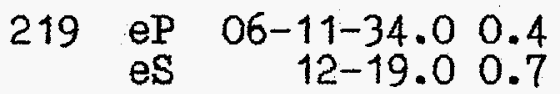

$$
0.05
$$

0.02

7. AKH

SKM $6.47 \quad 213+$ iP $06-11-35.2$

8. STE

$$
\text { SKM }
$$

$$
6.5
$$

$$
206+1
$$

$$
\begin{array}{rr}
\text { PM } & 36.0 \\
i & 12-06.0 \\
i & 24.0 \\
i & 58.4 \\
i & 13-21.0 \\
i & 42.4
\end{array}
$$

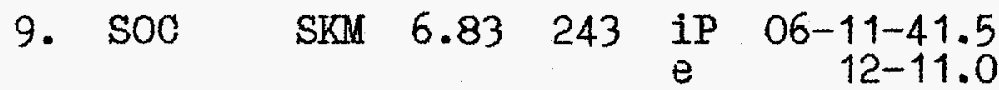

10. ANN

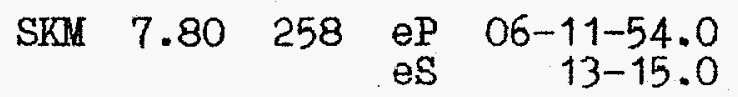




\begin{tabular}{|l|l|l|l|l|l|l|l|l|l|l|l|l|}
\hline 1 & 2 & 3 & 4 & 5 & 6 & 7 & 8 & 9 & 10 & 11 & 12 & 13 \\
\hline
\end{tabular}

12. Michnevo SKM $10.33 \quad 325$-iP $06-12-29.6 \quad 0.529 .6$

0.350

$\begin{array}{ll}0.5 & 0.150\end{array}$

13. OBN SKM 10.94322 -iP $06-12-38.0$

$$
\text { PM } \quad 0.21
$$

0.3

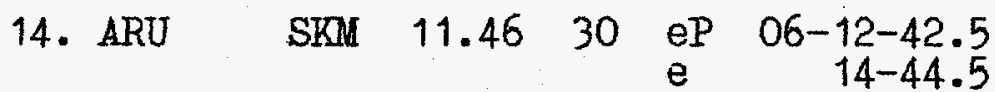

$\begin{array}{lllll}\text { SKD } & \text { IM } 19-06.0 & 12.0 & 0.5 & \text { MLV=3.6 }\end{array}$

15. SVE SKM $12.52 \quad 33$-iP $06-12-56.6$
SKM $12.52 \quad 33-$ IP $06-12-56.6$
0.4
0.21
$-2.7$
SKD
e $\quad 13-10.0$
$13-10.0$
$0.6 \quad \begin{array}{ll}\mathrm{MLH}=3.7 \\ \mathrm{MLV}=3.8\end{array}$

16. $\mathrm{BRV}$

SK $\quad 15.45 \quad 59+\underset{P M}{+i P} 06-13-34.0$

0.7

0.096

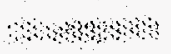

17. TAS SKM 16.19103 eP 06-13-(50.0)

SK

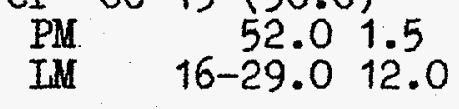

$\begin{aligned} & 0.2 \\ & 0.6\end{aligned} \mathrm{MLV}=(3.3)$

18. PUI

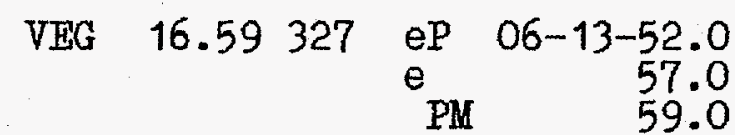

19. UZH

$$
\begin{aligned}
& \text { SKM } 17.43285 \text {-iP } \quad 06-14-02.5 \\
& \begin{array}{rr}
i & 10.0 \\
i & 14.0 \\
i & 21.0 \\
i & 37.0 \\
i & 59.0 \\
i & 15-09.0 \\
i & 38.0
\end{array}
\end{aligned}
$$

20. GAR SKM 18.02 108 iP $06-14-09.7 \quad 0.7$

0.06

21. KUL SK 18.32112 eP $06-14-10.8$

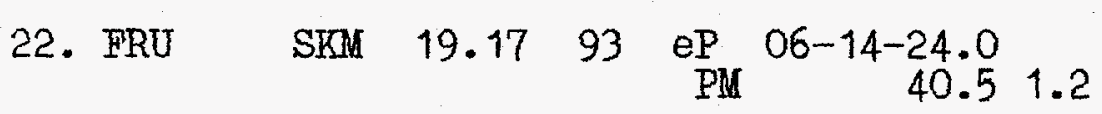

0.07 


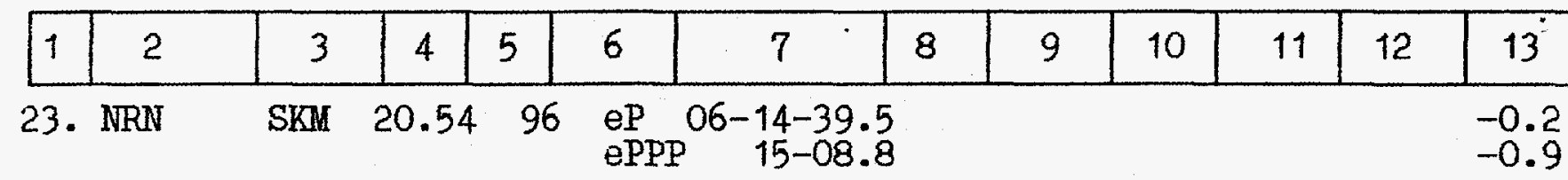

24. AAA SKM 20.6790 eP $06-14-40.0$

25. MUR SK 20.71105 eP $06-14-42.4$

26. $A A B$ SKM $20.81 \quad 89$ eP 06-14-42.2

$\mathrm{eP}$
$\mathrm{PM}$$\quad \begin{array}{llllll}06-14-42.2 & & & & & \\ 44.3 & 1.0 & 0.18 & 5.4 & \end{array}$

27. PRZ SKM $21.90 \quad 90$ eP $06-14-54.0$
PM $\quad 55.0 \quad 0.8$
0.125 .3

0.4

28. NVS SKM $23.3157+$ iP $06-15-08.9$

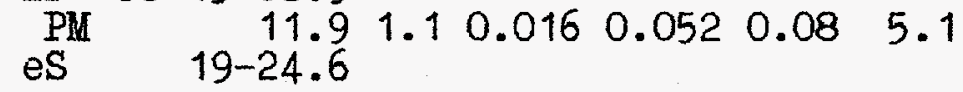

29. USK

SKM $24.24 \quad 67+i P \quad 06-15-17.0 \quad 0.9$

0.06

30. EIT

SKM $25.02 \quad 61+\underset{\text { PM }}{\text { iP }} \quad 06-15-23.8$

$0.08 \quad 5.2$

$-0.2$

31. NRI

SKM 29.88

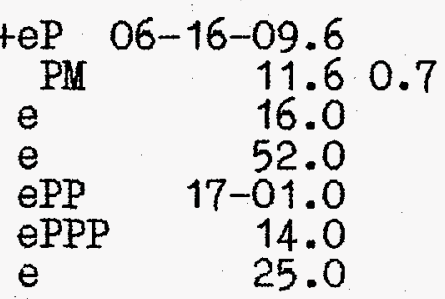

$0.01 \quad 4.9$

1.4

$-4.6$

e

25.0

$-5.4$

32. UEI SKM $29.9564+i P$ PM $06-16-09.40 .9$

0.02

33. BOD SKM $40.1549+$ iP $06-17-35.7$ $\begin{array}{lllllll}\text { PM } & 36.0 & 0.5 & 0.01 & 0.02 & 0.04\end{array}$

$5.6-0.4$

34. TIK

SKM 43.45 $\begin{array}{rrr}+e P & 06-18-04.5 \\ \text { PM } & 06.5 & 0.5 \\ \text { ePP } & 19-48.5\end{array}$

0.009

4.9

1.5

1.8

35. KLD SKM 53.11 $55 \quad P \quad$ 06-19-18.6

36. ILT SKM 60.22 18 eP 06-20-10.0 
73

AV3 16 october 1982 (region Astrachan) - explosion 4

USSR: $0=06-15-01.0$

$\varphi=46^{\circ}, 97 \mathrm{~N}$

$\lambda=48.73 \mathrm{E} \quad \mathrm{h}=0 \mathrm{KM}$

$\operatorname{MPV}(\mathrm{A})=5.2(11) \quad \operatorname{MLV}(\mathrm{B})=3.8(4)$

\begin{tabular}{|c|c|c|c|c|c|c|c|c|c|c|c|c|}
\hline \multirow[t]{2}{*}{ NN } & \multirow{2}{*}{$\begin{array}{c}\text { Kod } \\
\text { station }\end{array}$} & \multirow{2}{*}{$\begin{array}{l}\text { Chan- } \\
\text { nel }\end{array}$} & \multirow{2}{*}{$\Delta^{\circ}$} & \multirow{2}{*}{$A z^{\circ}$} & \multirow[t]{2}{*}{ Phase } & \multirow{2}{*}{$\begin{array}{l}\text { Arrival } \\
\text { time }\end{array}$} & \multirow[t]{2}{*}{ Ts } & \multicolumn{3}{|c|}{ A micrometr } & \multirow{2}{*}{$\underset{\mathrm{mb}}{\mathrm{Mag}}$} & \multirow[t]{2}{*}{ Res } \\
\hline & & & & & & & & NS & EW & $\mathrm{Z}$ & & \\
\hline 1 & 2 & 3 & 4 & 5 & 6 & 7 & 8 & 9 & 10 & 11 & 12 & 13 \\
\hline 1. & MAK & SKM & 4.16 & 193 & ${ }_{\mathrm{PH}}^{\mathrm{iP}}$ & $\begin{array}{r}06-16-02 \\
04\end{array}$ & 0.8 & & & 0.9 & & \\
\hline 2. & PYA & SKM & 5.00 & 236 & $\begin{array}{l}\text { eP } \\
i \\
i \\
i \\
i \\
i S \\
\text { IM }\end{array}$ & $\begin{array}{r}06-16-09 \\
21 \\
29 \\
37 \\
47 \\
17-24 \\
18-50\end{array}$ & 12.0 & & & 1.78 & $L V=3$. & $9.4 *$ \\
\hline
\end{tabular}

3. TI2 SKM $6.01 \quad 210$ eP $06-16-25.6$

4. BKR SKM 6.43215 -iP 06-16-34.0

PM $\quad 34.00 .8$

0.34

$-5 \cdot 2 *$

SKD $i_{\text {SM }} \quad 17-30.0$

0.47

5. KRV SKM $6.54 \quad 197$ 1P $06-16-33.0$

0.3

6. $A B S$

SKM $6.69222+$ iP $\quad 06-16-34.0 \quad 0.5$

0.06

7. AKH SKM 6.72,216 -iP 06-16-34.8

8. STE SKM 6.73209 tiP 06-16-35.0

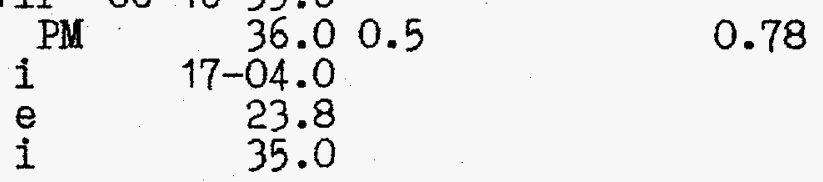

9. LEN VEG 7.13209 eP 06-16-43.0

10. $\mathrm{SOC}$

SKI

$244 e^{P} \quad 06-16-41.5$ 
74

\begin{tabular}{|c|c|c|c|c|c|c|c|c|c|c|c|c|}
\hline 1 & 2 & 3 & 4 & 5 & 6 & 7 & 8 & 9 & 10 & 11 & 12 & 13 \\
\hline
\end{tabular}

12 LNIK $\quad 8.17 \quad 180 \quad \mathrm{P} \quad 06-16-57.5$

13. ANN SKM $8.20 \quad 259$-iP $06-16-55.0$

14.Michnevo SKM $10.55 \quad 323$-iP $\quad 06-17-30.0 \quad 0.5 \quad 0.355 \quad 0.272 \quad 0.660$

15. OBN SKM 11.17321 iP $06-17-39.0$

$-6.0 *$

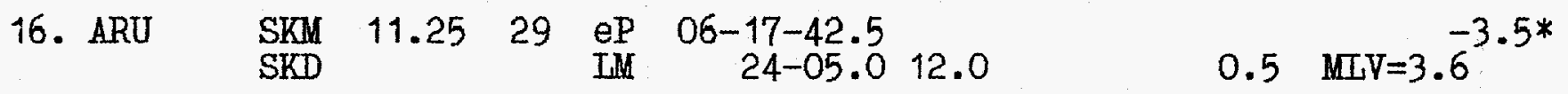

17. SVE SKM $12.2932+$ iP $06-17-56.0$

SKD . IM 25-00.0

$\begin{array}{llll}11.0 & 0.5 & 0.5 & 1.0 \quad \mathrm{MLH}=3.9^{-4.1 *}\end{array}$

18. BRV SK $15.10 \quad 58$ eP $06-18-34.0$

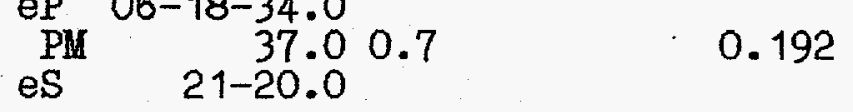

19. SAM SK 15.14111 eP $06-18-35.0$

20. TAS SK 15.80104 iP 06-18-(50.0)

$\begin{array}{lrrl} & & \\ \text { SKM } & \text { PM } & 52.01 .5 & 1.0 \\ \text { SK } & \text { PM } & 52.01 .3 & 0.52 \\ & \text { IM } & 21-23.010 .0 & 0.5 \mathrm{MLV}=(3.3)\end{array}$

21. PUL VEG $\begin{array}{rrrr}16.80 & 326 & \text { eP } & 06-18-51.0 \\ & \text { e } & 57.0 \\ & & \text { PM } & 59.0\end{array}$

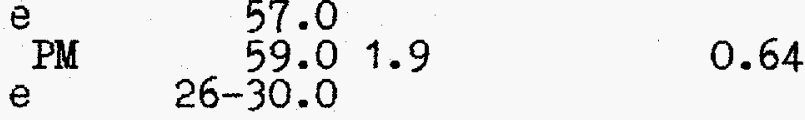

22. GAR SKM 17.64109 eP $06-19-08.20 .9 \quad 0.11$

23. UZH SKM $17.81285+$ iP $06-19-03.0$

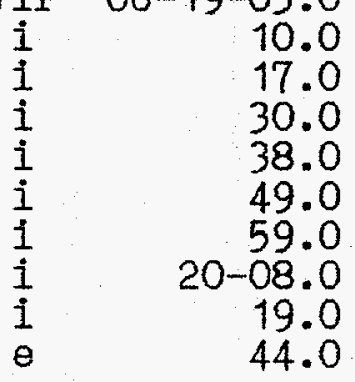


75

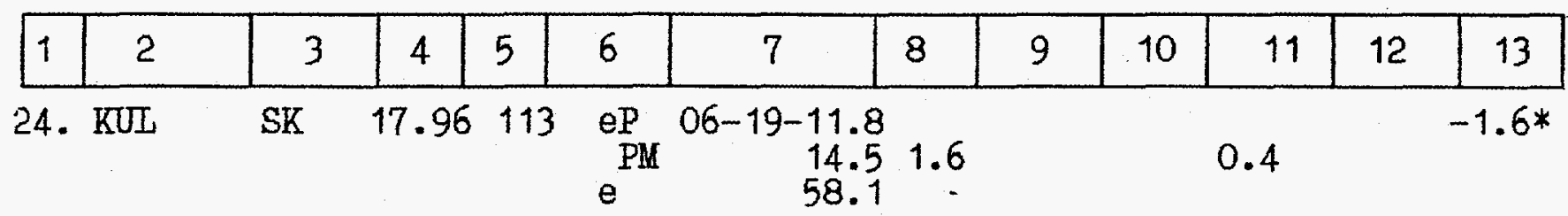

25. FRU SKM $18.7793-\mathrm{eP}$ 06-19-22.0

PM $28.00 .6 \quad 0.13 \quad-1.5$

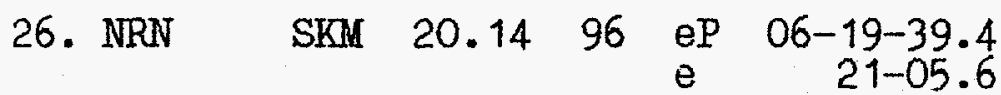

0.0

27. AAA SKM $20.26 \quad 90$ eP $06-19-40.0$

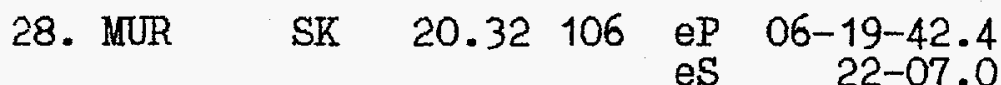

29. $A A B$ SM $20.40 \quad 89$ iP $06-19-42.2$
PM
44.21 .0
$0.42 \quad 5.8$
0.1

30. PRZ SKM $21.50 \quad 90$ eP 06-19-54.0

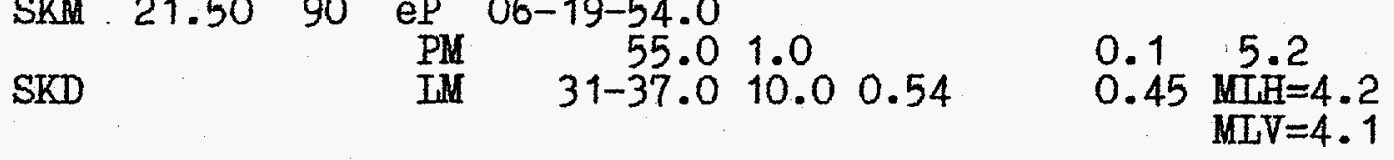

31. NVS SKM $22.9757+i P \quad 06-20-08.7$

$$
\begin{aligned}
& \begin{array}{llllllll}
\text { PM } & 15.7 & 1.0 & 0.062 & 0.116 & 0.182 & 5.5
\end{array}
\end{aligned}
$$

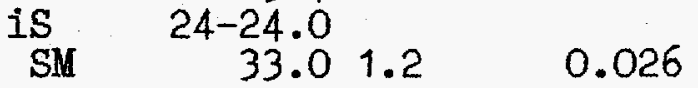

32. USK SKM $23.8667+i P \quad 06-20-17.5$

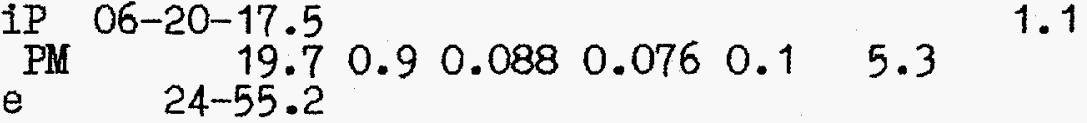

33. EIT SKM $24.66 \quad 61+$ iP $06-20-23.6$

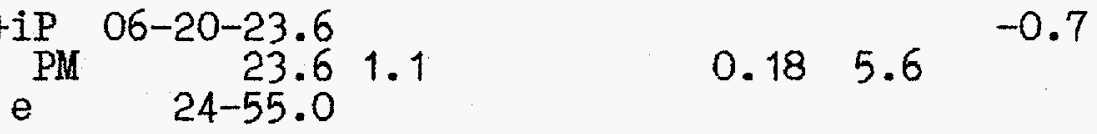

34. UEI SKM $29.57 \quad 64$ +iP $\quad 06-21-08.1 \quad 0.8 \quad 0.010 .03 \quad 0.06$

35. NRI SKM $29.6827+$ IP $06-21-09.2$

$$
\begin{aligned}
& \begin{array}{lllll}
\text { PM } & 11.3 & 0.9 & 0.03 & 5.1
\end{array} \\
& \begin{array}{lr}
e & 42.0 \\
i & 52.0 \\
e & 59.0 \\
\text { ePPP } & 22-15.0 \\
e & 30.0 \\
e & 23-11.0
\end{array}
\end{aligned}
$$


76

\begin{tabular}{|c|c|c|c|c|c|c|c|c|c|c|c|c|}
\hline 1. & 2 & 3 & 4 & 5 & 6 & 7 & 8 & 9 & 10 & 11 & 12 & 13 \\
\hline & & $\mathrm{KM}$ & 5. & & $\mathrm{~F}$ & & 0.6 & & & .01 & 4.9 & 0.6 \\
\hline
\end{tabular}

37. BOD SKM $39.83 \quad 49+i P \quad 06-22-35.7$ PM $\begin{array}{lllllll} & 06-22-35.7 & & & & & \\ 37.0 & 0.5 & 0.02 & 0.04 & 0.11 & 6.0\end{array}$

38. TIK

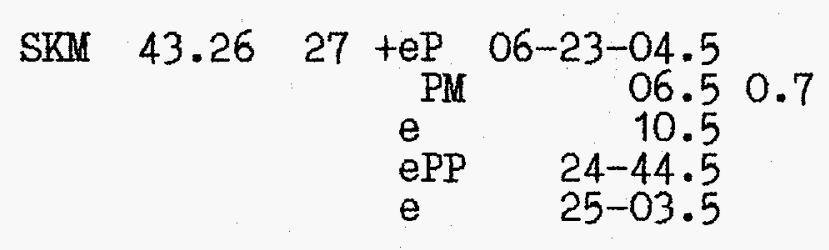$$
0.01(5.1)^{-0.7 *} \begin{array}{r}
-1.0 \\
-4.1
\end{array}
$$

39. YAK

SKM $46.12 \quad 40+{ }_{\text {PM }}^{\text {iP }}$ 06-23-26.0 28.0 0.9 $0.095 .8^{-2.2 *}$

40. KTD

SKM $\quad 52.77 \quad 55 \quad P \quad 06-24-18.2$

41. IIT SKM $60.07 \quad 18$ eP $06-25-09.0$

42. YSS SKM 60.1451 eP $06-25-11.3$ 
AZ1 22 April 1966 (Western Kazakhstan)

USSR: $0=02-58-02.27$

$\varphi=47.796 \mathrm{~N}$

$\lambda=47.917 \mathrm{E} \quad \mathrm{h}=0 \mathrm{~km}$

\begin{tabular}{|c|c|c|c|c|c|c|c|c|c|c|c|c|}
\hline \multirow[t]{2}{*}{$\mathrm{NN}$} & \multirow{2}{*}{$\begin{array}{l}\text { Kod } \\
\text { station }\end{array}$} & \multirow{2}{*}{$\begin{array}{l}\text { Chan- } \\
\text { nel }\end{array}$} & \multirow[t]{2}{*}{$\Delta^{\circ}$} & \multirow[t]{2}{*}{$A Z^{\circ}$} & \multirow[t]{2}{*}{ Phase } & \multirow{2}{*}{$\begin{array}{l}\text { Arrivel } \\
\text { time }\end{array}$} & \multirow[t]{2}{*}{$\mathrm{Ts}$} & \multicolumn{3}{|c|}{ A micrometr } & \multirow{2}{*}{$\underset{\mathrm{mb}}{\mathrm{Mag}}$} & \multirow[t]{2}{*}{ Res } \\
\hline & & & & & & & & NS & $E W$ & $\mathrm{Z}$ & & \\
\hline 1 & 2 & 3 & 4 & 5 & 6 & 7 & 8 & 9 & 10 & 11 & 12 & 13 \\
\hline 1. & GRO & SK & .72 & 200 & $\begin{array}{c}\text { eePn } \\
\text { S } \\
\text { IM }\end{array}$ & $\begin{array}{r}02-59-1 \\
03-00-4 \\
02-0\end{array}$ & $\begin{array}{l}1.0 \\
1.8 \\
9.0\end{array}$ & 0.62 & & $\begin{array}{l}0.4 \\
0.6\end{array}$ & \multicolumn{2}{|l|}{$\mathrm{LV}=$} \\
\hline
\end{tabular}

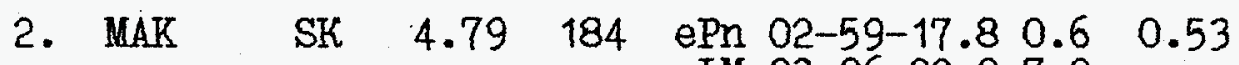
IM $03-06-02.07 .0$
$0.32 \mathrm{MLV}=3.09$

3. GOR SKM $6.40 \quad 206$ eePn 02-59-45.5 0.8

$$
\begin{aligned}
& S_{1}-1.1 \\
& \begin{array}{llll}
\text { S2 } & 03-01-57.5 & 2.6 & 0.159
\end{array}
\end{aligned}
$$

4. KPR SKM 6.79235 IPn 02-59-41.8 0.5

P $03-00-16.8 \quad 0.6$

0.038

0.053

5. BKR SKM $6.82 \quad 209$ iPn 02-59-42.8 0.9

SK 6.82 209 1Pn $02-59-42.80 .9$

0.485

SKM

$1 \quad 03-00-31.0$

0.1

6. ABS SH $7.04 \quad 213$ ePn 02-59-45.0

$\begin{array}{rrrrrr}\text { 7. SOC SKM } 7.12 \quad 237 \text { iPn } 02-59-47.0 & 0.5 & 0.12 \\ & & & 49.0 & 0.6 & 0.08\end{array}$

8. KRV SK $7.23 \quad 190$ Pn 02-59-47.0

9. STE SH $7.25202 \mathrm{e}(\mathrm{Pn})$ 02-59-48.4

10. GRS SK $8.37 \quad 188$ ePn 03-00-04.0

$\begin{array}{lllllll}\text { 11. Michnevo SRM } & 9.56 & 322 \text { iPn } & 03-00-26.0 & 0.45 & 0.123 \\ & & & \text { S } & 02-00.5 & 0.65 & 0.072\end{array}$

SK

0.8

0.167

12. ALU SH 9.85257 ePn 03-00-22.3 
78

\begin{tabular}{|c|c|c|c|c|c|c|c|c|c|c|c|c|}
\hline 1 & 2 & 3 & 4 & 5 & 6 & 7 & 8 & 9 & 10 & 11 & 12 & 13 \\
\hline 13. & IM & SH & 9.95 & 258 & eePn & $03-00-49.0$ & 1.0 & & & 0.057 & & - \\
\hline 14. & $\mathrm{AL}$ & SH & 10.11 & 256 & $i P_{i}$ & $\begin{array}{r}03-00-25.1 \\
37.0\end{array}$ & $\begin{array}{l}0.45 \\
0.6\end{array}$ & & & $\begin{array}{l}0.033 \\
0.023\end{array}$ & & \\
\hline
\end{tabular}

15. OBN Benioff 10.20 321 ePn 03-00-24.6

16. SVE SKM 11.9036 ePn 03-00-47.0

17. ASH SK 12.45138 ePn 03-01-03.0

18. BRV SKM $15.16 \quad 61{ }^{\mathrm{eP}} 03-01-32.9 \underset{1.8}{0} \quad 0.008^{0.006}$

19. RAK SKM 15.88280 eP $03-01-39.5$

20. MEZ SKM 16.28282 e(Pn) $03-02-05.2$

21. UZH SKM 17.07282 eP $03-01-57.30 .6 \quad 0.016$

22. GAR SKM 18.45110 eP $03-02-16.8 \quad 0.03$

23. KUL SKM 18.76114 eP $03-01-51.8$

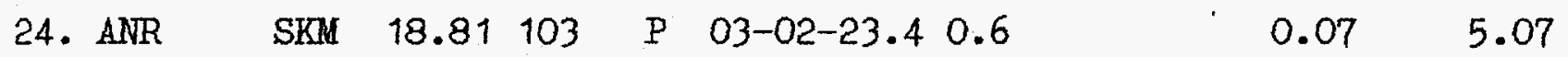

25. DZT VEG 18.90108 P $03-02-27.1$

26. III SK $20.63 \quad 90$ eP $03-02-41.4$

27. $A A B$ SK $21.06 \quad 91$ iP $03-02-45.4$

28. APA SKM 21.18344 IP $\begin{array}{llllll}\text { IP } & 3-02-44.0 \\ 26.2 & 18 & 1.4 & 1.1 & \text { MLH=4.36 }\end{array}$

29. KRM SKM $21.77 \quad 91$ eP $03-02-53.2$

30. Ust- USP $22.66 \quad 72$ iP $03-02-59.60 .8 \quad 0.017 \quad 4.52$ Kamenogorsk

31. ELT SKM $24.77 \quad 63$ eP $\quad 03-03-22.5 \quad 0.8$

$0.02 \quad 4.75$

32. CUR SKM $26.43 \quad 70$ eP $03-03-39.21 .2$

$0.02 \quad 4.67$

33. BOD SKM 39.7150 iP $03-05-34.00 .6$

$0.026-0.8$

34. TIK SKM $42.77 \quad 27$ iP $03-05-58.0 \quad 0.9$

$0.005 \quad 4.45 \quad 0$


79

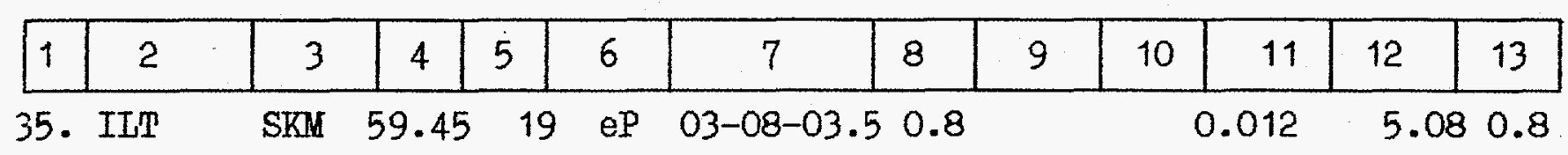

36. MIR SKM $119.10161 \underset{e}{\text { ePKP }}$ 03-15-00.0 
80

AZ2 1 June 1968 (Western Kazakhstan)

USSR: $0=04-01-57.6$

$\varphi=48^{\circ} 005 \mathrm{~N}$

$\lambda=47.850 \mathrm{E} \quad \mathrm{h}=23 \mathrm{~km}$

\begin{tabular}{|c|c|c|c|c|c|c|c|c|c|c|c|c|}
\hline \multirow[t]{2}{*}{$\mathrm{NN}$} & \multirow{2}{*}{$\begin{array}{c}\text { Kod } \\
\text { station }\end{array}$} & \multirow{2}{*}{$\begin{array}{l}\text { Chan- } \\
\text { nel }\end{array}$} & \multirow{2}{*}{$\Delta^{\circ}$} & \multirow{2}{*}{$A z^{\circ}$} & \multirow[t]{2}{*}{ Phase } & \multirow{2}{*}{$\begin{array}{l}\text { Arrival } \\
\text { time }\end{array}$} & \multirow[t]{2}{*}{ Ts } & \multicolumn{3}{|c|}{ A micrometr } & \multirow{2}{*}{$\begin{array}{r}\mathrm{Mag} \\
\mathrm{mb}\end{array}$} & \multirow[t]{2}{*}{ Res } \\
\hline & & & & & & & & NS & $E N$ & $\mathrm{Z}$ & & \\
\hline 1 & 2 & 3 & 4 & 5 & 6 & 7 & 8 & 9 & 10 & 11 & 12 & 13 \\
\hline
\end{tabular}

1. GRO SK $4.90 \quad 199$ Pn 04-03-13.0

$\begin{array}{lr}i(\mathrm{Pg}) & 41.5 \\ \mathrm{e}(\mathrm{S}) & 04-50.5\end{array}$

$\begin{array}{lllll}\text { SM } & 1.0 & 5.6 & 5.2 & 2.0 \\ \text { IM } & 8.0 & 4.2 & 2.4 & 3.4\end{array}$

2. MAK SH $4.99 \quad 184$ iP $04-03-15.6$

$\begin{array}{llllll}\mathrm{e} I \mathrm{~g} & 05-40.0 \\ \mathrm{eLR} & 07-18.6 & 8.0 & 4.3 & 4.0 & 4.0 \quad \mathrm{MLV}=4.13\end{array}$

3. PYA SK 5.19222 ePn 04-03-17.0

ePna 24.0

$-0.9$

$\mathrm{ePg} \quad 38.0$

4. GOR SKM $6.58205 \mathrm{i}(\mathrm{Pg})$ 04-04-08.0

5. TI2 SK $6.67 \quad 200 \quad$ Pn 04-03-37.0

$\mathrm{ePg} \quad 04-12.0$

e(Sg) $\quad 05-50.0$

elg $07-00.0$

6. BKR SKD 6.99208 ePn 04-03-41.5

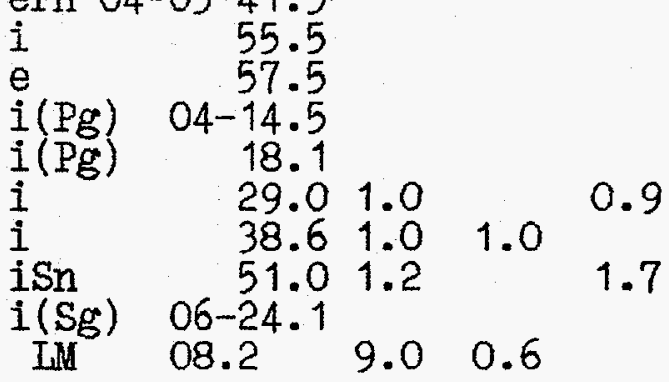

7. ABS SH $7.20 \quad 212+i \mathrm{Pn}$ 04-03-44.0

iPg $04-18.0$ 
81

\begin{tabular}{l|c|c|c|c|c|c|}
\hline 1 & 2 & 3 & 4 & 5 & 6 & 7 \\
\hline 8. STE & SH & 7.43 & 201 & iPn & $04-03-45.2$ \\
& & & & i & $04-42.2$ \\
& & & & iSn & $05-03.2$
\end{tabular}

9. ANN SKM 7.93 251 iPn 04-03-53.5

10. ERE SK 8.18 198 ePn 04-03-56.6

11. GRS SK $8.57188-i(\mathrm{Pn})$ 04-04-02.0

ePna 14.0

$\begin{array}{ll}-0.2 & 1.4\end{array}$

12. FEO SK 9.10255 ePn 04-04-11.0

$\begin{array}{ll}\text { esn } & 05-53.0 \\ e & 06-03.0\end{array}$

13. ALU SH $9.86 \quad 255$-iPn 04-04-20.1

\begin{tabular}{|c|c|}
\hline $\begin{array}{l}e^{P M} \\
\text { esn }\end{array}$ & $\begin{array}{c}24.0 \\
36.4 \\
05-52.7\end{array}$ \\
\hline
\end{tabular}

14. SIM SK 9.95257 ePn 04-04-20.0

ePna $\quad 31.0$

$\begin{array}{lr}\text { i } & 55.0 \\ \text { e } & 05-37.0\end{array}$

15. MOS SH $9.98 \quad 325$ ePn $04-04-22.0$

ePna $\quad 34.0$

e 46.0

ePg $\quad 05-12.0$

SK

ePn $\quad 06-12.0$

$\begin{array}{lr}\mathrm{e} & 07-06.0 \\ \mathrm{e} & 10.0\end{array}$

SK

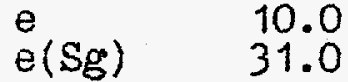

SKD

LM 09.5

$\begin{array}{llll}8.0 & 0.4 & 0.6 \quad \mathrm{MLV}=3.88\end{array}$

SKD

8.00 .4

0.5

0.3

16. YAL SH 10.12255 ePn 04-04-23.5

$\begin{array}{llllll}P M & 24.0 & 0.5 & 0.2 & 0.3 & -0.5 \\ \text { eSn } & 06-10.5\end{array}$ 
82

\begin{tabular}{|l|l|l|l|l|l|l|l|l|l|l|l|l|}
\hline 1 & 2 & 3 & 4 & 5 & 6 & 7 & 8 & 9 & 10 & 11 & 12 & 13 \\
\hline 17. KAT & SK 10.70 & 142 & ePn $04-04-33.0$ \\
e & $05-01.0$
\end{tabular}

18. SVE SKM $11.76 \quad 37 \quad$ Pn $04-04-44.0$

$11.0 \quad 0.5 \quad 0.5 \quad 0.9 \quad M L V=3.94^{3.3}$

19. VAN VEG $12.53 \quad 140$ ePn 04-04-59.0 $-1.4$ 20. ASH SK 12.64139 ePn 04-04-55.5

MLg $\quad 10-21.5 \quad 3.5$

1.1

3.4

21. KIS SK 12.87273 iPn 04-05-01.2

1.4

$\begin{array}{lr}\text { ip } & 13.0 \\ \text { isn } & 07-23.0 \\ \text { i } & 52.0 \\ \text { IM } & 11.5\end{array}$

22. BRV SKM
SKD

SKM $\quad 15.10 \quad 62-$ iPn $04-05-28.1$

$\begin{array}{rr}\text { PM } & \\ \text { eSn } & 08-10.7 \\ \text { eLg } & 11-28.3 \\ \text { IM } & \\ \text { iPn } & 04-05-36.0 \\ \text { in } & 44.0\end{array}$

$\begin{array}{ll}\mathrm{NL}_{1} & 18 \\ \mathrm{ML2} & 8 \\ \mathrm{ML} 3 & 6\end{array}$

$\begin{array}{lllll}8.0 & 0.3 & 0.5 & 0.5 \quad \text { MLV }=3.91\end{array}$

23. PUL

SK $\quad \begin{array}{ll}15.61325 & \text { iPn } \\ & \text { in } \\ & \text { NL1 } \\ \text { NL2 } \\ \text { NL3 } 3\end{array}$

$\begin{array}{llll}0.9 & -0.002 & -0.06 & 0.07 \\ 0.9 & 0.11 & 0.23 & 0.29\end{array}$

3.1

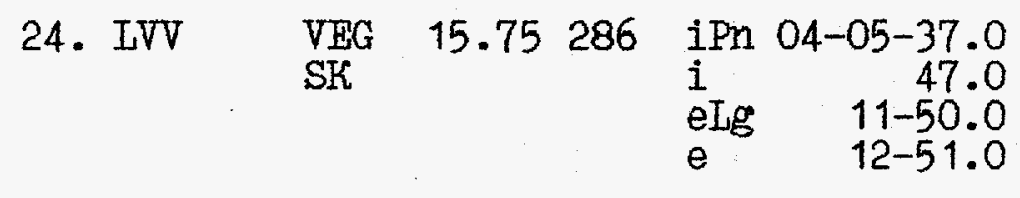

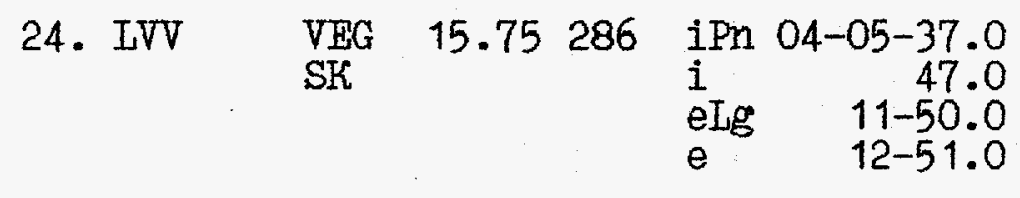

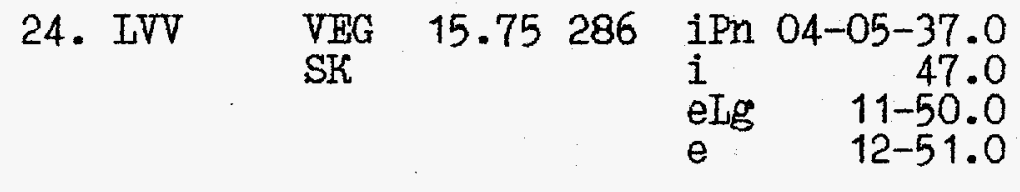

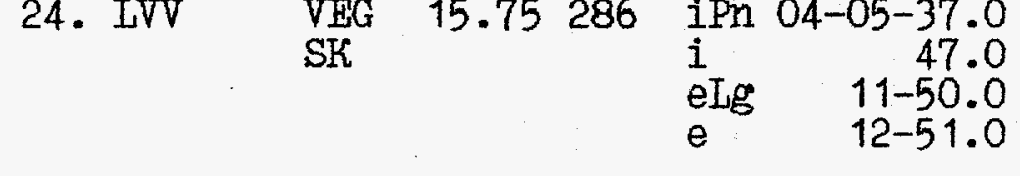

$\begin{array}{lllll}12 & 0.3 & 0.5 & 0.7 \quad M L V=3.99\end{array}$

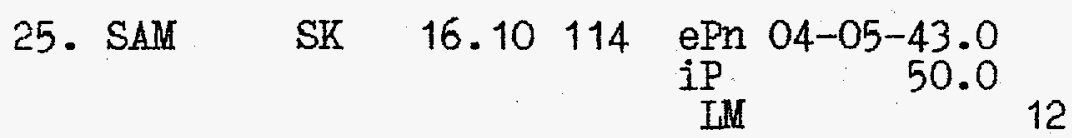

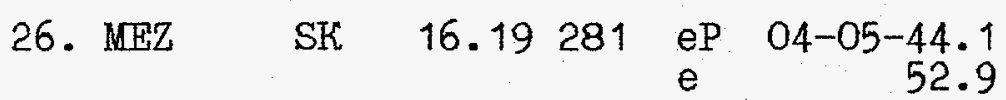

27. CHM SK $16.35 \quad 102$-P $04-05-45.0$

28. TAS SK $16.63106-e P n$ 04-05-48.5

1.2

$\begin{aligned} & 0.3 \\ & 0.5 \\ & 0.45\end{aligned} \quad M L V=4.04$

2.7

$0.7 \quad 0.4 \quad M L V=3.78$ 
83

\begin{tabular}{|c|c|c|c|c|c|c|c|c|c|c|c|c|}
\hline 1 & 2 & 3 & 4 & 5 & 6 & 7 & 8 & 9 & 10 & 11 & 12 & 13 \\
\hline 29. & & SKM & & & $\begin{array}{c}e(P n \\
i \\
i \\
i\end{array}$ & $\begin{array}{r}04-05-53.0 \\
56.0 \\
06-08.0\end{array}$ & $\begin{array}{l}1.0 \\
1.0 \\
1.0\end{array}$ & & & $\begin{array}{l}.023 \\
.067 \\
.14\end{array}$ & & 2.4 \\
\hline
\end{tabular}

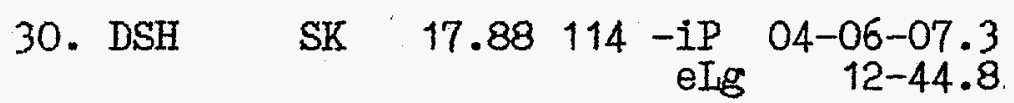

31. NAM SK 18.34104 -IP $04-06-11.8$

32. GAR SKM 18.57111 eP $04-06-15.0$

0.04

33. ANR SK, SKM 18.91103 eP1 04-06-19.0

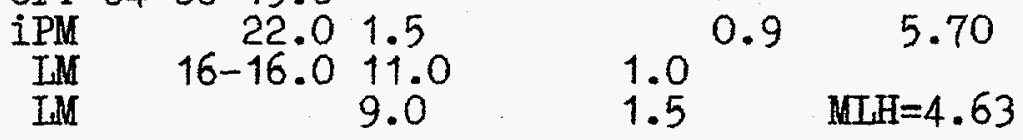

34. FRU SKM $19.44 \quad 95$ eP $04-06-25.0$

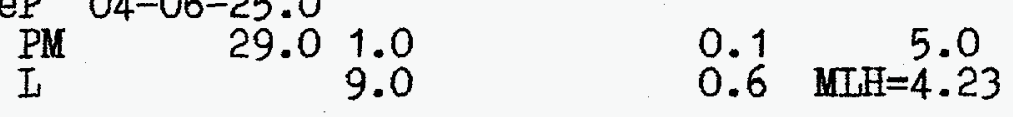

35. KRS SK 19.6494 iP $04-06-38.01 .0 \quad-0.6 \quad 5.98$

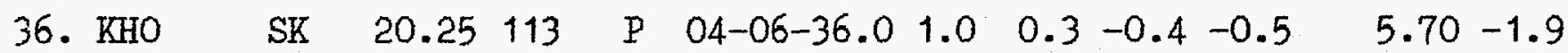

37. RYB SKM 20.5895 iP 04-06-48.0

38. ILI SKM 20.6890 iP 04-06-38.2

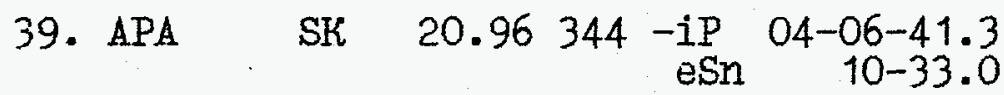

40. NRN SKM $20.98 \quad 98$ iP $04-06-43.4$

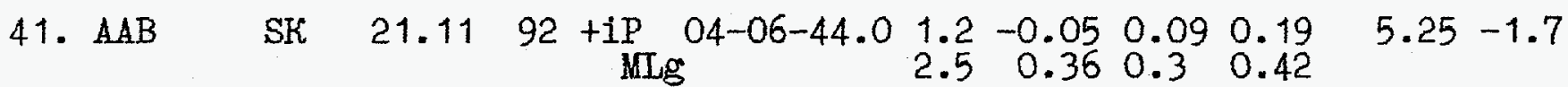

42. MUR SK $21.23 \quad 107$ eP $\begin{array}{rr}04-06-47.6 \\ 10-43.7\end{array}$

43. KRM SK 21.8292 iP 04-06-52.0

44. PRZ SK 22.1293 +P $04-06-55.9$ 
84

\begin{tabular}{|l|l|l|l|l|l|l|l|l|l|l|l|l|}
\hline 1 & 2 & 3 & 4 & 5 & 6 & 7 & 8 & 9 & 10 & 11 & 12 & 13 \\
\hline
\end{tabular}

46. ELT SKM $24.7163 \quad \mathrm{i}(\mathrm{P})$ 04-07-20.0 0.8

$0.21 \quad 5.76-1.5$

47. CUR SKM $26.40 \quad 70-i P \quad 04-07-37.4 \quad 1.0$

$0.1 \quad 5.45$

48. MOY SKM $33.8363+(\mathrm{P})$ 04-08-(11.0)

$29.5 *$

49. ZAK

SKM $35.5965+P \quad 04-08-58.5 \quad 1.2$

$0.014 \quad 4.77$

50. BOD

SKM $39.62 \quad 50+i P \quad 04-09-30.6 \quad 0.9$

$0.13 \quad 5.86-1.3$

51. TIK SKM $42.6128+i P \quad 04-09-56.01 .0$

$0.046 \quad 5.36$

52. TUP

$\begin{array}{llllllll}\text { SKM } & 43.76 & 53 & \text { iP } & 04-10-06.5 & 0.9 & 0.028\end{array}$

$0.0515 .46-2.8$

53. YAK

SKM $45.72 \quad 41+i P \quad 04-10-20.0 \quad 0.8$

$0.0925 .86-1.0$

54. KID

SK $52.72 \quad 55$ eP $04-11-14.0$

$-1.5$

55. VLA

SKM $56.24 \quad 61 \quad \underset{P M}{\text { iP }} 04-11-39.0$

0.5

0.04

56. III

SKM $59.26 \quad 19$ iP $04-12-01.00 .9-0.043$

0.031

57. YSS

SKM 59.91

52 ip $04-13-06.3 \quad 1.5$

$0.08 \quad 5.67$ 
85

AZ3 22 December 1971 (Westerm Kazakhstan)

USSR: $0=06-59-55.56$

$\theta=48^{\circ}, 09 \mathrm{~N}$

$\hat{\lambda}=48.18 \mathrm{E} \quad \mathrm{h}=0 \mathrm{~km}$

\begin{tabular}{|c|c|c|c|c|c|c|c|c|c|c|c|c|}
\hline NN & $\begin{array}{c}\text { Kod } \\
\text { station }\end{array}$ & $\begin{array}{c}\text { Chan- } \\
\text { nel }\end{array}$ & $\Delta^{\circ}$ & $\mathrm{Az}^{\circ}$ & Phase & $\begin{array}{c}\text { Arrival } \\
\text { time }\end{array}$ & \multicolumn{2}{|c|}{$\mathrm{Ts}$} & \multicolumn{3}{|c|}{ A miorometr } & \multicolumn{2}{c|}{$\begin{array}{c}\text { Mag } \\
\text { mb }\end{array}$} & Res \\
\hline 1 & 2 & 3 & 4 & 5 & 6 & 7 & 8 & 9 & 10 & 11 & 12 & 13 \\
\hline
\end{tabular}

1. MAK SH 5.10186 iPn $07-01-15.7$

IM $\begin{array}{llll}6 & 12 & 12 & 3.5 \quad \text { MLV }=4.2\end{array}$

2. PYA SKM 5.40223 iPn 07-01-18.0

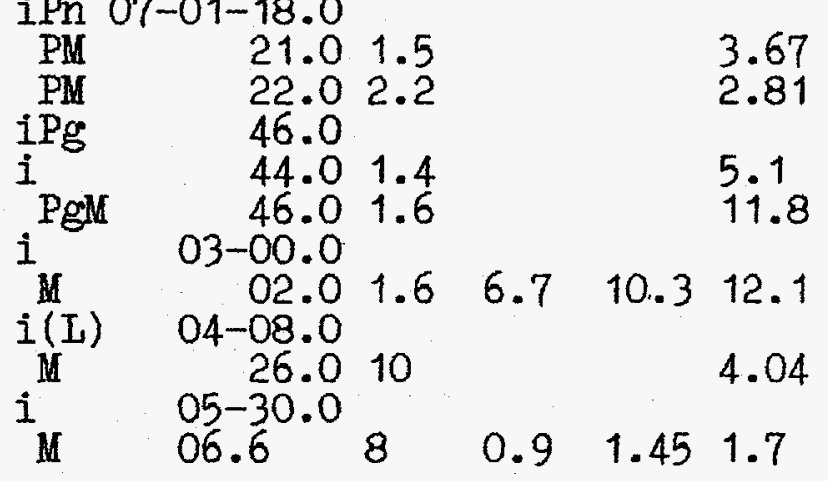

3. TI2 SK $6.82 \quad 202$ ePn 07-01-37.0

e $\quad 02-36.0$

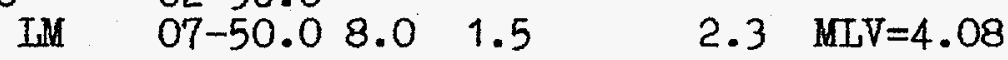

4. ZUG SH $7.12 \quad 221$-iPn 07-01-44.0

PM $0.5 \quad 3.0$

5. BKR SKM 7.17 209 +iPn $07-01-42.51 .4$

SKD Pn 0.8

$i \mathrm{Pg} \quad 02-19.51 .0$

$i(\mathrm{Sn}) \quad 03-19.6 \quad 1.0$

i $\quad 04-07.51 .2$

1.3

SK

$\begin{array}{lll}\text { I } & 05.3 & 14 \\ \text { IN } & 05.7 & 12\end{array}$

6. ABS SKM $7.39213+$ tPn 07-01-45.8 0.6

$\begin{array}{llll}\mathrm{ePg} & 02-17.8 & 1.0 & 0.9\end{array}$

1.0

0.04

1.2

0.88

2.35

1.5

1.36 
86

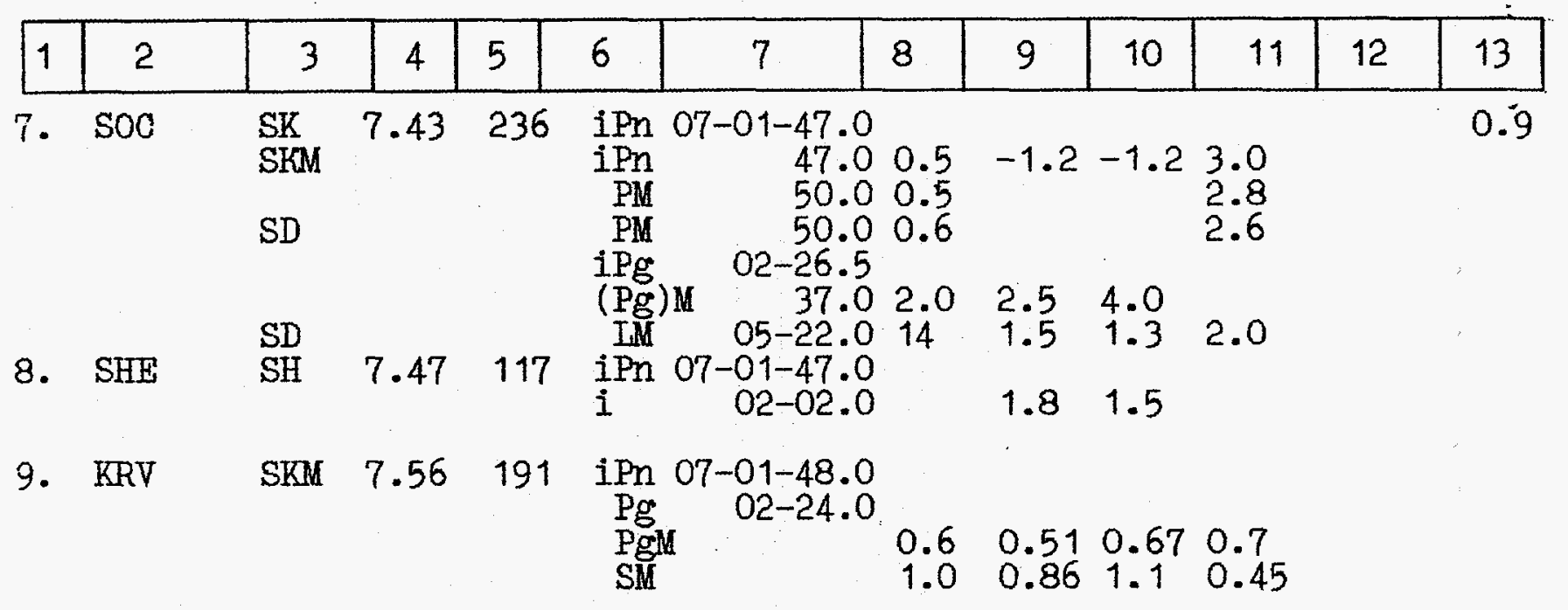

10. BAK SK $7.81 \quad 170$ iPn 07-01-52.0

$$
\begin{array}{lllll}
i & 02-36.0 & & & \\
i(I g) & 05-47.0 & & & \\
I M & 08-47.0 & 10 & 5.2 & 2.0
\end{array}
$$

11. ANN SKM $8.17 \quad 251$ iPn 07-01-39.0

$$
\begin{array}{lllllll}
\text { SD } & i(\mathrm{Sn}) & 02-30.5 & & & & \\
\mathrm{IM} & 05.5 & 8.0 & 2.0 & 2.3 & 2 & \mathrm{MLH}=4.14
\end{array}
$$

12. ERE SK $8.34 \quad 200$ ePn 07-01-58.0

$$
\begin{array}{lllll}
\text { ISn } & 04-24.0 & & & \\
\text { LM } & 09 & 7.0 & 1.25 & 1.13
\end{array}
$$

13. GRS SK 8.69190 -iPn 07-02-02.0

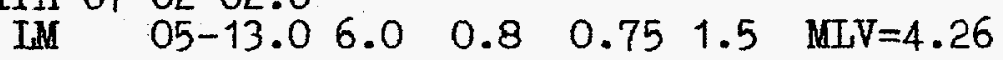

14. LNK SH $9.37177 \mathrm{e}(\mathrm{Pn})$ 07-02-13.5

$\begin{array}{rrrrrrrr}\text { 15. Michnevo SKM } & 9.44 & 321+\text { iPn } & 07-02-15.0 & 0.7 & 1.5 & 1.28 & 1.29 \\ \text { SK } & & \text { PM } & 16.0 & 0.4 & 2.1 & 2.06 & 2.36\end{array}$

16. MOS SH 10.05324 ePn 07-02-24.0

$\begin{array}{lrlr}\text { SH } & 10.05324 & \text { ePn } & 07-02-24.0 \\ \text { SK } & & \text { e } & 30.0 \\ \text { SD } & & \text { e } & 36.0 \\ \text { SDK } & & \text { e } & 46.0 \\ \text { SD } & & \text { e } & 52.0 \\ \text { SK } & & \text { ePg } & 03-18.0 \\ & & \text { eSn } & 04-40.0 \\ & & \text { e(Ig) } & 05-16.0 \\ & & \text { e } & 40.0\end{array}$

SKD

LM $07.3^{4} 14$ 
87

\begin{tabular}{|c|c|c|c|c|c|c|c|c|c|c|c|c|}
\hline 1 & 2 & 3 & 4 & 5 & 6 & 7 & 8 & 9 & 10 & 11 & 12 & 13 \\
\hline 17. & ALU & SH & 10.09 & 255 & $\begin{array}{l}-i P n \\
P \mathbb{P M} \\
e \\
e S n\end{array}$ & $\begin{array}{r}07-02-22.0 \\
24.0 \\
33.0 \\
04-06.0\end{array}$ & 0.7 & & & 1.4 & & \\
\hline 18. & OBN & $\begin{array}{l}\text { SKM } \\
\text { SK } \\
\text { PU } \\
\text { SKD }\end{array}$ & 10.09 & 319 & $\begin{array}{l}+i P n \\
i(S) \\
i(S S \\
I M\end{array}$ & $\begin{array}{r}07-02-23.6 \\
04-40.0 \\
55.0 \\
07-40.0\end{array}$ & $\begin{array}{l}1.0 \\
10 \\
10 \\
10\end{array}$ & $\begin{array}{l}4.2 \\
8.0 \\
3.4\end{array}$ & $\begin{array}{l}1.8 \\
\\
3.5 \\
3.6 \\
3.7\end{array}$ & $\begin{array}{l}3.6 \\
3.0 \\
3.5\end{array}$ & $\begin{array}{l}M L V=L \\
M L V= \\
M L V=\end{array}$ & $\begin{array}{l}0.9 \\
8 \\
1 \\
8\end{array}$ \\
\hline
\end{tabular}

19. SIM SH 10.19257 ePn 07-02-24.0

$$
\begin{array}{lrrrrr}
\text { e(S) } & 04-19.0 & & & & \\
\text { SM } & 20.0 & 0.9 & 0.73 & & \\
\text { SM } & & 1.0 & & 0.42 & \\
\text { iPn } & 07-02-24.8 & & & & \\
\text { Pn } & 25.8 & 0.6 & 0.8 & 0.6 & 1.5 \\
\text { Sn } & 04-13.6 & & & &
\end{array}
$$

20. YAI SH 10.36255 iPn 07-02-24.8

21. KAT SK 10.64144 eTh 07-02-30.0

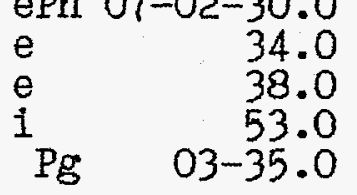

22. SVE SKM 11.5436 iPn $07-02-43.0$

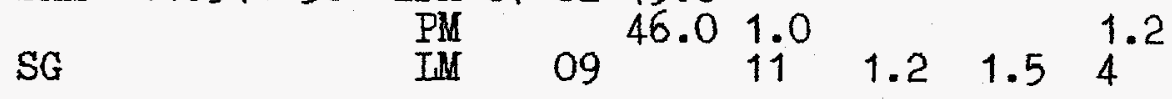

23. VAN SKM 12.45141 ePn 07-02-52.0

24. ASH SKM $12.56140 \mathrm{e}(\mathrm{Pn}) 07-02-55.0$

25. KIS SK 13.09272 ePn 07-03-03.0 1.5

$\mathrm{SD}$

$$
\begin{array}{lll}
i & \multicolumn{1}{c}{15.0} & \\
\text { iLg } & 08-18.0 & \\
\text { i } & 27.0 & \\
\text { IM } & 09.3^{13}
\end{array}
$$

$1.7 \mathrm{MLV}=4.25$

26. CRA SKD,SH 14.84279 iP 07-03-26.0

$$
\begin{aligned}
& \text { SH } \\
& \text { SKD, SH } \\
& \text { SKD } \\
& \text { SH } \\
& i_{\text {SP }} \quad 03-34.0 \\
& \begin{array}{lll}
1.0 & 2.0 & 2.0 \\
1.2 & 1.8 &
\end{array}
\end{aligned}
$$


88

\begin{tabular}{|l|l|l|l|l|l|l|l|l|l|l|l|l|}
\hline 1 & 2 & 3 & 4 & 5 & 6 & 7 & 8 & 9 & 10 & 11 & 12 & 13 \\
\hline
\end{tabular}

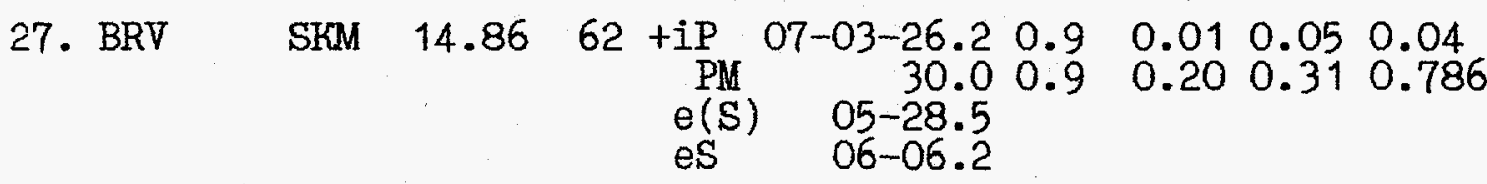

2.4

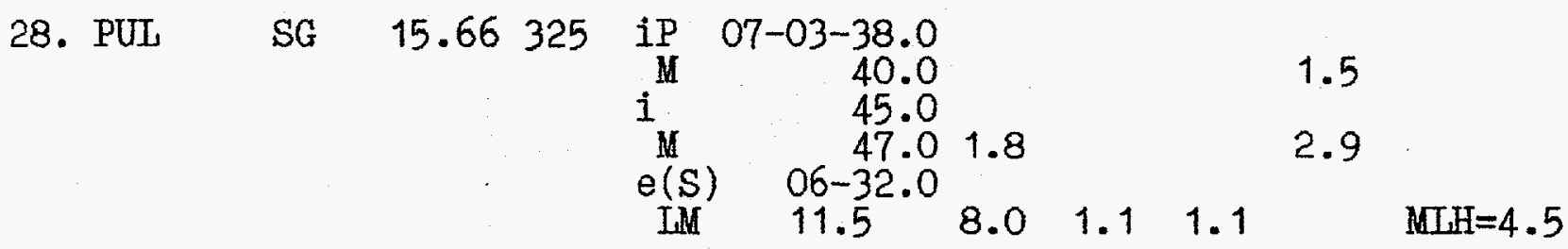

29. SAM SK 15.93115 e(P) $07-03-40.0$

30. LWV

SKD. 15.94285

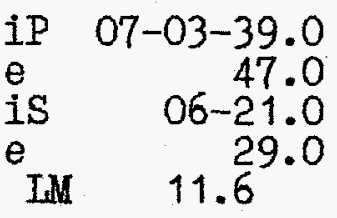

31. MEZ SKM 16.40281 eP $07-03-46.7$

$\begin{array}{lr}\mathrm{e} & 53.7 \\ i & 06-55.7\end{array}$

32. UZH SKM $17.19281 i(P) \quad 07-03-52.71 .0$

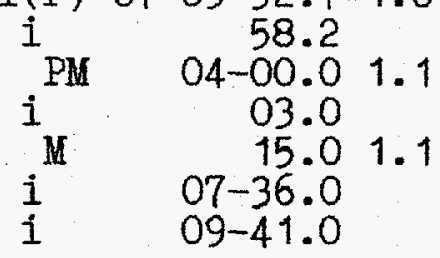

0.012

3.6

33. DSH SK 17.71115 +iP $\begin{array}{r}07-04-05.0 \\ 07-30.09 .0\end{array}$

34. GAR $\begin{array}{lrrrr}\text { SKM } & 18.39111+\text { iP } & 07-04-13.1 & 0.9 \\ \text { SK } & & \text { iF } & 04-13.1 & 1.8\end{array}$

SKM

SK

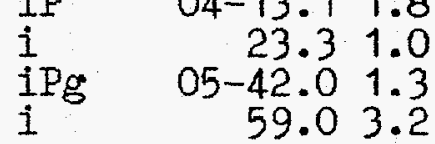

$1.5 \quad \mathrm{MLV}=4.6$

0.47

0.8

0.625

0.225

0.4 
89

\begin{tabular}{|l|l|l|l|l|l|l|l|l|l|l|l|l|}
\hline 1 & 2 & 3 & 4 & 5 & 6 & 7 & 8 & 9 & 10 & 11 & 12 & 13 \\
\hline
\end{tabular}

35. FRG SKM 18.54106 teP $07-04-14.3$

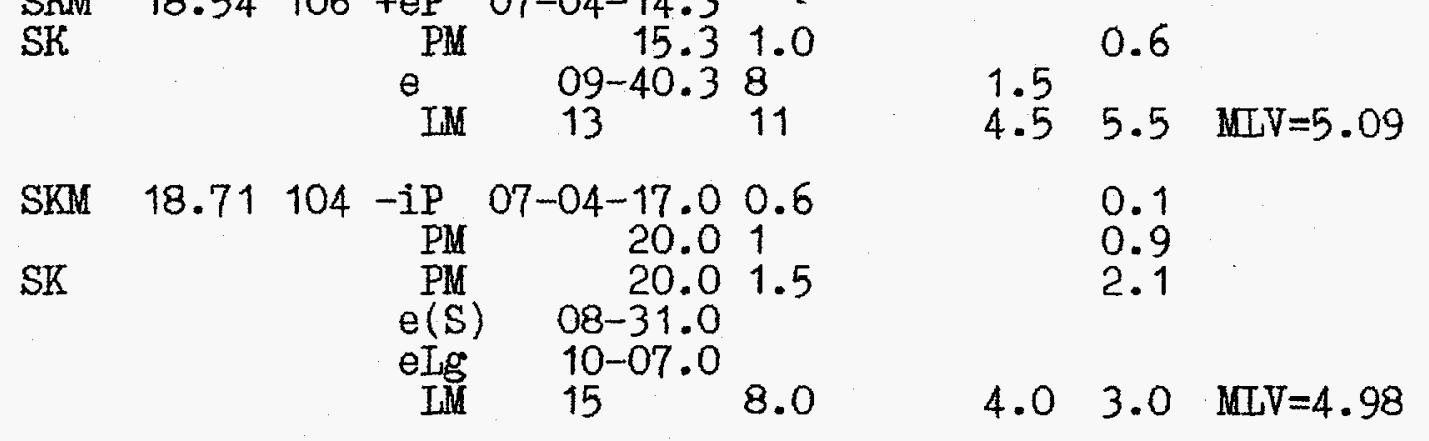

37. FRU SKM 19.23 96 iP $07-04-23.5$

$\begin{array}{llrlrl}\text { SKD } & \text { PM } & 29.0 & 0.8 & & \\ & \text { IM } & 14-20.0 & 10 & 1.5 & \\ \text { MLH }=4.58\end{array}$

38. KHO SK $20.08113 \quad P \quad 07-04-33.7$

$-0.6$

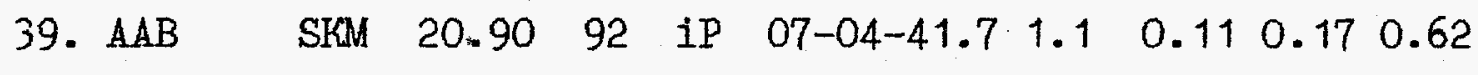

40. APA SKM 20.94344 iP $07-04-42.6$

$\begin{array}{llrrr}\text { SH } & \text { i } & 43.3 & \\ \text { SKM } & \text { PM } & 45.0 & 1.0 & 1.3 \\ \text { SH } & \text { iS } & 08-27.8 & \end{array}$

41. MUR SK $21.04 \begin{array}{lllllll}108 & \text { iP } & \begin{array}{r}07-04-45.1 \\ 08-41.1\end{array} & 0.6 & -0.5 & 0.8 & 0.8\end{array}$

42. PRZ SKM $21.90 \quad 94$ eP $07-04-54.0$

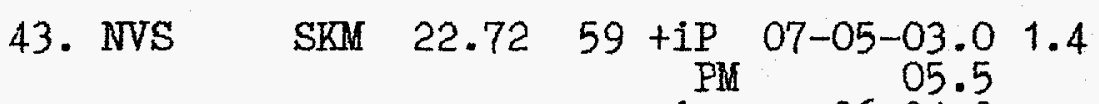

44. ELT SKM $24.77 \quad 63$ iP $07-05-19.11 .0$

45. UEI SKR $29.44 \quad 66$ iP $07-06-05.213$

0

36. ANR

$$
i^{\mathrm{PM}} \quad 06-01.0
$$


90

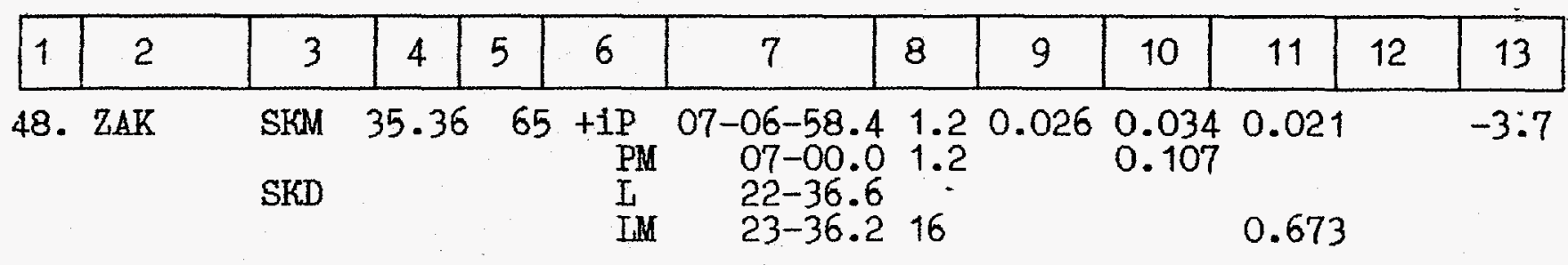

49. IRK SKM $35.42 \quad 62+\underset{P M}{\mathrm{eP}}$ 07-06-57.0 58.0

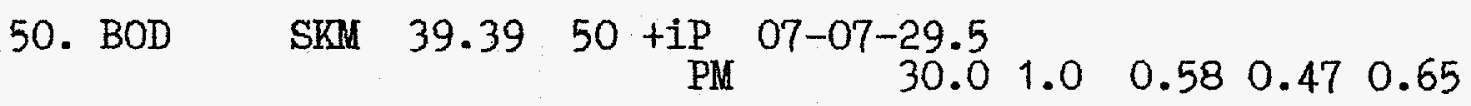

51. TIK SK, SKM 42.4328 iP 07-07-56.0

$$
\begin{array}{lll}
\text { SKM } & \text { PM } & 58.0 \\
\text { SK } & 1_{\text {IM }} & 09-39.0 \\
& \text { IM } & 31.8
\end{array}
$$

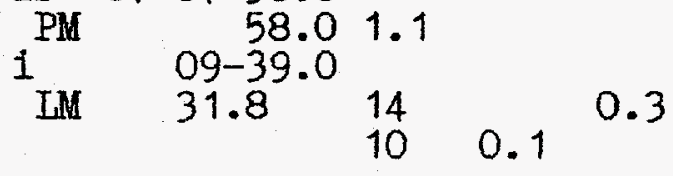

52. TUP SKM $43.53 \quad 54$ tiP $\quad 07-08-05.7 \quad 0.8 \quad 0.05 \quad 0.06 \quad 0.15$

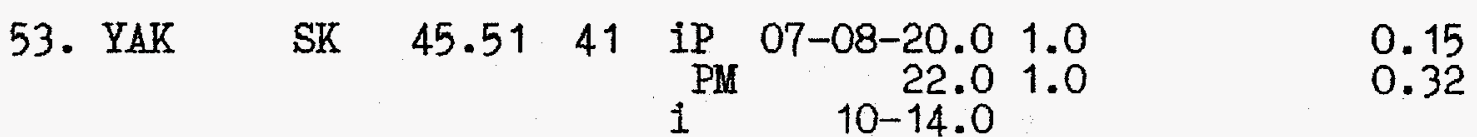

54. KED USP 52.4955 ix $07-10-12.0$

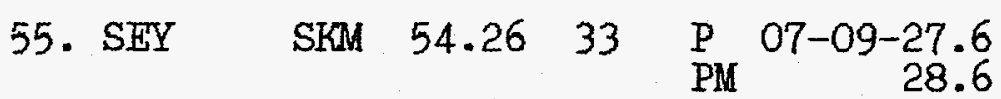

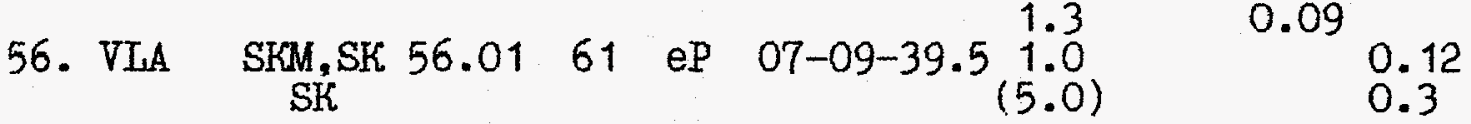

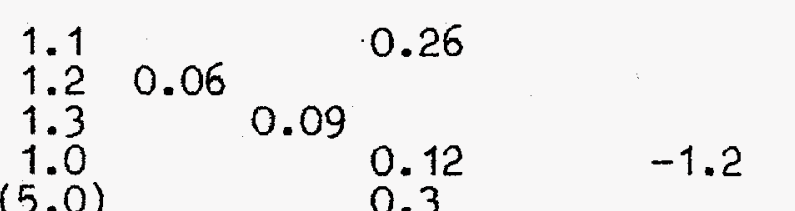

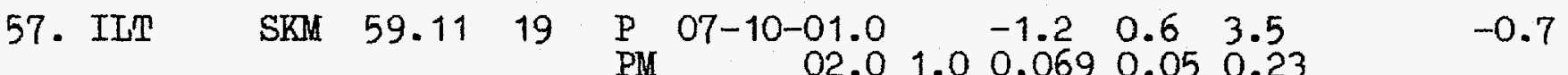

58. YSS SKM $59.68 \quad 52$ eP $\quad$ PM $\begin{array}{rr}-10-06.4 \\ 08.0\end{array}$

59. MIR SKM 119.32 161 ePKP 07-18-47.0

60. NVL SKM 121.41 193 IPKP 07-19-03.0 $1.0 \quad 0.02$ 
AZ4 29 July 1976 (Westerm Kazakhstan)

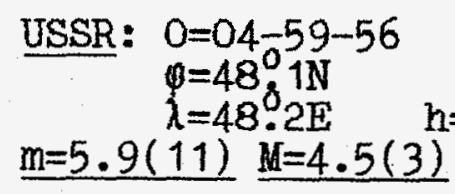

\begin{tabular}{|c|c|c|c|c|c|c|c|c|c|c|c|c|}
\hline NN & $\begin{array}{c}\text { Kod } \\
\text { station }\end{array}$ & $\begin{array}{c}\text { Chan- } \\
\text { nel }\end{array}$ & $\Delta^{\circ}$ & Az & Phase & $\begin{array}{c}\text { Arrival } \\
\text { time }\end{array}$ & Ts & \multicolumn{3}{|c|}{ A miorometr } & Mag \\
\cline { 5 - 9 } & & & & & Res & EW & 2 & & \\
\hline 1 & 2 & 3 & 4 & 5 & 6 & 7 & 8 & 9 & 10 & 11 & 12 & 13 \\
\hline
\end{tabular}

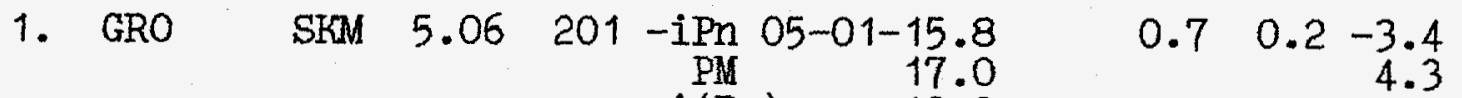

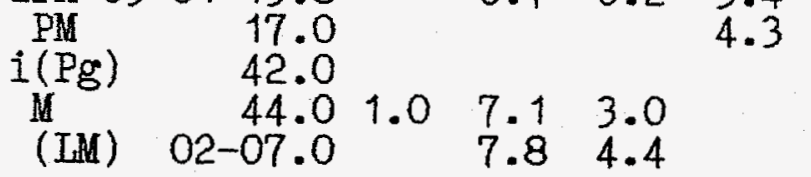

ML.H $=4.4$

$\sin$

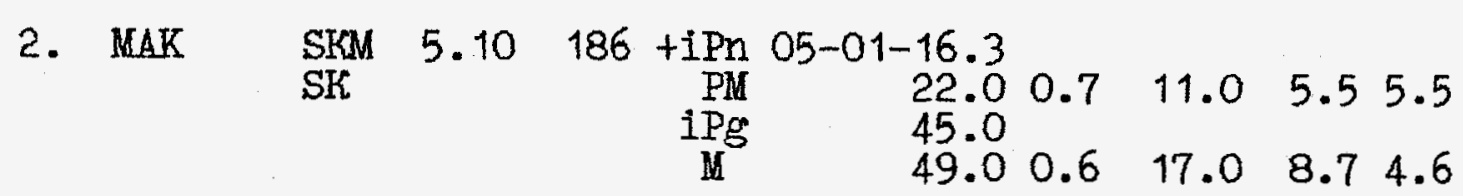

3. PYA SK 5.42223 ePn 05-01-19.0

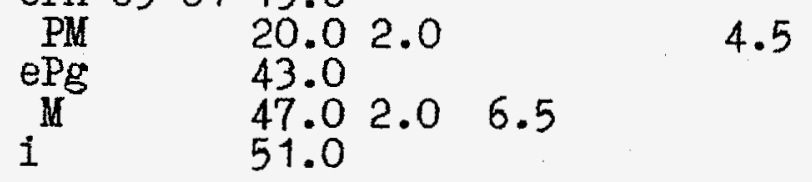

4. TI2 SKM $6.84202 \quad$ Pn $05-01-39.0$

5. SHKS SKM $6.94186+$ iPn 05-01-40.5

6. BKR SKM 7.18 209 iPn 05-01-43.6

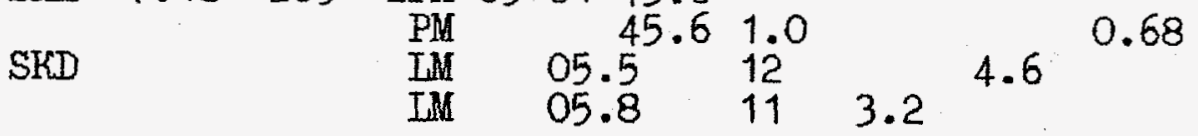

7. SOC SKM 7.45236 iPn 05-01-49.0

SKD $\quad$ iFg $02-25.0$

$$
2.5^{1.6}
$$

8. KRV

$$
\text { SKM 7.57. } \begin{array}{rrr} 
& -i P n & 05-01-47.0 \\
& i \text { PM } & 02-14.0 \\
& i(S) & 54.0
\end{array}
$$

0.50 
92

\begin{tabular}{l|r|r|r|r|l|r|}
\hline 1 & 2 & 3 & 4 & 5 & 6 & 7 \\
\hline 9. & STE & SKM & 7.60 & 202 & iP & $05-01-48.2$ \\
10. BAK & SK & 7.81 & 170 & iPn & $05-01-54.0$ \\
& & & & & i & $02-00.0$ \\
& & & & & i & 12.0
\end{tabular}

11. IEN SKD 7.96 205 ePn 05-01-57.0

12. ANN

SKD

$8.18 \quad 251$

$\begin{array}{ccccc}\text { iP } & 05-01-58.0 & 0.5 & 1.0 & 1.0 \\ \mathrm{e} & 02-11.0 & & & \\ \text { IM } & 07.8 & 9.0 & 1.5 & 1.3\end{array}$

$2.0 \mathrm{NLV}=4.0$

13. $\operatorname{ERE}$

SK

$\begin{array}{rrr}8.35200 & \text { iPn } & 05-01-59.0 \\ & \text { iPg } & 02-40.0 \\ & i & 05-01.0\end{array}$

14. GRS

VEG

$$
\begin{aligned}
& \text { 8.70 } 190+\text { iPn 05-02-04.0 } \\
& \text { i } \\
& 17.6 \\
& \text { i } \quad 26.2 \\
& \text { e } 33.2 \\
& \begin{array}{llll}
\mathrm{e}(\mathrm{Pg}) & 46.2 & 1.2 & 1.05
\end{array}
\end{aligned}
$$

15. Michnevo SKM $9.44 \quad 320$-eP $05-02-16.0$

16. OBN

$$
\text { SKM } 10.09319
$$

$$
\begin{array}{lrr}
\text { ePn } & 05-02-28.0 \\
\text { PM } & 32.0 & 1.0 \\
\text { eS } & 04-24.0 \\
\text { M } & 07-50.0
\end{array}
$$

17. ALU

SH

SK

$$
\begin{array}{llll}
10.10255 \text { iP } & 05-02-23.6 & 0.6 \\
& \text { PM } & 24.6 & 0.6 \\
& \text { IM } & 08.4 & 16.0
\end{array}
$$

18. SIM

SK
SH
SK
SH
SK
SH
SK
SKD
SK

10.20

$$
257-
$$

$$
e^{\text {PM }}
$$

$\begin{array}{lll}\mathrm{eI} & 06.3 & \\ \mathrm{IIM} & 08-09.014 \\ \mathrm{IIM} & 34.0 & 10\end{array}$

$$
\begin{array}{rr}
27.0 & 0.4 \\
43.0 & \\
-20.0 & \\
21.0 & 1.0 \\
23.0 & 1.0 \\
43.0 &
\end{array}
$$$$
0.5
$$$$
\text { 04-20.0 }
$$$$
1.0 \quad 0.6
$$$$
\begin{array}{ll}
0.4 & 0.6
\end{array}
$$

19. ARU SKM
10.46 
93

\begin{tabular}{|c|c|c|c|c|c|c|c|c|c|c|c|c|}
\hline 1 & 2 & 3 & 4 & 5 & 6 & 7 & 8 & 9 & 10 & 11 & 12 & 13 \\
\hline & & & & & M & $\begin{array}{l}-04- \\
08-\end{array}$ & 12 & 1.0 & 1.5 & 2.0 & $\mathrm{VLH}=$ & \\
\hline
\end{tabular}

20. KAT SK 10.64144 ePn 05-02-32.0

21. ASH SKM 12.56140 ePn 05-02-55.2

$\begin{array}{llrrrr} & i & 57.2 & & & \\ \text { SK } & e(S) & 05-05.0 & 1.0 & 1.0 & \\ & \text { LM } & 13-39.1 & 9.0 & & 1.2\end{array}$

22. KIS SK $13.10272-$ iPn 05-03-04.0

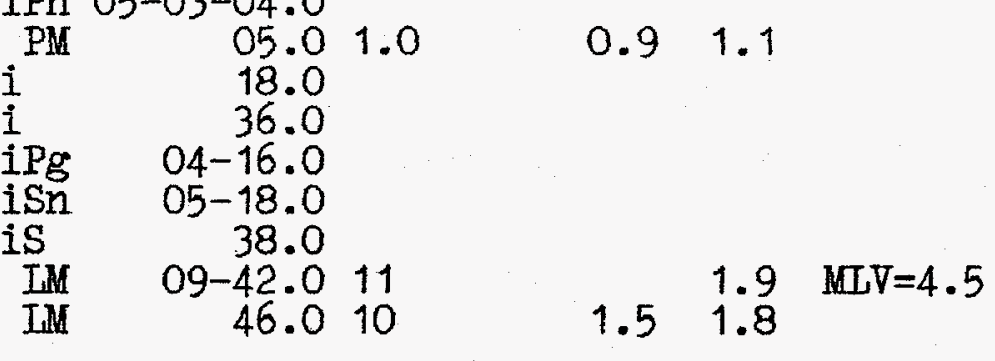

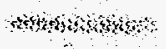

23. MIK

$S D$

$\mathrm{SK}$

$\begin{array}{lllr}\text { SK } & 14.20302 \text { eP } & 05-03-18.0 \\ \text { SD } & & \text { eL } & 09.4 \\ & & & 10-59.0\end{array}$

IM $10-59.012$

2.0

24. PUI

$\begin{array}{lrrr}\text { VEG } & 15.66 & 325+i P & 05-03-38.5 \\ \text { SG } & \text { PM } & 48.0 & 1.3 \\ \text { SD } & \text { e(S) } & 06-27.0 & \\ \text { SG } & \text { LM } & 11-16.0 & 9.0 \\ \text { IM } & 18.0 & 10\end{array}$

25. SAM SK 15.92115 iP $05-03-40.5$

26. IVV SKD 15.95285 -iP $05-03-40.0$

\begin{tabular}{ll} 
& 49.0 \\
$e$ & $04-18.0$ \\
$e$ & $05-50.0$ \\
$\mathrm{e}$ & $07-06.0$ \\
$\mathrm{M}$ & $11-47.0$ \\
\hline
\end{tabular}

0.9

0.8

$0.5 \quad 1.5 \quad \begin{array}{ll}\mathrm{MLH}=4.3 \\ \mathrm{MLH}=4.2\end{array}$

27. TAS SKM 16.43107 -iP $05-03-48.0$

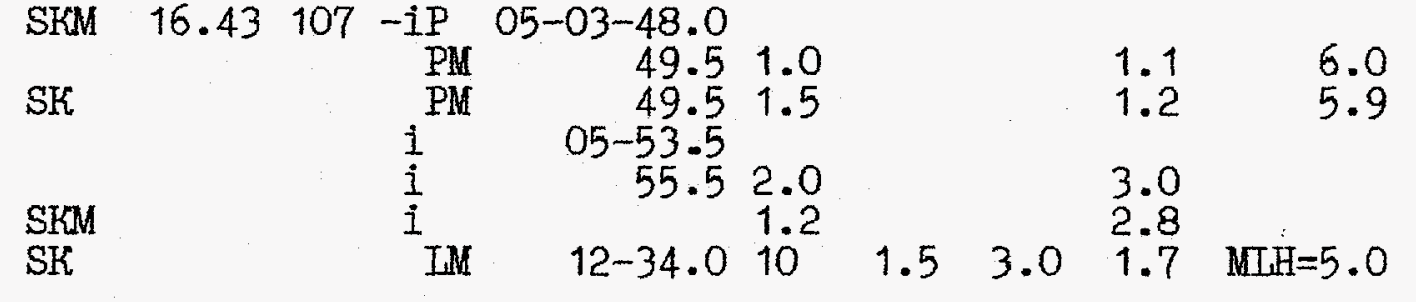


94

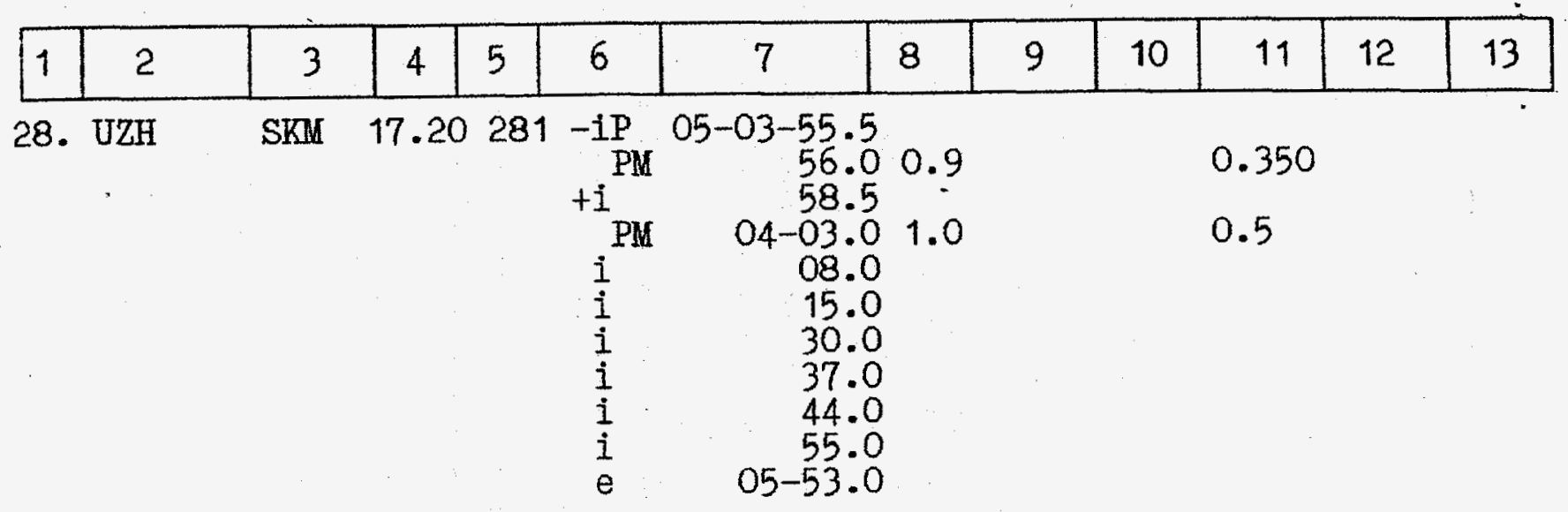

29. DSH SH $17.70115+$ iP $05-04-06.0$

30. NAM SK 18.14104 -iP $05-04-21.0$

31. ANR SKM 18.70104 eP $05-04-18.0$

$\begin{array}{llrrrrrr}\text { SKM } & 18.70 & 104 & \text { eP } & \text { O5-04-18.0 } & & & \\ \text { SK } & & \text { PM } & 22.0 & 1.4 & & & 1.6 \\ \text { SKM } & & \text { PM } & 23.2 & 1.3 & & & 1.43 \\ \text { SK } & & i & 05-32.0 & 1.2 & & 1.0 & \\ & & \text { e } & 09-07.0 & 4.0 & 1.0 & & \\ & & \text { IM } & 14-06.0 & 10 & 2.0 & 2.2 & \\ & & \text { IM } & 16-30.0 & 9.0 & 2.2 & 3.5 & 2.2\end{array}$

32. KUL SK 18.71115 +iP 05-04-18.4
$\begin{array}{lrr}P M & 21.4 & 1.0 \\ \text { (S) } & 10-45.4\end{array}$
1.3

(6.8)

33. FRU

SKM

$\begin{array}{lr}\text { ep } & 05-04-24.0 \\ i & 28.0\end{array}$

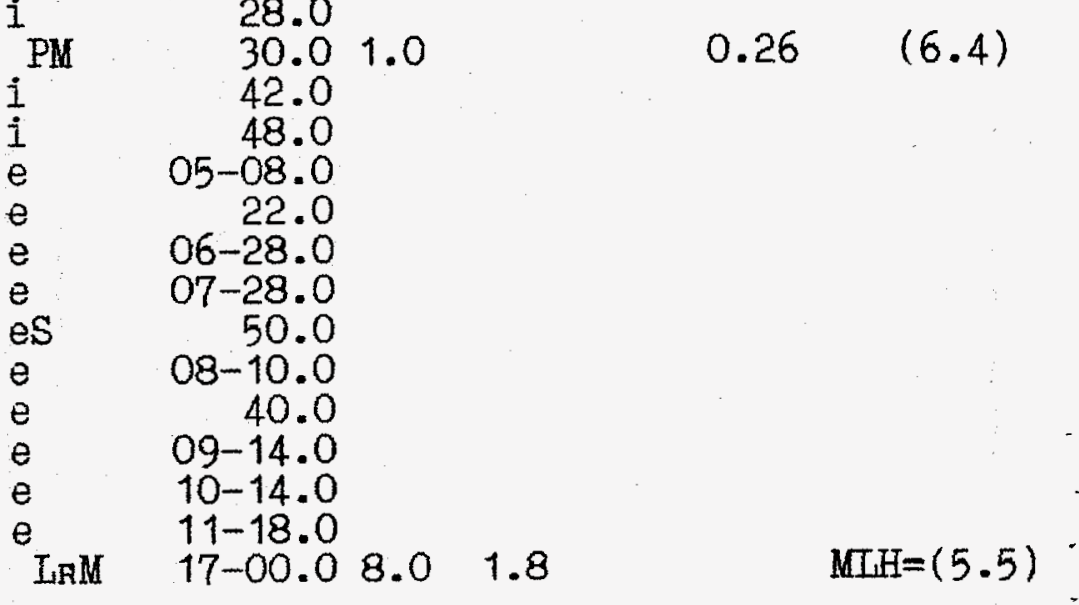

34. KHO SK 20.07113 P $05-04-35.0$ 
95

\begin{tabular}{|l|l|l|l|l|l|l|l|l|l|l|l|l|}
\hline 1 & 2 & 3 & 4 & 5 & 6 & 7 & 8 & 9 & 10 & 11 & 12 & 13 \\
\hline
\end{tabular}

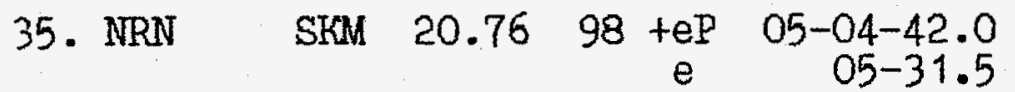

36. $\mathrm{AAB}$ SKM

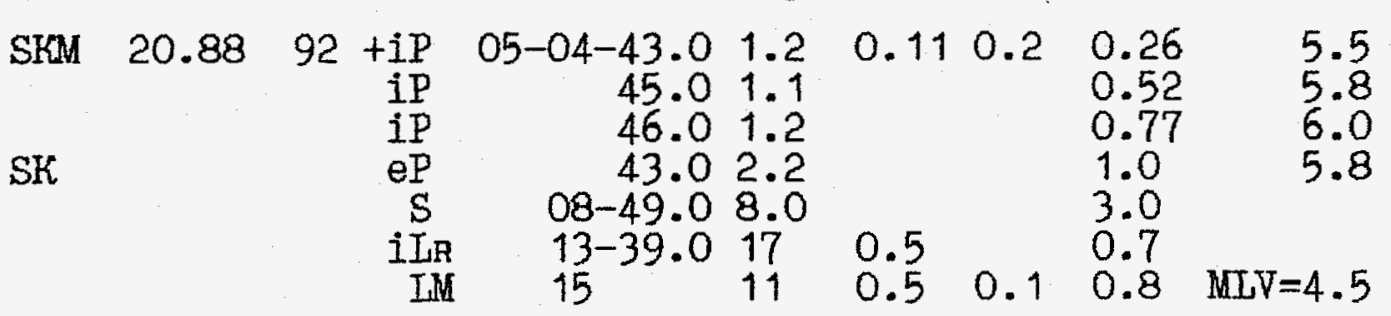

37. APA

$$
\begin{aligned}
& \begin{array}{lrlr}
\text { SKM } & 20.93343 & \text { iP } & 05-03-44.0 \\
\text { SKD } & & \text { e(S) } & 07-33.0 \\
& & \text { IM } & 13.2
\end{array} \\
& \begin{array}{lllll}
12.0 & 1.4 & 1.0 & 1.8 & \operatorname{MLV}=4.5 \\
& & & \operatorname{MLH}(4.7)
\end{array}
\end{aligned}
$$

38. PRZ SKM $21.89 \quad 93+i \mathrm{P} \quad 05-04-55.0$

$$
\text { PM } \quad 59.01 .0 \quad 0.20 \quad 5.5
$$

39. NVS SKM $22.70 \quad 59+$ iP $05-05-03.5$

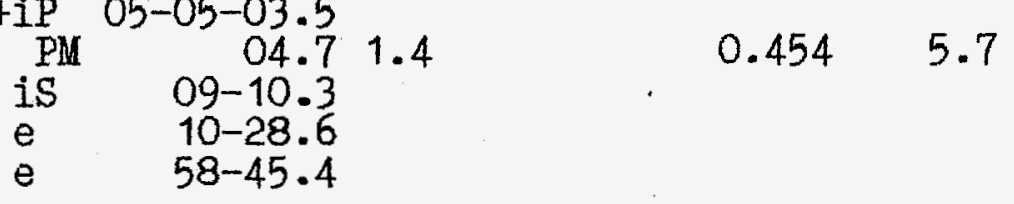

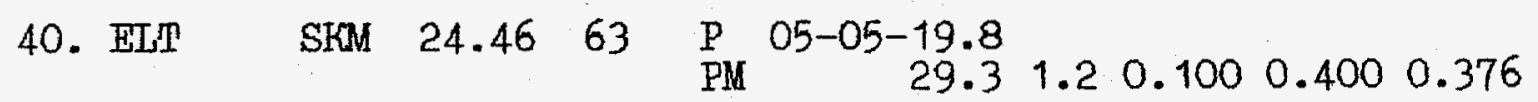

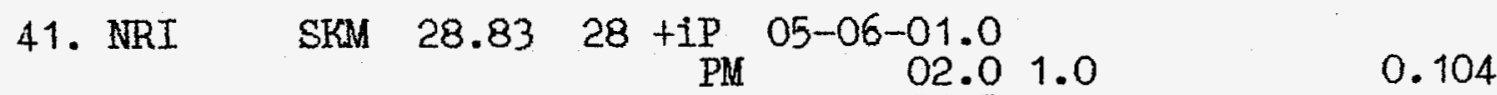

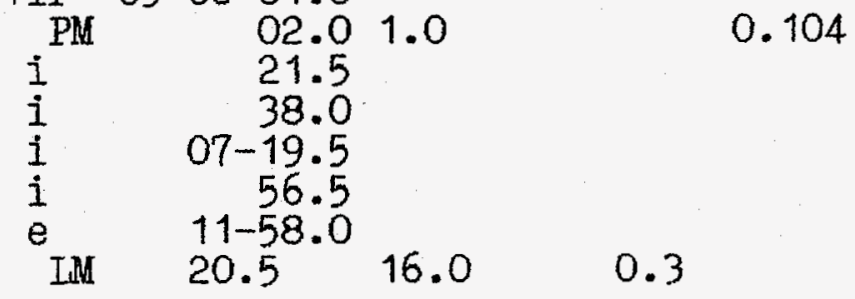

42. UEI SKM $29.42 \quad \begin{array}{rrrrrrrr}6-i P & \text { iS } & \begin{array}{r}05-06-05.5 \\ 13-10.5\end{array} & 1.0 & 0.04 & -0.03 & -0.09 & 5.8\end{array}$

43. MOY SEM $33.58 \quad 64+$ PM $05-09-36.0 \quad 1.0 \quad 0.07 \quad 5.7$

SKD

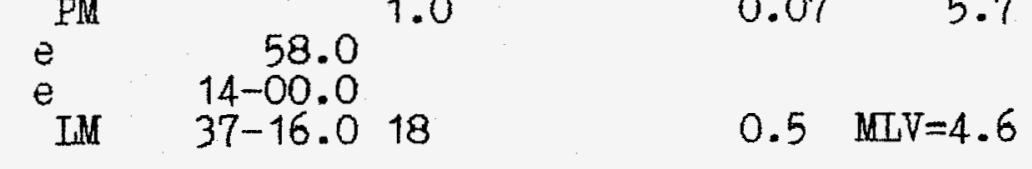


96

\begin{tabular}{|c|c|c|c|c|c|c|c|c|c|c|c|c|}
\hline 1 & 2 & 3 & 4 & 5 & 6 & 7 & 8 & 9 & 10 & 11 & 12 & 13 \\
\hline & & $\begin{array}{l}\text { SKM } \\
\text { SKD }\end{array}$ & 35.3 & & $\begin{array}{r}+1 \\
e \\
e\end{array}$ & $\begin{array}{r}05-07 \\
08 \\
10 \\
11\end{array}$ & $\begin{array}{l}0.8 \\
1.0 \\
8.0\end{array}$ & 0.49 & 0.62 & 0.07 & & \\
\hline
\end{tabular}

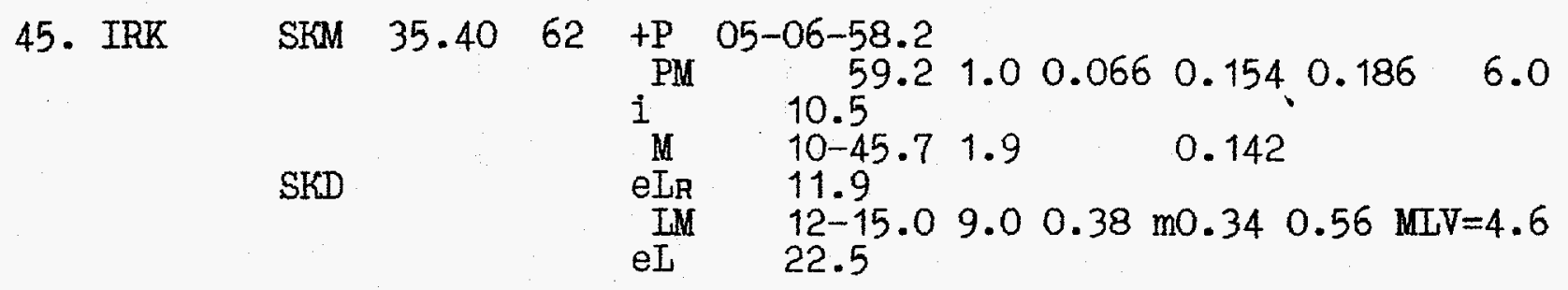

$\begin{array}{ll}\text { 46. TIK } & \text { SKM } \\ & \text { SK } \\ \text { SKM }\end{array}$

SK

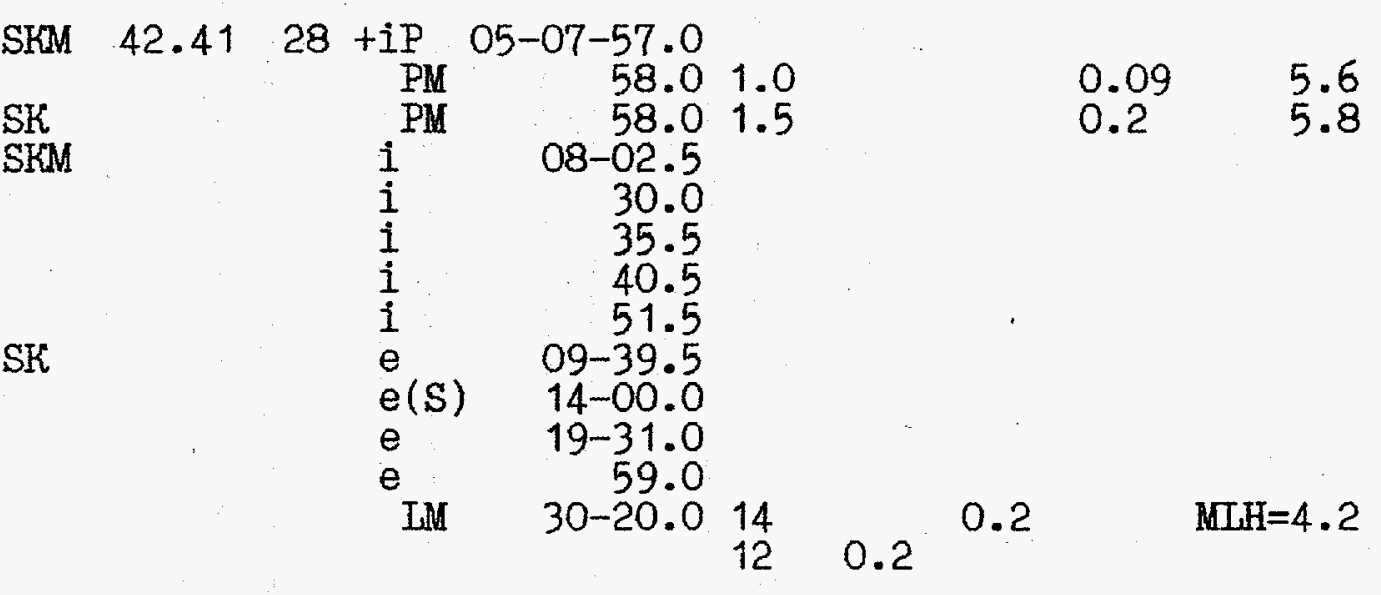

47. TUP SKM $43.51 \quad 54$-iP $05-08-05.92 .0 \quad 0.0720 .113 \quad 0.220$

48. YAK SKM $45.49 \quad 41$ eP $05-08-13.6$

49. SEY SKM $54.2433+i P \quad 05-09-28.5$
PM $\quad 29.8$
1.0
0.17
6.1

50. IIT

SKM 59.09 $19+\underset{P M}{+i P}$
$i$
$i$
$i$
$i$
$i$
$e$
$e$
$i$

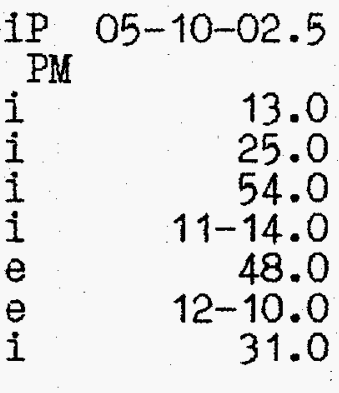

$\begin{array}{lllll}1.0 & 0.054 & 0.046 & 0.17 \quad 6.1\end{array}$ 
97

\begin{tabular}{|c|c|c|c|c|c|c|c|c|c|c|c|c|}
\hline 1 & 2 & 3 & 4 & 5 & 6 & 7 & 8 & 9 & 10 & 11 & 12 & 13 \\
\hline & & $\mathrm{KD}$ & & & $\begin{array}{l}\text { eS } \\
e \\
e\end{array}$ & $\begin{array}{l}21- \\
26-\end{array}$ & & & & & & \\
\hline
\end{tabular}

51. YSS

$$
\begin{aligned}
& \text { SKM } 59.66 \quad 52+i P \text { 05-10-07.3 }
\end{aligned}
$$

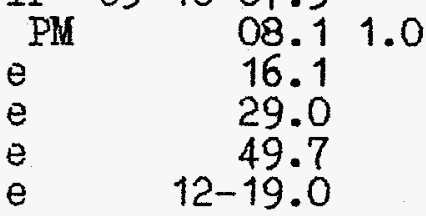$$
0.19 \cdot 6.2
$$

52. NVL SKM 121.42 193 ePKiKP 05-18-51.5 
98

AZ5 30 September 1977 (Westerm Kazakhstan)

USSR: $0=06-59-55.5$

$\varphi=47^{\circ}, 97 \mathrm{~N}$

$\lambda=48.28 \mathrm{E} \quad \mathrm{h}=0 \mathrm{~km}$

$m=5.0(9)$

\begin{tabular}{|c|c|c|c|c|c|c|c|c|c|c|c|c|}
\hline \multirow[t]{2}{*}{$\mathrm{NN}$} & \multirow{2}{*}{$\begin{array}{c}\text { Kod } \\
\text { station }\end{array}$} & \multirow{2}{*}{$\begin{array}{l}\text { Chan- } \\
\text { nel }\end{array}$} & \multirow{2}{*}{$\Delta^{0}$} & \multirow{2}{*}{$A z^{\circ}$} & \multirow[t]{2}{*}{ Phase } & \multirow{2}{*}{$\begin{array}{l}\text { Arrival } \\
\text { time }\end{array}$} & \multirow[t]{2}{*}{$\mathrm{Ts}$} & \multicolumn{3}{|c|}{ A micrometr } & \multirow{2}{*}{$\begin{array}{r}\mathrm{Mag} \\
\mathrm{mb}\end{array}$} & \multirow[t]{2}{*}{ Res } \\
\hline & & & & & & & & NS & $E W$ & Z & & \\
\hline 1 & 2 & 3 & 4 & 5 & 6 & 7 & 8 & 9 & 10 & 11 & 12 & 13 \\
\hline 1. & MAK & SKM & 4.94 & 188 & $\begin{array}{r}{ }^{8}+\operatorname{iPn}_{\mathrm{eSn}} \\
\mathrm{IM}\end{array}$ & $\begin{array}{r}07-01-15 \\
02-24 \\
04-10\end{array}$ & 14.0 & 1.0 & 0.9 & 0.6 & $\begin{array}{l}\mathrm{MV}= \\
\mathrm{ILH}=\end{array}$ & $\begin{array}{l}0.8 \\
1) \\
5)\end{array}$ \\
\hline
\end{tabular}

2. PYA SKM $5.34 \quad 225$ ePn $07-01-18.8$

3. BEI VEG $5.46 \quad 226+$ iPn $07-01-18.9 \quad 0.2 \quad 0.02 \quad 0.04 \quad 0.10$

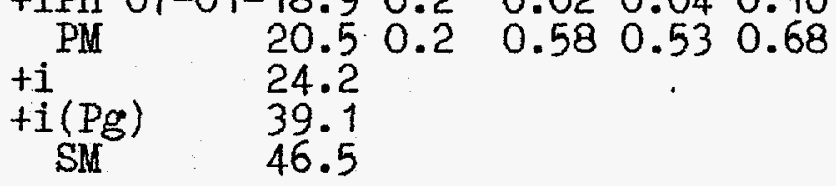

4. TI2 SK 6.70203 ePn 07-01-37.0

e $02-09.0$

e(S) $\quad 03-15.0$

e( (Lg) $\quad 59.0$

5. ZUG SK $7.05 \quad 222$ ePn 07-01-32.0

6. ABS SKM 7.29214 eP $07-01-45.6$

7. SOC SKM 7.41237 iPn 07-01-46.1

$\begin{array}{lr}i & 58.9 \\ i & 04-21.8 \\ \text { eLg } & 59.0\end{array}$

8. STE SKM $7.47 \quad 204$ iP $07-01-47.0$

$\begin{array}{rr}i & 02-18.4 \\ i & 30.6 \\ i & 44.0\end{array}$

9. LEN SKD $7.83 \quad 206$ e $07-02-23.0$ 


\begin{tabular}{|c|c|c|c|c|c|c|c|c|c|c|c|c|}
\hline 1 & 2 & 3 & 4 & 5 & 6 & 7 & 8 & 9 & 10 & 11 & 12 & 13 \\
\hline 10. & & $\begin{array}{l}\text { VEG } \\
\text { SK }\end{array}$ & 8.54 & 190 & $\begin{array}{l}-i p n \\
i \\
e \\
e s\end{array}$ & $\begin{array}{r}07-02-02.0 \\
15.0 \\
04-06.0 \\
40.0\end{array}$ & 0.8 & & & -0.2 & & -1.9 \\
\hline
\end{tabular}

11. Michnevo SKM $9.63 \quad 321$-iPn 07-02-15.2 0.4

0.315

12. ALU

SH

$$
\begin{array}{ccc}
10.14257-e P n & 07-02-22.0 \\
e^{P M} & 26.0 & 0.5 \\
e & 38.0 \\
e & 55.0 \\
e(S) & 04-09.0
\end{array}
$$

13. MOS

$\begin{array}{ll}\text { SH } & 10.21324 \\ \text { SK } & \\ \text { SD } & \\ \text { SD } & \\ \text { SK } & \end{array}$

SKD

$$
\begin{aligned}
& \text { e } \quad 07-02-12.0 \\
& 30.0 \\
& \begin{array}{ll}
\text { e } & 36.0 \\
\text { e } & 46.0
\end{array} \\
& \text { e } 52.0 \\
& \text { ePg 03-18.0 } \\
& \text { esn 04-40.0 } \\
& \text { e(Ig) 05-16.0 } \\
& \text { IM } 07.314
\end{aligned}
$$$$
-14.1 *
$$

14. OBN SKM $10.28319+$ IPn 07-02-26.1

$$
\begin{array}{llrl}
\text { SK } & \text { PM } & 30.0 & 0.8 \\
& \text { ePg } & 03-05.0 \\
& \text { eSn } & 04-20.0 \\
\text { SKD } & \text { e } & 05-12.0 \\
& \text { eL } & 08-02-30.0 & 24.0
\end{array}
$$

15. ARU SKM $10.57 \quad 32$ ePn 07-02-28.7

$$
\begin{array}{lr}
\text { e } & 31.5 \\
\text { eSn } & 04-27.7 \\
\mathrm{e} & 07.6
\end{array}
$$

SKD

16. SVE SKM $11.6536+$ iPn $07-02-43.0$

$$
\begin{aligned}
& \begin{array}{lr}
\text { PM } & 45.3 \\
\text { e } & 58.0 \\
\mathrm{e} & 03-05.0 \\
\mathrm{e} & 20.0 \\
\text { eSn } & 04-52.0
\end{array} \\
& 0.12 \quad 5.5^{-2.8}
\end{aligned}
$$

17. ASH SK 12.37140 Pn 07-02-47.3

$$
\begin{array}{lllll}
\text { SKM } & -i & 03-06.6 & 0.6 & \\
\text { SK } & +i S n & 05-14.3 & 1.3 & 0.19
\end{array}
$$

$2.3 \quad N L V=4.15$

0.15 
100

\begin{tabular}{|c|c|c|c|c|c|c|c|c|c|c|c|c|}
\hline 1 & 2 & 3 & 4 & 5 & 6 & 7 & 8 & 9 & 10 & 11 & 12 & 13 \\
\hline 18. & BRV & SKM & 14.87 & 62 & $-i P$ & $07-03-26.4$ & 0.7 & & & 0.15 & & $-2: 3$ \\
\hline \multirow[t]{2}{*}{19.} & \multirow[t]{2}{*}{ SAM } & \multirow[t]{2}{*}{ SK } & \multirow[t]{2}{*}{15.78} & \multirow[t]{2}{*}{115} & \multirow{2}{*}{$\begin{array}{l}e P \\
e \\
-i \\
e(S) \\
\text { LM }\end{array}$} & \multirow{2}{*}{$\begin{array}{r}07-03-36.0 \\
40.6 \\
46.8 \\
06-49.0 \\
12.59\end{array}$} & 0.6 & & & 0.4 & & \multirow[t]{2}{*}{-5.2} \\
\hline & & & & & & & $\begin{array}{l}6.0 \\
8.0\end{array}$ & & 0.4 & 0.4 & $\mathrm{MLH}=4$ & \\
\hline
\end{tabular}

20. TAS SKM 16.31106 eP 07-03-44.0

SK

$$
\begin{array}{lrllll}
\text { PM } & 53.5 & 1.2 & 1.0 & 0.2 & 0.3 \\
e & 09-13.5 & & & & \\
e & 10-09.5 & & & & \\
e & 12-00.0 & & & & \\
\text { eI } & 08-17-50.0 & & & &
\end{array}
$$

$5.9^{-3.9 *}$

21. UZH SKM $17.31282+\underset{P M}{+P} \begin{array}{r}07-03-58.5 \\ 04-03.5\end{array}$

$$
\begin{array}{lrr}
i & 08.0 & \\
i & 13.0 & \\
i & 06-40.0 \\
\text { iSn } & 07-10.0 & \\
e & 08-10.0 & \\
e & 12-25.0 & \\
\text { e } & 20-20.0 & \\
\text { LM } & &
\end{array}
$$$$
0.8
$$$$
0.015
$$$$
8^{-1.2}
$$

22. DSH SH $17.56 \quad 115$ eP $07-04-04.0$

23. GAR SKM 18.25111 iP 07-04-12.2

$$
\text { PM } 12.2 \quad 1.2
$$

0.08

5.3

24. FRG SKM 18.41106 eP $07-04-13.7$

$\begin{array}{lllll}\text { 25. KUL SK } 18.57115 & \mathrm{eP} 07-04-16.0 \\ \mathrm{e}(\mathrm{Lg}) & 10-47.0\end{array}$

26. ANR

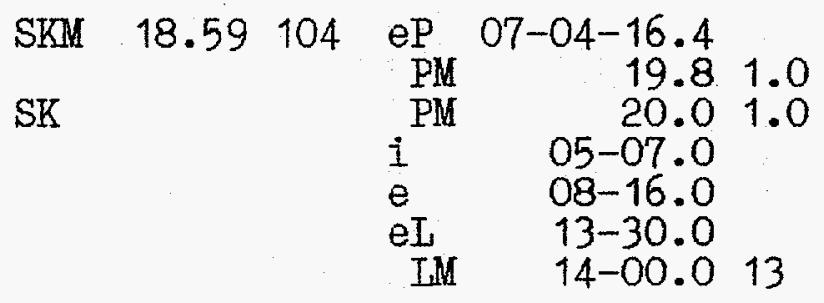

0.15

$5.6^{-0.5}$ 
101

\begin{tabular}{|c|c|c|c|c|c|c|c|c|c|c|c|c|}
\hline 1 & 2 & 3 & 4 & 5 & 6 & 7 & 8 & 9 & 10 & 11 & 12 & 13 \\
\hline 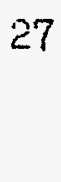 & RRU & SKM & 19.1 & 9 & & $07-04$ & 0.8 & 0.04 & & & & \\
\hline
\end{tabular}

28. KHO SK 19.93113 eP $07-04-33.0$

29. $\mathrm{AAB}$ SKM $20.8092+\underset{\mathrm{PM}}{\mathrm{iP}}$ 07-04-41.0

$$
\begin{array}{llllllll}
\mathrm{iP} & 07-04-41.0 & & & & & & -0.2 \\
\text { PM } & & 1.2 & 0.009 & 0.009 & 0.033 & & \\
\text { PM1 } & 42.0 & 1.5 & 0.031 & 0.023 & 0.076 & 4.9 & \\
\text { PM2 } & 42.0 & 1.5 & 0.053 & 0.039 & 0.083 & 5.0
\end{array}
$$

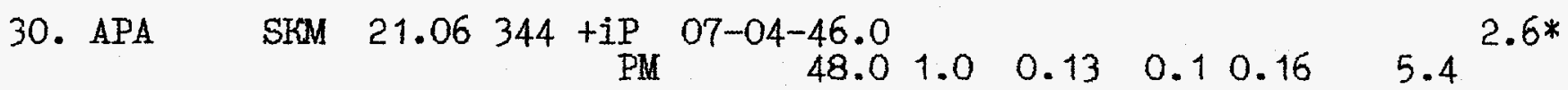

31. NVS SKM $22.73 \quad 59+\underset{P M}{i P} \begin{array}{llllllll}07-05-01.3 & 03.3 & 1.4 & 0.02 & 0.026 & 0.056\end{array}$

सकाष

$\mathrm{SD}$

$$
\begin{aligned}
& \text { es } \quad 08-52.3 \\
& \text { i 09-08.0 } \\
& \text { IM } \quad 16-35.012 .0 \quad 0.6
\end{aligned}
$$

32. ELT SKM $24.4763+i P$ 07-05-18.6

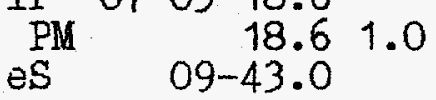

$$
\begin{aligned}
& 0.100 \quad 5.3^{1.5}
\end{aligned}
$$

33. NRI

$0.017 \quad 4.7^{1.3}$

SKM $28.96 \quad 28$ eP $07-05-59.5$

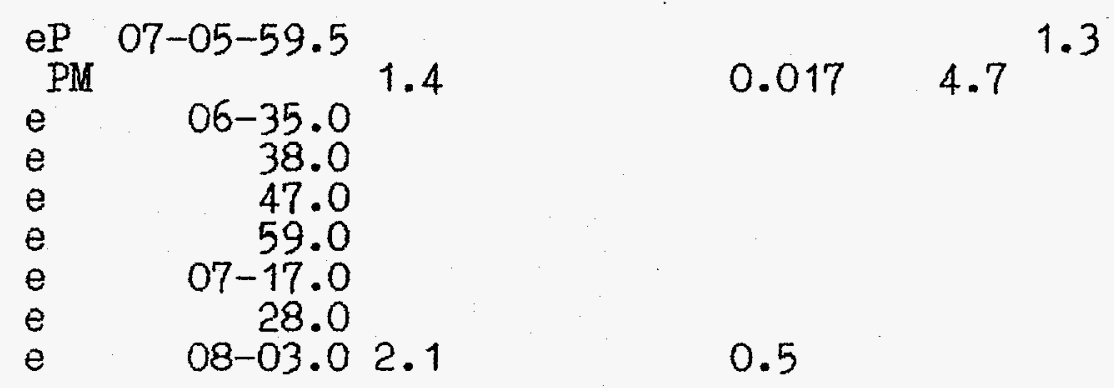

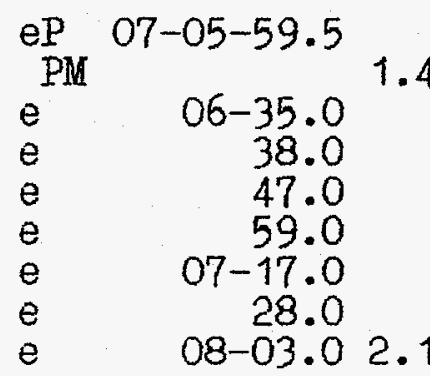

34. MOY SKM 33.5963 teP $07-06-41.8$

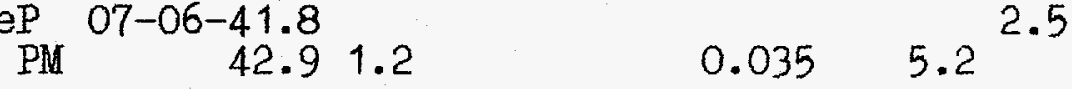

35. ZAK SKM $35.3565+\underset{P M}{\mathrm{iP}} 07-06-57.1$

$$
\begin{array}{lllll}
\mathrm{PM}_{\mathrm{M}}^{\mathrm{N}} & 09-25.4 & 1.3 & 0.013 & 4.7^{2.6} \\
1.2 & 0.01 &
\end{array}
$$

36. BOD SKM 39.4450 +iP $07-07-29.0$

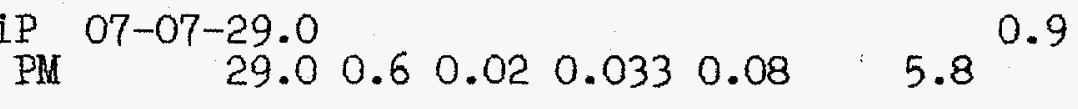




\begin{tabular}{l|c|c|c|c|c|c|c|c|c|c|c|c|}
\hline 1 & 2 & 3 & 4 & 5 & 6 & 7 & 8 & 9 & 10 & 11 & 12 & 13 \\
\hline 37. IIT
\end{tabular}


2. Analysis of the data from seismological bulletines.

Bulletines from Soviet sesimic stations include information on arrival times, amplitudes, periods and magnitudes of seismic signals recorded from individual explosions at the site of Azgir and group explosion of the series Vega-3. All the parameters of the seismic waves were measured by operators at seismic stations and magnitudes were determined from tables of calibrating functions from [18]. The principal goal of the analysis of the bulletines was to evaluate a possibility to use the data to solve following tasks:

- to regionalize the data available from Soviet PNE's;

- to reveal relationships between parameters of seismic waves in regional and teleseismic zones and yield/depth of explosions; - to evaluate relative seismic efficienoy of explosions in different rock media.

Time/distance curves for principal seismic phases at regional distances (to $3000 \mathrm{~km}$ ) were estimated from the data of the explosions conducted within the caspian depression. Epicentral distances were determined by standard location procedure used by USSR seiamic service. Travel times of seismio phases were counted from minute marks without tenths of seconds. Such a procedure allowed to identify principal seismic phases and estimate their apparent velooities.

Figure 37 presents experimental time/distance curves 
104

calculated Irom the five explosions at Azgir. Phases' identification was done by the simpliest procedure without dynamic parameters and by approximation of experimental points by lines.

Pn wave is in the first arrival to $15^{\circ}$ with apparent velocity of $8.17 \mathrm{~km} / \mathrm{sec}$. Apparent velocity of the first arrival increases then to $12 \mathrm{~km} / \mathrm{sec}$ at $60^{\circ}$. It is worth noting that the data from the event $A-1$ show high scattering up to several seconds due to low amplitude of seismic waves. It means that low yield (less than $1 \mathrm{kt}$ ) explosions can be mislocated from teleseismic data up to $100 \mathrm{~km}$.

Pg wave follows Pn wave and have apparent velocity of 6.01 $\mathrm{km} / \mathrm{sec}$. This wave, however, is not of the highest amplitude in seismio records as it is in various regions. Sn wave is distinct to a distance of 16 to 18 degrees with apparent velocity of 4.57 $\mathrm{km} / \mathrm{sec}$. Sg and Ig waves can not be traces in whole the range of observations and are associated with arrivals in velocity window from 3.6 to $3.0 \mathrm{~km} / \mathrm{sec}$ (marked Ig in Figure). Surface waves have no distinct arrivals and their peak arrivals are included in the bulletines. Note, that peak amplitudes of surface waves are close to those of longitudinal waves at distances to $10^{\circ}$ and higher at large distances. To construct more precise time/distance curves dynamic parameters from origin records should be used, of course. But it is too hard to collect them 
this time.

To construct time/distance curve from the Vega data is a hard task since there are not enough data on following arrival times in the bulletines. Iinear time/distance curve of Pn wave in the range from 4 to 13 degrees has apparent velocity of 8.17 $\mathrm{km} / \mathrm{sec}$ which coinside with similar value for Azgir. Note, that this value also coinsides in emror limits with apparent velocity estimated in [19] from the Vega-4 series. It was also mentioned in [19] that apparent velocity of $8.13 \mathrm{~km} / \mathrm{sec}$ is the highest of Pn wave throughout the north-east part of the Russian platform, Baikal Rift and the south of the West-Siberian plate.

The data on amplitudes of longitudinal and suriace waves included in the bulletines are presented in the form of peak vertical amplitude / distance curves in Figures 38 thru 41. Peak vertical amplitude in longitudinal wave was always measured in time window from 0 to 20 seo from the first arrival, i.e. before Pg wave arrival.

Figures 38 and 39 show peak amplitudes of Iongitudinal waves from 5 explosions at Azgir. Despite high scattering all the ourves have monotonioal charaoter and are differentiated by yield. More detailed curves are not available due to high variation of amplitudes at individual stations. But looal maximum at $20^{\circ}$, where amplitude is 2 to 3 times higher than average, can be noted at the curves from the larger explosions 
106

$\mathrm{A}-3, \mathrm{~A}-4$ and $\mathrm{A}-2$. Note also systematic amplitude overestimation by stations Bodaibo, Yakutsk, Seimohan, Iultin looated within the Easterm Siberia and stations Andijan, Tashkent located within the Fergana depression filled by thiok sediments. Stations Zakamensk near the Baikal Rift, Norilsk and Tiksi. near the Arktic coast show underestimated amplitudes. Regionalization of anomal amplitude variation induced by local geological structure should be a task of Iuture investigation in the frame of optimal location of regional control networks.

Note in Figure 39 also relatively low amplitude from the explosion $\mathrm{A}-5$ of $9.3 \mathrm{kt}$ yield in comparison with amplitude from the explosion A-4 of 58 kt yield. Effective yield of A-5 estimated from (26) is two times lower than real one. This phenomena was also revealed from spectral analysis of local data (chapter 3).

Similar features are observed in amplitude/distance curves from the explosions $7 \mathrm{~T}$ (the first) and $3 \mathrm{~T}$ (fourth) at Vega in Figure 40. The data from 3T, which was of larger yield, are higher in the curves (station comparison) and have higher scattering induced by interference with previous explosions.

Measurements of surface waves are available in a Iimited amount only from the Azgir explosions. Available peak vertical amplitudes of suriace waves are presented in Figure 41 . It is hard to estimate attenuation due to lack of data. It is 
interesting that surface wave amplitudes from $A-5$ are similar or higher than from $A-3, A-4$, and $A-2$ which were of larger yield (2.5 to 6.5 times). This effect is opposite to observed in longitudinal waves from $A-5$ and probably can be related to the larger depth of burial.

Surface wave amplitudes at the stations Andijan, Fergana and Tashkent are also higher relative to adjacent stations.

Table 10 summarizes mean periods of longitudinal waves, Tp, body wave magnitudes, $m$, and surface wave magnitudes from vertical MLV and horizontal MLH components. The parameters are estimated from the bulletines of Soviet seismic stations and foreign stations compiled at the IDG for all the Soviet PNE's. The periods were measured in the range from 5 to $60^{\circ}$ from soviet stations and from 18 to $100^{\circ}$ from foreign stations with standard deviation of $0.05 \mathrm{sec}$ in relation to mean value. Station magnitudes, $m$, were averaged in the range beyond $19^{\circ}$ with standard deviation of 0.05 over 30 observations and with standard deviation of 0.10 to 0.07 over smaller data sets. Magnitudes MLV and MLH were estimated only from Soviet stations to a distance of $4050^{\circ}$ and periods of 6 to 20 sec by using calibration [18]. The number of observations is shown in brackets near all the parameters.

As clear from table 10, periods of longitudinal waves from foreign stations for low-yield $A-1$ and deep $A-5$ explosions are 
108

Table 10. Periods of longitudinal waves and magnitudes of the explosions at Azgir and Vega.

\begin{tabular}{|c|c|c|c|c|c|c|}
\hline $\begin{array}{c}\text { Explo- } \\
\text { sions }\end{array}$ & \multicolumn{2}{|c|}{$\begin{array}{c}\text { Foreign } \\
\text { stations }\end{array}$} & \multicolumn{4}{|c|}{ Soviet stations } \\
\cline { 2 - 7 } & Tpo & $\mathrm{m}$ & $\mathrm{T}_{p}$ & $\mathrm{~m}$ & MLV & MLH \\
\hline A-1 & $0,72(10)$ & $4,74(9)$ & $0.73(16)$ & $4,69(5)$ & $3,75(3)$ & $4,47(1)$ \\
A-5 & $0,64(35)$ & $5,08(38)$ & $0,97(16)$ & $5,16(7)$ & $4,14(4)$ & $4,10(2)$ \\
A-2 & $0,86(24)$ & $5,49(17)$ & $0,99(15)$ & $5,50(11)$ & $3,95(8)$ & $3,98(10)$ \\
A-4 & $0,89(68)$ & $5,92(66)$ & $1,02(25)$ & $5,92(11)$ & $4,37(15)$ & $4,38(15)$ \\
A-3 & $0,90(37)$ & $6,06(36)$ & $0,97(27)$ & $6,10(11)$ & $4,39(16)$ & $4,33(15)$ \\
$7 \mathrm{~T}$ & $0,72(60)$ & $5,19(56)$ & $0,80(19)$ & $5,29(8)$ & $3,70(4)$ & $3,78(2)$ \\
$6 \mathrm{~T}$ & $0,69(65)$ & $5,23(63)$ & $0,77(19)$ & $5,31(7)$ & $3,66(3)$ & $3,89(1)$ \\
$5 \mathrm{~T}$ & $0,68(66)$ & $5,22(62)$ & $0,74(19)$ & $5,19(7)$ & $3,64(3)$ & $3,78(1)$ \\
$3 \mathrm{~T}$ & $0,73(74)$ & $5,41(70)$ & $0.78(18)$ & $5,43(9)$ & $3,89(4)$ & $4,02(2)$ \\
\hline
\end{tabular}

Iower than for other explosions at Azgir. Soviet data show such a feature only for A-1. Periods from Vega explosions are shorter than from Azgir (A-2, A-3, and A-4) . Periods of surface waves slowly grow with distance, and those of longitudinal waves do not depend on distance except the closest distances below $10^{\circ}$.

Wagnitudes, m, from Soviet and foreign stations differ not more than 0.1 units, although the number of observations at Soviet stations is Iimited (5 to 11). Note also that magnitude of A-5 is closer to 5.1 than to 5.0 from ISO and USSO data. 
Magnitude of 39 from foreign stations with large number of measurements $(\sigma= \pm 0.05)$ is 0.2 units larger than magnitudes of other explosions of the same yield of $8.5 \mathrm{kt}$ at the same site Vega. From (26) this difference corresponds to the yield of $13.5 \mathrm{kt}$ of $3 \mathrm{~T}$ which is valid. In this case one can assume that teleseismic magnitudes are sensitive to small variations of yield even for group explosions with $5 \mathrm{~min}$ delay. Soviet stations do not reveal such a difference in the limits of accuracy because of little observations.

Surface wave magnitudes are not enough to study magnitude relation to yield and depth. Surface wave magnitudes are almost absent from $A-1$ and $A-5$ explosions where they are available only in the closest range to 10 degrees with corresponding shorter periods of 6 to 9 seconds. OnIy orude differentiation by yield obviously can be done from MLV and MLH. So, Vegd explosions of 8.5 to $13 \mathrm{kt}$ show Iower MLV of 3.6 to 3.9 melative to Azgir explosions $\mathrm{A}-2, \mathrm{~A}-3$, and $\mathrm{A}-4$ with yields from 25 to $65 \mathrm{kt}$ and MLV from 4.0 to 4.4 .

The preliminary analysis of seismological bulletines has shown that the data available can be used to deteot explosions in salt with yield as low as $1 \mathrm{kt}$, to estimate their yields with high accuracy, and probably reveal regional characteristios of seismic waves in different geological structures. Local seismic data in the range from 0 to $260 \mathrm{~km}$ can not be used for yield 
110

estimation due to high variation induced by complex geological structure as show above. To reveal regional characteristics of seismic wavefield it is necessary in future to differentiate the data from bulletines by path direotions inside individual homogeneous geological structures of the earth crust and upper mantle. Data from regional Soviet seismic networks should also be included when available.

3. Seismic efficiency of underground nuclear explosions in salt. It is well known with a certain degree of confidence that 42 underground explosions from 122 peaceful nuclear explosions conducted in the USSR were detonated in saIt. Almost all the explosions (except project Tavda) which were aimed to constmot underground cavities for gas and oil storage as well as waste disposal have been fired in thick salt deposites. The explosions were conducted under the projects Azgir, Vega, Lira, Saphir, Magistral, and Neva-2 [1]. Two explosions Fakel and Pamuk detonated in order to extinguish fire were also conducted in salt since they were planned to be conduoted in salt from a broad geological data available.

Peaceful underground nuclear explosions conducted for the DSS studies were not specially associated with certain geological structures but the only constraint was a containment of the explosions and absence of ground water pollution. Thus 
geological constraints were of minor importance especially in the regions with limited geological information. Final geological structure was determined from drillhole data and geological formation to be used was chosen from in the depth range of containment. We have information that among the DSS explosions following were conducted in salt: Region 1 and 2 (Orenburg Region, near town of Buzuluk), Horizon-3 and Neteorite-2 (town of Norilsk at Taimyr peninsula), Batholit-2 (town of Aktubinsk in Kazakhstan) and Batholit-1 (Evenkiya). It was well known that the event Batholit-2 was in thick salt layer, and explosions near Norilsk were conducted in layered medium laminated by salt, dolomite and anhydrite layers.

We will use body wave magnitude/yield relation in order. to study seismic efficiency of salt explosions. Network magnitudes from USGS, ISC and USSO Center in Obninsk, USSR, catalogs have been compiled. Table 11 includes important original information on the explosions as well as related magnitudes. It is worth noting that only the first events from the series of Vega-2,3,4,5, Lira-1,2 and 3T, 11T of Vega-3,4 were used since seismic signals from following explosions are contaminated by coda of the first explosions and magnitude estimates are not oorect. Explosions $3 \mathrm{~T}$ and $11 \mathrm{~T}$ were included in the analysis since they were of different yield relative to other explosions of the Vega project. Yields and depths in Table were borrowed 
Table 11. True origin data on yield and depth of Soviet peacelul nuclear explosions in salt and body waves network magnitudes.

\begin{tabular}{|c|c|c|c|c|c|c|c|c|c|c|}
\hline N & Title & Region & Date & Q, & Depth, & $\begin{array}{l}\text { Soaled } \\
\text { depth, }\end{array}$ & \multicolumn{2}{|c|}{$m$} & Notes \\
& & & dd mm yy & $k t$ & $m$ & $m / k t^{1 / 3}$ & US & ISO & USSR & \\
\hline 1 & 2 & 3 & 4 & 5 & 6 & 7 & 8 & 9 & 10 & 11 \\
\hline
\end{tabular}

\begin{tabular}{|c|c|c|c|c|c|c|c|c|c|c|}
\hline 1 & Azgir-1 & $\begin{array}{l}\text { Gur'ev } \\
\text { reg',Kaz.SSR }\end{array}$ & 22.04 .66 & 1.1 & 161.3 & 156 & 4.7 & 4.7 & - & \\
\hline 2 & Azgir-2 & $-"-$ & 01.07 .68 & 25 & 597.2 & 199 & 5.5 & 5.5 & - & \\
\hline 3 & Azgir-3 & $-"-$ & 22.12 .71 & 64 & 987 & 247 & 6.0 & 6.0 & - & \\
\hline 4 & Azgir $r-4$ & $-"-$ & 29.07 .76 & 58 & 997.6 & 258 & 5.9 & 5.9 & 5.9 & \\
\hline 5 & Azgix-5 & $-n-$ & $17 \cdot 10.78$ & 74 & $970+1040$ & 272 & 5.8 & 5.8 & 6.0 & double \\
\hline 6 & Azgir -6 & $-"-$ & 17.01 .79 & 68.5 & $994+1064$ & 278 & 6.0 & 6.0 & 5.9 & double \\
\hline 7 & Azgir-7 & $-11-$ & 24.10 .79 & 33 & $917+982$ & $(306)$ & 5.8 & 5.8 & 5.7 & double \\
\hline 8 & Azgir-8 & $-" 1-$ & 14.07 .79 & 21 & $\begin{array}{l}847+914 \\
+980\end{array}$ & $(352)$ & 5.6 & 5.6 & 5.6 & triple \\
\hline 9 & Vega-1 $1 \mathrm{~T}$ & $\begin{array}{c}\text { Astrakhan } \\
\text { reg. }\end{array}$ & 8.10 .80 & 8.5 & 1050 & 514 & 5.2 & 5.2 & 5.2 & \\
\hline 10 & Vega-2 4T & $-"$ & 26.09 .81 & 8.5 & 1050 & 514 & 5.2 & 5.2 & 5.1 & \\
\hline 11 & Vega-3 7T & $-11-$ & 16.10 .82 & 8.5 & 974 & 477 & 5.2 & 5.2 & 5.0 & \\
\hline 12 & Vega-3 $7 \mathrm{~T}$ & $-n-$ & 16.10 .82 & 13.5 & 1057 & 444 & 5.4 & 5.4 & 5.2 & \\
\hline 13 & Vega-4 8T & $-11-$ & 24.09 .83 & 8.5 & 1050 & 514 & 5.1 & 5.2 & 4.8 & \\
\hline 14 & Vega-4 $11 \mathrm{~T}$ & $-" n-$ & 24.09 .83 & $(3.5)$ & 920 & 606 & 4.9 & 5.0 & 4.7 & \\
\hline 15 & Vega-5 $14 T$ & $-11-$ & 27.10 .84 & 3.2 & $(1000)$ & 678 & 5.0 & 5.0 & 4.7 & \\
\hline 16 & Lira-1 $1 T$ & $\begin{array}{l}\text { Uralsk } \\
\text { reg,Kaz.SSR }\end{array}$ & 10.07 .83 & 13.5 & 907 & 381 & 5.3 & 5.3 & 5.4 & \\
\hline 17 & Lira-2 & $-" n-$ & 21.07 .84 & 13.5 & $(816)$ & 343 & 5.4 & 5.4 & 5.4 & \\
\hline
\end{tabular}




\begin{tabular}{|c|c|c|c|c|c|c|c|c|c|c|}
\hline 1 & 2 & 3 & 4 & 5 & 6 & 7 & 8 & 9 & 10 & 11 \\
\hline 18 & Magistral & $\begin{array}{c}\text { Orenburg } \\
\text { reg. }\end{array}$ & 25.06 .70 & 2.3 & 702 & 532 & 4.9 & - & - & \\
\hline 19 & Saphir-2 & $-" 1-$ & 30.09 .73 & $(6.6)$ & 1144.6 & 531 & 5.2 & 5.2 & - & \\
\hline 20 & Region-1 & $-"-$ & 21.09 .72 & 2.3 & 485 & 367 & 5.1 & 5.0 & - & \\
\hline 21 & Batholit-2 & $\begin{array}{l}\text { Aktubinsk } \\
\text { reg, Kaz.SSR }\end{array}$ & 3.10 .87 & 8.5 & 1002 & 491 & 5.2 & 5.3 & 5.1 & \\
\hline 22 & Saphir-1 & $\begin{array}{r}\text { Orenburg } \\
\text { reg. }\end{array}$ & 22.10 .71 & 15 & 1142.3 & 462 & 5.3 & 5.2 & - & \\
\hline 23 & Region-2 & $-"-$ & 24.11 .72 & 2.3 & 675 & 511 & 4.7 & 4.5 & - & \\
\hline 24 & Batholit -1 & $\begin{array}{l}\text { Evenkiskii } \\
\text { nat. distr. }\end{array}$ & 01.11 .80 & 8 & 720 & 360 & 5.2 & 5.2 & 5.4 & \\
\hline 25 & Neva-2 & Yakut ASSR & 12.08 .87 & 3.2 & 815 & 553 & 5.0 & 5.0 & 5.2 & \\
\hline 26 & Horizon-3 & $\begin{array}{l}\text { Taimyr } \\
\text { nat. dist. }\end{array}$ & 29.09 .75 & 7.6 & 8833.6 & 424 & 4.8 & 4.8 & - & thin layer \\
\hline 27 & Meteorite-2 & $-2-11-$ & 26.07 .77 & 13.0 & 850 & 362 & 4.9 & 5.0 & - & $-" 1-$ \\
\hline 28 & Pamuk & Uzbek SSR & 21.05 .68 & 47 & 2440 . & 676 & 5.4 & 5.4 & - & deep \\
\hline 29 & Fakel & $\begin{array}{l}\text { Kharkov } \\
\text { reg, USSR }\end{array}$ & 09.07 .72 & 3.8 & 2483 & 1592 & - & 4.8 & - & deep \\
\hline 30 & Azgir-5 & $\begin{array}{l}\text { Gur'ev } \\
\text { reg, Kaz.SSR }\end{array}$ & 30.09 .77 & 9.3 & 1503.6 & 715 & 5.1 & 5.0 & 5.0 & deep \\
\hline
\end{tabular}

from [1] except the cases when more precise estimates were known. Unoorreoted values are bracketed. It is olear irom the Table that USGS and ISO magnitudes are available almost for all the explosions and differ from each other not more than 0.1 units of magnitude. Magnitudes determined from Soviet stations are only from 1976 and the number of stations used is not large. Thus we used ISC magnitudes since they used the largest number 
of stations. USGS magnitude estimate is used onIy for the event Nagistral where ISC magnitude is not available.

Figure 42 displays yield/magnitude curve from the data presented in Table 11. Iinear regression procedure in the form

$$
m=a+b \log q
$$

was used to average the data. The data from the 21 first explosions from Table 11 were used in linear regression. So only explosions in the south-east part of the Russian platfrom and adjacent regions of Kazakhstan (Astrakhan, Orenburg Regions of Russia, and Gur'ev, Ural'sk and Aktubinsk Regions of Kazakhstan) were used. The explosions conducted in Ukrain, Uzbekistan and Siberia (Neva-2, Batholit-1, Horizon-3, Meteorite-2) were not used as well as such outlayed experiments as Saphir-1 and Region-2.

The regression is as follows

$$
m=4.628( \pm 0.040)+0.695( \pm 0.034) \operatorname{logq}(26)
$$

and is characterized by correlation coefficient of 0.978 and standard deviation of 0.080 units of magnitude. This means $20 \%$ accuracy of $\mathrm{m}$ determination at least in the regions under investigation (platfroms with thick sediments), yield range from 1 to $65 \mathrm{kt}$, and depth range from 160 to $1100 \mathrm{~m}$ ( scaled depths from 150 to $600 \mathrm{~m} / \mathrm{kt}^{1 / 3}$ ).

One of the important features of the curve in Figure 26 is outlaying ( below curve) of the deep exploisons A-5, Fakel, 
Pamuk. This implies lower seismic efficiency of deep explosions at least at a frequency of $1 \mathrm{~Hz}$. The regression line is determined by explosions from $160 \mathrm{~m}$ to $1100 \mathrm{~m}$ deep, and deep explosions A-5, FakeI and Pamuk were at depths of 1500 to 2500 m. Effective seismic efficiency of deep explosions relative to "normal" is two times lower for A-5 and 3 to 3.5 times lower for Fakel and Pamuk. It is important that seismic efficiency correlates with absolute depth but not with soaled depth.

outlaying of the explosions in Norilsk Region can be related to complex geological structure with layers of carbonates and anhydrite prevailing. The causes for the explosions Saphir-2 and Region-1 to by out of the regression are not clear but may be associated with low accuracy of magnitude determination. The explosions conducted at the sites Neva-2 and Batholit-1 within the Easterm Siberia are consistent with the regression.

Similar relationship was obtained in [19] from smaller data. set of $q$, where $q$ was in relative units. The two relationships are coinside in the limits of accuracy. The data from the Norilsk Region are consistent with relationship for carbonates in $[19]$. 


\section{CONCLUSIONS}

This work is a continuation of the investigations conducted by the IDG in the field of creation of data bank of Soviet peaceful nuclear explosions (PNE) and comparative study of seismic efficiency of underground explosions of different types (nuclear and chemical, underground and cratering, tamped and decoupled, individual and group) detonated in various rock media. The work is done under Iinancial support of IINL (contract N B280344).

The report extends data bank on PNE's by validated true origin information on 42 underground nuclear explosions in salt conducted in different geological regions of the FSU from Ukraine at the coast to Yakutiya at the east,. and from the northerm wast of Eurasia to the south of Uzbekistan. For the majority of the tamped explosions conducted at Azgir and Vega sites there are locations and shot times included. Geological sections are described in detail for Azgir and Vega as well as physical and mechanical properties of salt. All the described explosions were conducted in boreholes in the depth range from 160 to $2500 \mathrm{~m}$ and yield range from 1 to $65 \mathrm{kt}$.

Seismic data bank is added by 296 digitized seismic waveforms on magnetic tapes with epicentral distance ranging from 0 to $260 \mathrm{~km}$ in local zone of 5 tamped individual explosions at the site Azgir and 4 explosions of the series Vega-3. 
Bulletines of Soviet seismic stations at epicentral distances ranging from 4 to $60^{\circ}$ are also included and contain arrival times, amplitudes, periods, and magnitudes of different seismic phases. Amplitudes and periods of displacement, velocity, and acceleration in body wave measured in the nearby zone at numerous temporary stations are also included.

At the moment, the data bank of the IDG contains seismic waveforms from nearby zone and Bulletines of permanent soviet stations for 10 individual explosions in salt (tamped and in cavities) at Azgir and 10 explosions in salt at Vega., as well as for 3 explosions in granite conducted under PNE program.

The report also includes results of experimental study of seismic waves at local, regional and teleseismic distances from the explosions at the sites Azgir and Vega located within the Caspian depression of the Russian platform.

Characteristic features of seismic wavefield were revealed as a result of the study in local zone (to $180-260 \mathrm{~km}$ ) which are related to complex geological structure of the sites (thick sediments, salt-dome tectonios, abrupt diping of the domes: slopes, strong differentiation of elasti properties at geological boundaries). Principal features of local seismic wavefield are as follows:

- dominating body waves with weak surface waves;

- dominating converted PS-waves (convertion at the boundary 
between salt rock and overlaying rocka) at horizontal component and long duration of oscillations;

- presence of high amplitude critically reflected waves from different interfaces in the geological section.

Spectral processing of local seismic waveforms from underground nuolear explosions in salt at Azgir allowed to compare different modeIs of seismic source function. Spectral analysis revealed relationship of spectral amplitude and yield in varions frequency bands. Relationships of peak amplitude of displacement and velocity and such characteristics as yield and range were obtained in local zone of the Azgir explosions. Amplitude/distance curve from the Vega explosions has a peak associated with critical reflection. The amplitude/distance curves are characterized by strong scattering with standard deviation of two times from averaced value. Naximum variation of amplitude at a permanent station from nearby explosions of equal yield at Vega can be as large as 10 times. Stochastic variability of seismio signals does not allow to reveal yield variation of 1.5 to 2.5 times and depth variation of 1.5 times from amplitudes and periods in nearby zone beyond $10 \mathrm{~km}$. Spectral analysis has shown, however, that spectral amplitudes at low frequency indicate lower seismic efficiency of deep explosions in salt.

Thus, the results of this study show that in inhomogeneous, 
layered structure many geophysical factors disturb seismic waverield and make its struoture very complicated deoreasing. information in seismic signal related to the source of seismic waves.

It is shown in the report that data from seismological bulletines allow to study characteristios of seismic signal in regional and teleseismio zones and to obtain those quantitave relationships to explosion parameters.

Periods of Iongitudinal waves from low-yield and deep explosions at Azgir measured in the range from $18^{\circ}$ to $100^{\circ}$ are 20 to $25 \%$ shorter than those of other explosions at the same site. Amplitudes of longitudinal waves measured at Soviet permanent seismic stations in the range $4^{\circ}$ to, $60^{\circ}$ depend on yield by regular law and show 2 times lower sesimio efficiency of the deepest explosion A-5 at Azgir. This explosion is also characterized by higher intencity of surface waves. Surface wave amplitudes from A-5 are close to those of from 3 to 6 times larger explosions at depth of 600 to $1000 \mathrm{~m}$.

Regional pecularities of some Soviet seismic stations are revealed. Some stations overestimate amplitude of located at the east of the USSR (Yakutiya, Magadan Region, Chukotka) and within Fergana Valley (Uzbekistan). Some stations underestimate amplitude and are located near the Baikal Rift and northem cost of Russia. Apparent velocity of $P_{n}$ wave to a distance of $15^{\circ}$. 
obtained from time/distance curve of Vega and Azgir explosions is $8.17 \mathrm{~km} / \mathrm{sec}$. The velocity in higher than obtained from explosions at the north-east of the Russian platform, the south of the West-Siberian plate, and the Baikal Rift [19].

Longitudinal wave magnitude/yield relation was obtained from 21 explosion ranging from 1 to $65 \mathrm{kt}$ conducted in salt within the territory of the caspian depression and adjacent regions. Selsmic efficiency of very deep explosions $(2500 \mathrm{~m})$ is 3 times lower than that of explosions at depth of $1100 \mathrm{~m}$. Yield estimates are 20 to $25 \%$ accurate at confidence level of 0.7 .

The results obtained indicate that low-frequency teleseismic signals are not so sensitive to variations of geological conditions in the upper part cross-section of source region as local signals and reflects variations of source parameters much better. Teleseismic data from explosions larger than $1 \mathrm{kt}$ allow to estimate reliably the explosion parametes (yield and depth) from magnitude. Hence, by our opinion, regional networks of seismic monitoring should work in cooperation with teleseismic stations located in mioroseismically "quite" sites and supplied by high capacity broad-band (to $15-20 \mathrm{~Hz}$ ) seismic equipment.

Thus, the results obtained in the report give an knowledge about pecularities of seismic waves in the broad range from $0^{\circ}$ to $60^{\circ}$ from explosions in salt domes at the territory of ancient 
platform covered by thick sediments and characterized by strong differentiation of elastic properties. It is supposed in future to complete data bank creation on original and seismic data from Soviet peaceiul nuclear explosions. Following scientilic task will be of the highest priority:

- regionalization of seismic characteristics by types of geological and tectonic counditions;

- determination of deteotion treshold and study of seismic efficiency of low-yield explosions (less than 2-3 kt) in various rock media;

- detailed study of deep explosions $(1500$ to $3000 \mathrm{~m}$ ) with low seismic efficienoy.

The planned studies are supported by a large number of proper sources from Soviet PNE's [1], seismic data from temporary stations in local zone of the explosions, and bulletines from permanent seismic stations of the FSU oompled in the IDG. Moreover, it is supposed to collect seismic records from permanent seismic stations with waveforms from selected explosions to a distance of $3000 \mathrm{~km}$. To reveal regional charaoteristios of seismic wavefield it will be necessary to separate seismic data by directions of propagation inside relatively homogeneous geological structures of the earth orust. and upper mantle.

It is assumed that the results of planned studies will be 
used to improve procedures of seismic monitoring of underground nuclear explosions conducted with evasion in the regions with similar geological conditions. 
RETERENCES

1. Nuclear explosions in the USSR. Issue 4. Peaceful nuolear explosions (Ed. V.N.Mikhailov). Moscow, 1994. (in Russian).

2. Passechnik I.P., Sultanov D.D. Dominating seismio body waves from explosions. Proceedings of Hyảroproekt, N20, Moscow, 1971. (in Russian).

3. Sharpe J.A. The production of elastic waves by explosion pressures 1. Theory and empirioal observations. Geophysios, $7,144-154,1942$

4. Muller R.A., Murphy J.R. Seismic characteristios of underground nuclear detonations. Part 1. Seismic spectrum soaling. Bulletin of Seismological Society of America, 61, N6, $1675-1692,1971$.

5. Rodionov V.N., Adushkin V.V., Kostyuchenko V.N. et.aI., Mechanic effect of underground explosion, Nedra, 1971. (in Russian).

6. Rodean G., Seismology of nuclear explosions, 1974

7. Zamyshlaev, B.V., Evterev, I.S., Models of dynamic deformation and destmuction of rocks, Nauka, 1990. (in Russian).

8. Bychenkov, V.A., S.V. Dem'yanovsky, G.V. Kovalenko et.aI., Seismic efficiency of tamped underground explosion, Problems of nuclear soience and engineering, Ser. Theoretio and 
applied physics, N2, 1992. (in Russian).

9. Korotiov, P.F., B.M. Prosvimina. Numerioal simulation of explosion in elastic-plastic medium and some problems of simulation. Doklady AN SSSR (Reports of Aoademy of Sciences), N.228, N1, 1976. (in Russian).

10. Korotkov, P.F., B.M. Prosvimina. On the scaling law and energy distribution of explosion in elastio-plastic medium, PMTF, N2, 1980. (Applied Nathematios and Theoretioal physics). (in Russian).

11. Kostyuchenko, V.N., V.N. Rodionov. On the generation of seismic waves by large-scale underground explosions in hard rocks. Izv. AN.SSSR, Ser. Earth's physios, N10, 1974. (in Russian).

12. Denny M.D., Goodman D.M. A case Study of the Seismio Source Function: Salmon and Sterling Reevaluated. J.Geophys. Res, 95, N B12, 1990.

13. Denny M.D., Johnson L.R. The explosion Seismic Source funotion: models and soaling laws reviwed. Explosion Souroe Phenomenology, Am. Geophys UN., 1991.

14. Hensinkveld M.F. Caloulation on seismio ooupling of underground explosions in salt. Lawrence Iivermore Nation. Labor., CA, UCRL-53103, 1981.

15. Springer D., Denny M., Healy J., Mickey W. The Sterling experiment: Decoupling of seismio waves by a shot-generated 
cavity. J. Geophys. Res., 73, 5995-6011, 1968.

16. Sadovskyi, M.A., V.N. Kostyuchenko. On the explosion. generated seismic wave attenuation in rocky massif. Doklady AN SSSR, V.301, N6, 1988. (in Russian).

17. Kostyuchenko V.N., Seismic source function of large-scale underground explosions. Dynamic processes in the geospheres. IDG RAS. Moscow. Nauka. P. 132-136,1994.

18. Rules of production and processing of observations at seismic stations of USSR Unified network of seismic observations. "Nauka", Moskow, 1982. (in Russian).

19. Sultanov D.D. Investigation of seismic efficiency of soviet peaceful nuclear explosions conducted in various geological conditions. Report IDG under the project 01-0204-33-0537-543, Center Seismic Studies, USA, 1993. 
126

FIGURE CAPMIONS

Fig. 1 Relative positions of the explosions at the Azgir site.

Fig.2 Lithologioal seotion of the $A-2$ and $A-5$ boreholes.

Fig.3 Positions of technology (T) and exploring boreholes and points of seismic observations (1) at the Vega site. Isolines of salt roof are arawn.

Fig.4 Lithological section of the 1 T borehole at Vega.

Fig.5 Geological cross-section of the seitov salt dome along a profile through the boreholes $1 \mathrm{~T}, 3 \mathrm{~T}$ and $4 \mathrm{~T}$, exploring boreholes $1 \mathrm{P}$ and $2 \mathrm{P}$, and structural borehole 260 .

Fig.6 Scheme of seismic observations at the Vega site.

Fig.7 Scheme of technology boreholes $(-)$, temporary seismic stations ( ) and populated areas (1) in the Azgir Region.

Fig.8 Typical frequency characterics of seismic channels of displacement, velocity and acceleration.

Fig.9 Attenuation of peak amplitude of radial component of particle velocity from $A-1$.

Fig. 10 Attenuation of peak amplitude of radial component of particle velocity from $\mathrm{A}-2$.

Fig.11 Attenuation of peak amplitude of radial component of 
particle velocity from $A-3$.

Fig.12 Attenuation of peak amplitude of radial component of particle velocity from $A-4$.

Fig. 13 Attemuation of peak amplitude of radial component of particle velocity from $A-5$.

Fig.14 Period of peak amplitude of radial particle velocity as a function of distance at Azgir site.

Fig. 15 Attenuation of peak amplitude of vertical component of displacement at Vega site.

Fig.16 Variations of amplitude of seismic signals at permanent seismic stations from explosions of equal yields at Vega.

Fig. 17 Periods of seismic waves as a function of distance at Vega site. Notation:+ -explosions with $q=8.5 \mathrm{kt}$.

- -explosion 11T; q=3.5kt

a -explosion 3T; $q=13.5 \mathrm{kt}$

Fig.18 Displacement potential $\Phi(\tau)$ (upper graph) and its spectrum $\Phi^{\prime}(w)$ (lower graph) for the event Salmon. Experimental values from sensors at various ranges are marked by different symbols [14].Solid lines are predictions from model [11] and dashed Iines - from model $[9 ; 10]$.

Fig.19 Speotra of vertical displacement recorded at the 
town of Kharabali from the event $A-1$ in differenet time windows $(3.2,5,8,10$ and $18 \mathrm{sec})$. Thick solid line is for model [11], and dashed line is for Sharpe's model.

Fig.20 Speotra of vertical displacement recorded at the town of Kharabali from the event A-2. See figure 19 for notations.

Fig.21 Spectra of vertical displacement recorded at the town of tharabali from the event $A-3$. See figure 19 for notations.

Fig.22 Spectra of vertical displacement recorded at the town of Kharabali from the event A-4. See figure 19 for notations.

Fig.23 Spectra of vertical displacement recorded at the town of Kharabali from the event A-5. See figure 19 for notations.

Fig.24 Digital filtering of the record of vertical displacement at Kharabali from $\mathrm{A}-1$ explosion. Filters marked by numbers in circles: $1-0.7$ to 1 $\mathrm{Hz} ; 2-1$ to $1.5 \mathrm{~Hz} ; 3-1.5$ to $2 \mathrm{~Hz} ; 4-2$ to 2.8 $\mathrm{Hz} ; 5-2.8$ to $3.9 \mathrm{~Hz} ; 6-3.9$ to $5.6 \mathrm{~Hz}$. Seismogram is in the upper part, time marks - in the lower part.

Fig.25 Digital filtering of the record of vertical 
129

displacement at Kharabali from A-2 explosion. See figure 24 for notations.

Fig.26 Digital filtering of the record of vertical displacement at Kharabali from $A-3$ explosion. See figure 24 for notations.

Fig.27 Digital filtering of the record of vertical displacement at tharabali from A-4 explosion. See figure 24 for notations.

Fig.28 Digital filtering of the record of vertical displacement at Kharabali from A-5 explosion. See figure 24 for notations.

Fig.29 Averaged spectral amplitudes, S, as a function of yiled, q, for a set of filteres from. figure 24 .

Fig.30 Comparison of spectrum of vertical displacement at Tharabali ( time window is of 18 sec) from $A-1$ with averaged spectra for a set of six bandpass filteres shown at figure 24.

Fig.31 Comparison of spectrum of vertical displacement at Tharabali ( time window is of $18 \mathrm{sec}$ ) from A-2 with averaged spectra for a set of six bandpass filteres shown at figure 25 .

Pig.32 Comparison of spectrum of vertical displacement at Kharabali ( time window is of $18 \mathrm{sec}$ ) from $\mathrm{A}-3$ with averaged spectra for a set of six bandpass filteres 
shown at figure 26.

Fig.33 Comparison of spectrum of vertical displacement at Kharabali (time window is of $18 \mathrm{sec}$ ) from A-4 with averaged spectra for a set of six bandpass filteres shown at figure 27.

Fig.34 Comparison of spectrum of vertical displacement at Kharabali. ( time window is of $18 \mathrm{sec}$ ) from A-5 with averaged spectra for a set of six bandpass filteres shown at figure 25.

Fig.35 Spectra of vertical displacement at Kharabali (time window is of $10 \mathrm{sec}$ ) related to the spectrum of $\mathrm{A}-3$ explosion. Spectra of the explosions marked as 3 $A-3 ; 4-A-4 ; 5-A-5$.

Fig.36 Averaged spectra of vertical displacement at Kharabali related to averaged speotrum of the event $\mathrm{A}-2\left(\mathrm{~S}_{2}\right) . \mathrm{S}_{1}$ is the averaged spectrum of $\mathrm{A}-1$; $\mathrm{S}_{3}$ is the averaged spectrum of $\mathrm{A}-2 ; \mathrm{S}_{4}$ is the averaged spectrum of $A-4$; Ss is the averaged spectrum of $A-5$.

Fig.37 Time-distance curve from the Azgir explosions.

Fig.38 Peak vertical displacement amplitude in longitudinal wave as a funotion of distance from explosions $A-1$ $(0), A-2(\bullet), A-3(\Delta)$.

Fig.39 Peak vertical displacement amplitude in longitudinal wave as a function of distance from explosions $\mathrm{A}-4$ 
(v) and $A-5(+)$.

Fig.40 Peak vertical displacement amplitude in longitudinal wave as a function of distance from explosions 7 T (•) and $3 \mathrm{~T}(\Delta)$ at Vega.

Fig.41 Peak vertical displacement amplitude in surface wave as a function of distance from explosions $A-1$ (0), $A-2(\bullet), A-3(\Delta), A-4(\nabla)$ and $A-5(+)$ at Azgir.

Pig.42 Body wave magnitude, $m$, vs. yield for soviet peaceful nuclear explosions in salt. 


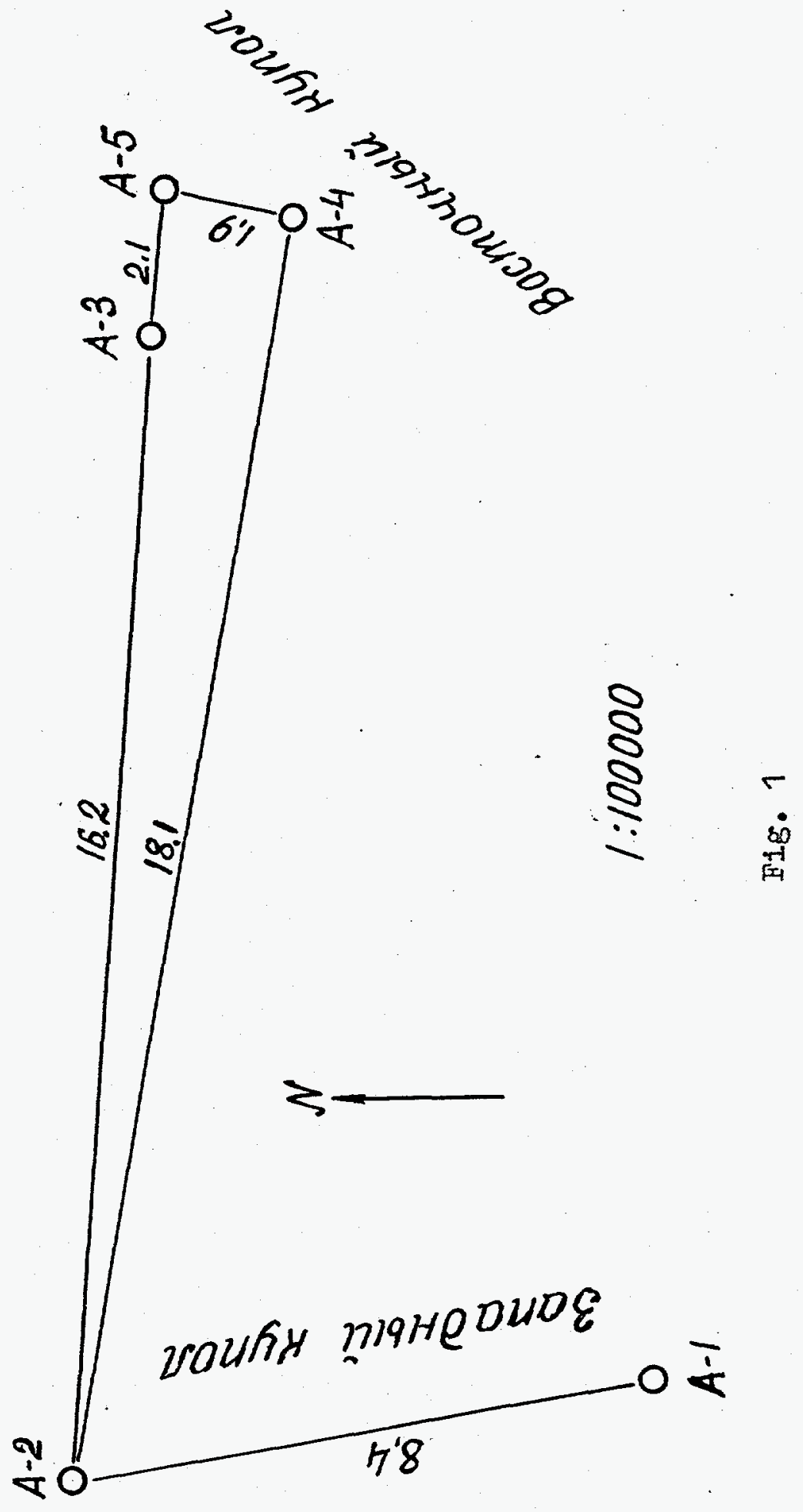




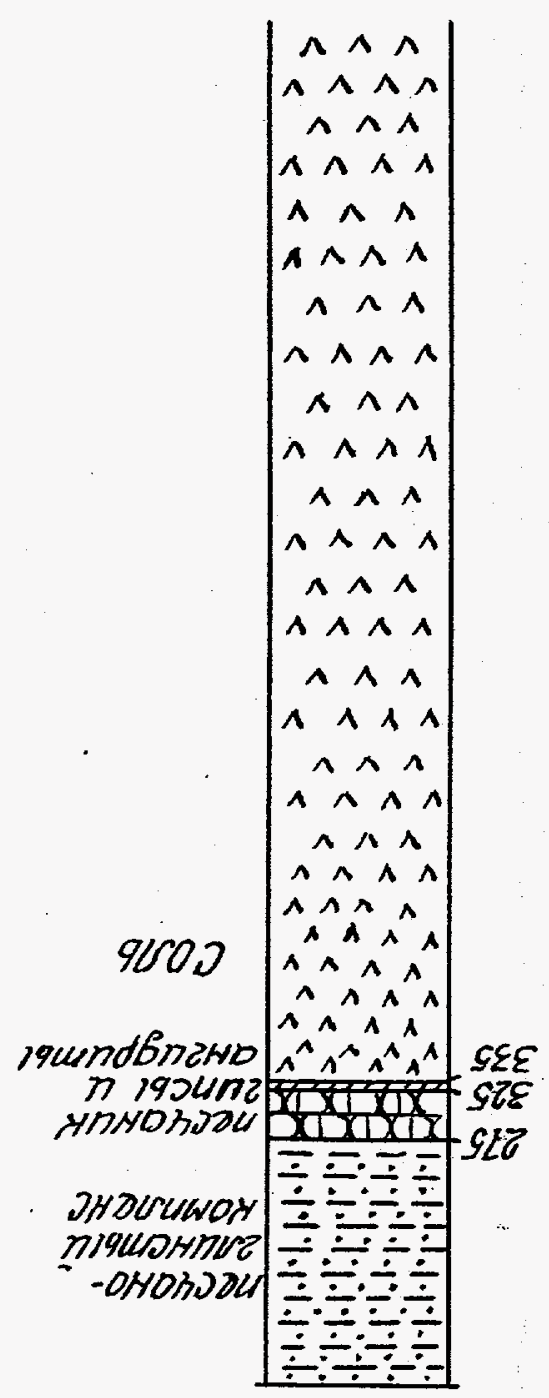

S-V

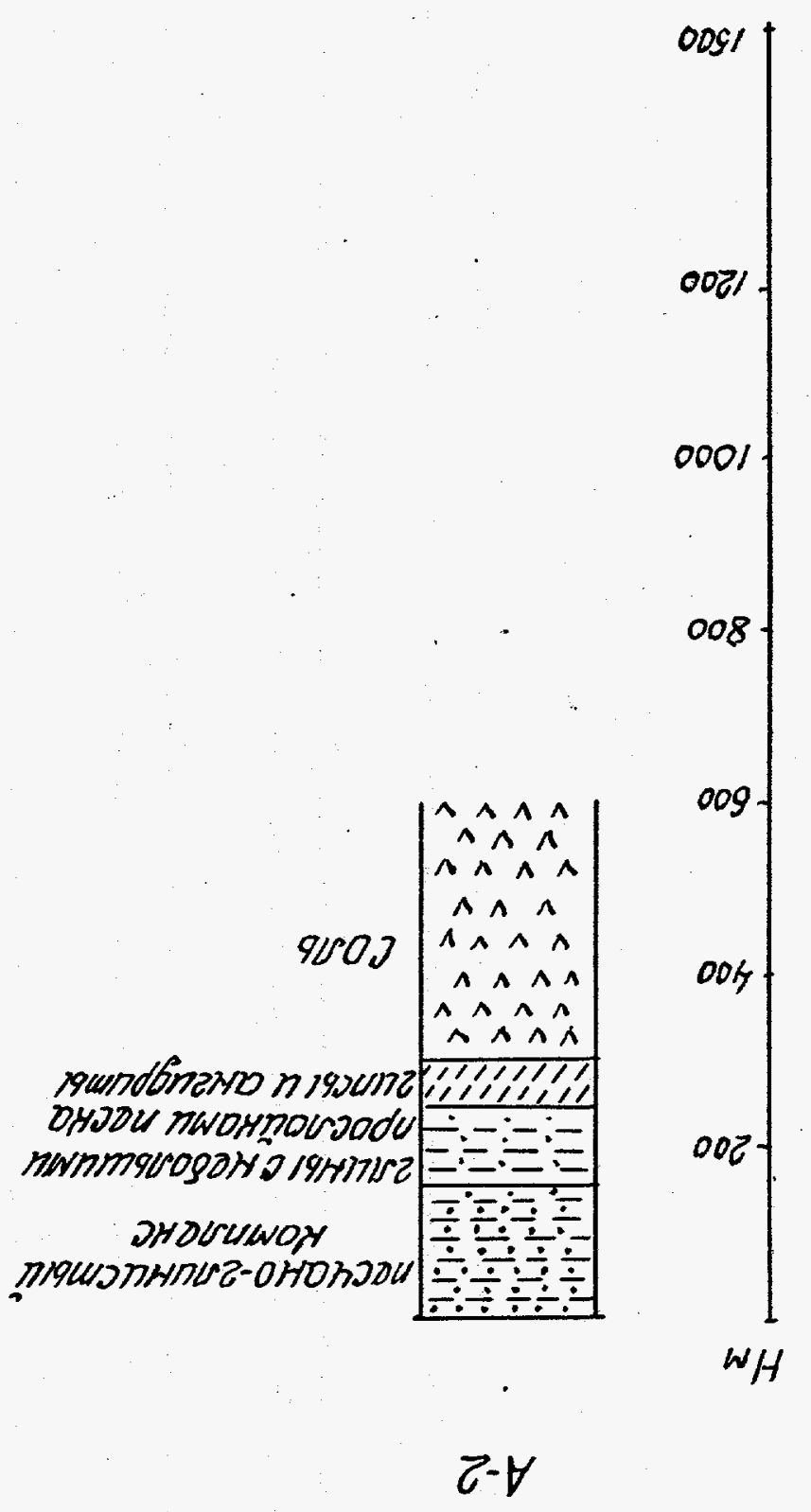

65s 


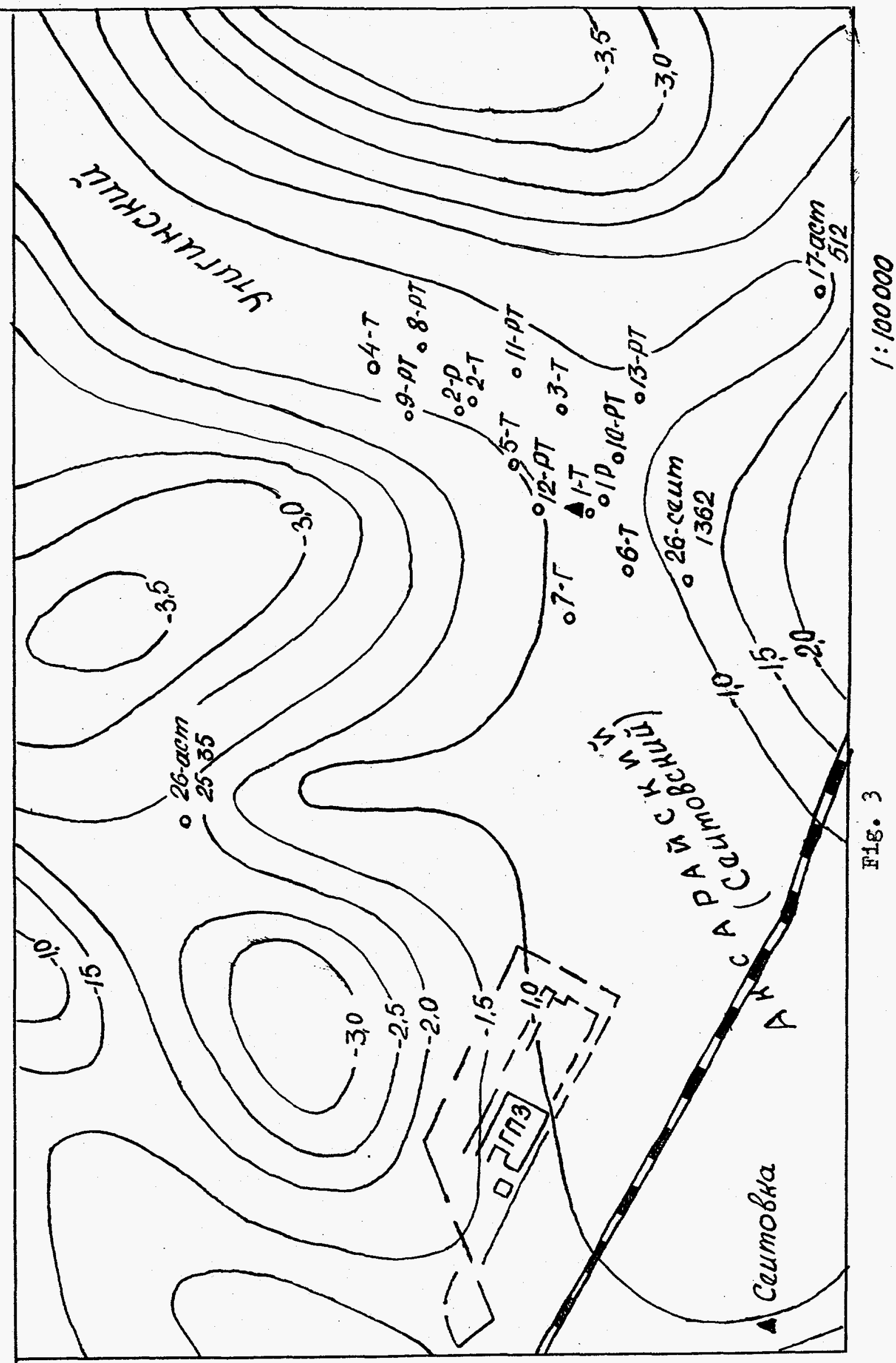


Cross bection of bore hole at the site Vega

\begin{tabular}{|c|c|c|c|}
\hline 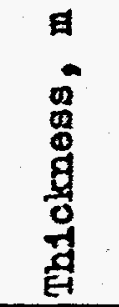 & 吾 & 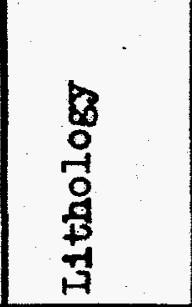 & Description of rocks \\
\hline 172 & 170 & 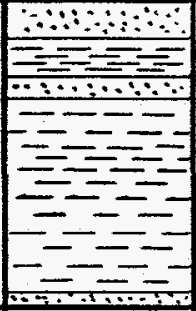 & $\begin{array}{l}\text { Clay with sand banda. } \\
\qquad \nabla_{p}=1800 \mathrm{~m} / \mathrm{s}\end{array}$ \\
\hline 458 & 625 & 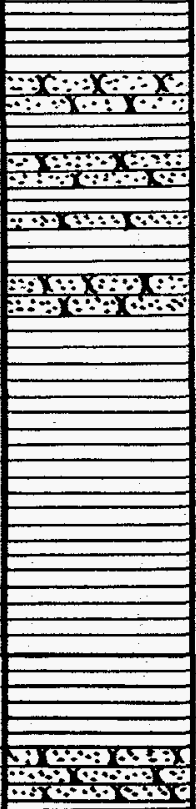 & $\begin{array}{l}\text { Clay with sandstone bands } \\
\qquad \nabla_{p}=2200 \mathrm{~m} / \mathrm{s}\end{array}$ \\
\hline 36 & 660 & & Argill1te \\
\hline 38 & 700 & 业 & Ilnestone, marl \\
\hline 23 & 725 & $\Lambda_{\wedge}^{\wedge} \wedge$ & Anhydrite \\
\hline & 1050 & $\begin{array}{c}+++ \\
++ \\
+++ \\
++ \\
+++ \\
++ \\
+++ \\
++ \\
+++ \\
++ \\
+++ \\
++ \\
+++\end{array}$ & $\begin{array}{l}\nabla_{p}=4120 \mathrm{~m} / \mathrm{s} \\
\nabla_{s}=2100 \mathrm{~m} / \mathrm{s}\end{array}$ \\
\hline
\end{tabular}

FIg. 4 . 

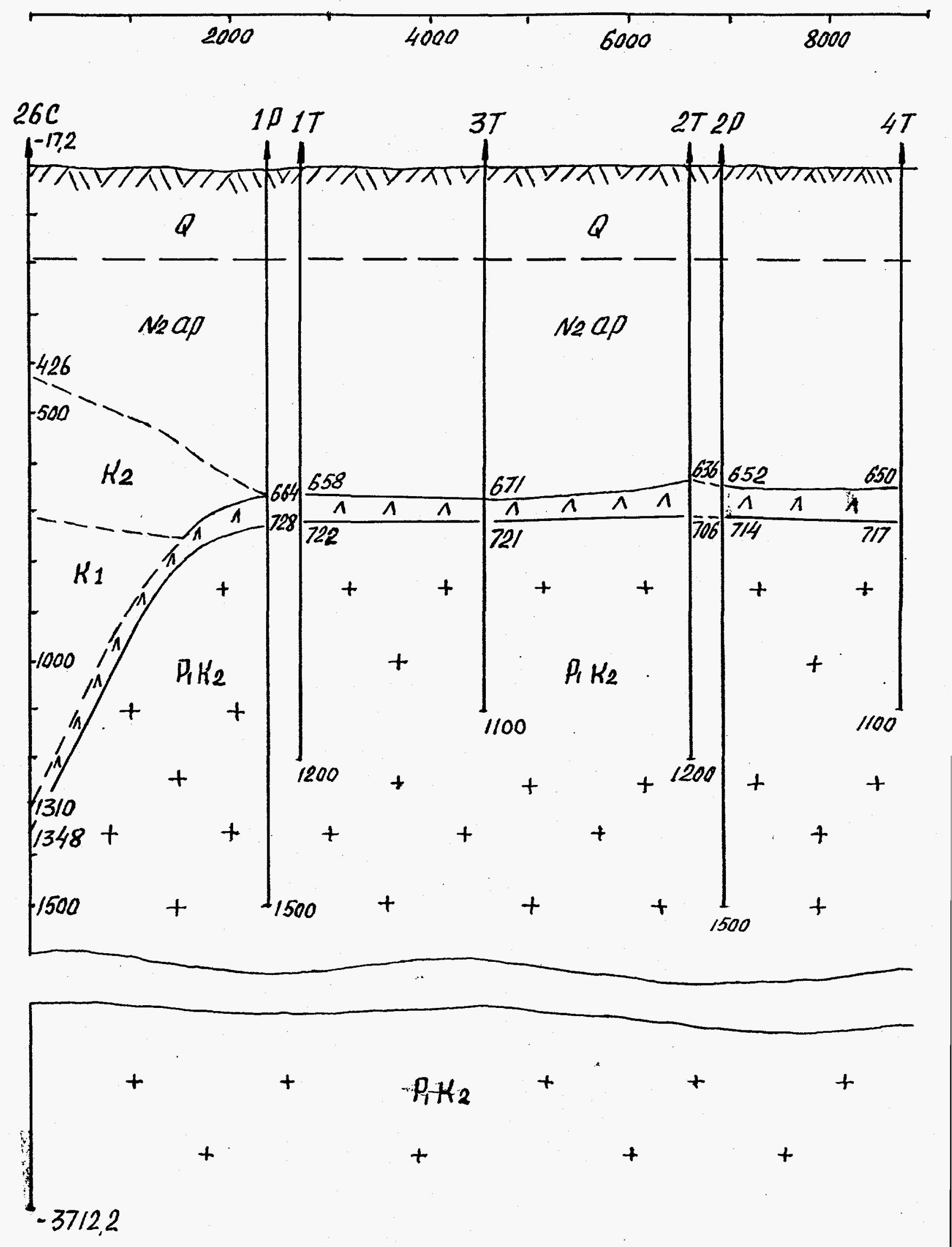

Fig. 5 


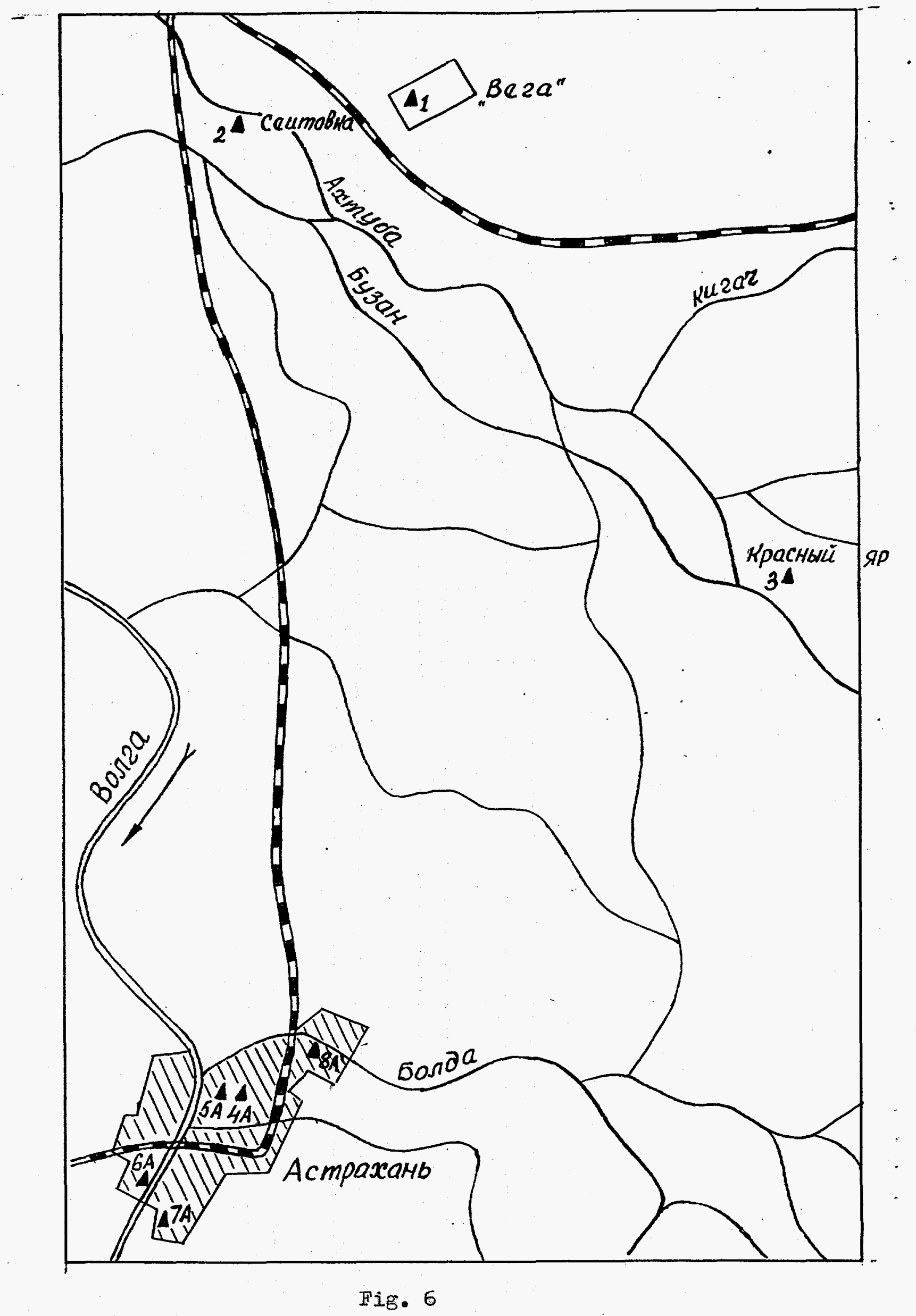




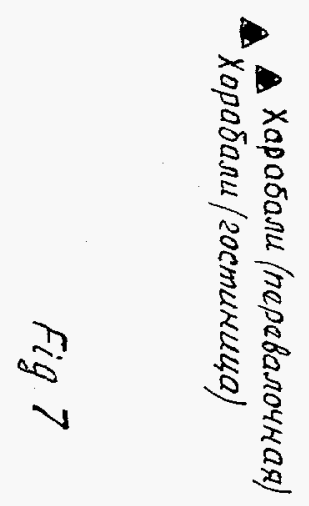

3
$\dot{4}$
$\dot{8}$
0
8
8
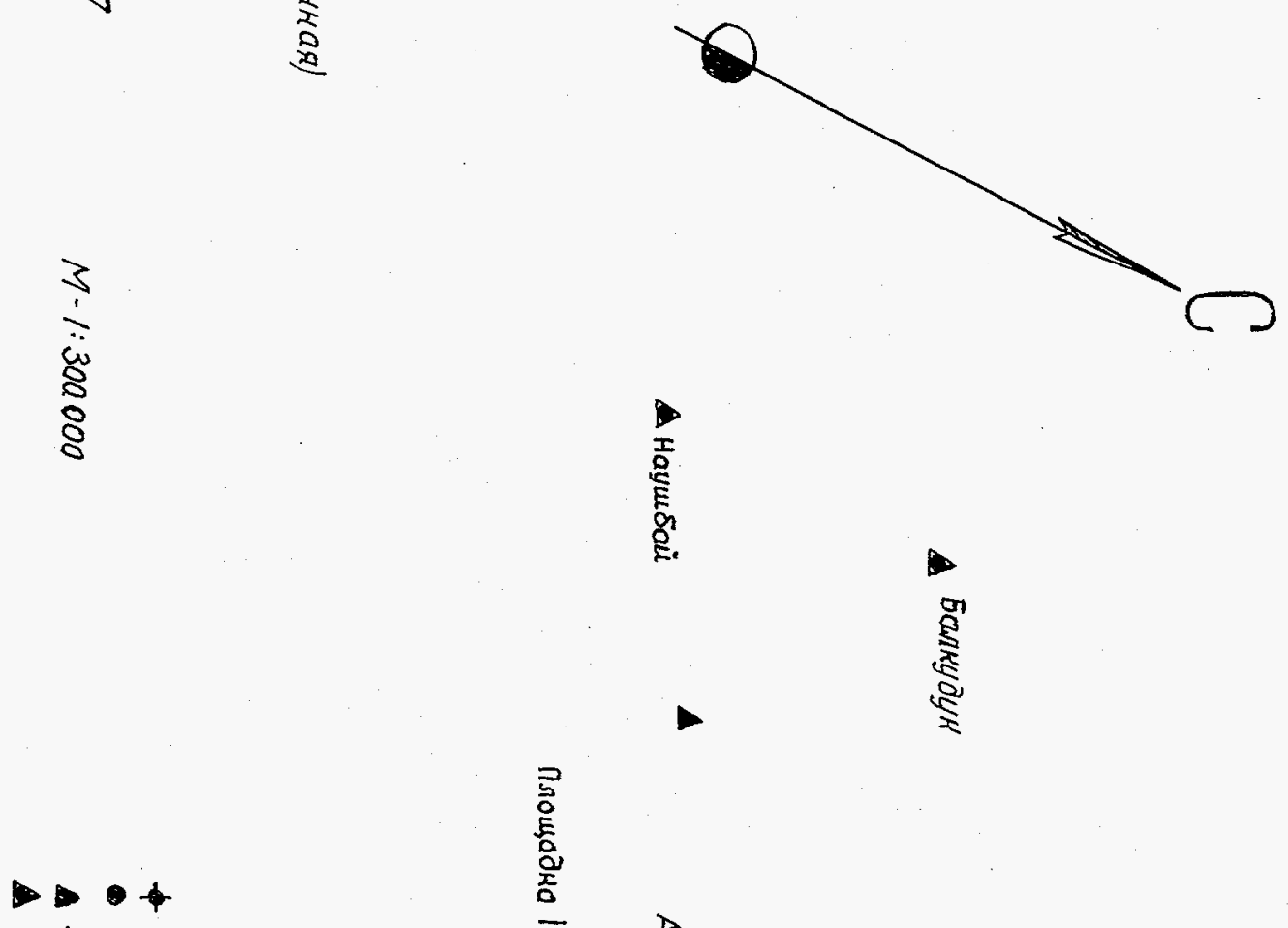

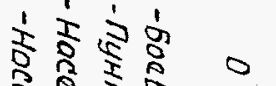

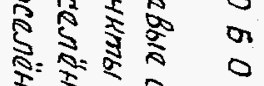

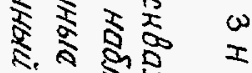

관ㄹำ

然

告

3 i

今

종

존

ล

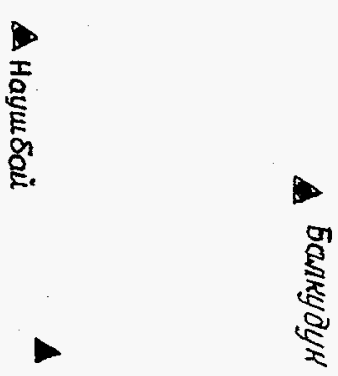

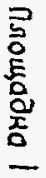

sogens
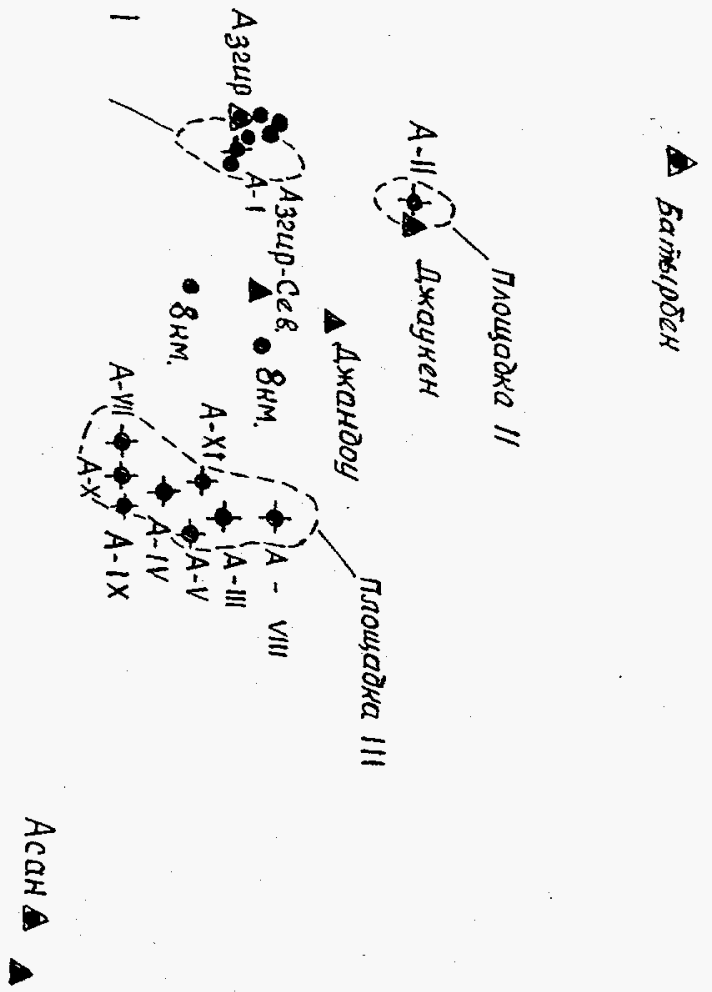


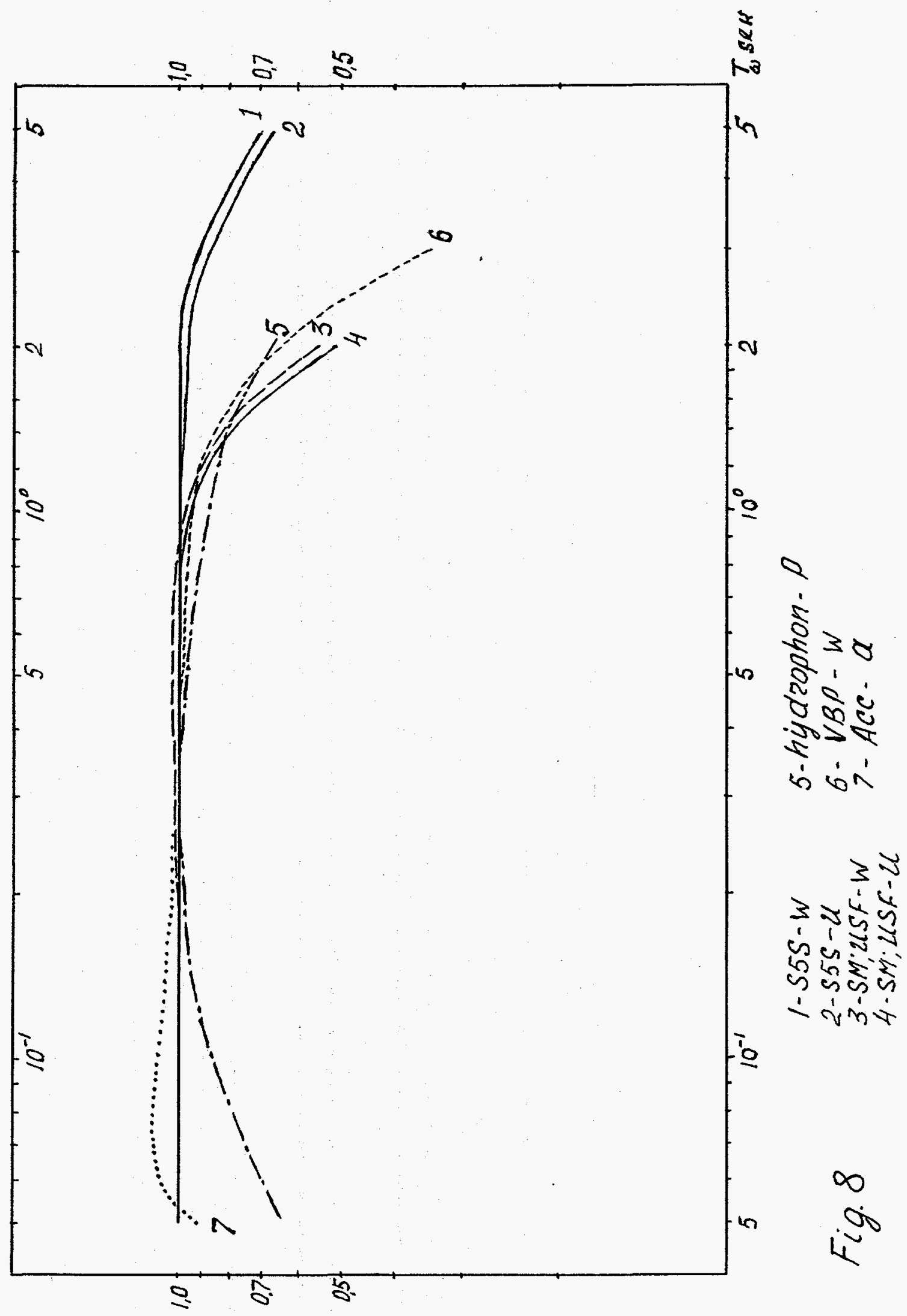




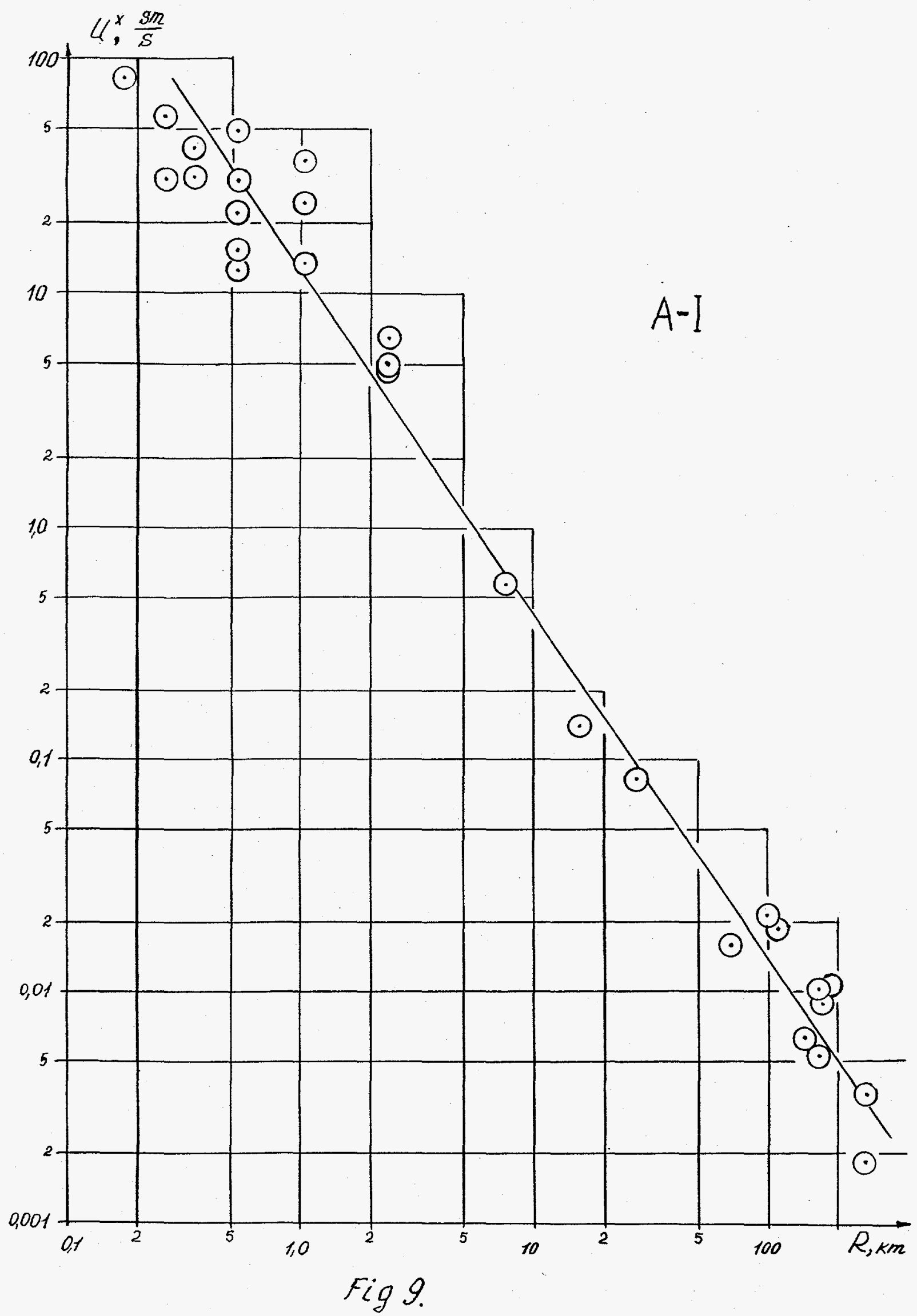




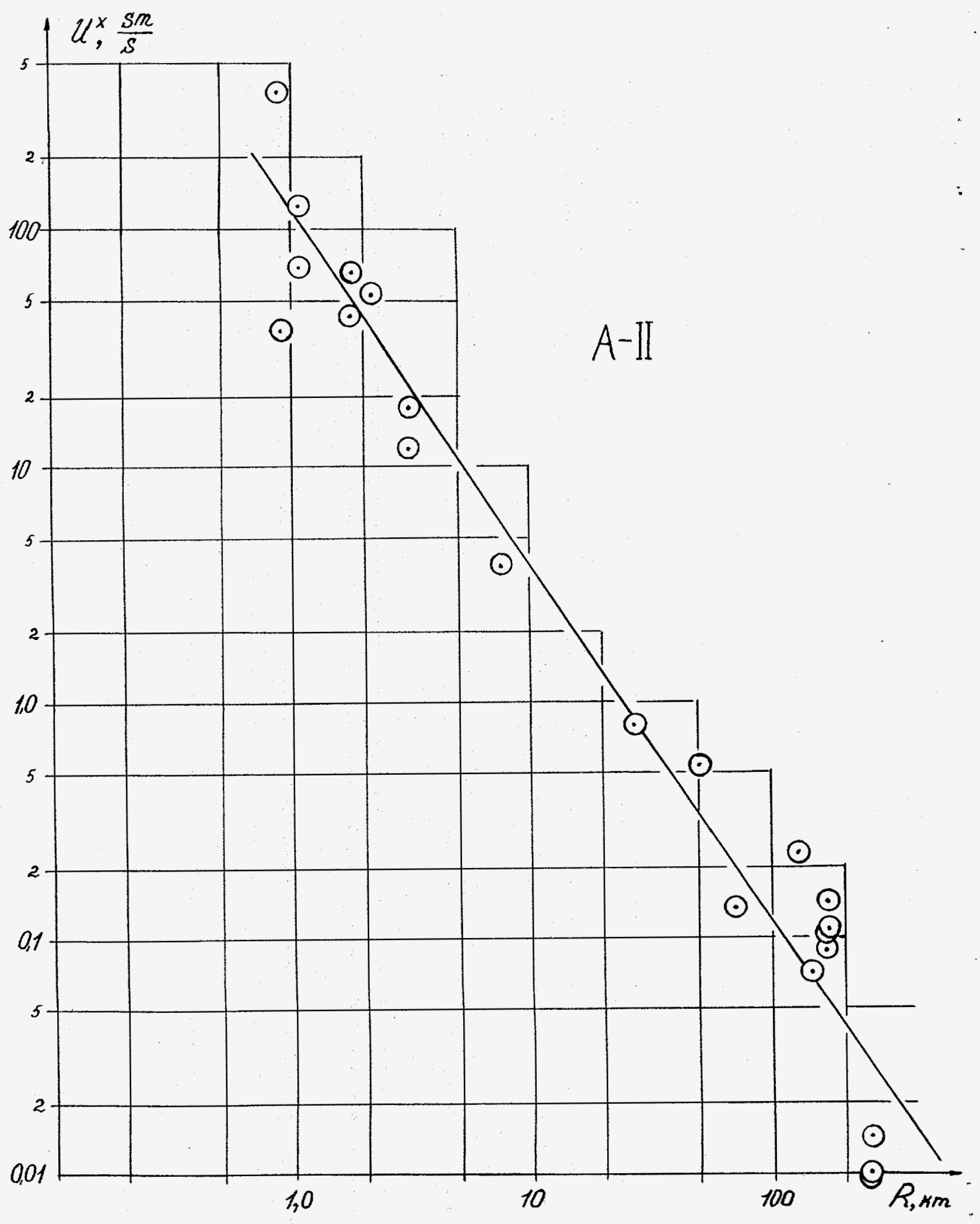

Fig 10 


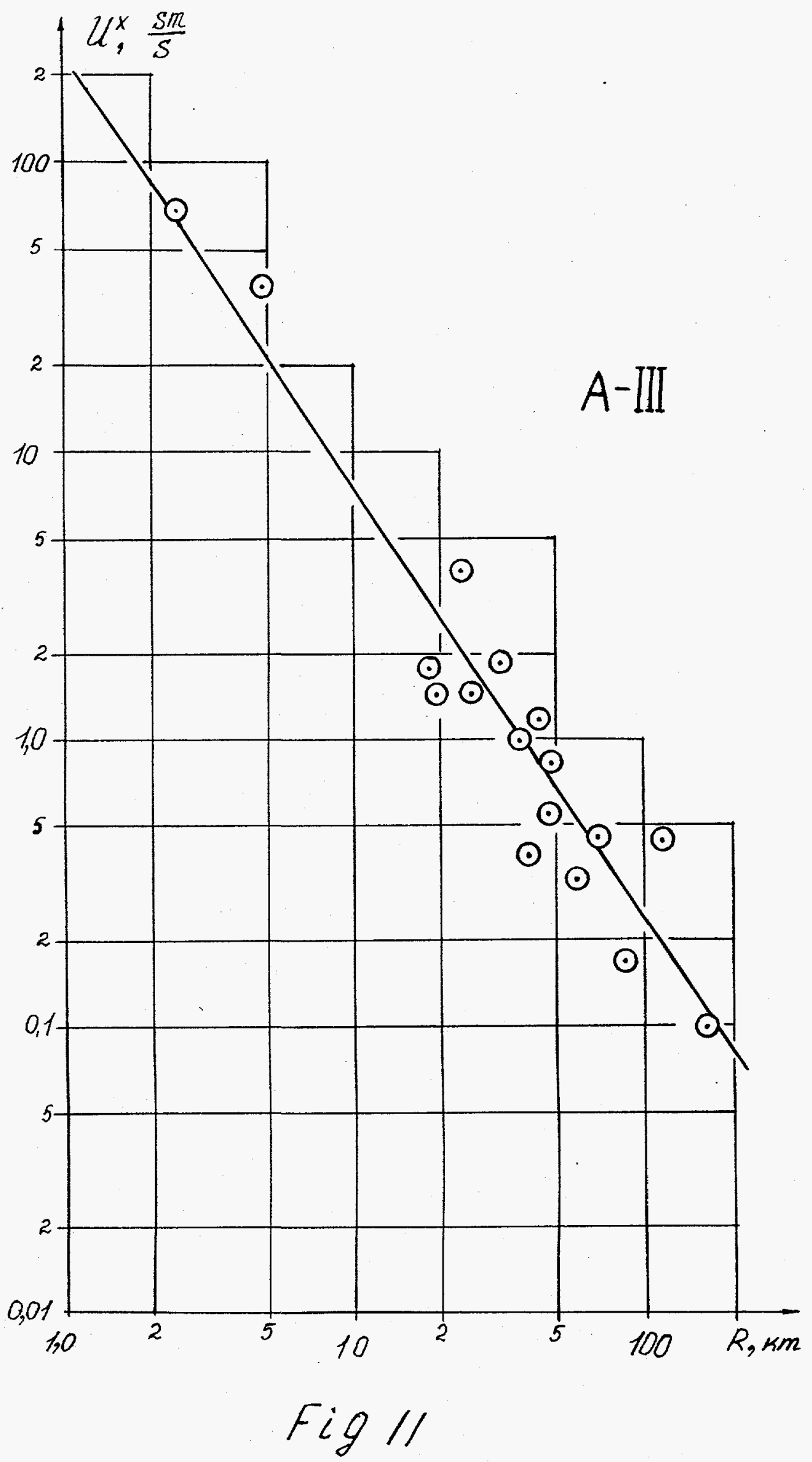




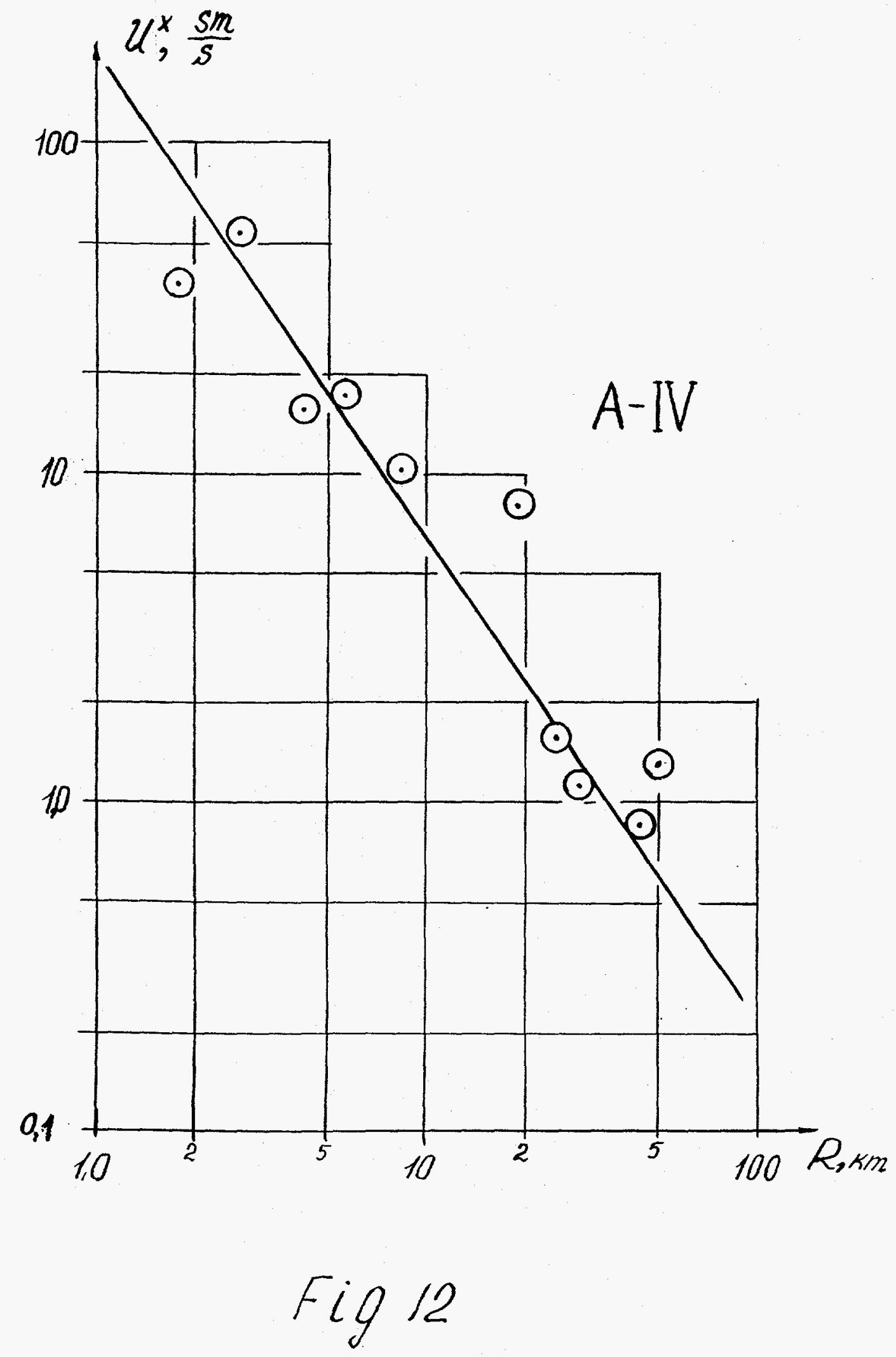




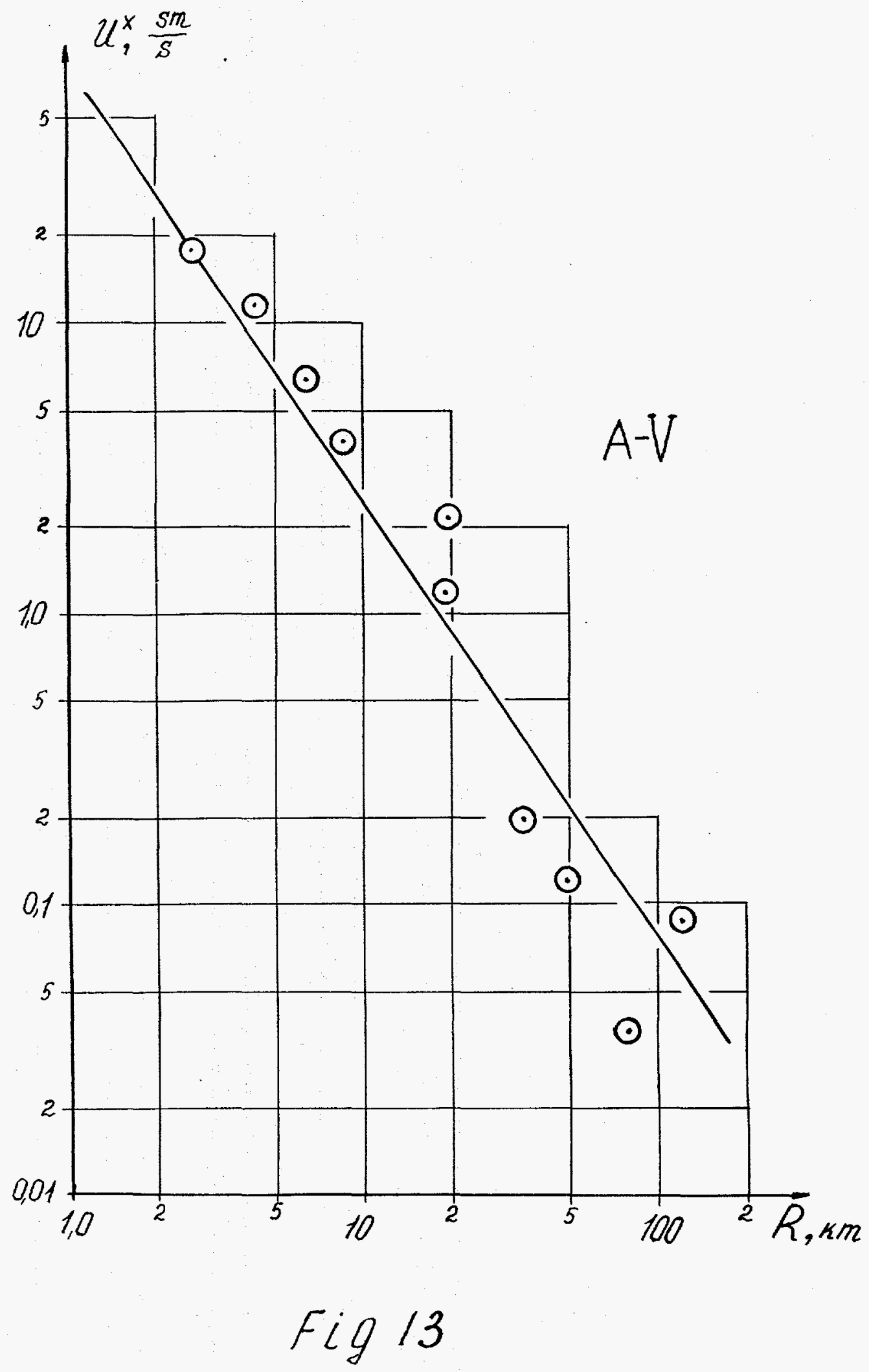




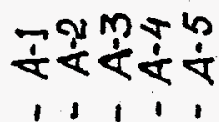

1. $10^{\prime} \dot{x}^{\prime}$

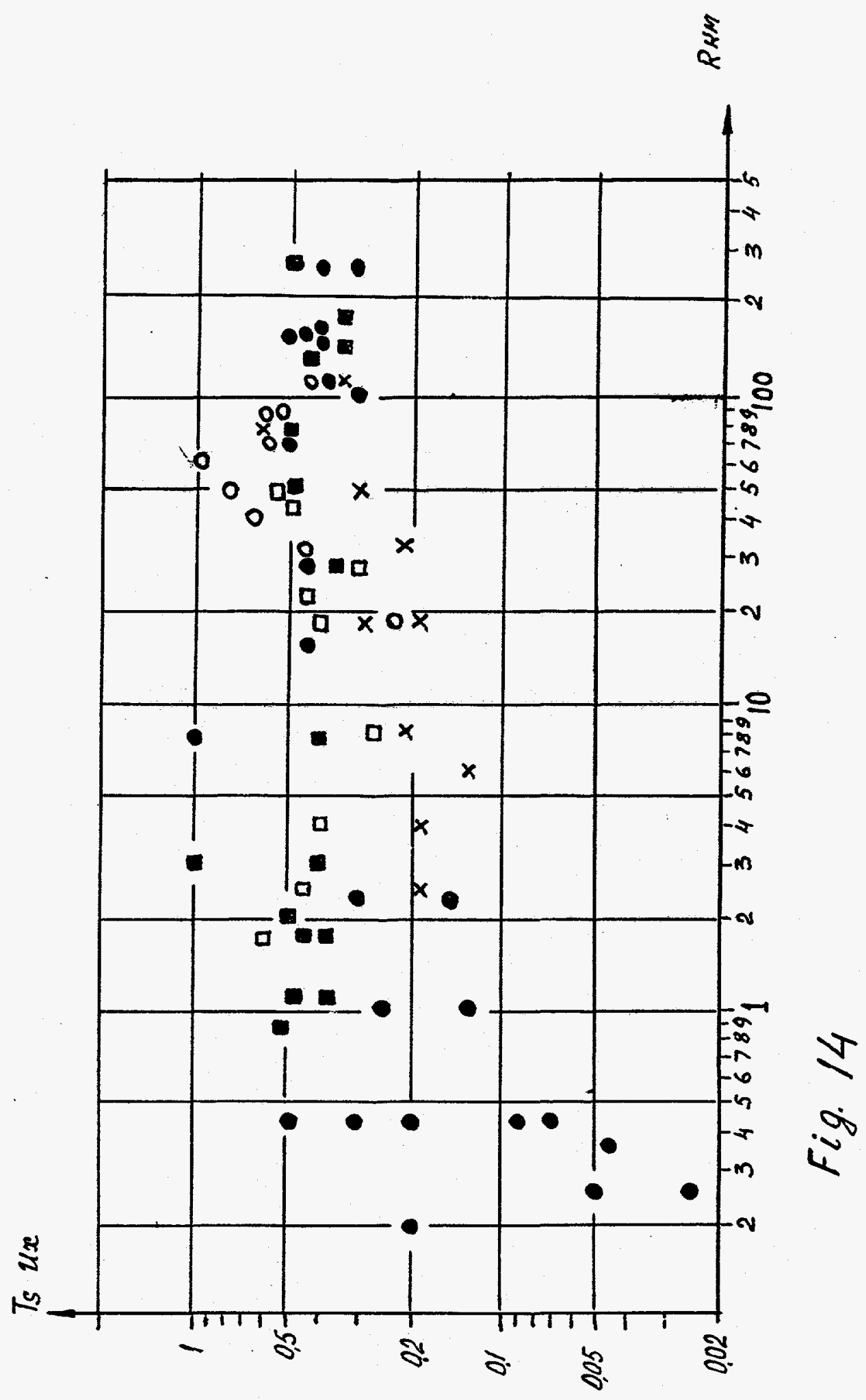




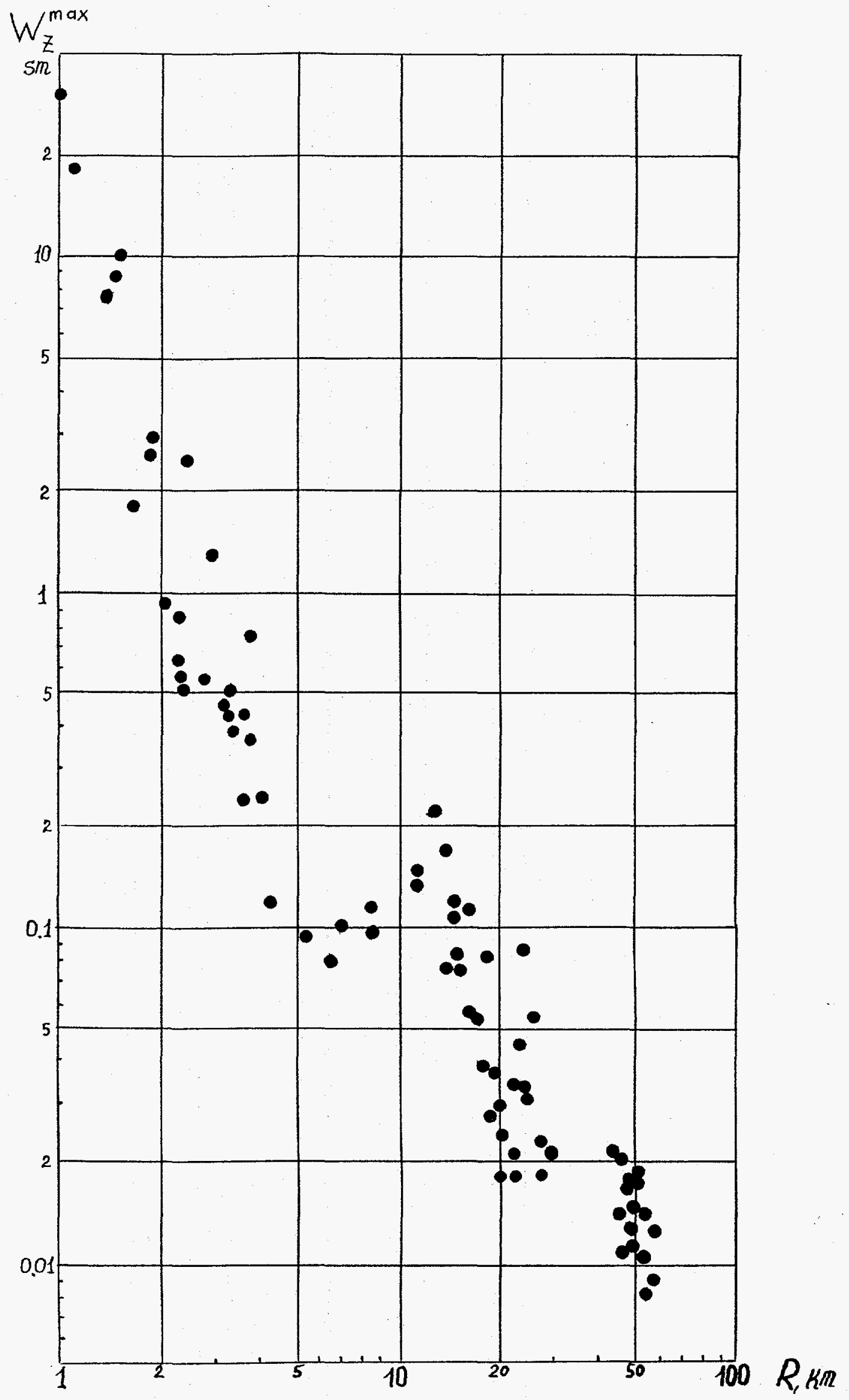

Fig. 15 

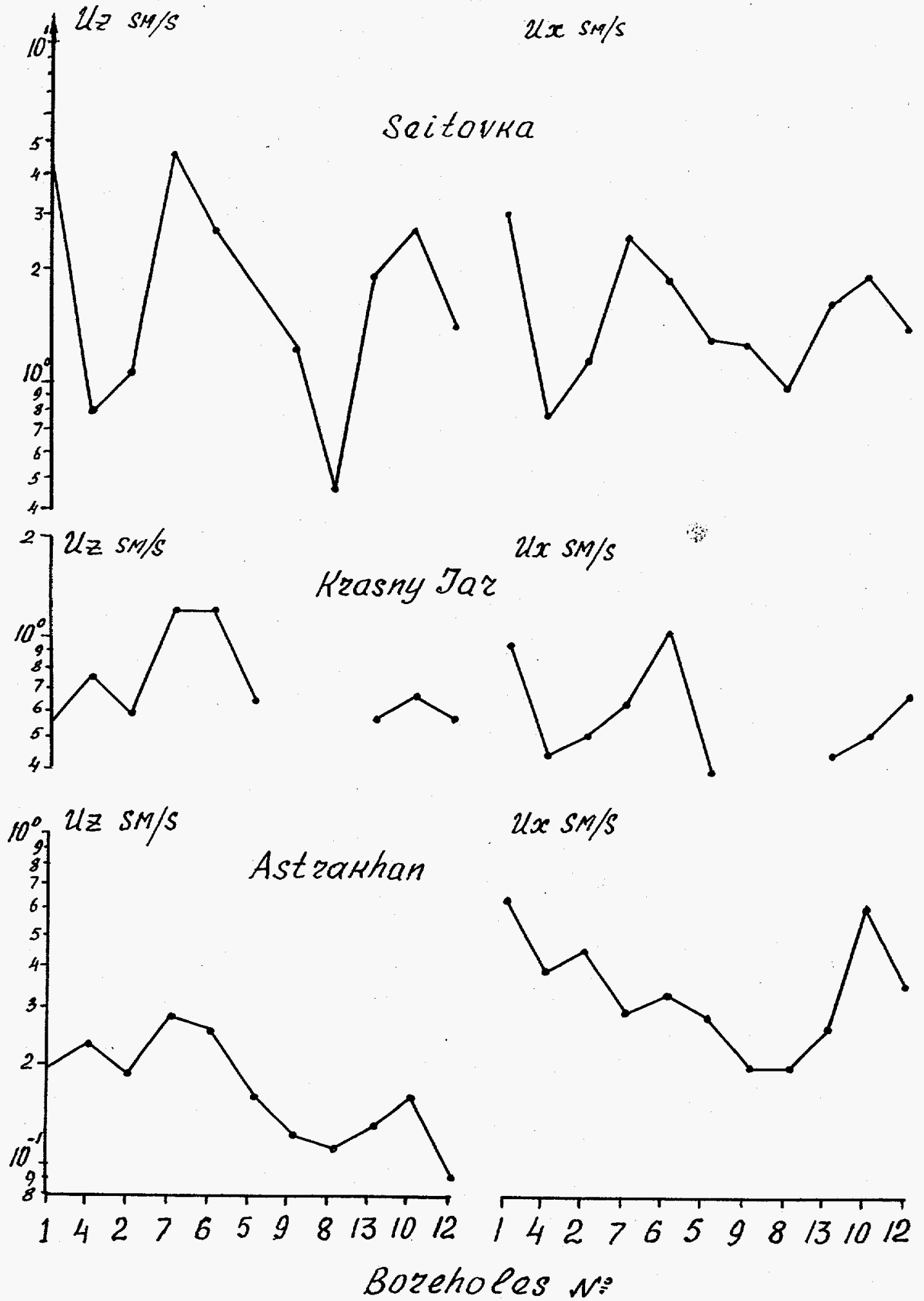

Fig 16 

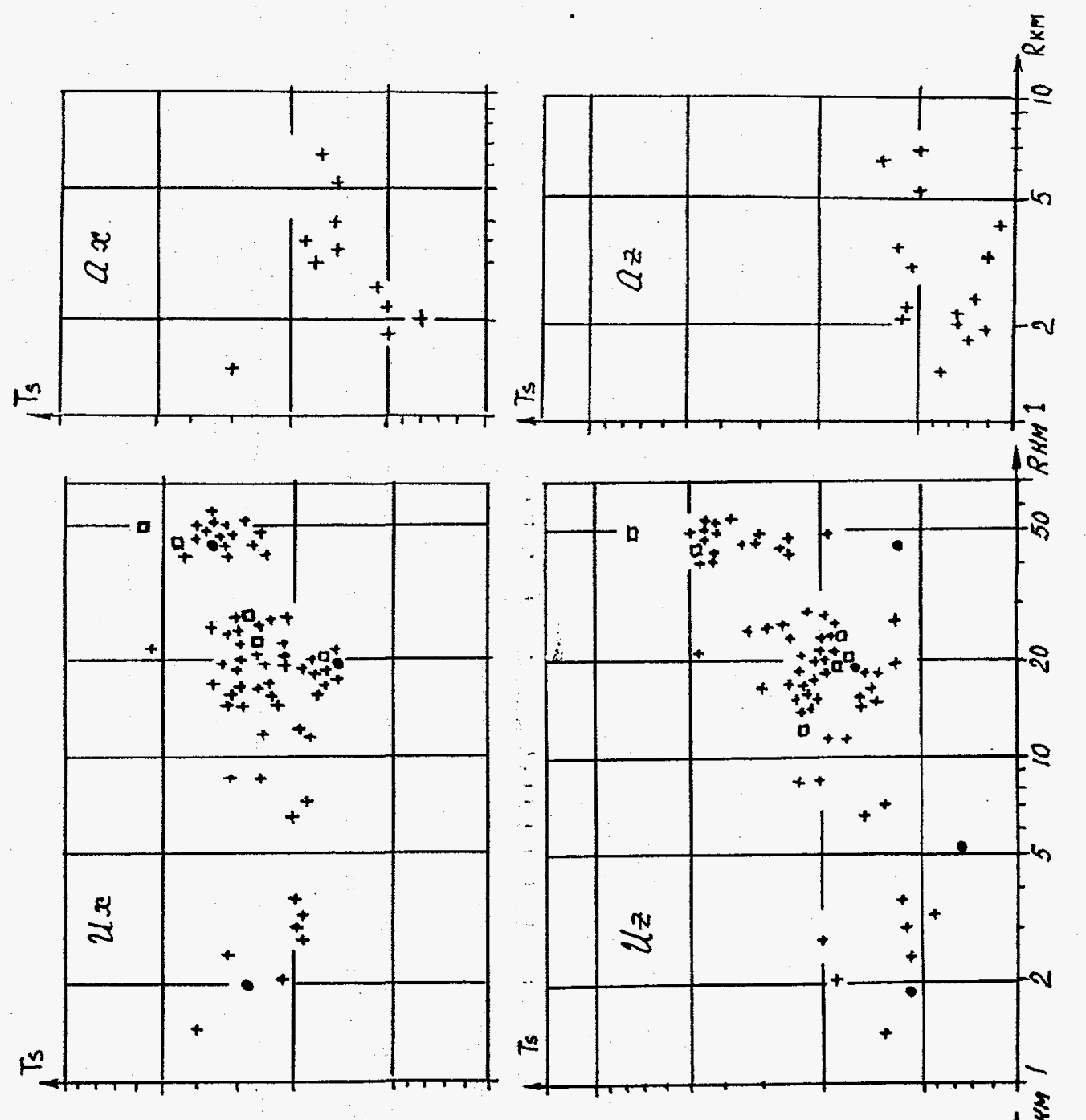

mos 340

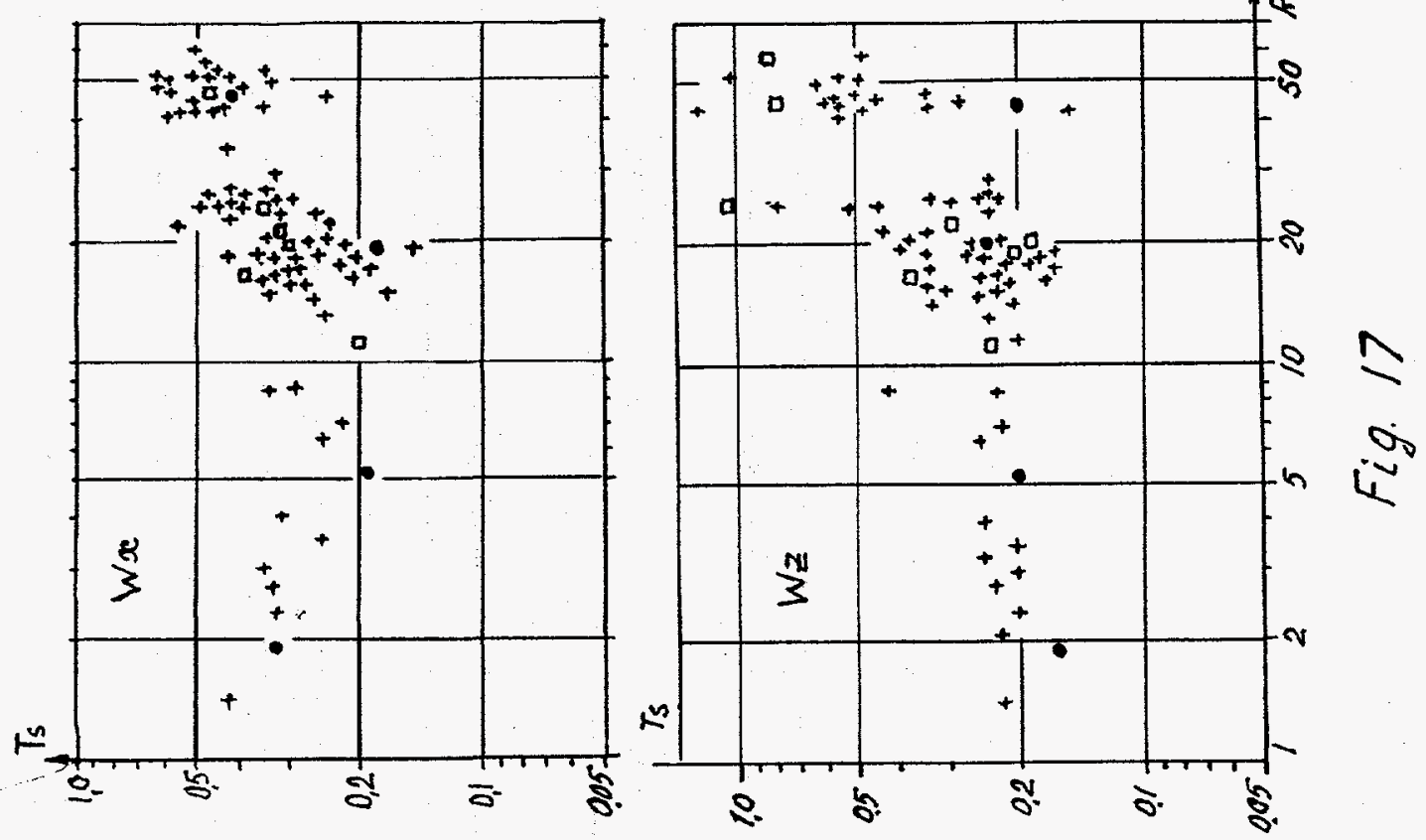



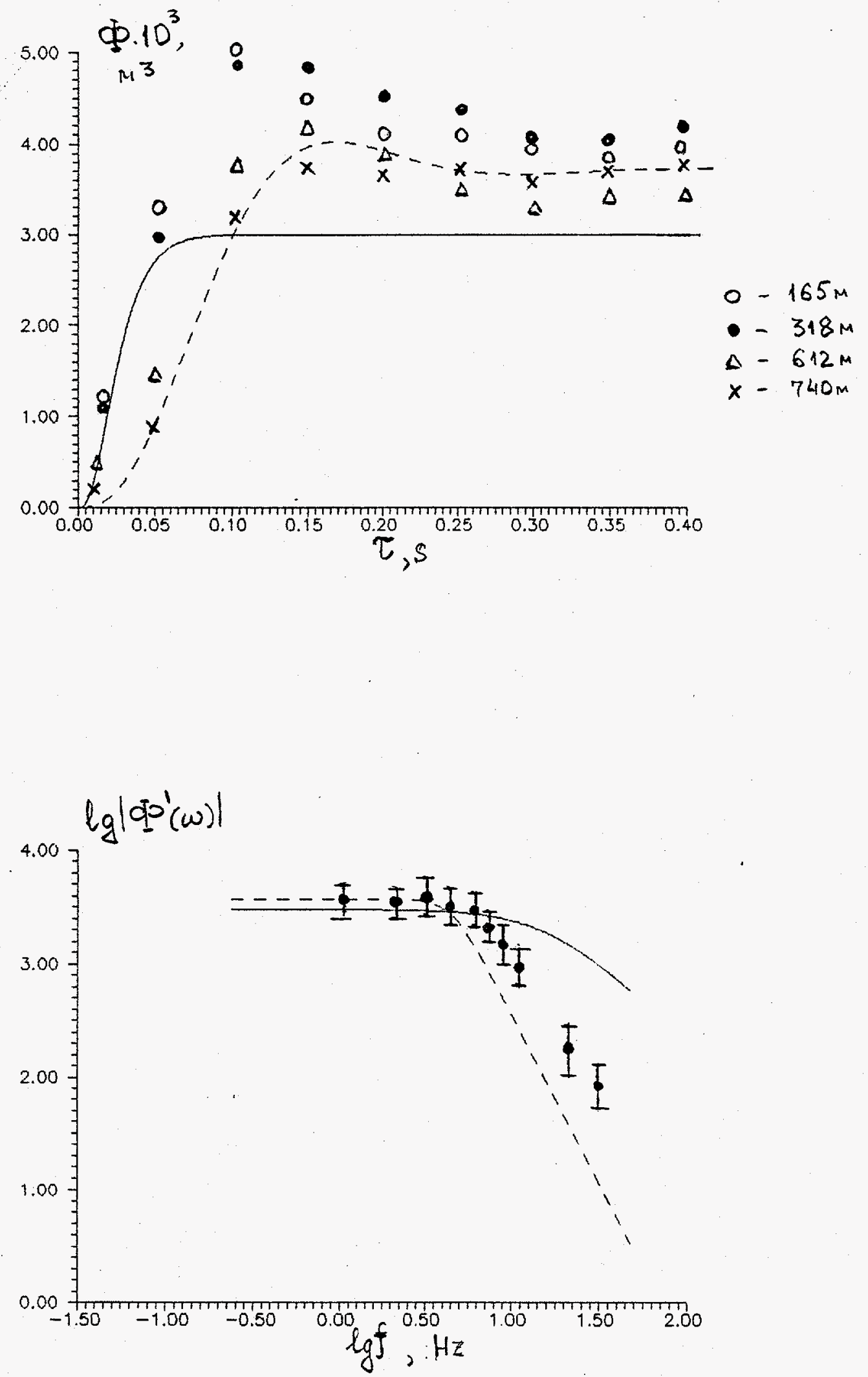

Fig 18 


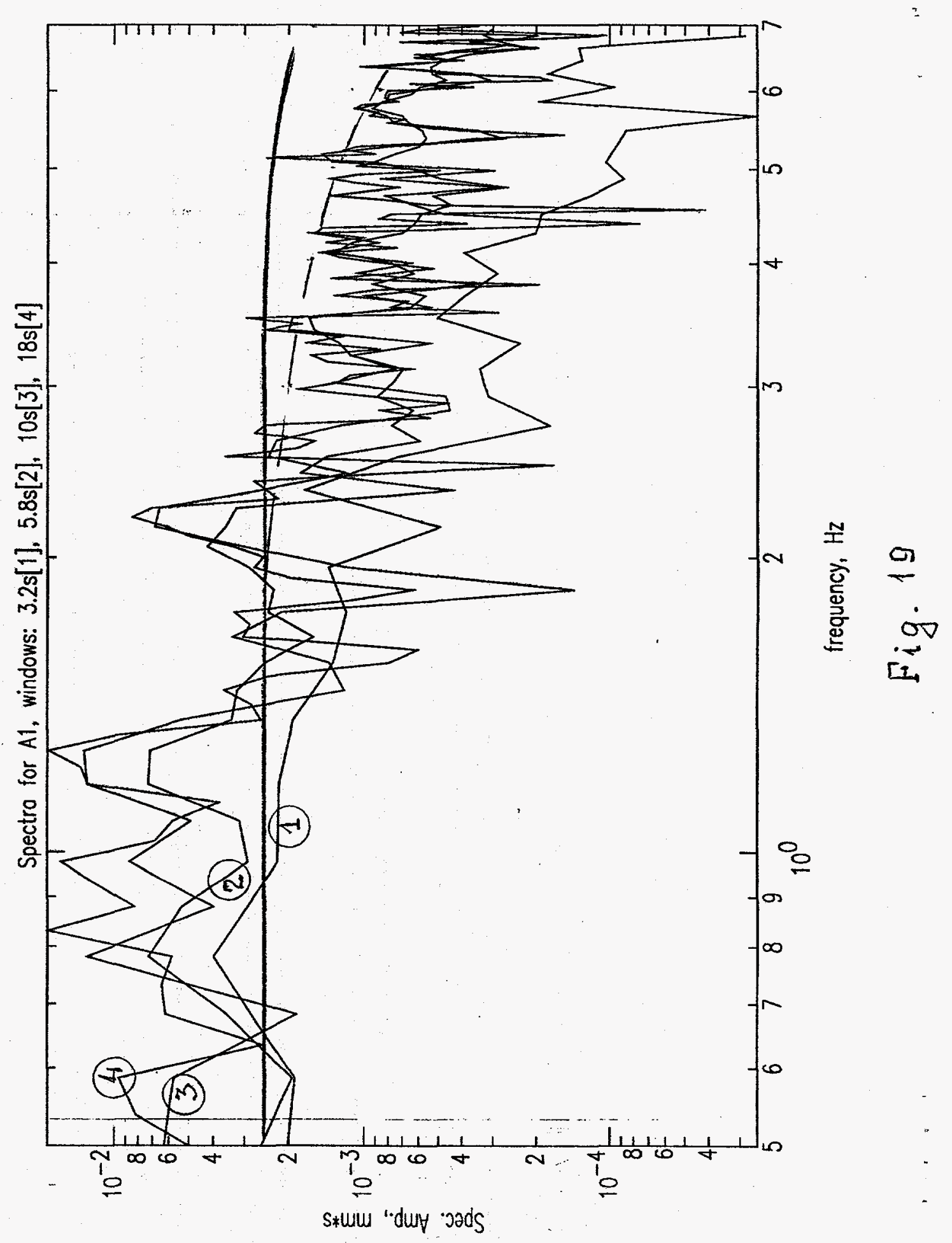




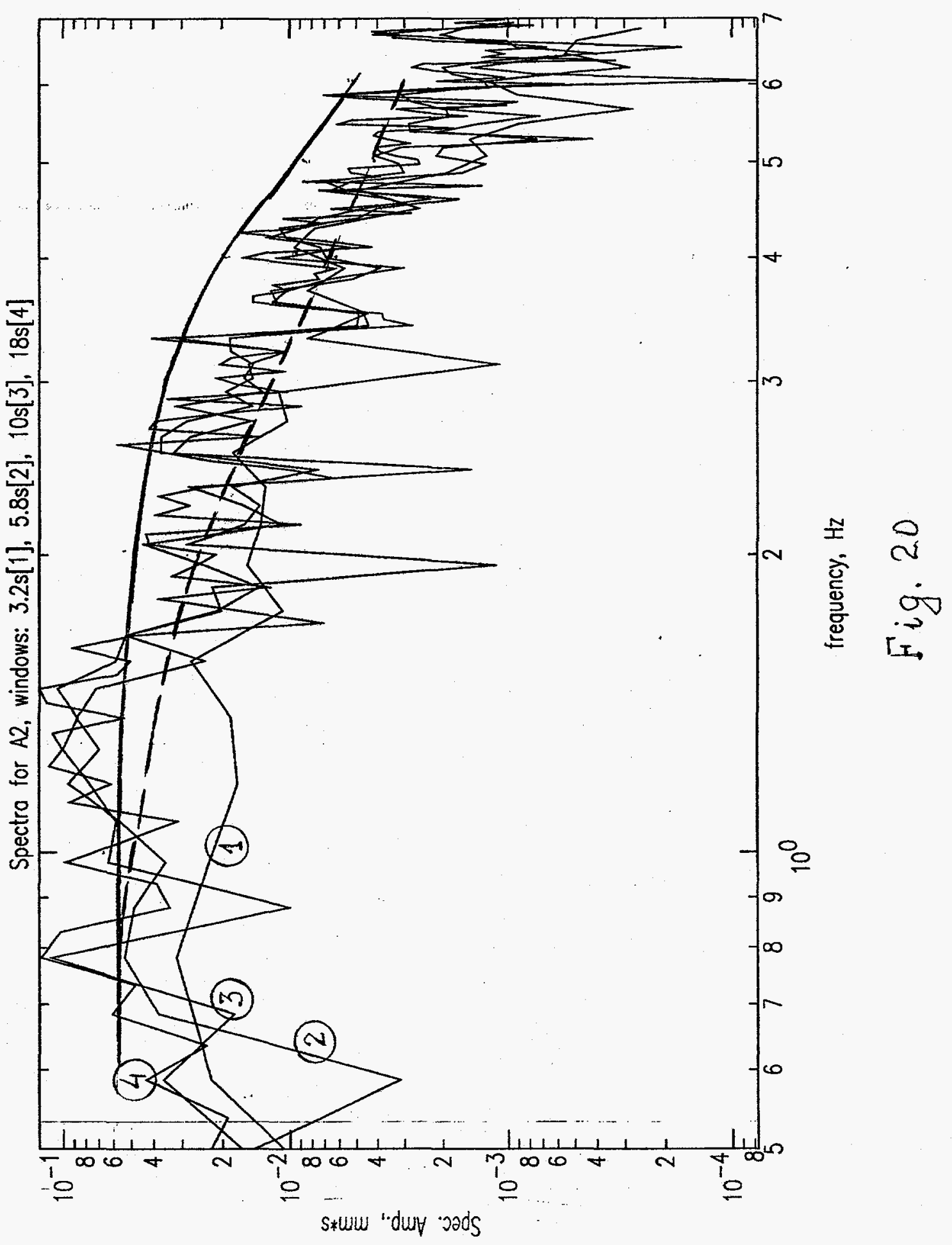




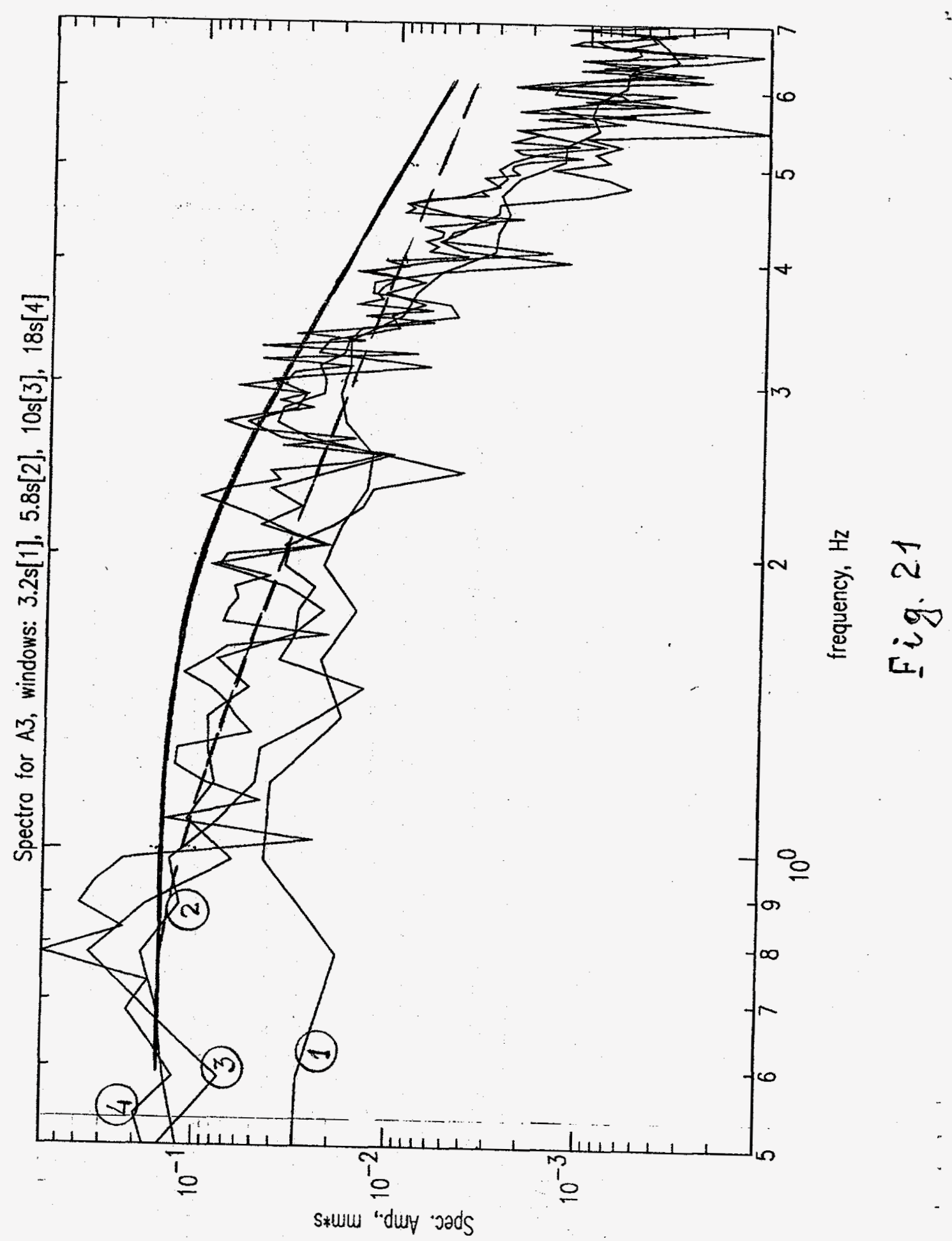




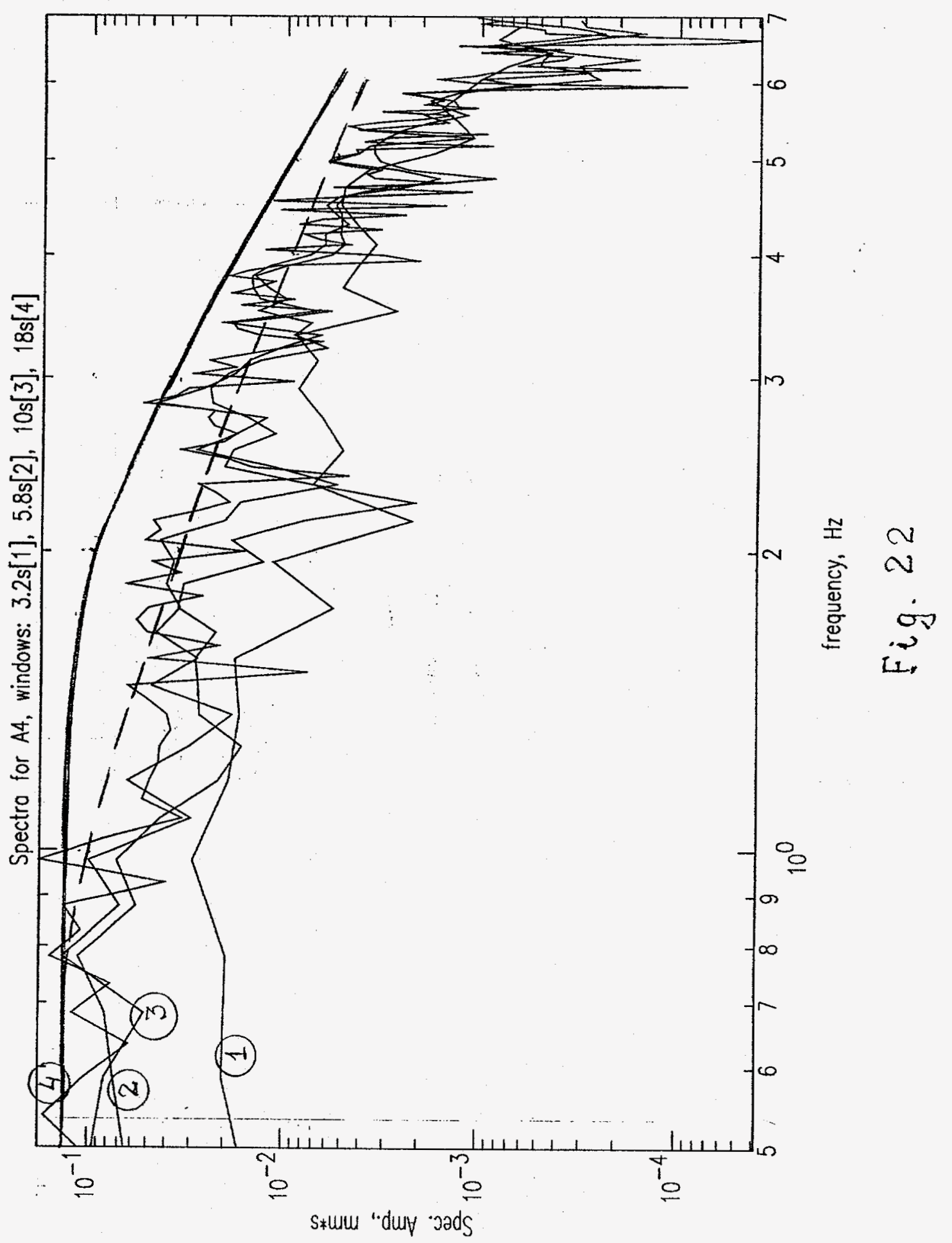




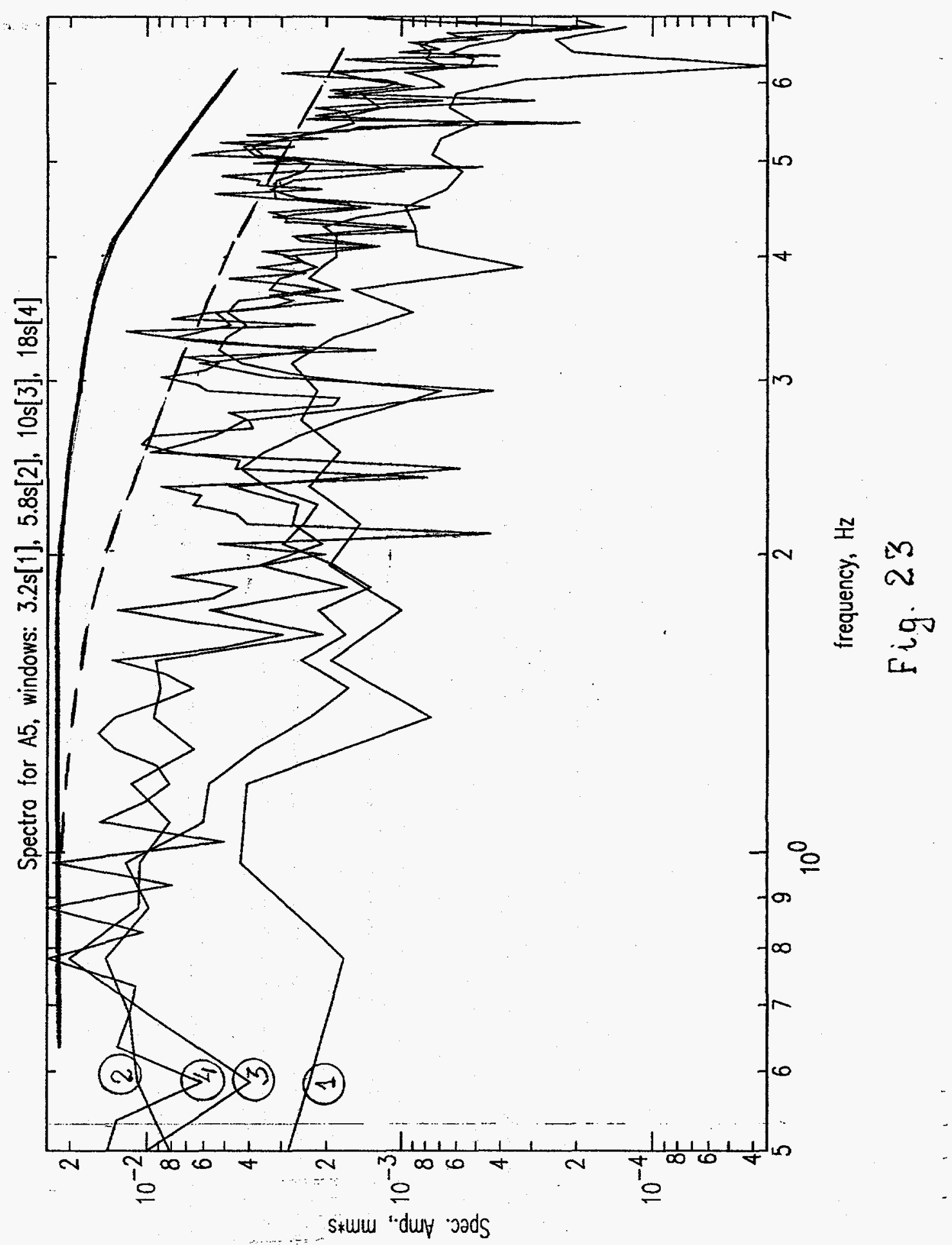




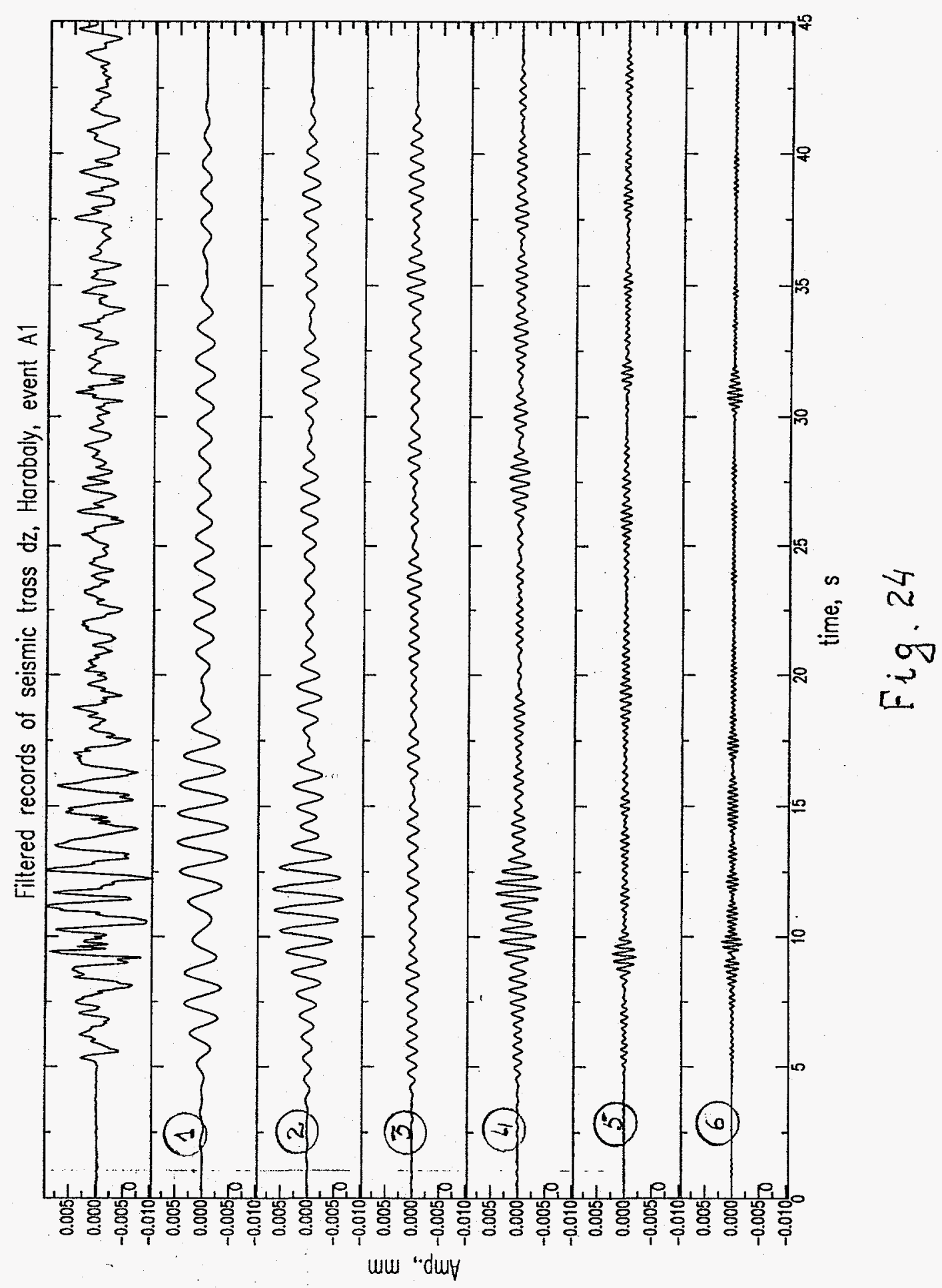


sz B ?

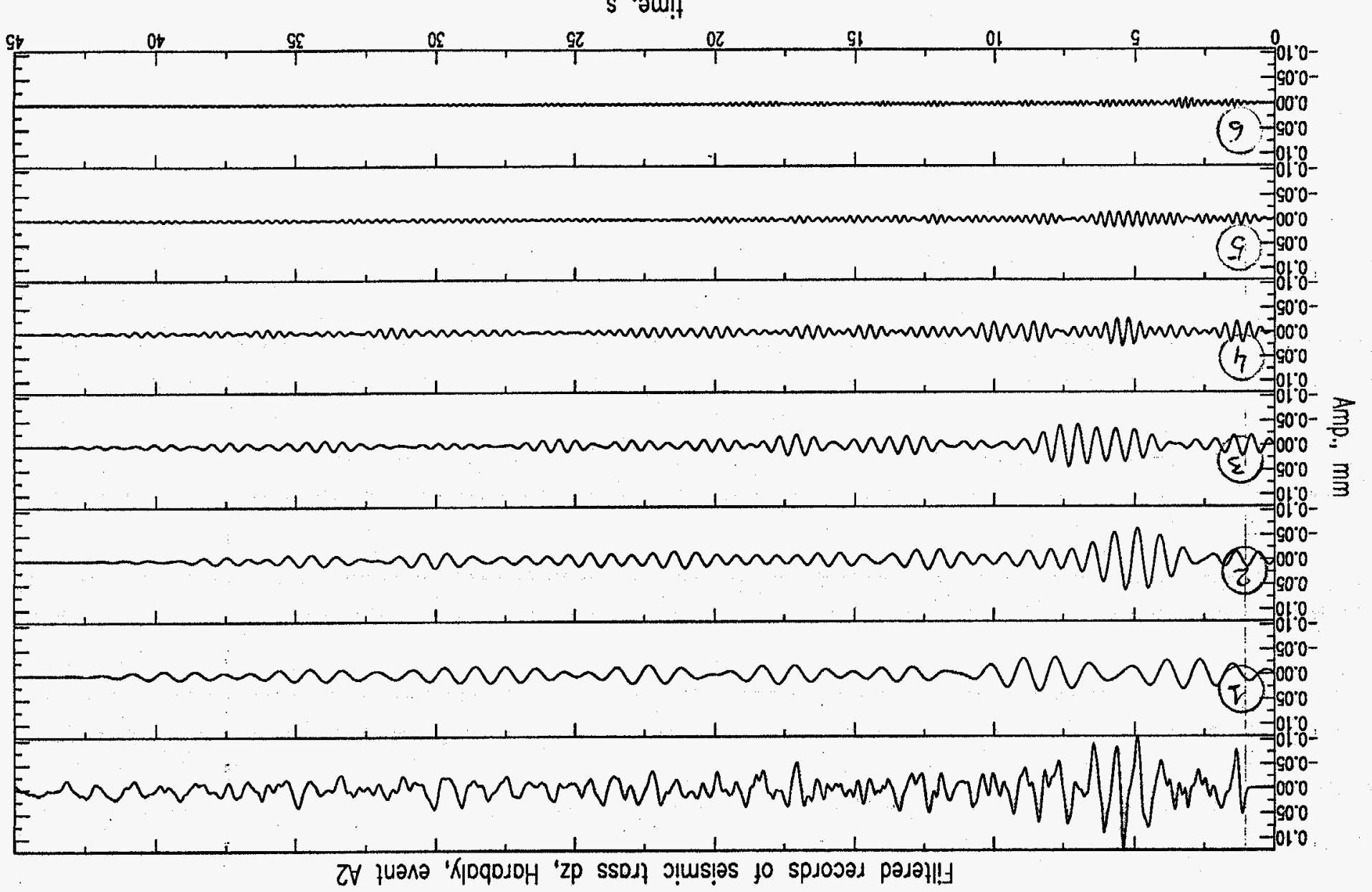


Filtered records of seismic trass $d z$, Horaboly, event $A 3$

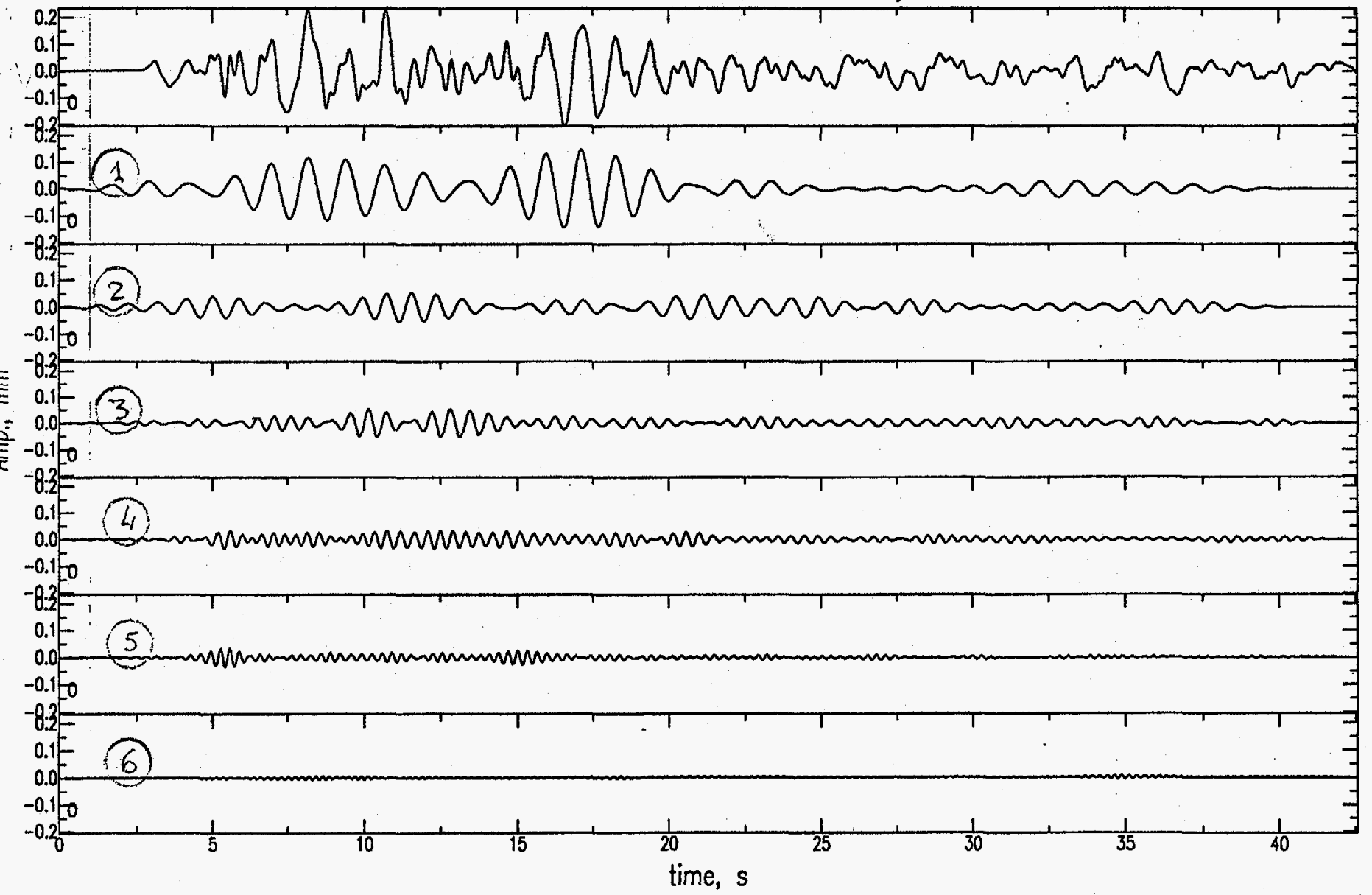

Fig.26 


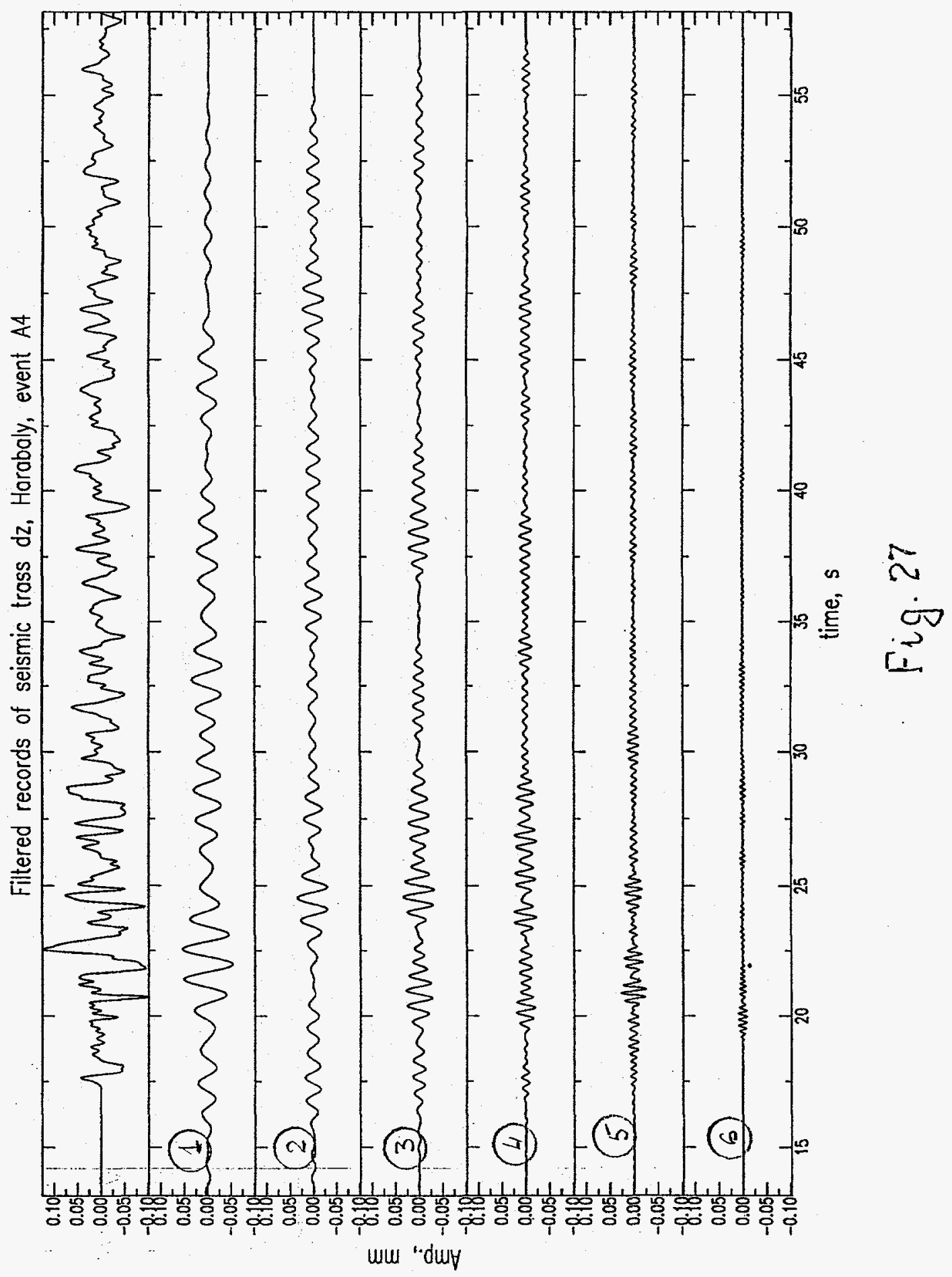


Filtered records of seismic tross dz, Horabaly, event A5

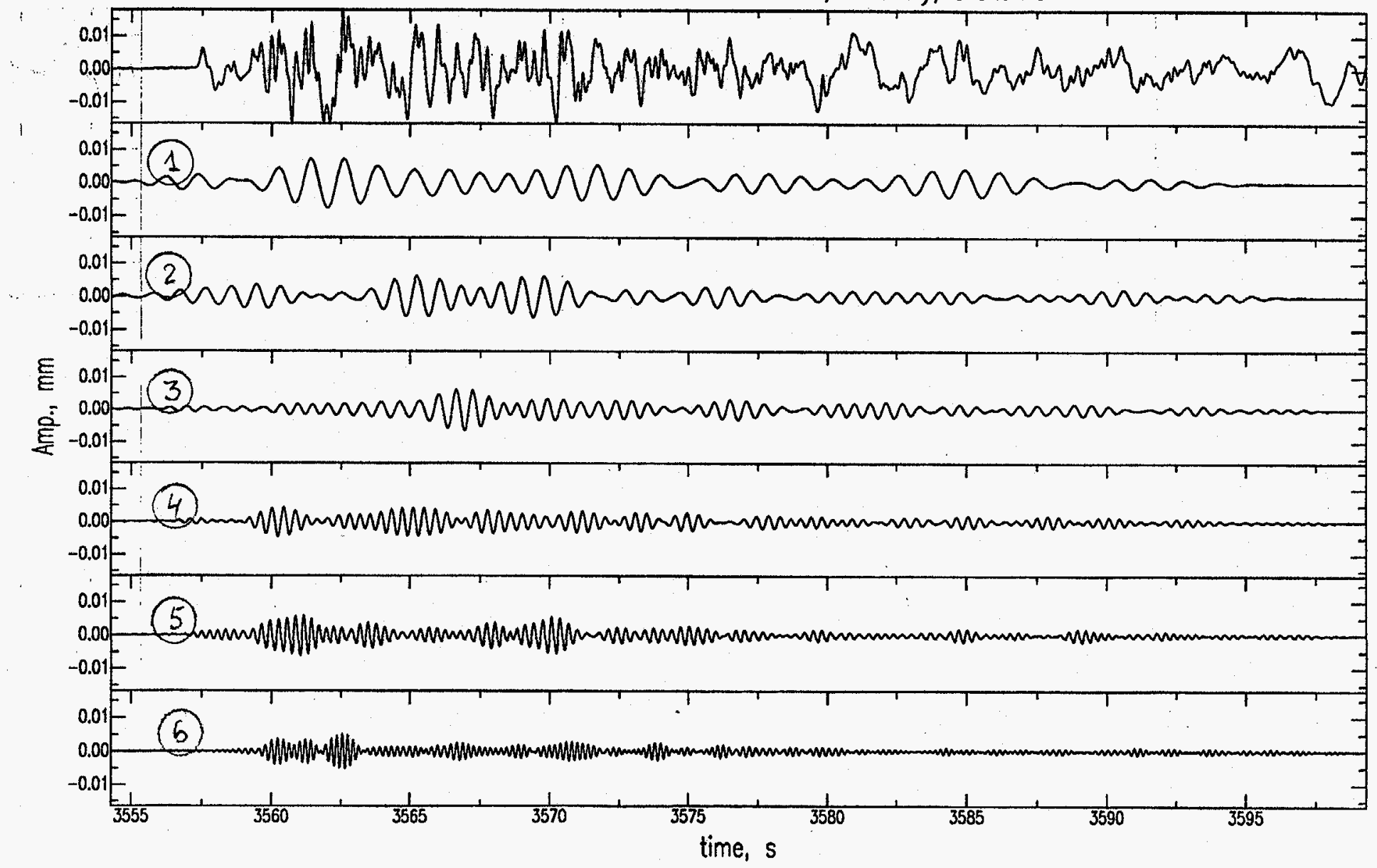

Eig. 28 


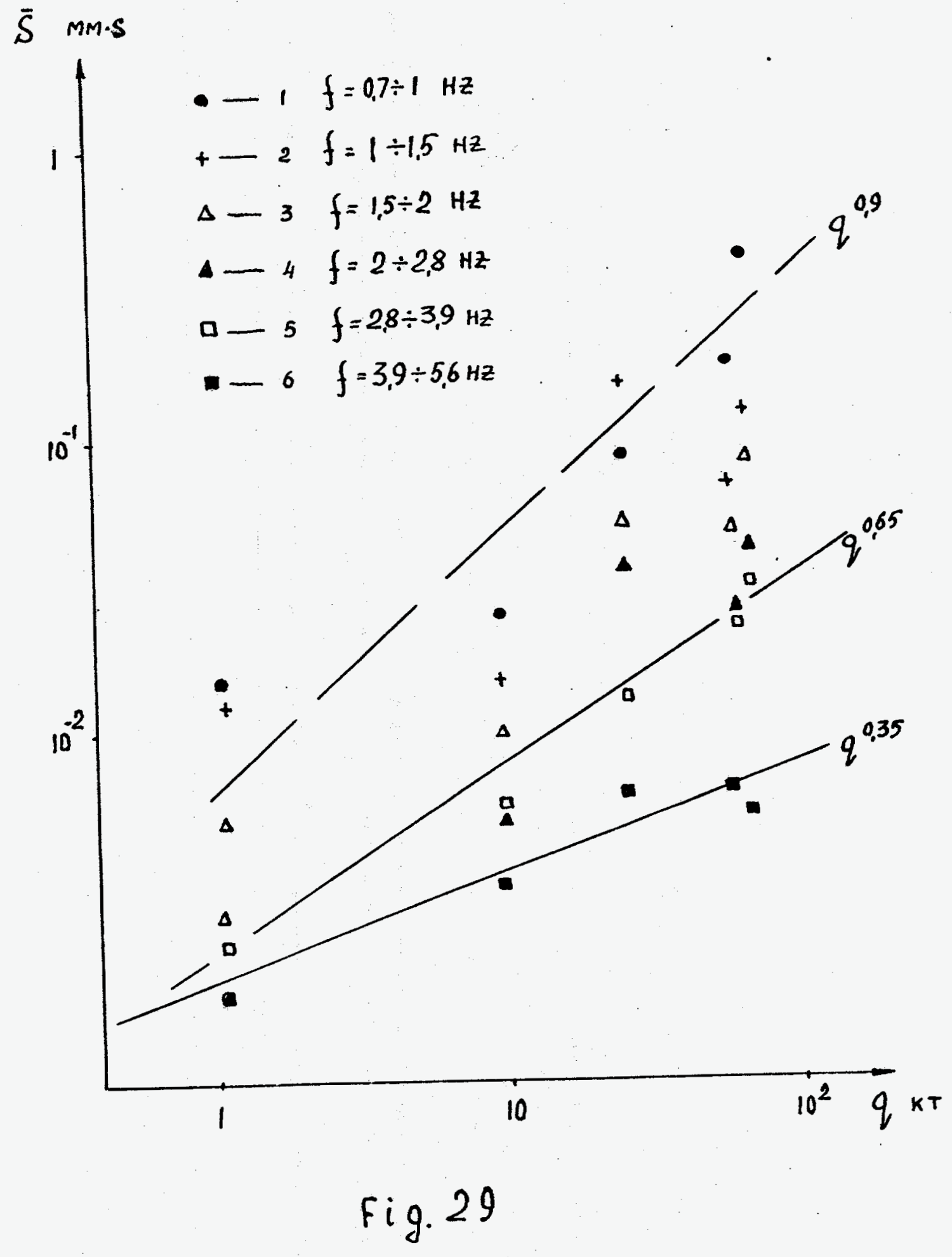


mas

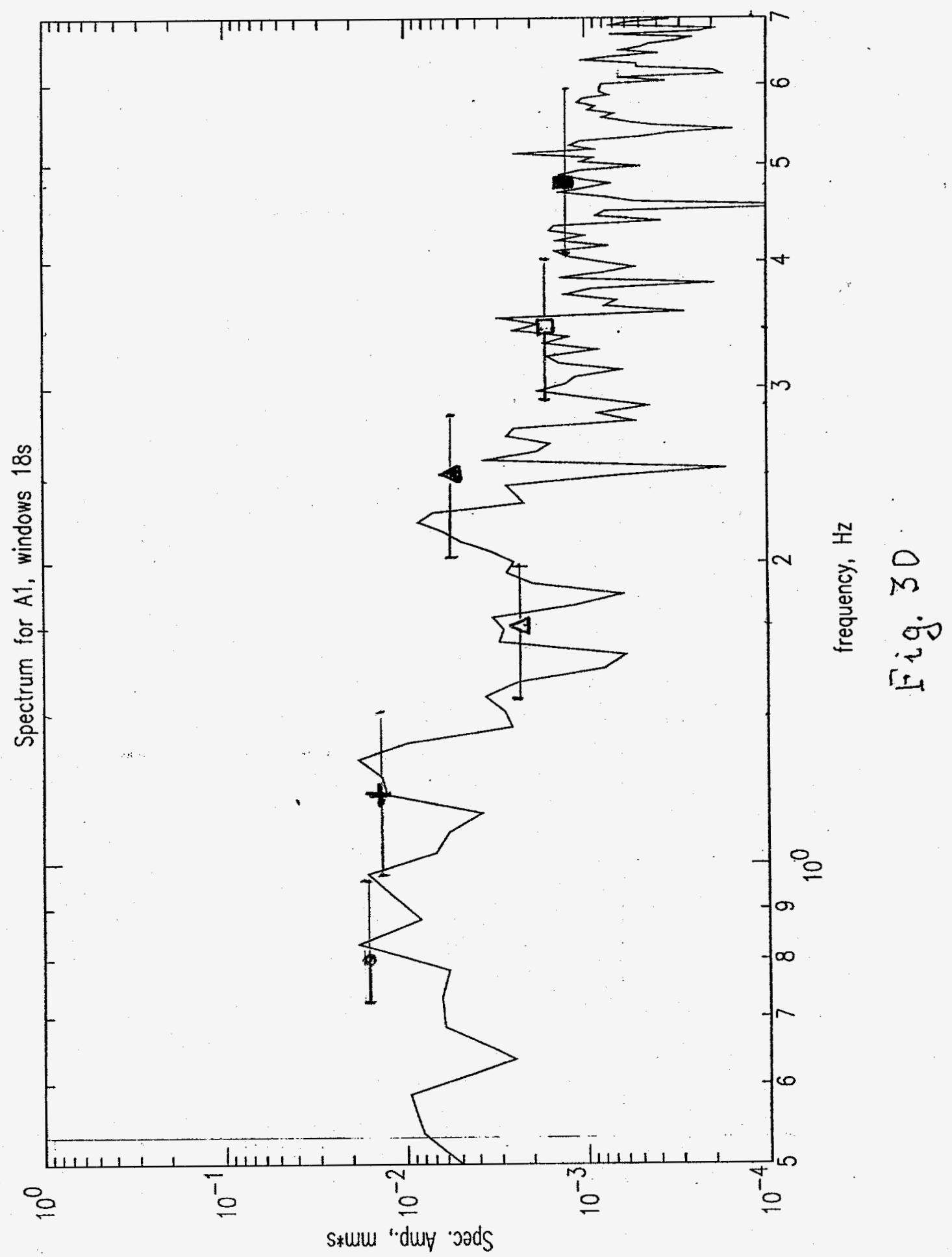




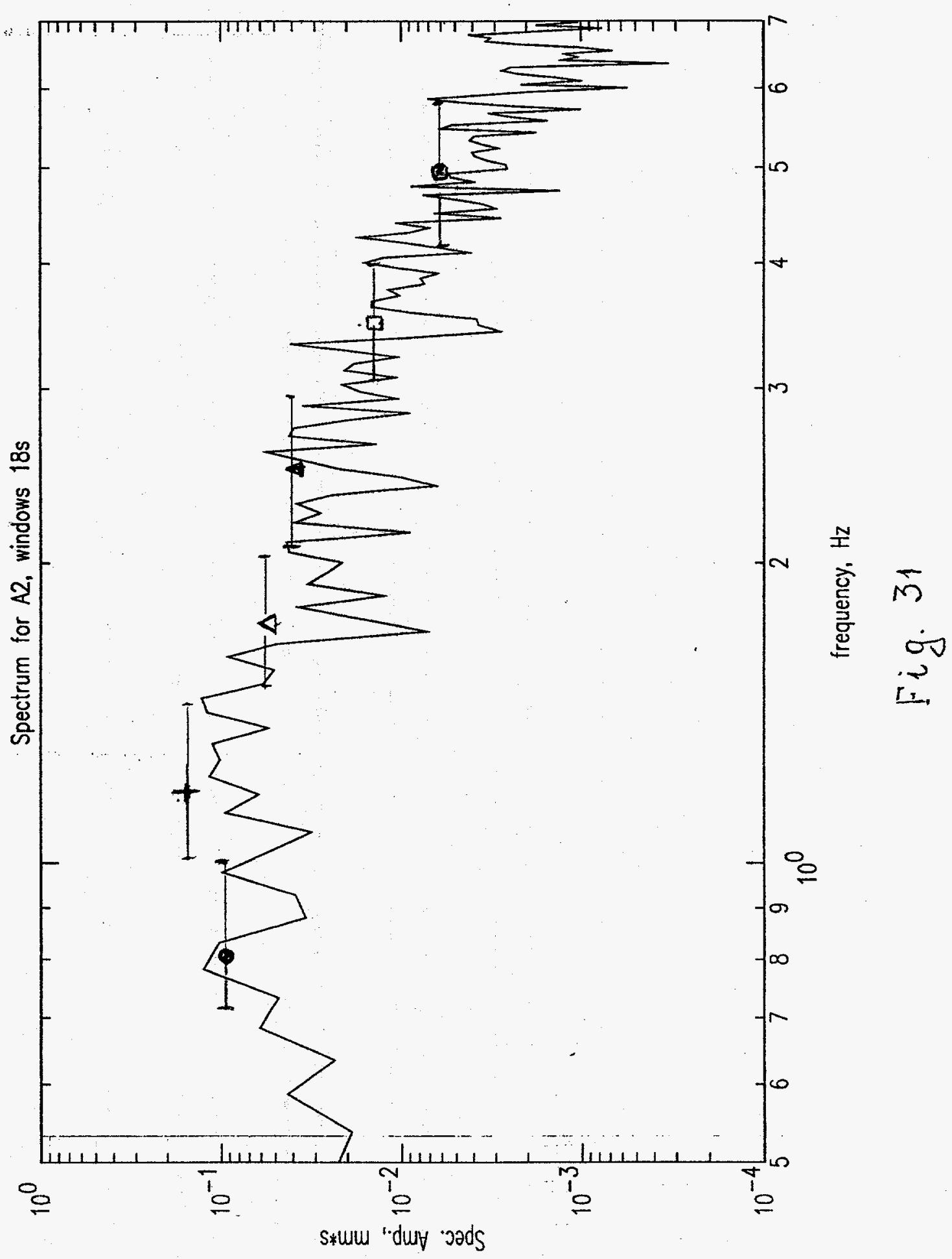




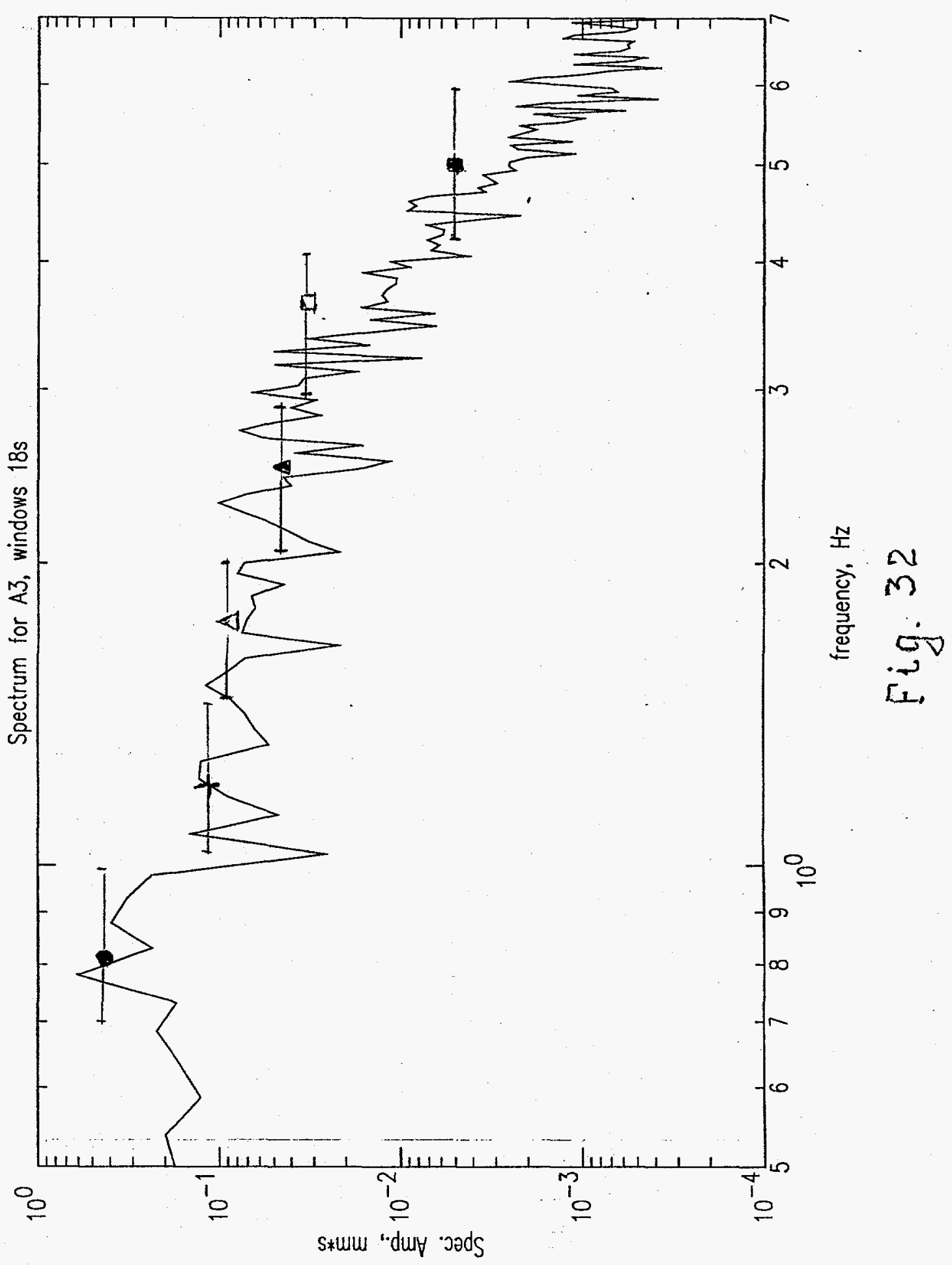




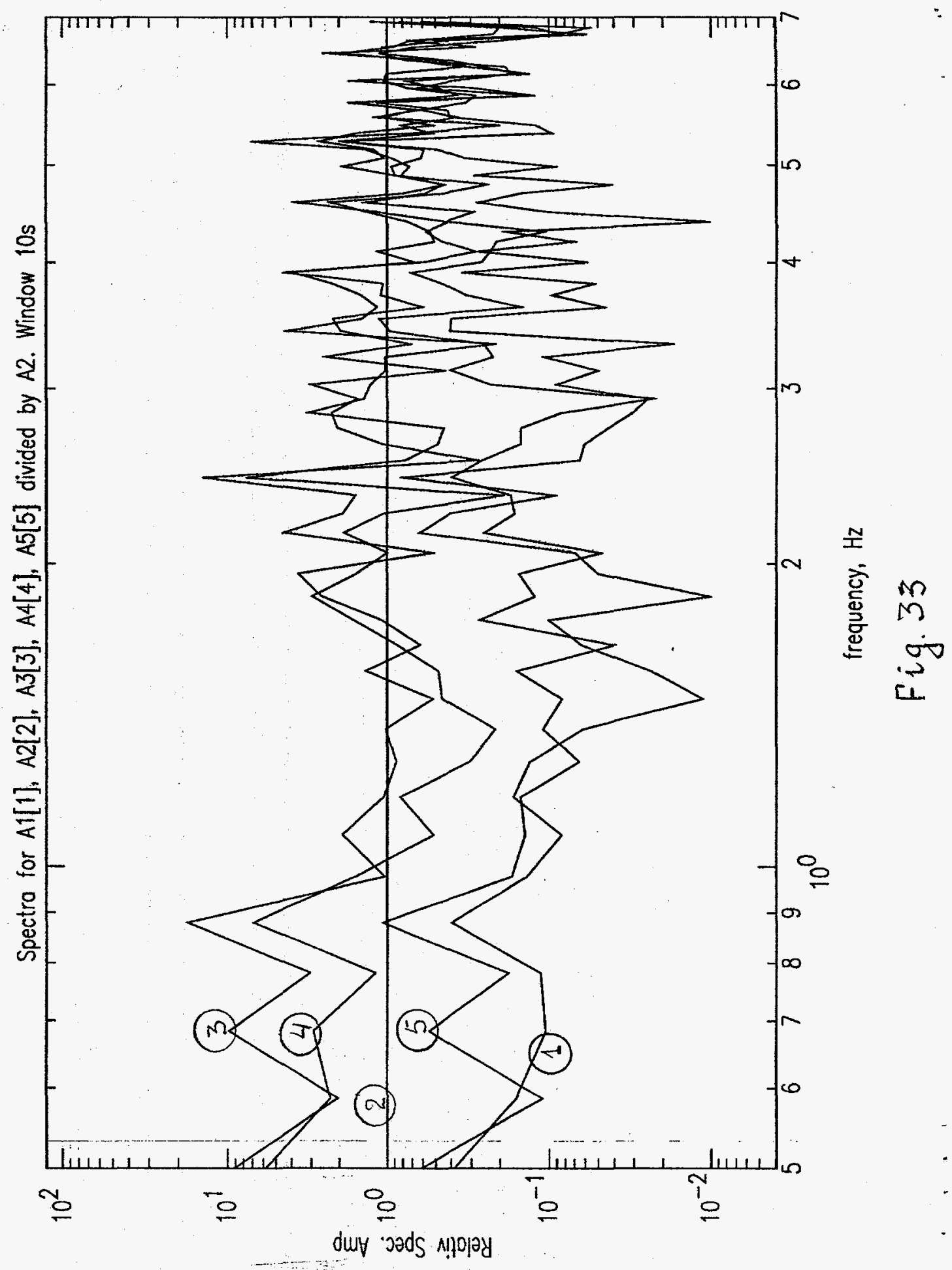




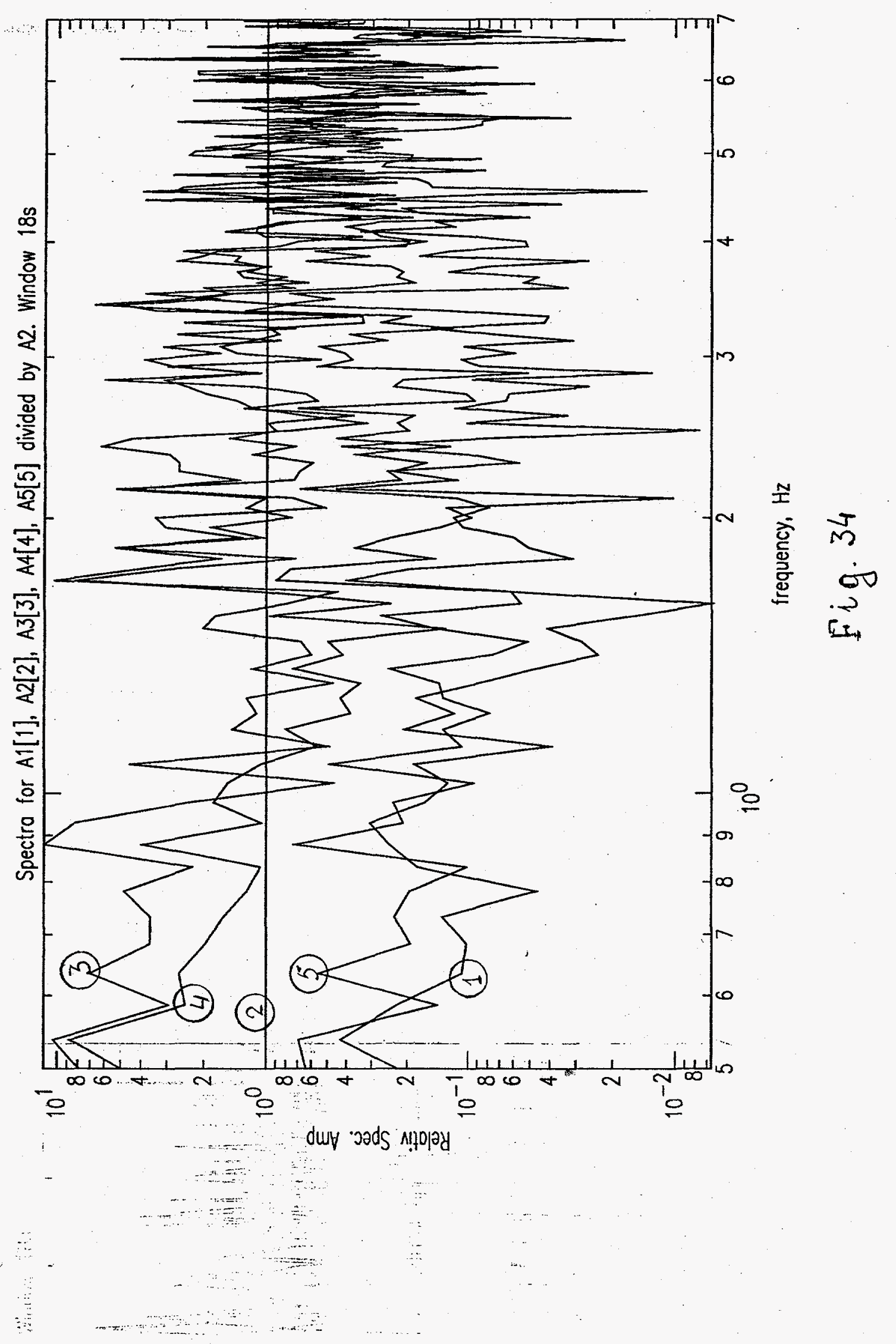


34946

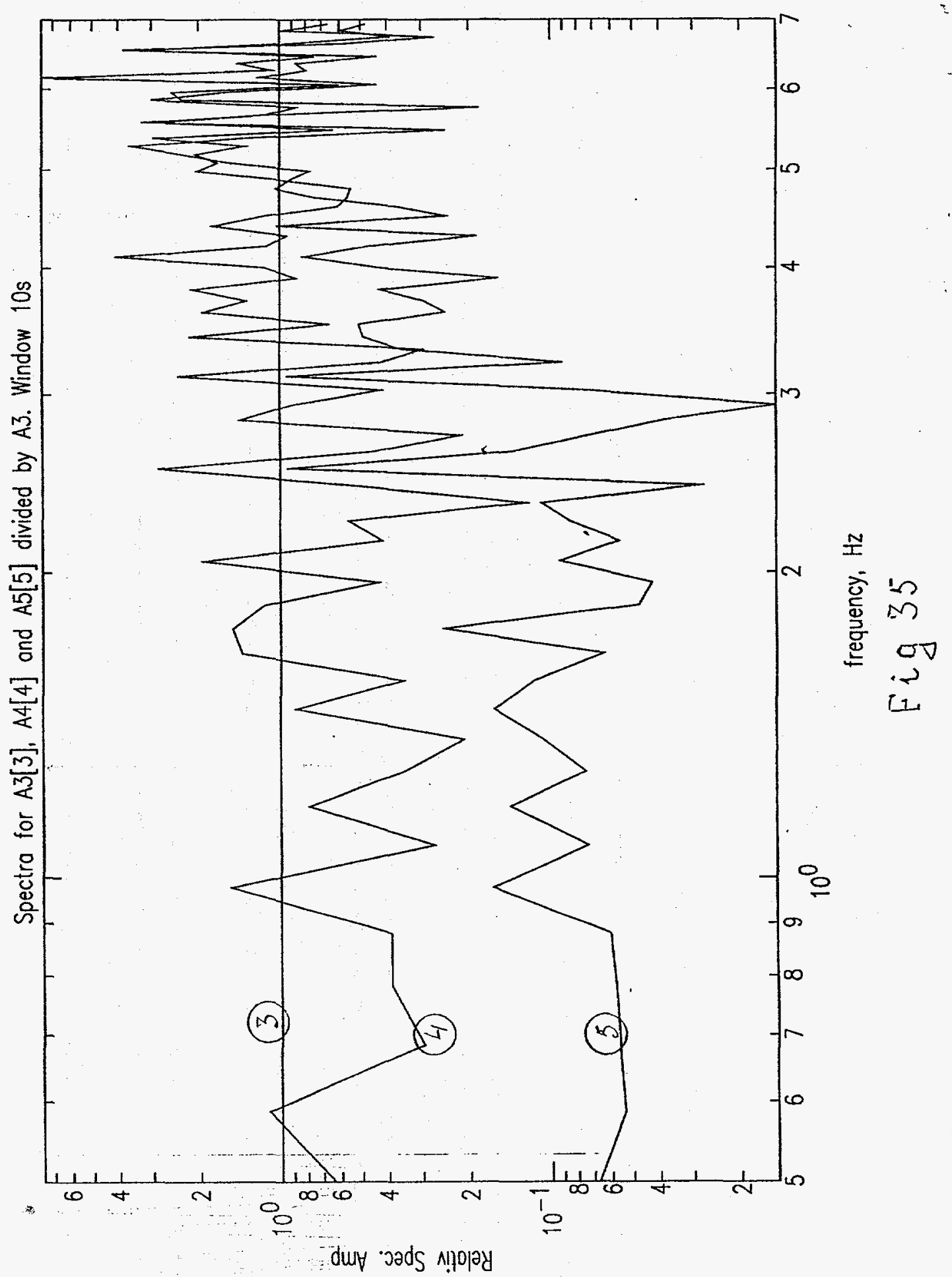



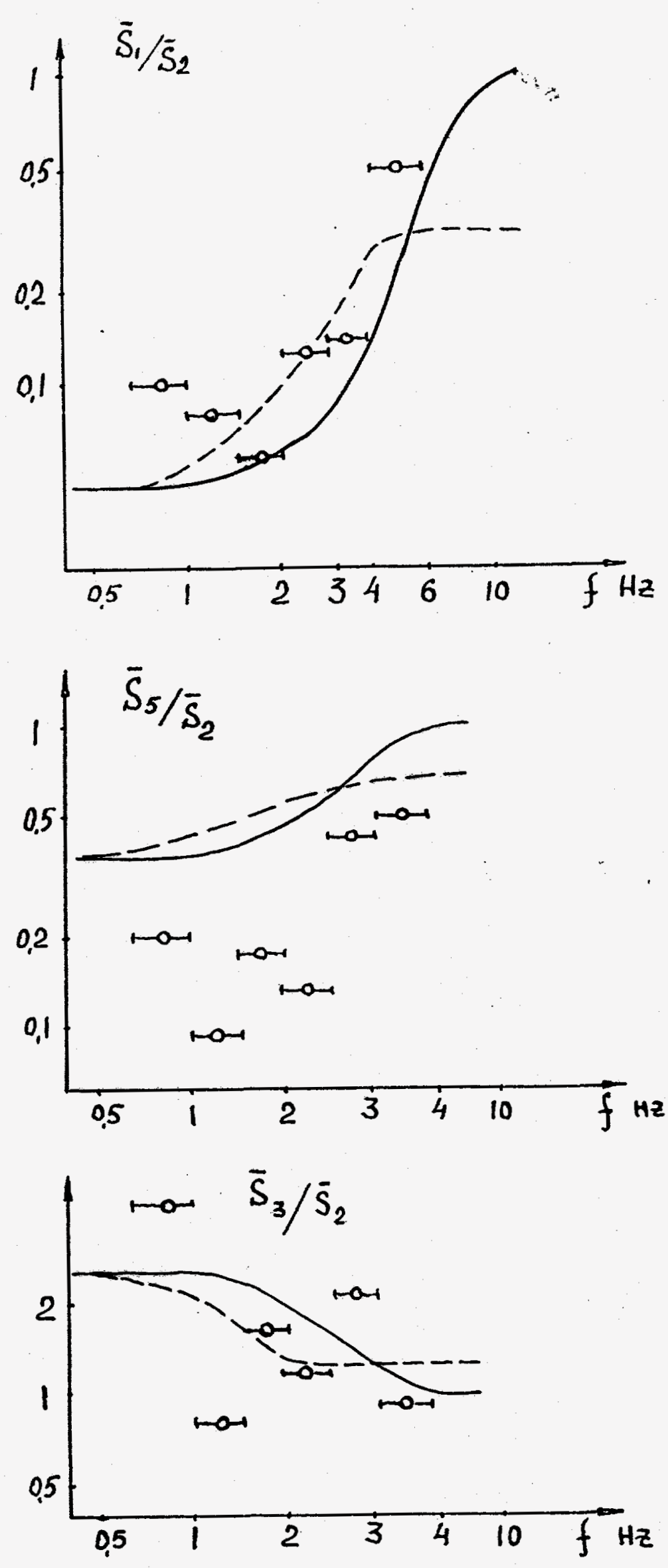

Fig. 36 


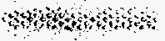

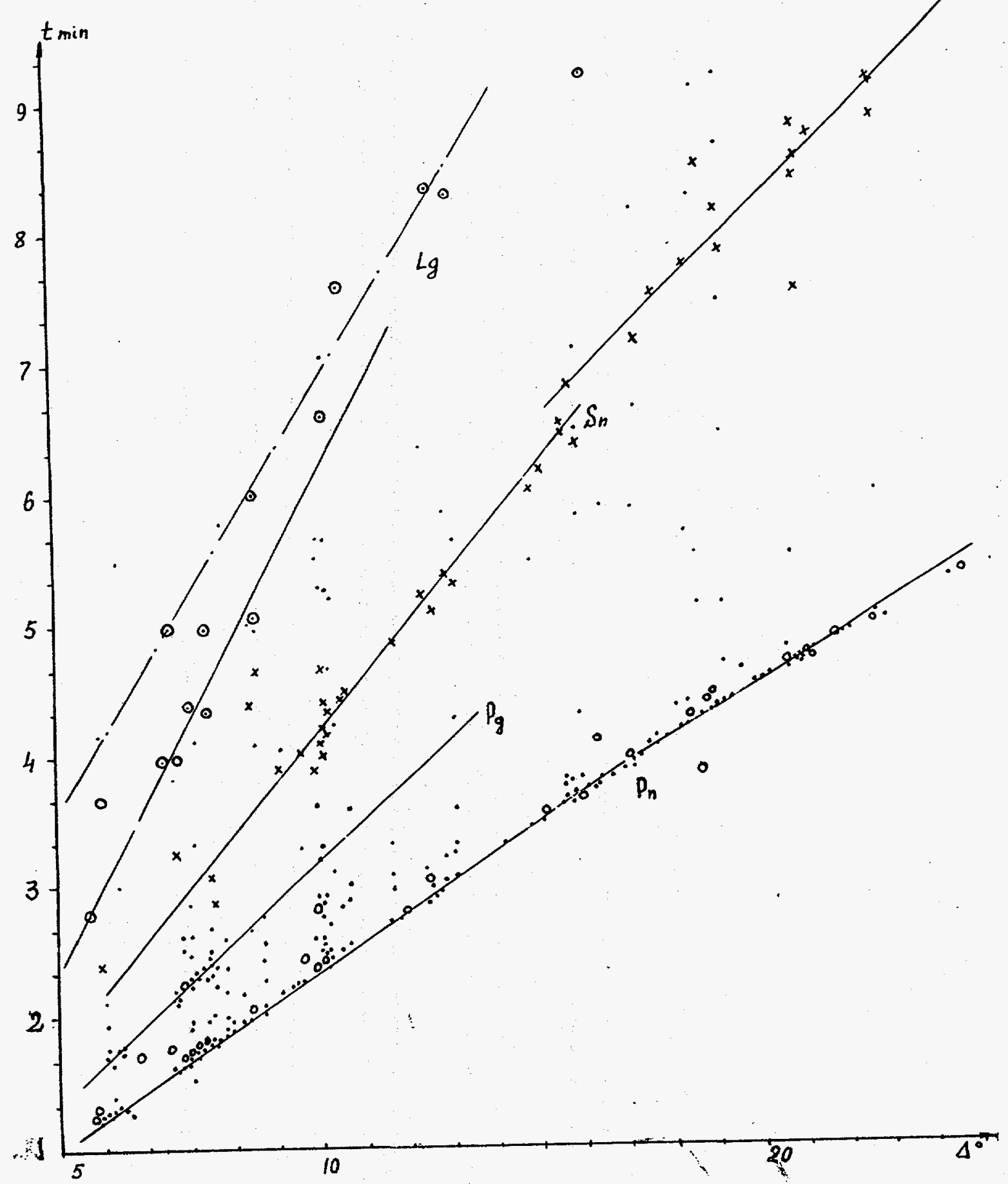

Fig. 37 


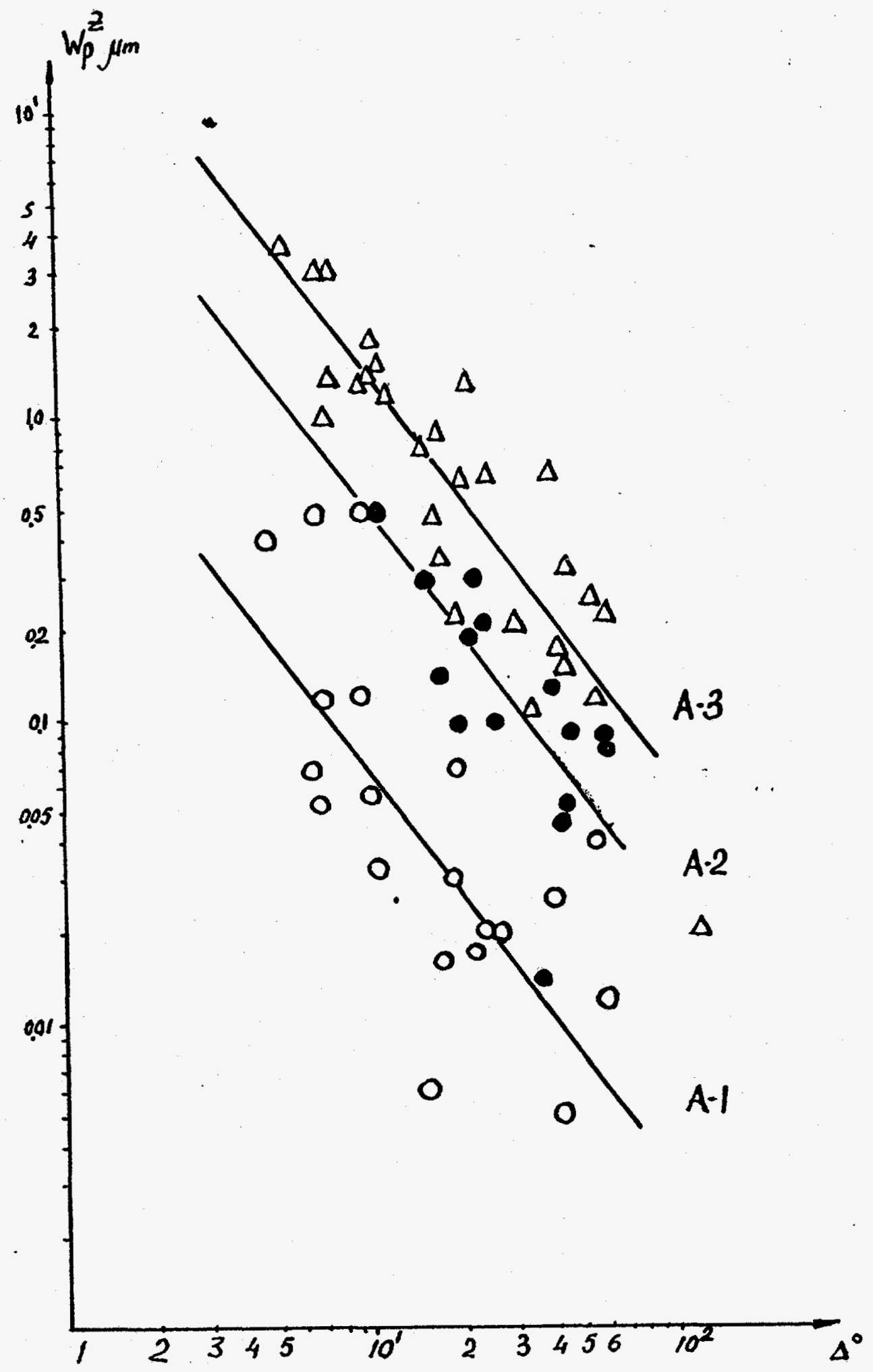

Fig. 38 


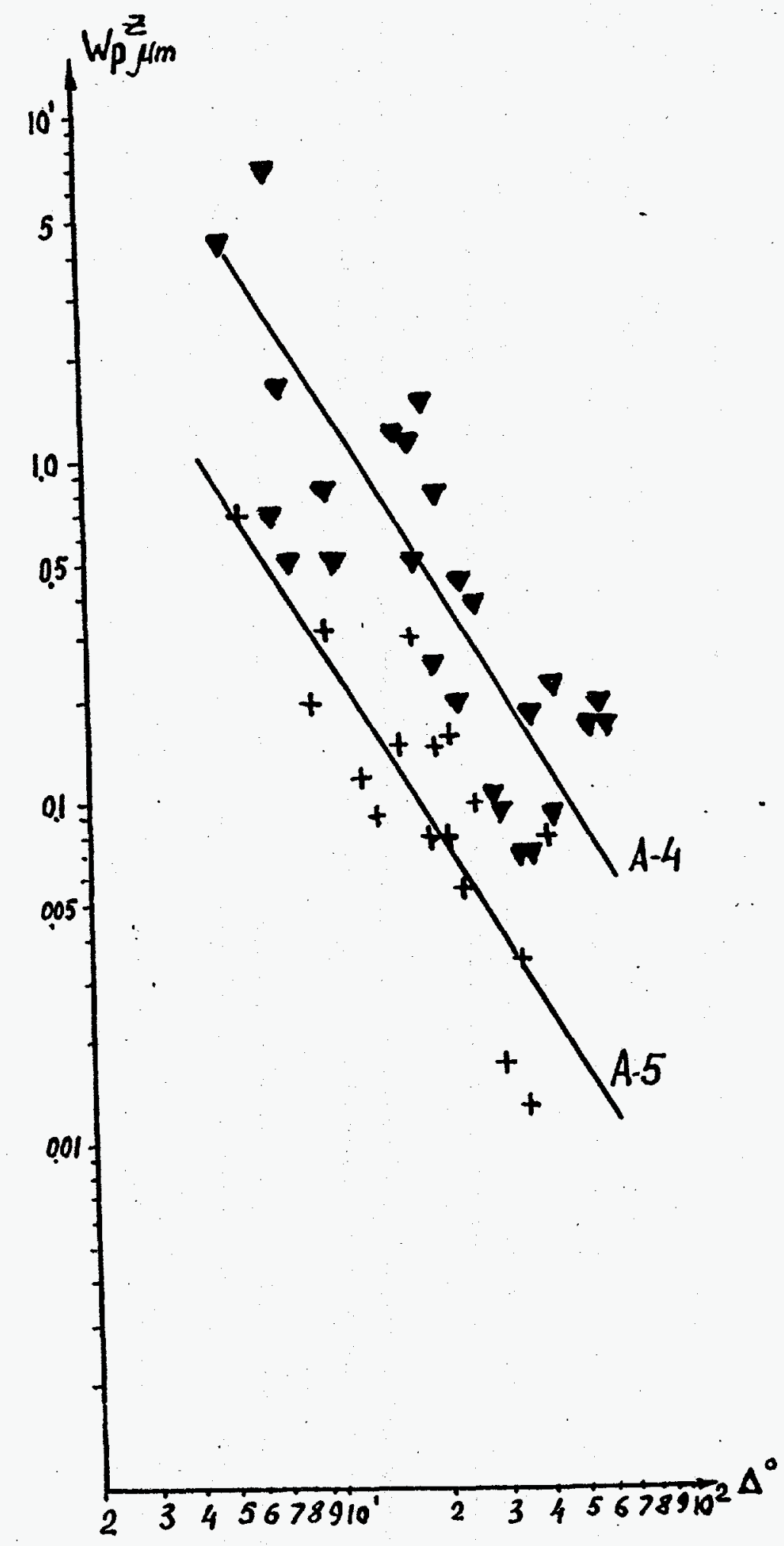

Fig. 39 


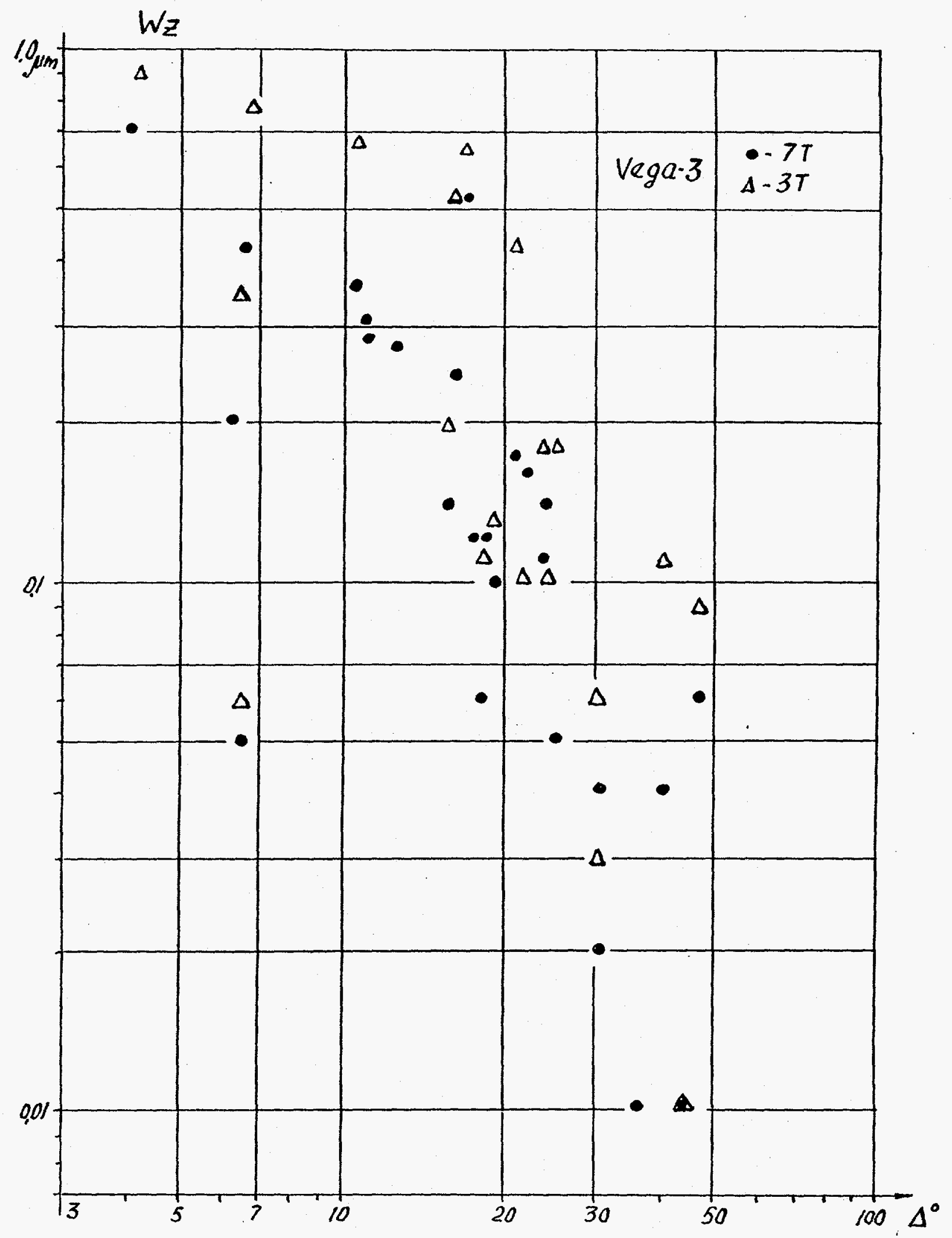

Fig. 40 


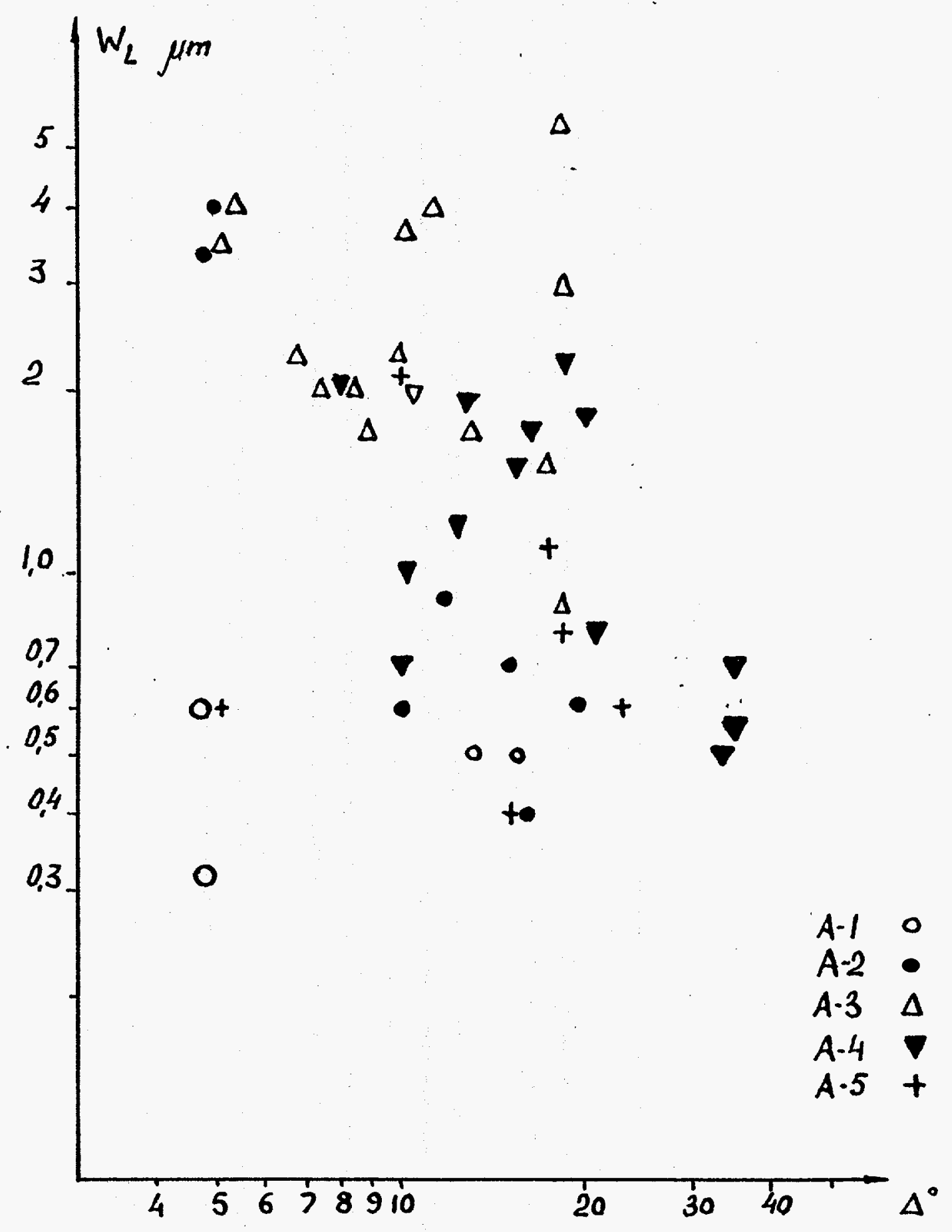

Fig. 41 


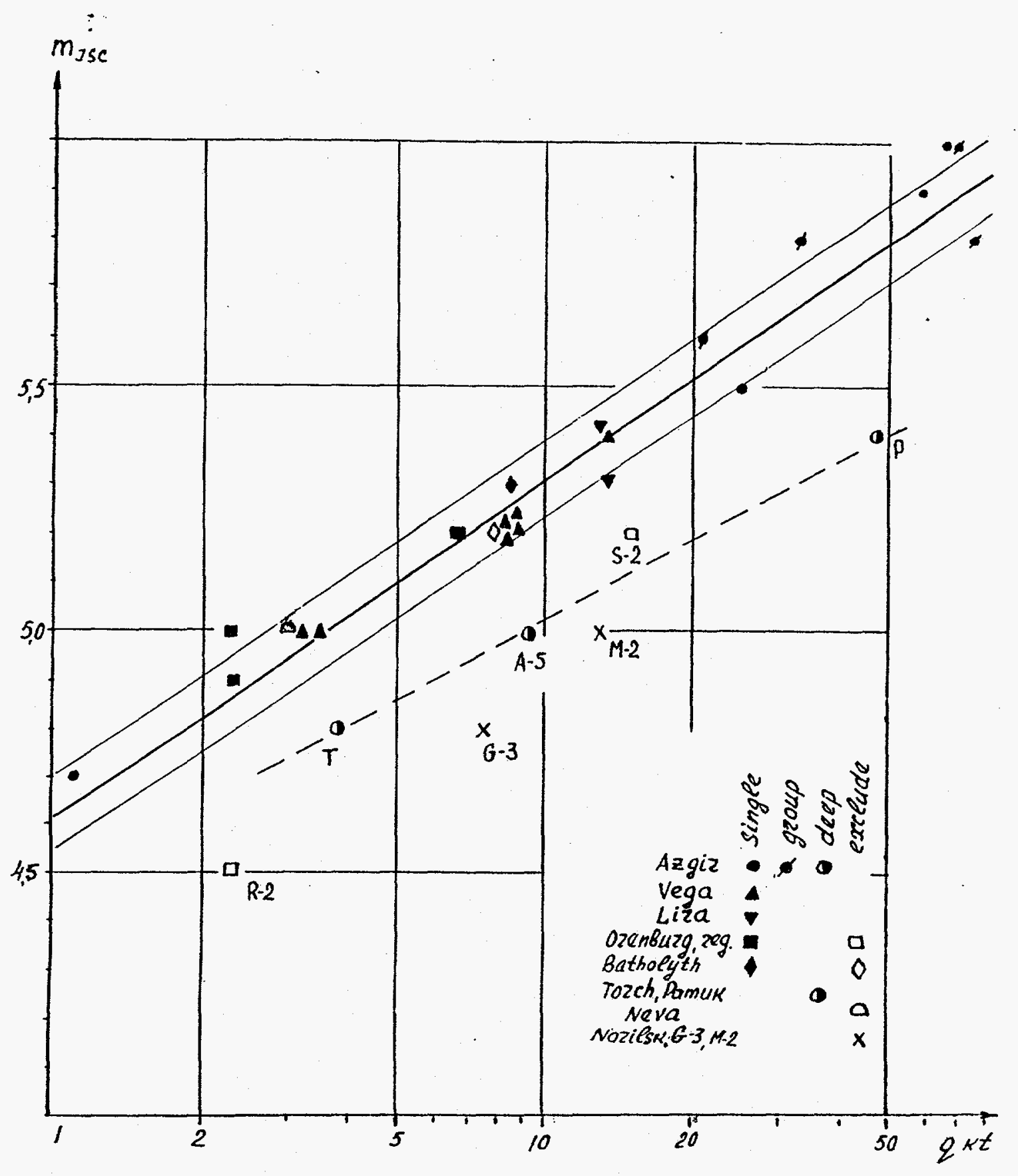

Fig. 42 
APPENDIX 1. DIGITIZING PROOEDURE AND IIST OF DIGITAI WAVEFORMS

Experimental recording was onduoted onto photographio paper and then digitized. Digitized waveforms were put in direetories with rollowing tities:

$$
\begin{aligned}
& \text { Azgir-1 - Az1 } \\
& \text { Azgir-2 - AZ2 } \\
& \text { Azgir-3 - Az3 } \\
& \text { Azgir-4 - AZ4 } \\
& \text { Azgir-5 - AZ5 } \\
& \text { Vega-3 - AV4 }
\end{aligned}
$$

Three components of displecement ( $d$ or $s$ ) and velocity ( $v$ ) were usually recorded at each point of the observation. Instruments were oriented in vertical $(z)$, and. two horizontal $(x)$ and $(y)$ directions with $x$-component oriented in perpendicular direction.

Instruments distribution and the number of observation points for each experement are presented in Tables. These Tables summarize information on the epicentral distances, azimuths of radial components, functions of motion $(z d, z v, z a, x d, \ldots, y d, \ldots)$. These Tables contain also the names of the data files, start time and length of the records of the digitized intervals of the record. In some cases the absolute timing was absent and only total duration of the digitized. record is written. 


\section{Azgir-1}

\begin{tabular}{|c|c|c|c|c|c|c|}
\hline sta & $\mathrm{r}, \mathrm{km}$ & Azim & compon. & start time & dur. & file names \\
\hline aht & 140 & 105 & $\begin{array}{l}x d, y d, z d, \\
x v, y v\end{array}$ & $2^{h} 58^{m} 23.150^{s}$ & 99 & az1.ant.t?? \\
\hline anbs & 175 & 357 & $x d, y d, z d$ & $2^{h} 58^{m} 21.642^{8}$ & 167 & az1.anbs.t?? \\
\hline anbu & 175 & 367 & $\begin{array}{l}\mathrm{xd}, \mathrm{yd}, \mathrm{zd} \\
\mathrm{xv}, \mathrm{yv}\end{array}$ & $2^{h} 58^{m} 21.642^{g}$ & 102 & az1.anbu.t?? \\
\hline app & 175 & 357 & $\begin{array}{l}x d, y d, z d \\
x v, y v\end{array}$ & - & 66 & az1.app.t?? \\
\hline atr & 175 & 357 & $x \bar{d}, y d, z d$ & - - & 98.5 & az1.atr.t?? \\
\hline blh & 112 & 100 & $x d, y d, z d$ & $2^{h_{1}} 58^{m} 20.377^{s}$ & 75 & az1.blh.t?? \\
\hline bsk & 97 & 110 & $\begin{array}{l}x d, y d, z d \\
x V\end{array}$ & $2^{\mathrm{h}} 58^{\mathrm{m}} 8.774^{\mathrm{s}}$ & 116.5 & az1.bsk.t?? \\
\hline$h r$ & 69 & 45 & $\begin{array}{l}x d, y d, z d \\
x v\end{array}$ & $2^{\mathrm{h}} 58^{\mathrm{m}} 8.528^{\mathrm{s}}$ & 152.5 & az1.hr.t?? \\
\hline hrb & 69 & 45 & $x d, y d, z d$ & $2^{\mathrm{h}} 58^{\mathrm{m}} 10.528^{\mathrm{s}}$ & 146 & az1.hrb.t?? \\
\hline $\mathrm{kpr}$ & 180 & 110 & $x d, y d, z d$ & $2^{\mathrm{h}} 58^{\mathrm{m}} 27.9^{\mathrm{s}}$ & 92 & az1.kpr.t?? \\
\hline $\operatorname{vrp}$ & 270 & 110 & $\begin{array}{l}x d, y d, z d \\
x v, y v\end{array}$ & $2^{h} 58^{m} 27.265^{s}$ & 96 & $a z 1 . v r p . t ? ?$ \\
\hline
\end{tabular}


Azgir-2

\begin{tabular}{|c|c|c|c|c|c|c|}
\hline sta & $\mathrm{r}, \mathrm{km}$ & Azim & compon. & start time & dur. & file names \\
\hline 011 & 1.17 & - & $x d, z d$ & $--\ldots$ & 1.84 & az2.011.t?? \\
\hline 017 & 1.71 & - & $x d, z d$ & $\ldots$ & 3.34 & az2.017.t?? \\
\hline 030 & 3.06 & -- & $x d, z d$ & - - - - & 6.27 & az2.030.t?? \\
\hline 078 & 7.8 & - & $x d, z d$ & $-\cdots$ & 5.32 & az2.078.t?? \\
\hline ah & 160 & 110 & $z d, x v, z v$ & - & 98.5 & az2.ah.t?? \\
\hline anb & 175 & 357 & $\begin{array}{l}\mathrm{xd}, \mathrm{yd}, \mathrm{zd} \\
\mathrm{zS}, \mathrm{xv}, \mathrm{yv}\end{array}$ & $4^{\mathrm{h}} 2^{\mathrm{m}} \cdot 26.0^{\mathrm{g}}$ & 66 & az2.anb.t?? \\
\hline apd & 175 & 357 & $\begin{array}{l}x d, y d, z d \\
x v, y v\end{array}$ & $4^{\mathrm{h}} 2^{\mathrm{m}} 35.65^{\mathrm{s}}$ & 79 & az2.apd.t?? \\
\hline atr & 175 & 357 & $\begin{array}{l}\mathrm{xd}, \mathrm{yd}, \mathrm{zd} \\
\mathrm{xv}, \mathrm{yv}\end{array}$ & $4^{\mathrm{h}} 2^{\mathrm{m}} 25.26^{\mathrm{s}}$ & 122 & az2.atr.t?? \\
\hline$h r$ & 75 & 45 & $\begin{array}{l}x d, y d, z d \\
x v, y v, z v\end{array}$ & - - - & 54 & az2.hr.t?? \\
\hline st & 170 & 0 & $x d, y d$ & $4^{\mathrm{h}} 2^{\mathrm{m}} 18.97^{\mathrm{g}}$ & 106 & az2.st.t?? \\
\hline $\operatorname{tro}$ & 175 & 357 & $\mathrm{xd}, \mathrm{yd}, \mathrm{zd}$ & $4^{\mathrm{h}} 2^{\mathrm{m}} 25.9^{\mathrm{s}}$ & 93.5 & az2.tro.t?? \\
\hline $\mathrm{vkr}$ & 270 & 110 & $\begin{array}{l}x d, y d, z d \\
x v\end{array}$ & - - & 146 & az2.vkr.t?? \\
\hline vig & 270 & 110 & $\frac{x d, y d, z d}{y v, z v}$ & 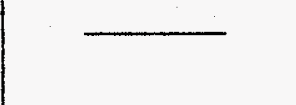 & 137 & az2.vIg.t?? \\
\hline$\nabla r p$ & 270 & 110 & $\begin{array}{l}\mathrm{xd}, \mathrm{zd}, \mathrm{zs} \\
\mathrm{xv}, \mathrm{yv}\end{array}$ & $4^{\mathrm{h}} 2^{\mathrm{m}} 35.2^{\mathrm{g}}$ & 117 & az2.vrp.t?? \\
\hline
\end{tabular}


A4

Azgir-3

\begin{tabular}{|c|c|c|c|c|c|c|}
\hline sta & $\mathrm{r}, \mathrm{km}$ & Azim & compon. & start time & dur. & file names \\
\hline 020 & 2.0 & -- & $x d, y d, z d$ & $6^{\mathrm{h}} 59^{\mathrm{m}} 59.1^{\mathrm{s}}$ & 8.5 & $a z 3.020 . t ? ?$ \\
\hline 045 & 4.5 & 318 & $\mathrm{xd}, \mathrm{yd}, \mathrm{zd}$ & $6^{\mathrm{h}} 59^{\mathrm{m}} 59.105^{\mathrm{z}}$ & 8.4 & az3.045.t?? \\
\hline 182 & 18.2 & 57.5 & $\mathrm{xd}, \mathrm{yd}, \mathrm{zd}$ & $7^{\mathrm{h}} 0^{\mathrm{m}} 2.1^{\mathrm{s}}$ & 27.5 & az3.182.t?? \\
\hline 230 & 23 & -- & $x d, y d, z d$ & $7^{\mathrm{h}} 0^{\mathrm{m}} 4.1^{\mathrm{g}}$ & 22 & $a z 3.230 . t ? ?$ \\
\hline 255 & 25.5 & 105.5 & $\mathrm{xd}, \mathrm{yd}, \mathrm{zd}$ & $6^{h} 59^{m} 59.1^{s}$ & 49 & $a 23.255 . t ? ?$ \\
\hline 420 & 42 & - & $x d, y \tilde{a}, z d$ & $7^{h} 0^{m} 8.1^{g}$ & 26 & $a z 3.420 . t ? ?$ \\
\hline 21 & 17.8 & -- & $\mathrm{xd}, \mathrm{yd}, \mathrm{zd}$ & $6^{h} 59^{m} 59.764^{s}$ & 54.5 & az3.a1.t?? \\
\hline aht & 154 & 101 & $\begin{array}{l}\mathrm{xd}, \mathrm{yd}, \mathrm{zd} \\
\mathrm{zs}, \mathrm{XV}, \mathrm{yv}\end{array}$ & $7^{\mathrm{h}} 0^{\mathrm{m}} 20.508^{\mathrm{s}}$ & 149 & az3.aht.t?? \\
\hline$a n b$ & 175 & 358 & $\begin{array}{l}\mathrm{xd}, \mathrm{yd}, \mathrm{zd} \\
\mathrm{zS}, \mathrm{XV}, \mathrm{yV}\end{array}$ & $7^{\mathrm{h}} \mathrm{O}^{\mathrm{m}} 24.857^{\mathrm{g}}$ & 220 & az3.anb.t?? \\
\hline bsk & 113 & 103 & $\begin{array}{l}\mathrm{xd}, \mathrm{yd}, \mathrm{zd} \\
\mathrm{zs}, \mathrm{xv}, \mathrm{yv} \\
\end{array}$ & $7^{\mathrm{h}} 0^{\mathrm{m}} 16.87^{\mathrm{s}}$ & 127 & az3.bsk.t?? \\
\hline hrob & 84 & -- & $\begin{array}{l}\mathrm{xd}, \mathrm{yd}, \mathrm{zd} \\
\mathrm{zs}, \mathrm{xv}, \mathrm{yv}\end{array}$ & $7^{\mathrm{h}} 0^{\mathrm{s}} 13.59^{\mathrm{s}}$ & 122 & az3.hrb.t?? \\
\hline $\mathrm{ksh}$ & 40 & -- & $\begin{array}{l}\mathrm{xd}, \mathrm{yd}, \mathrm{zd} \\
\mathrm{zs}, \mathrm{xv}, \mathrm{yv} \\
\end{array}$ & $7^{\mathrm{h}} 0^{\mathrm{m}} 5.03^{8}$ & 122 & az3.ksh.t?? \\
\hline $\operatorname{shb}$ & 47.5 & 53 & $x d, z d$ & $7^{\mathrm{h}} 0^{\mathrm{m}} 7 \cdot 1^{\mathrm{s}}$ & 124 & az3.shb.t?? \\
\hline
\end{tabular}


Azgir-4

\begin{tabular}{|c|c|c|c|c|c|c|}
\hline sta & $\mathrm{r}, \mathrm{km}$ & Azim & compon. & start time & dur. & file names \\
\hline$a 1$ & 17.8 & 55 & $\begin{array}{l}\mathrm{xd}, \mathrm{yd}, \mathrm{zd} \\
\mathrm{xv}, \mathrm{yv}, \mathrm{zv}\end{array}$ & $5^{\mathrm{h}} 0^{\mathrm{m}} 1.427^{\mathrm{s}}$ & 53.5 & az4.a1.t?? \\
\hline 23 & 2.3 & 194 & $\mathrm{za}, \mathrm{zV}, \mathrm{zd}$ & $\ldots$ & 22 & az4.a3.t?? \\
\hline ant & 154 & 101 & $\begin{array}{l}x d, y d, z d \\
x v, y v, z v\end{array}$ & $5^{\mathrm{h}} 0^{\mathrm{m}} 25^{\mathrm{s}}$ & 151 & az4.art.t?? \\
\hline bsk & 115 & 103 & $\begin{array}{l}x d, y d, z d \\
x v, y v, z v\end{array}$ & $5^{\mathrm{h}} 0^{\mathrm{m}} 20.138^{\mathrm{s}}$ & 97 & az4.bsk.t?? \\
\hline$h u r b$ & 85 & 4 & $\begin{array}{l}x d, y d, z d \\
x v, y v, z v\end{array}$ & $5^{\mathrm{h}} 0^{\mathrm{m}} 13.148^{\mathrm{s}}$ & 162 & az4.hrb.t?? \\
\hline $\mathrm{ksh}$ & 35 & 52 & $\begin{array}{l}x d, y d, z d \\
x v, y v, z v\end{array}$ & $5^{\mathrm{h}} 0^{\mathrm{m}} 4.61^{\mathrm{s}}$ & 117 & az4.ksh.t?? \\
\hline
\end{tabular}

\begin{tabular}{|c|c|c|c|c|c|c|}
\hline sta & r,km & Azim & compon. & start time & dur. & lile names \\
\hline a1 & 18 & -- & $\begin{array}{c}\mathrm{xd}, \mathrm{zd}, \mathrm{p} \\
\mathrm{xv}, \mathrm{zV}\end{array}$ & $7^{\mathrm{h}} 0^{\mathrm{m}} 0.665^{\mathrm{s}}$ & 15.5 & az5.a1.t?? \\
\hline bsk & 115 & 103 & $\begin{array}{l}\mathrm{xd,yd,zd} \\
\mathrm{xv}, \mathrm{yv}, \mathrm{zV}\end{array}$ & $7^{\mathrm{h}} 0^{\mathrm{m}} 16.33^{\mathrm{s}}$ & 126 & az5.bsk.t?? \\
\hline hrb & 75 & 41 & $\begin{array}{l}\mathrm{xd}, \mathrm{yd}, \mathrm{zd} \\
\mathrm{xv}, \mathrm{yv}\end{array}$ & $7^{\mathrm{h}} 0^{\mathrm{m}} 12.72^{\mathrm{s}}$ & 164 & az5.hrb.t?? \\
\hline
\end{tabular}




\begin{tabular}{|c|c|c|c|c|c|c|}
\hline sta & $\mathrm{r}, \mathrm{km}$ & Azim & compon. & start time & dur. & file names \\
\hline agr & 42.5 & 14 & $\begin{array}{l}x d, y d, z d \\
x v, y v, z v\end{array}$ & $6^{\mathrm{h}} 0^{\mathrm{m}} 5.068^{\mathrm{s}}$ & 53 & v31.agr.t?? \\
\hline $\mathrm{kr} r$ & 25.8 & 11 & $\begin{array}{l}\mathrm{xd}, \mathrm{yd}, \mathrm{zd} \\
\mathrm{xv}, \mathrm{yv}, \mathrm{zv}\end{array}$ & $6^{\mathrm{h}} \cdot 0^{\mathrm{m}} 3.96^{\mathrm{s}}$ & 45 & v31.kr.t?? \\
\hline stv & 14.6 & 75 & $\begin{array}{l}x d, y d, z d \\
x v, y v, z v\end{array}$ & $6^{\mathrm{h}} 0^{\mathrm{m}} 2.765^{\mathrm{s}}$ & 27.5 & v31.stv.t?? \\
\hline $\mathrm{kp}$ & 2.235 & 62 & $\mathrm{xa}, \mathrm{ya}, \mathrm{za}$ & $6^{\mathrm{h}} 0^{\mathrm{m}} 0.09^{\mathrm{s}}$ & 12.5 & $\mathrm{v} 31 . \mathrm{kp} . \mathrm{t??}$ \\
\hline
\end{tabular}

Vega 3-2

\begin{tabular}{|c|c|c|c|c|c|c|}
\hline sta & $\mathrm{r}, \mathrm{km}$ & Azim & compon. & beg. time & Iong. & file names \\
\hline agr & 41 & 14 & $\begin{array}{l}\mathrm{xd}, \mathrm{yd}, \mathrm{zd} \\
\mathrm{xv}, \mathrm{yv}, \mathrm{zV}\end{array}$ & $6^{h} 5^{m} 5.058^{z}$ & 45.5 & v32.agr.t?? \\
\hline $\mathrm{kr}$ & 24.2 & 11 & $\begin{array}{l}\mathrm{xd}, \mathrm{yd}, \mathrm{zd} \\
\mathrm{xv}, \mathrm{yv}, \mathrm{zV}\end{array}$ & $6^{\mathrm{h}} 5^{\mathrm{m}} 3.96^{\mathrm{g}}$ & 35 & v32.kr.t?? \\
\hline stv & 15.6 & 75 & $\begin{array}{l}x d, y d, z d \\
x V, y v, z V\end{array}$ & $6^{\mathrm{h}} 5^{\mathrm{m}} 2.765^{\mathrm{a}}$ & 20 & v32.stv.t?? \\
\hline $\mathrm{kp}$ & 1.508 & 62 & $\mathrm{xa}, \mathrm{ya}, \mathrm{za}$ & $6^{\mathrm{h}} 5^{\mathrm{m}} 0.09^{\mathrm{s}}$ & 14.5 & v32.kp.t?? \\
\hline
\end{tabular}

\section{Vega 3-3}

\begin{tabular}{|c|l|l|c|l|c|c|}
\hline sta & $\mathrm{r}, \mathrm{km}$ & Azim & compon. & start time & dur. & file names \\
\hline agr & 45 & 14 & $\begin{array}{l}\text { xd,yd,zd } \\
\text { xv,yv,zv }\end{array}$ & $6^{\mathrm{h}} 10^{\mathrm{m}} 5.068^{\mathrm{s}}$ & 46 & v33.agr.t?? \\
\hline $\mathrm{kr}$ & 26 & 11 & $\begin{array}{c}\mathrm{xd,yd,zd} \\
\mathrm{xv}, \mathrm{yv}, \mathrm{zv}\end{array}$ & $6^{\mathrm{h}} 10^{\mathrm{m}} 3.96^{\mathrm{s}}$ & 8.5 & v33.kr.t?? \\
\hline stv & 18.1 & 75 & $\begin{array}{l}\text { xd,yd,zd } \\
\text { xv,yv,zv }\end{array}$ & $6^{\mathrm{h}} 10^{\mathrm{m}} 2.765^{\mathrm{s}}$ & 24.5 & v33.stv.t?? \\
\hline $\mathrm{kp}$ & 1.648 & 62 & $\mathrm{xa,ya,za}$ & $6^{\mathrm{h}} 10^{\mathrm{m}} 0.09^{\mathrm{s}}$ & 15 & v33.kp.t?? \\
\hline
\end{tabular}


Vega $3-4$

\begin{tabular}{|c|c|c|c|l|c|c|}
\hline sta & $\mathrm{r}, \mathrm{km}$ & Azim & compon. & start time & dur. & file names \\
\hline agr & 44.5 & 14 & $\begin{array}{l}\mathrm{xd}, \mathrm{yd}, \mathrm{zd} \\
\mathrm{xv}, \mathrm{yv}, \mathrm{zv}\end{array}$ & $6^{\mathrm{h}} 15^{\mathrm{m}} 5.068^{\mathrm{g}}$ & 52.5 & v34.agr.t?? \\
\hline $\mathrm{kr}$ & 25 & 11 & $\begin{array}{c}\mathrm{xd}, \mathrm{yd}, \mathrm{zd} \\
\mathrm{xv}, \mathrm{yv}, \mathrm{zv}\end{array}$ & $6^{\mathrm{h}} 15^{\mathrm{m}} 3.96^{\mathrm{s}}$ & 46 & v34.kr.t?? \\
\hline $\mathrm{stv}$ & 19 & 75 & $\begin{array}{c}\mathrm{xd}, \mathrm{yd}, \mathrm{zd} \\
\mathrm{xv}, \mathrm{yv}, \mathrm{zv}\end{array}$ & $6^{\mathrm{h}} 15^{\mathrm{m}} 2.765^{\mathrm{s}}$ & 27.5 & v34.stv.t?? \\
\hline $\mathrm{kp}$ & 1.935 & 62 & $\begin{array}{c}\mathrm{xa}, \mathrm{ya}, \mathrm{za} \\
6^{\mathrm{h}} 15^{\mathrm{m}} 0.327^{\mathrm{g}}\end{array}$ & 11 & v34.kp.t?? \\
\hline
\end{tabular}

The image of the original record was obtained using the OPENSCAN program from a scanner with 300 dpi resolution. Operational field of the scanner is of $8.5 * 17$ inches. The original seismograms are usually of larger length than 17". So those were divided into several sections with some overlapping.

To obtain digital waveforms the program $n X s c a n$ was used. So at the first stage, the images were converted by prep_nxs program. Then a section with a length proportional to a half a second was chosen Irom the image by time marks ( half a seoond is the smallest time between time marks). When digitized, each waveform was edited (noise was usualiy due to orossing by different waveforms and other marks on photographic paper). Time marks as well as "zero line" were also digitized besides working channels. It is very important to digitize "zero Iines" or dead channels. It provides an opportunity to remove from a digitized waveform trend related to the position of paper at the scamer operational field and perpendicular motion 
of photographic paper during record. Next fragment of wave form was digitized with overlaping proportional to a half a second.

To obtain the complete seismogram (waveform) from sections, a programm connect_wform was used. This FORTRAN program has following functions:

- time marks processing;

- vertical deviations correction;

- connection of the fragments;

- visual control of connection in overlapping section;

- output of the whole seismogram with a given sampling rate.

To convert digitized waveforms from scan format into SAC format a program scantosac written by J.Coyne (CSS) was used. This program was a little bit modified. There are two modifications of this program:

scantosac.rew - to change polarity of the signal

scantosac - no change of polarity

The changes inserted into scantosac program are following: - the maximum length of input and output data amrays is increased to 20000 points:

- the sense of Xm was changed. Now in this tield is information on the corrsponding channel amplification is given in $\mathrm{mm}$ of record per mm actual motion, particle velocity in $\mathrm{mm} /(\mathrm{mm} / \mathrm{s})$ and particle acceleration - in $\mathrm{mm} /\left(\mathrm{cm} / \mathrm{s}^{2} / 9.81\right)$, and $\mathrm{mm} / \mathrm{Pa}$ for pressure. So output is in $\mathrm{mm}$ for displacement, in $\mathrm{mm} / \mathrm{s}$ for velocity and in $\mathrm{g}$ for acceleration, and Pascals for pressure; 
A9

- station name field is extended to 6 characters and component field to 2 characters.

To use these programs all the original information is written into header files. These header files oontain following data:

- comment string contains the title of the explosion, epicentral range and azimuth to the ground zero, and type of sensor; of sensetivity of seismometer (accelerograph);

- string 2 - name of input file of scan format;

- string 3 - name of output file of sac format;

- string 4 - station name (5-6 characters) compiled from short explosion title, its ordering number and epicentral distance in hundreds of meters or short name of the explosion (3 characters). One blank separated next field containing component $(\mathrm{x}, \mathrm{y}$ or $\mathrm{z}$ ) and motion $(\mathrm{z}-\mathrm{ycceleration,} \mathrm{y}-$ velocity, $d(s)$ - displacement, or $p$ for pressure);

- string 5 - comments to string 6 ;

- string 6 - date of record, start time of record (if no this field is filled by nuIls end time of record ( or total duration of record), station coordinates (nulls if no), scanner resolution (dpi), amplification in unites desribed above;

- string 7 - comments to string 8;

- string 8 - date of explosion, origin time, coordinate of the ground zero, depth and magnitude.

sacess program converted sac format into oss format., Each 
explosion (experiment) has its own directory with three subdirectories named:

. $/ \mathrm{dir} / \mathrm{HEADER}$ - contains header of waveforms;

./dir/SAC - waveform in SAC format

.$/$ dir/CSS - waveforms in CSS format

Original name of a file for each record of each component was written under following naming convention:

- title.dist.tcomp where short name (title) of an experiment with sequential number in a series (for example Az1);

- dist - distance in hundreds of meters or short station name;

- $t$ - means whole seismogram has been connected;

- comp - component of motion (fo examples dx - radial component of displacement).

Connect_wiom software description.

This programm has been developed in order to connect different fragments of the digitized seismograms into one digital waveform.

How to run the program

To start the program type connect wiorm. Then the program in interactive regime will request the name of the first fragment of the record. The names of following fragments have to differ only in one digit $(2,3$,ete.). The position of this digit is determined automatically as the closest digite to 
A.11

the end of the name. If input of the name is correct, the program reads tr: names of all the fragments and requests to input start and end time of the first section. If the file with time marks (timing) exists (its name has to differ only in last two characters, tm, from the name of the first fragments), the program compares inserted duration of the section with calculated from times marks. If these durations coinside the program requests start and end times of the second iragments etc. If time intervals do not coinside, the proyram prints the length (in half a seconds) of the already processed record and quits. Then all the fragments input successfully, the program requests desired sampling rate (samples/seo).

The output of the program is a file with a name, where instead of the fragment number is a character $t$ (total). Input files: files of the seismogram fragments, time marks, "zero line".

Example:

$$
\begin{aligned}
& A z 1 . h r b . O d x ; A z 1 . h r b .0 t m ; A z 1 . h r b .01 n ; \\
& A z 1 . h r b .1 d x ; A z 1 . h r b .1 t m ; A z 1 . h r b .1 \text { In; } \\
& \ldots \ldots \ldots \ldots, \ldots \ldots \ldots \ldots \ldots ; \ldots \ldots \ldots \ldots
\end{aligned}
$$

These files differ only in last two character for data time and "zero line" ( $d x, t m$, In respectively).

Output file: whole seismogram (waveform) file. Its name differ only in one character $t$ from fragment name.

Example: Az1.hro.tdx 


\section{Algorythm:}

Time line processing.

Time line consists of rectangular impulses generated by precise clock. Positive as well as negative impulses ocoure in a second. Time interval between positive and negative impulses is of about $0.5 \mathrm{~s}$ and constant. Thus time intervals between positive and negative impulses were processed separately, and two funotions length of seismogram against time were constructed. Then both functions were approximated by splines and by using least squares technique the correct durations of the first and second "half a second" were determined. Then unified time/length dependence was estimated which was used for correotion of the rate variations.

Detrending and perpendioular oscillations removing:

To detrend a record related to position of a paper seismogram at the soanner and remove perpendicular osoillations of photographic paper we have digitized the records from dead channels ("zero lines"). These records were filtered by low-frequenoy filters and were substructed from working chamels.

\section{Section connection.}

At first stage, each section of a record was approximated by splines. The sum of squared residals between two fragments in overlaping interval was calculated depending on relative 
positions. By minimizing this sum the correct connection was. selected. Connection control was conducted by digital and visual ways. In the letter case a part of overlapping was displayed on monitor.

Output file formation.

According to sampling rate chosed, low-frequenoy filtering of each fragment by means of spline was carried out. Filter parameters were selected to reduce high-frequency oscillations beyond Nyquiest Irequency to neglegible level. Then from spline parameters and for given sampling rate final waveform was calculated. Output file format is the same as input file. 


\section{REFERENCES}

1. Nuclear explosions in the USSR. Issue 4. Peaceful nuclear explosions (Ed. V.N.Mikhailov). Moscow, 1994. (in Russian).

2. Passechnik I.P., Sultanov D.D. Dominating seismic body waves from explosions. Proceedings of Hydroproekt, N20, Moscow, 1971. (in Russian).

3. Sharpe J.A. The production of elastic waves by explosion pressures 1. Theory and empirical observations. Geophysics, $7,144-154,1942$.

4. Muller R.A., Murphy J.R. Seismic charaoteristics of underground nuolear detonations. Part 1. Seismic spectmm scaling. Bulletin of Seismological Society of America, 61, N6, $1675-1692,1971$.

5. Rodionov V.N., Adushkin V.V., Kostyuchenko V.N. et.a.., Mechanio effect of underground explosion, Nedra, 1971. (in Russian).

6. Rodean G., Seismology of nuolear explosions, 1974

7. Zamyshlaev, B.V., Evterev, I.S., Models of dynamic deformation and destruction of rocks, Nauka, 1990. (in Russian).

8. Bychenkov, V.A., S.V. Dem'yanovsky, G.V. Kovalenko et.aI., Seismic efficiency of tamped underground explosion, Problems of nuolear soience and engineering, ser. Theoretic and 
applied physios, N2, 1992. (in Russian).

9. Korotkov, P.F., B.M. Prosvimina. Numerical simulation of explosion in elastio-plastio medium and some problems of simulation. Doklady AN SSSR (Reports of Academy of Sciences), N.228, N1, 1976. (in Russian).

10. Korotkov, P.F., B.M. Prosvimina. On the scaling Iaw and energy distribution of explosion in elastic-plastic medium, PMTF, N2, 1980. (Applied Mathematios and Theoretical physies). (in Russian).

11. Kostyuchenko, V.N., V.N. Rodionov. On the generation of seismic waves by large-scale underground explosions in hard rocks. Izv. AN.SSSR, Ser. Earth's physics, N10, 1974. (in Russian).

12. Denny M.D., Goodman D.H. A case Study of the Seismic Source Function: SaImon and Sterling Reevaluated. J.Geophys. Res, 95, N B12, 1990.

13. Denny M.D., Johnson I.R. The explosion Seismic Source function: models and scaling laws reviwed. Explosion Source Phenomenology, Am. Geophys UN., 1991.

14. Hensinkveld M.F. Calculation on seismic coupling of underground explosions in salt. Iawrence Iivermore Nation. Labor., CA, UCRL-53103, 1981.

15. Springer D., Denry M., Healy J., Miokey w. The Sterling experiment: Decoupling of seismic waves by a shot-generated 
cavity. J. Geophys. Res., 73, 5995-6011, 1968.

16. Sadovskyi, M.A., V.N. Kostyuchenko. On the explosion generated seismic wave attenuation in rocky massif. Doklady AN SSSR, v.301, N6, 1988. (in Russian).

17. Kostyuchenko V.N., Seismic source function of large-scale underground explosions. Dynamic processes in the geospheres. IDG RAS. Moscow. Nauka. P. 132-136,1994.

*This work was performed under the auspices of the U.S. Department of Energy by Lawrence Livermore National Laboratory under contract No. W-7405-Eng-48. 